\title{
The antihypertensive effect of propranolol : an animal study into the mechanisms through which beta- adrenoceptor blocking drugs lower blood pressure
}

Citation for published version (APA):

Smits, J. F. M. (1980). The antihypertensive effect of propranolol : an animal study into the mechanisms through which beta-adrenoceptor blocking drugs lower blood pressure. [Doctoral Thesis, Maastricht University]. Rijksuniversiteit Limburg. https://doi.org/10.26481/dis.19801010js

Document status and date:

Published: 01/01/1980

DOI:

10.26481/dis.19801010js

Document Version:

Publisher's PDF, also known as Version of record

Please check the document version of this publication:

- A submitted manuscript is the version of the article upon submission and before peer-review. There can be important differences between the submitted version and the official published version of record.

People interested in the research are advised to contact the author for the final version of the publication, or visit the DOI to the publisher's website.

- The final author version and the galley proof are versions of the publication after peer review.

- The final published version features the final layout of the paper including the volume, issue and page numbers.

Link to publication

\footnotetext{
General rights rights.

- You may freely distribute the URL identifying the publication in the public portal. please follow below link for the End User Agreement:

www.umlib.nl/taverne-license

Take down policy

If you believe that this document breaches copyright please contact us at:

repository@maastrichtuniversity.nl

providing details and we will investigate your claim.
}

Copyright and moral rights for the publications made accessible in the public portal are retained by the authors and/or other copyright owners and it is a condition of accessing publications that users recognise and abide by the legal requirements associated with these

- Users may download and print one copy of any publication from the public portal for the purpose of private study or research.

- You may not further distribute the material or use it for any profit-making activity or commercial gain

If the publication is distributed under the terms of Article $25 \mathrm{fa}$ of the Dutch Copyright Act, indicated by the "Taverne" license above, 


\title{
THE ANTIHYPERTENSIVE EFFECT OF PROPRANOLOL.
}

\author{
An animal study into the mechanisms through \\ which beta-adrenoceptor blocking drugs \\ lower blood pressure.
}


Referenten: $\quad$ Prof. Dr. K.H. Rahn

Prof. Dr. J.M. van Rossum

Part of the studies in this thesis have been performed during a stay of the author in the laboratories of Prof. T.G. Coleman (Department of Physiology and Biophysics, University of Mississippi Medical School, Jackson, Miss. USA). This was made possible by a grant of the Dutch Heart Foundation.

The publication of this thesis has been made possible by generous donations by the Dutch Kidney Foundation and Imperial Chemical Industries, The Netherlands. 


\section{THE ANTIHYPERTENSIVE EFFECT OF PROPRANOLOL.}

An animal study into the mechanisms through

which beta-adrenoceptor blocking drugs lower blood pressure.

PROEFSCHRIFT TER VERKRIJGING VAN DE GRAAD VAN DOCTOR IN DE GENEESKUNDE AAN DE RIJKSUNIVERSITEIT LIMBURG TE MAASTRICHT OP GEZAG VAN DE RECTOR MAGNIFICUS PROF. DR. W.H.F.W. WIJNEN, HOOGLERAAR IN DE FACULTEIT DER GENEESKUNDE, VOLGENS BESLUIT VAN HET COLLEGE VAN DEKANEN IN HET OPENBAAR TE VERDEDIGEN OP VRIJDAG 10 OKTOBER 1980, DES NAMIDDAGS TE 16.00 UUR IN DE AULA VAN DE UNIVERSITEIT

DOOR

JOZEF FRANCISCUS MARIA SMITS

GEBOREN TE TILBURG

1980

Druk: Coenen b.v. Simpelveld 
VOOR DOORTJE,

VOOR MIJN OUDERS 


\section{DANKWOORD (Acknowledgments)}

Het is een goede gewoonte om in een proefschrift een woord van dank te richten tot de mensen die aan de totstandkoming ervan hebben bijgedragen.

Het zou een misvatting, te denken, dat proefschriften het werk zijn van één persoon.

Op de eerste plaats wil ik mijn promotor, Prof. Dr. H.A.J. Struyker Boudier, bedanken. Harry, zonder jouw stimulerende begeleiding alsook de daadwerkelijke steun bij de uitvoering van een groot aantal experimenten, zou dit boekje niet geworden zijn wat het is. Nogmaals dank voor de vele uren en met name week-ends dat ik op je kon rekenen.

De beide referenten, Prof. Dr. K.H. Rahn en Prof. Dr. J.M. van Rossum, dank ik voor de wijze waarop zij altijd belangstelling getoond hebben voor mijn werk en het kritisch lezen van het manuscript van dit boek.

Voor een prettige sfeer rondom de uitvoering van de in dit boek beschreven experimenten werd voortdurend zorggedragen door Helma van Essen. Carina Kasbergen en Lily Vervoort. Door hun nauwgezetheid en niet aflatend enthousiasme was het mogelijk een groot aantal technieken te ontwikkelen en toe te passen.

Al mijn collega's wil ik danken voor de belangstelling die zij steeds voor mijn werk hebben getoond. Met name Rob Evenwel, Jos Kleinjans en Henk Thijssen hebben door uitvoerige discussies zeker bijgedragen aan de inzichten die in dit proefschrift naar voren zijn gebracht.

De mensen in de mechanica- en electronica-werkplaats, die mijn (vaak wilde) ideeën verder gestalte gaven, moeten zeker niet vergeten worden.

Tijdens de laatste, slopende periode vóór het uitkomen van dit boekje heb ik een onmisbare steun gevonden in Ans Lippinkhof en Nelly Baltussen die mijn onduidelijke handschrift en inconsequent taal-gebruik hebben weten om te zetten in een feilloos manuscript.

A special word of gratitude should go to all the people in the laboratories of Dr. Tom Coleman in Jackson, Miss.. I would like to thank Dr. Tom Coleman and Dr. Tom Smith not only for offering me lab-facilities and the actual performance of a great number of experiments, but certainly also for making working in the lab as pleasant as it was. Their families should know that I really enjoyed their kind hospitality. Some day I hope to be in the oppurtunity to offer them mine.

Doortje, jou dank ik op de laatste maar zeker niet de minste plaats. Ik ben ervan overtuigd dat de periode vóór het uitkomen van een proefschrift voor de echtgenote van een promovendus zwaarder is, dan voor de promovendus zelf. En hoewel ik je de vele uren dat ik er voor jou in feite niet was nooit zal kunnen teruggeven, hoop ik dit in de toekomst weer een beetje goed te kunnen maken. 


\section{CONTENTS}

1. Introduction

1.1 Pharmacological properties of the beta-adrenoceptor blocking drugs 15

1.2 Pharmacokinetics of propranolol

1.3 The antihypertensive effect of propranolol: hemodynamic pattern of the response and proposed mechanisms of action

1.4 Antihypertensive effects of propranolol in experimental hypertension

1.5 The present thesis

2. Materials and methods

2.1 Animals

2.2 Measurement of blood pressure

2.3 Measurement of venous pressure

2.4 Measurement of cardiac output

2.5 Measurement of plasma volume

2.6 Injections in unrestrained rats

2.6.1 Intravenous injections

2.6.2 Intracerebroventricular injections $\quad 55$

2.7 Infusions in unrestrained rats

2.7.1 The osmotic minipump

2.7.2 Subcutaneous infusions 58

2.7.3 Intracerebroventricular infusions 58

2.7.4 Intra-arterial infusions 58

2.8 Quantitation of beta-adrenoceptor blockade 59

2.9 Afferent denervation of baroreceptors $\quad 59$

$\begin{array}{ll}2.10 \text { Measurement of baroreflex sensitivity } & 60\end{array}$

2.11 Measurement of urinary excretion of water and sodium 61

2.12 Measurement of ${ }^{3} \mathrm{H}$-propranolol and its total metabolites in biological fluids and tissues

2.13 Measurement of propranolol in plasma $\quad 65$

2.14 Measurement of plasma protein binding $\quad 65$

$\begin{array}{ll}2.15 & \text { Determination of plasma renin activity } \\ \end{array}$ 


\section{ONE DOSE STUDIES}

3. Pharmacokinetics of propranolol after a single subcutaneous injection in conscious SHR

3.1 Introduction

3.2 Experimental protocol $\quad 69$

3.3 Results 70

3.3.1 Plasma levels of propranolol as a function of time 70

3.3.2 Tissue levels of propranolol as a function of time $\quad 70$

3.3.3 Tissue levels of total propranolol metabolites as a function of time

3.4.4 Relation between plasma concentration and protein binding of propranolol

4. Time-course of beta-adrenoceptor blockade following a single subcutaneous injection of propranolol in conscious SHR

4.2 Experimental protocol 78

4.3 Results $\quad 78$

4.3.1 Time-course of cardiac beta-adrenoceptor blockade 78

4.3.2 Time-course of blockade of vascular beta-adrenoceptors $\quad 78$

4.4 Discussion

5. Effects of a single subcutaneous injection of propranolol on blood pressure and heart rate in conscious SHR

5.1 Introduction 83

5.2 Experimental protocol 83

$\begin{array}{lll}5.3 \text { Results } & 84\end{array}$

5.3.1 Effects on heart rate $\quad 84$

5.3.2 Effects on blood pressure 86

$\begin{array}{ll}5.4 \text { Discussion } & 87\end{array}$

6. Further characterization of the hemodynamic effects of a single subcutaneous injection of propranolol in conscious SHR 91

6.1 Introduction $\quad 91$

6.2 Experimental protocol 91

6.3 Results 93

6.3.1 Effects on cardiac output 93

6.3.2 Effects on stroke volume index 93

6.3.3 Effects on total peripheral vascular resistance 93

$\begin{array}{ll}6.4 \text { Discussion } & 95\end{array}$ 
7. Effects of single intracerebroventricular injections of propranolol in conscious SHR

7.1 Introduction

7.2 Experimental protocols

7.3 Results

7.3.1 Peripheral beta-adrenoceptor blockade

100

7.3.2 Plasma concentration-time profile

101

7.3.3 Effects on heart rate

103

7.3.4 Effects on blood pressure 104

7.4 Discussion

104

8. The baroreceptor-reflex following a single injection of propranolol in conscious SHR

$\begin{array}{ll}8.1 \text { Introduction } & 107\end{array}$

$\begin{array}{ll}8.2 \text { Experimental protocols } & 107\end{array}$

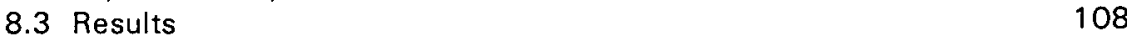

8.3.1 Modification of effects by afferent denervation of baroreceptors 108

8.3.2 Propranolol and baroreflex sensitivity 111

8.4 Discussion 112

9. Effects of a single subcutaneous injection of propranolol on plasma renin activity in conscious unrestrained SHR

9.1 Introduction

9.2 Experimental protocol

9.3 Results

9.4 Discussion

10. Effects of a single subcutaneous injection of propranolol on plasma volume in conscious SHR

10.1 Introduction

10.2 Experimental protocols

10.3 Results

10.3.1 Effects on plasma volume

10.3.2 Effects on venous pressure

10.4 Discussion

11. Effects of a single subcutaneous injection of propranolol on urinary excretion of water and sodium in conscious SHR

11.1 Introduction

11.2 Experimental protocol

11.3 Results

126

11.4 Discussion 


\section{LONG-TERM STUDIES}

12. Disposition of propranolol and its total metabolites following long-term infusion: subcutaneous vs. intracerebroventricular infusion 133

12.1 Introduction

12.2 Experimental protocol 133

12.3 Results 135

12.3.1 Excretion of propranolol and its metabolites 135

12.3.2 Plasma levels during long-term infusion 136

12.3.3 Disposition of propranolol and its total metabolites 136

$\begin{array}{ll}12.4 \text { Discussion } & 139\end{array}$

13. Hemodynamic effects of long-term subcutaneous infusion of propranolol

13.1 Introduction 143

$\begin{array}{ll}13.2 \text { Experimental protocols } & 143\end{array}$

$\begin{array}{ll}13.3 \text { Results } & 144\end{array}$

13.3.1 Effects on heart rate 144

13.3.2 Effects on blood pressure $\quad 145$

13.3.3 Effects on cardiac output 145

13.3.4 Effects on stroke volume index 147

$\begin{array}{ll}\text { 13.3.5 Effects on peripheral resistance index } & 147\end{array}$

13.3.6 Plasma propranolol levels 147

$\begin{array}{ll}13.4 \text { Discussion } & 148\end{array}$

14. Effects of long-term intracerebroventricular infusion of propranolol on blood pressure and heart rate in conscious SHR

14.1 Introduction 151

14.2 Experimental protocol 151

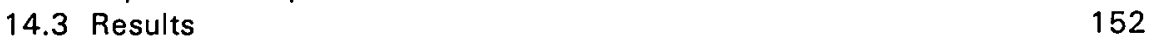

14.3.1 Effects on heart rate 152

14.3.2 Effects on blood pressure 153

14.3.3 Plasma propranolol levels 154

$\begin{array}{ll}14.4 \text { Discussion } & 155\end{array}$

15. Effect of long-term infusion of propranolol on plasma renin activity in conscious, unrestrained SHR 159

$\begin{array}{ll}15.1 \text { Introduction } & 159\end{array}$

15.2 Experimental protocol 159

$\begin{array}{ll}15.3 \text { Results } & 160\end{array}$

$\begin{array}{ll}15.4 \text { Discussion } & 161\end{array}$ 
16. Effects of long-term infusions of propranolol on plasma volume in conscious, unrestrained SHR

16.1 Introduction

16.2 Experimental protocol

16.3 Results

16.4 Discussion

17. General discussion and conclusions

17.1 Pharmacokinetics of propranolol in SHR

17.2 Acute hemodynamic effects of propranolol in SHR

17.3 Long-term hemodynamic effects of propranolol in SHR

17.4 Conclusions

Summary

Samenvatting

Appendix I. A physiological model for the distribution and elimination of propranolol in the rat

Appendix II. Simulations of some proposed hypotheses for the mechanism of antihypertensive action of beta-adrenoceptor blocking drugs in a computer-model for blood pressure regulation

References

Curriculum vitae 


\section{List of abbreviations}

\begin{tabular}{|c|c|c|}
\hline $\mathrm{b} / \mathrm{min}$ & : & beats per minute \\
\hline BRS & : & baroreflex sensitivity \\
\hline b.w. & : & body weight \\
\hline $\mathrm{Cl}$ & : & cardiac index \\
\hline $\mathrm{CO}$ & : & cardiac output \\
\hline CVP & : & central venous pressure \\
\hline GFR & : & glomerular filtration rate \\
\hline HR & $:$ & heart rate \\
\hline i.a. & $:$ & intra-arterial \\
\hline i.c.v. & : & intracerebroventricular \\
\hline i.m. & $:$ & intramuscular \\
\hline i.p. & $:$ & intraperitoneal \\
\hline i.v. & : & intravenous \\
\hline MAP & : & mean arterial pressure \\
\hline $\mathrm{mm} \mathrm{Hg}$ & $:$ & millimetres mercury \\
\hline PRA & : & plasma renin activity \\
\hline RBF & $:$ & renal blood flow \\
\hline s.c. & $:$ & subcutaneous \\
\hline SHR & $:$ & spontaneously hypertensive rat(s) \\
\hline SV & $:$ & stroke volume \\
\hline SVI & : & stroke volume index \\
\hline TPR & $:$ & total peripheral resistance \\
\hline TPRI & $:$ & total peripheral resistance index \\
\hline$U_{v}$ & $:$ & urinary water excretion \\
\hline $\mathrm{U}_{\mathrm{V}} \mathrm{Na}$ & : & urinary sodium excretion \\
\hline WKy & $:$ & Wistar-Kyoto \\
\hline
\end{tabular}




\section{INTRODUCTION.}

\subsection{Pharmacological properties of beta-adrenoceptor blocking drugs.}

Stimulation of cardiac adrenoceptors leads to an increase in heart rate and myocardial contractility, which in turn increase myocardial work and oxygen consumption. On the basis of this, drugs that should be capable of selectively blocking these adrenoceptors, which are called beta-adrenoceptors according to Ahlquist (1948), were designed in the early 60 's for the treatment of angina pectoris (Black and Stephenson, 1962). Besides this, their effects on the myocardial conduction system might be helpful in treatment of cardiac arrhythmias. However, since their introduction, betaadrenoceptor blocking drugs have un-expectedly been shown to have benificial effects in the treatment of a variety of disease-states like hypertension, hyperthyroidism, schizophrenia, anxiety states, migraine, hypertrophic obstructive cardiomyopathy, addictive drug withdrawal syndromes, glaucoma and they also may have a protective action in the early phase following acute myocardial infarction.

A comprehensive review on the clinical use of beta-adrenoceptor blocking drugs in these diseases has recently appeared (McDevitt, 1979) and this aspect will not be discussed further here. This very wide applicability, together with a low incidence of serious side effects resulting from beta-adrenoceptor blockade per se, has inspired pharmaceutical industries to synthetize these drugs in a great variety. Several nonbeta-adrenoceptor blocking properties are shared by a number of them and these will be discussed below. A restriction which should be made here is, that in the further context of this thesis some new drugs (e.g. labetalol and bufurarol), which, besides blocking beta-adrenoceptors, are also capable of blocking alpha-adrenoceptors, are excluded from the discussion. This thesis is primarily concerned with cardiovascular effects of beta-adrenoceptor blockade. Since the blockade of vascular alphaadrenoceptors (which leads to vasodilation) causes hemodynamic effects which are entirely different from those elicited by beta-adrenoceptor blockade, these drugs are not comparable with pure beta-adrenoceptor blocking drugs. For this reason their implementation in discussions is omitted in this thesis.

Chemically, most beta-adrenoceptor blocking drugs may be classified as substituted aryloxypropanolamines or phenoxypropanolamines. An exception to this is sotalol, as is shown in figure 1.1. This figure contains structural formulas of the betaadrenoceptor blocking drugs that are most frequently used in therapy and/or research. The common feature, which determines their affinity for beta-adrenoceptors, is derived from the beta-adrenergic agonist isoprenaline and consists of the 2(or 3-) C-atom side chain with a terminal nitrogen, substituted with an isopropyl or tert-butyl group, whereas also beta-adrenoceptor blocking drugs have been synthetized with another bulky $\mathrm{N}$-substituent. However, most of these agents contain the isopropyl-group. In the side chain a beta-hydroxy-group is essential whereas also the configuration of the (asymmetric) beta-C-atom is crucial for beta-adrenoceptor affinity. Both for alprenolol (Äblad et al., 1967) and propranolol (Howe and Shanks, $1966)$ it has been shown that only the (-)-stereo-isomers possess appreciable affinity for beta-adrenoceptors. Other properties like local anesthetic effects (which will be 
briefly discussed below) are shared by both enantiomers. The availability of these stereo-isomers is of great value for mechanistic studies.

Besides their affinity for beta-adrenoceptors these drugs share a number of other properties which may be attained or abolished by substitution in the molecule.

These more or less common features include membrane stabilizing effects (local anesthetic properties; quinidine-like effects), intrinsic sympathicomimetic activity (ISA, partial agonist properties) and more pronounced affinity for either beta ${ }_{1}$ - or beta $_{2}$ - adrenoceptors, which in the case of greater beta 1 - affinity, is mostly called cardioselectivity. These properties are contained in table 1.I.

The beta-adrenoceptor blocking drugs in figure 1.1 have been depicted in two columns, the left hand column containing non-selective beta-adrenoceptor blocking drugs, whereas those in the right hand column have a more pronounced affinity for beta 1 - adrenoceptors. It seems from the figure that this property may be introduced by para-substitution in the general aryloxypropanolamine-structure, although acebutolol, containing two meta substituents, is an exception to this. Drugs with a more pronounced affinity for beta 2 - adrenoceptors like butoxamine, have not been included in the figure and will not be discussed here because most of the benificial effects, and certainly those on the cardiovascular system, derive from a beta ${ }_{1}$ adrenoceptor blockade. However, beta $_{2}$ - adrenoceptor selectivity may be introduced by substitution of the side chain with an alpha-methyl-group.

Another subdivision, which has been made in figure 1.1 by the interrupted line, is between those drugs with and without intrinsic sympathicomimetic activity. This property may be introduced by polar substitution of the ring.

Increasing lipophilicity enhances the membrane-stabilizing effects. Drugs possessing this property are marked with an asterisk in the figure.

There are only a few beta-adrenoceptor blocking drugs which may be regarded as relatively pure, i.e. they only possess beta-adrenoceptor blocking properties. These are sotalol, atenolol and metoprolol. The others all have one or more of the other features besides this basic property. Thus, one may ask whether it is really betaadrenoceptor blockade which determines their therapeutic applicability in a number of disease-states. The present thesis deals with the antihypertensive effects of betaadrenoceptor blockade, and with regard to this therapeutic use the question posed above can be answered in a positive sense. All drugs combined in table 1.1 are antihypertensive agents, with the exception of d-propranolol, the stereo-isomer of propranolol which possesses all general features but is devoid of beta-adrenoceptor blocking properties. In humans it has been shown incapable of lowering blood pressure (and heart rate) at a dose-level where racemic propranolol does (WaalManning, 1970; Rahn et al., 1974). Thus, it seems that beta-adrenoceptor blockade indeed determines the property.

Intrinsic sympathicomimetic activity and beta ${ }_{1}$ - adrenoceptor selectivity are sometimes claimed to extend the possible therapeutic use in patients where a-selective beta-adrenoceptor blockade is contra-indicated (for instance in asthmatic patients). Their possible relevance for therapy has recently been reviewed extensively 
(Frishman, 1979). Where ISA and beta ${ }_{1}$ - adrenoceptor selectivity alter the pattern of antihypertensive response, these aspects will be included in discussions in the further course of this thesis.

general formula: $\mathrm{R}-\mathrm{C}-\mathrm{C}-\mathrm{C}-\mathrm{N}-\mathrm{C}_{\mathrm{O}}^{\mathrm{C}}$

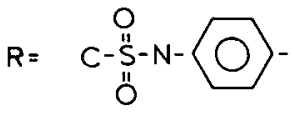

sotalol

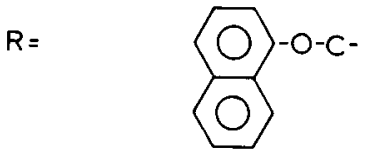

$R=$<smiles>CC(=O)OC=Cc1ccc(CC(N)=O)cc1</smiles>

atenolol

$R=$<smiles>COC#Cc1ccc(OC)cc1</smiles>

metoprolol

propranolol

$R=$

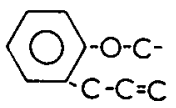

alprenolol *

$R=$

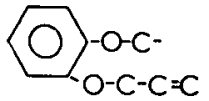

oxprenolol

$R=$

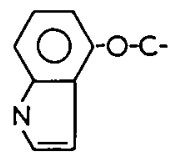

$R=$

$R=$

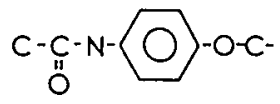

practolol<smiles>C=CC(=O)Nc1cccc(OC(C)=O)c1</smiles><smiles>C=CO</smiles>

acebutolol

pindolol

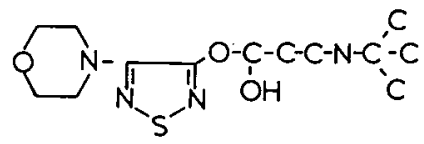

timolol

Figure 1.1. Structural formulas of a number of beta-adrenoceptor blocking drugs. Substances in the right hand column possess a greater affinity for beta 1 - than for beta $_{2}$-adrenoceptors. Furthermore, the interrupted horizontal line divides substances with (lower part) and without (upper part) intrinsic sympathomimetic activity. Drugs possessing local anesthetic properties are marked with an asterisk. 
Table 1.I. Comparison of pharmacological properties shared by a number of beta-adrenoceptor blocking drugs.

\begin{tabular}{|c|c|c|c|c|}
\hline Drug & $\begin{array}{l}\text { Beta- } \\
\text { blocking }\end{array}$ & $\begin{array}{l}\text { Membrane } \\
\text { stabilization }\end{array}$ & ISA & $\begin{array}{l}\text { Affinity } \\
\text { beta } 1>\text { beta }_{2}\end{array}$ \\
\hline Acebutolol & + & + & + & + \\
\hline Alprenolol & $t$ & + & ++ & 0 \\
\hline Atenolol & ++ & 0 & 0 & + \\
\hline Metoprolol & ++ & \pm & 0 & + \\
\hline Oxprenolol & + & + & ++ & 0 \\
\hline Pindolol & +++ & + & +++ & 0 \\
\hline Practolol & + & 0 & ++ & + \\
\hline (-) Propranolol & ++ & ++ & 0 & 0 \\
\hline (t) Propranolol & 0 & ++ & 0 & 0 \\
\hline Sotalol & + & 0 & \pm & 0 \\
\hline Timolol & $+t+$ & 0 & 0 & 0 \\
\hline
\end{tabular}

\subsection{Pharmacokinetics of propranolol.}

It is impossible to discuss the pharmacokinetic properties of all beta-adrenoceptor blocking drugs here, because of the variety of these drugs which are available for research and clinical use and the enormous amounts of pharmacokinetic data which have been gathered on them. Excellent reviews on the clinical pharmacokinetics of propranolol (Shand, 1976; Routledge and Shand, 1979) and of beta-adrenoceptor blocking drugs in general have recently appeared (Johnsson and Reghàrd, 1976a, b; Frishman, 1979). A number of pharmacokinetic data on the most important drugs of this class in man have been summarized in table 1.Il. Propranolol, being the subject of this thesis, will be discussed here in more detail.

The discussion below will first of all focus on basic pharmacokinetic processes of distribution and elimination, and the factors determining them for propranolol. Thereafter, pharmacokinetics of orally administered propranolol in man will be discussed. 
The distribution of propranolol in the body following an intravenous bolus-injection of the drug is a very rapid process, having a half-life of approximately 10 minutes in man. The distribution volume $V_{d} \beta$ of propranolol has been reported to be $3.4 \mathrm{l} / \mathrm{kg}$ in man (Routledge and Shand, 1979) and varies extensively between species; values from 1 $1 / \mathrm{kg}$ in monkeys and $5 \mathrm{l} / \mathrm{kg}$ in rats have been observed (Evans et al., 1973a).

Distribution of a drug depends on two major factors. The first of these is uptake and binding to tissues. A lypophilic drug may be expected to have a larger volume of distribution than a hydrophilic drug, because of better membrane-penetration. Propranolol, which is a highly lipid-soluble substance as is indicated by a partititioncoefficient of 5.4 between octanol and water at pH $=7.0$ (Johnsson and Reghard, 1976a) may be expected to possess extensive tissue-penetration.

The second factor determining distribution is in fact a limiter of the first one. Unless there is a very avid active uptake process involved, the only amount of drug available for tissue-penetration is the fraction which is free in plasma. A number of drugs do, however, bind extensively to plasma proteins. For propranolol plasma proteinbinding in man is around $93 \%$, and this limits its distribution and shortens alpha-halflife. In fact, species differences in distribution volume cited above, entirely depend upon species differences in plasma protein-binding (Evans et al., 1973a). The combination of the two factors results in rapidity and extent of distribution as mentioned above.

Binding of propranolol to plasma proteins is not only albumin-binding. It has been suggested that plasma albumin binds $62 \%$ of the drug in man, which is based on binding-studies to a $5 \mathrm{~g} / \mathrm{l}$ human-serum-albumin solution (Evans et al., 1973a). However, a recent study by Sager et al. (1979) indicates that binding in human plasma is largely to alpha ${ }_{1}$ - acid glycoprotein which was shown to be responsible for $75 \%$ of binding of propranolol at therapeutic plasma levels. Increases in alpha ${ }_{1}$ - acid glycoprotein, which occur in several inflammatory diseases, have been shown to greatly influence plasma protein-binding of propranolol, which is also indicative for an important contribution of binding of the drug to this protein (Piafsky et al., 1978). Not only disease may influence protein-binding in plasma. In fact, plasma proteinbinding of propranolol has been shown to be dependent upon concentration of the drug, a saturation of binding occurring at high concentrations in several species (Evans et al., 1973a; Zaagsma et al., 1977). Although saturation of protein-binding in human plasma only diminishes at concentrations higher than $\simeq 700 \mathrm{ng} / \mathrm{ml}$ (Evans et al., 1973a), in the rat, which is the species used in the present study, saturation of plasma protein-binding occurs already at drug-levels which are quite low $(\simeq 100$ $\mathrm{ng} / \mathrm{ml}$.). This will, theoretically, lead to an increase in distribution volume with increasing dose. This was, in fact, shown in the rat by Schneck et al. (1977).

In man, distribution of drugs can only be derived from concentration-time curves which are usually obtained in plasma. Animal experiments, however, offer the possibility to get detailed information on distribution. Organ distribution has been studied extensively in several species, including mice (Masuoka and Hansson, 1967; 


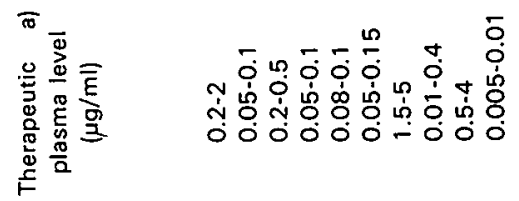

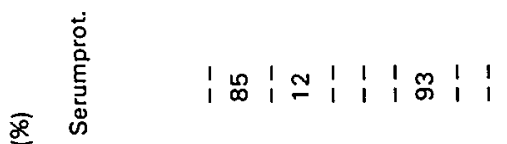

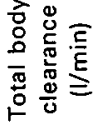

|

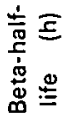

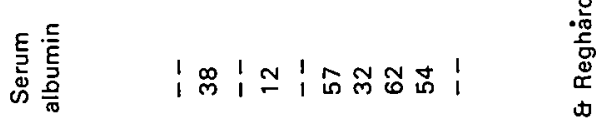

突

市

†

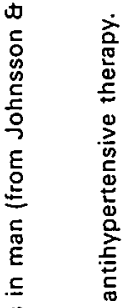

の

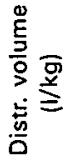

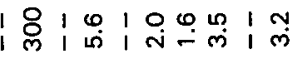

$\frac{4}{\pi} \cdot \bar{E}$

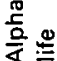

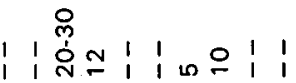

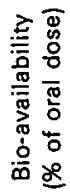

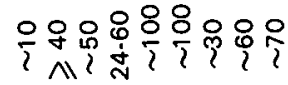

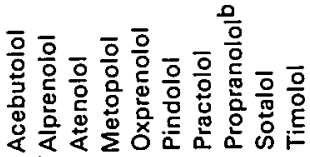

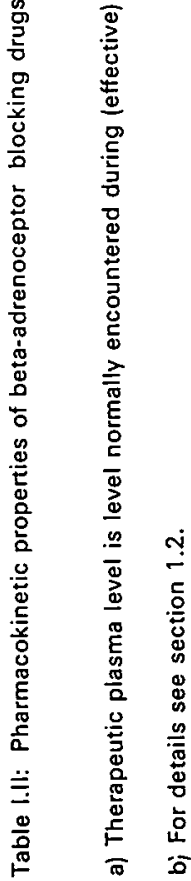


Levy et al., 1976), rats (Laverty and Taylor, 1968; Garvey and Ram, 1975a; Schneck et al., 1977; Elghozi et al., 1979; Street et al., 1979), monkeys and dogs (Hayes and Cooper, 1971). All these studies indicate an extensive uptake of propranolol in a variety of tissues, highest concentrations being noted in lungs, kidney and brain. From figures presented in the study by Schneck and co-workers (1977) it may be calculated that in the rat no active binding occurs to any tissue possibly with the exception of the lungs, for which in fact an active binding has been shown (Dollery and Junod, 1976). The study by Elghozi et al. (1979), who measured propranolol contents in certain brain nuclei of rats as a function of time revealed a retention in a number of these, however, half-life of disappearance from total brain did not differ from plasma half-life; the significance of this observation is not clear, since alprenolol did not influence the binding to these nuclei. In mice, retention in several tissues has been suggested (Levy et al., 1977), although the specificity of the (radio-immuno-) assay these authors used, may, however, be doubted. One study has reported on brain levels of propranolol in patients which had been treated with intravenous d-propranolol for paraquat poisoning (Myers et al., 1975b). In this study brain levels of propranolol following long-term infusion were found to be 15-fold higher than plasma propranolol levels. So in man tissue binding of propranolol to the brain may be more extensive than in other species, although it is very well possible that paraquat (which is a quaternary ammonium compound, like propranolol under physiological conditions) influences protein-binding, thus, resulting in artificially high tissue levels. Organ distribution will be discussed in chapters 4 and 12 of this thesis.

In conclusion, the distribution of propranolol through the body is rapid and extensive. It is determined predominantly by plasma protein-binding and lypophilicity, the former being variable in a number of conditions.

\section{ELIMINATION OF PROPRANOLOL.}

The half-life of the beta-phase of the plasma concentration-time curve of propranolol has been shown to vary between species and values of $40 \mathrm{~min}$ in rats (Shand et al., 1972) and several hours in man (Routledge and Shand, 1979) have been reported. Plasma half-life in the beta-phase is determined by volume of distribution and clearance. Factors influencing the former have been discussed above.

Propranolol is cleared from the body almost exclusively through metabolism, as is reflected by a recovery of unchanged drug in urine and feces of only $1-4 \%$ of the total amount of drug (Hayes and Cooper, 1971). Side chain deamination and oxidation as well as ring-oxidation lead to a number of metabolites, the most important of which are shown in figure 1.2.

One of these metabolites, the ring-oxidation product 4-hydroxy-propranolol, has been subject of discussion. It is the most interesting metabolite because it possesses beta-adrenoceptor blocking activity comparable to that of the parent drug (Fitzgerald and $O^{\prime}$ Donnell, 1971). Until very recently it was believed to be formed solely after oral ingestion of the drug (cf. Routledge and Shand, 1979). The reason for this was not clear, because it was established that the substance is formed through livermetabolism (Tindell et al., 1978). However, using highly specific and sensitive assaymethods Walle and co-workers (1980) have shown that the metabolite also occurs in 
human plasma following intravenous propranolol. The ratio of metabolite and parent drug is much lower after parenteral than after oral administration of the drug. This results from first-pass phenomena, which will be discussed below.

Metabolites are excreted as such and as conjugates (predominantely glucoronides). Man and monkey excrete only $2 \%$ of the total dose in feces, whereas in dogs and rats this fraction constitutes $25 \%$ of the total amount (Hayes and Cooper, 1971).

Clearance of propranolol from blood in man is approximately $1 \mathrm{l} / \mathrm{min}$ which is comparable to liver blood flow. Also in dogs $(34 \mathrm{ml} / \mathrm{min} . \mathrm{kg} \mathrm{b.w}$.) and monkeys $(14 \mathrm{ml} / \mathrm{min} . \mathrm{kg} \mathrm{b} . \mathrm{w}$.) clearance is close to liver blood flow (Evans et al., 1973a). Shand et al. (1972) reported a clearance value of $92 \mathrm{ml} / \mathrm{min}$. $\mathrm{kg}$ b.w. in rats after 2.5 $\mathrm{mg} / \mathrm{kg}$ intravenously. This would be indicative for extra-hepatic metabolism in this species. Others (Schneck et al., 1977) have reported values of $85 \mathrm{ml} / \mathrm{min}$. $\mathrm{kg} \mathrm{b} . \mathrm{w}$. and $63 \mathrm{ml} / \mathrm{min}$. $\mathrm{kg} \mathrm{b.w}$. for 1.5 and $7.5 \mathrm{mg} / \mathrm{kg}$ intravenously, the latter value approximating liver blood flow in rats.

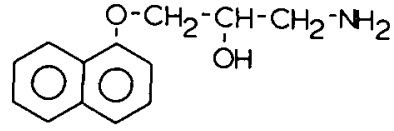

N.desisopropyl-propranolol

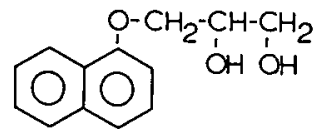

propranolol-glycol

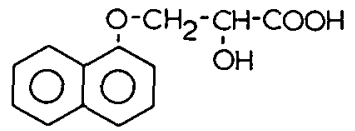

$\alpha \cdot$ naftoxy-lactic acid<smiles>CC(C)NCC(O)COc1ccc(O)c2ccccc12</smiles>

4-hydroxy-propranolol

Figure 1.2. Structural formulas of the major metabolites of propranolol.

Liver uptake of propranolol has been shown to be an extremely avid process.

Evans et al. (1973b) found evidence for a high affinity uptake process in isolated perfused rat livers, which has, however, limited capacity ( $400 \mu \mathrm{g} / \mathrm{g}$ liver). A more detailed study by Anderson and co-workers (1978) revealed two uptake mechanisms in a comparable preparation. One of these has a high affinity (dissociation constant 3 $\mu \mathrm{g} / \mathrm{ml})$ but limited capacity $(500 \mu \mathrm{g} / \mathrm{g}$ liver) whereas the other has a dissociation constant of $160 \mu \mathrm{g} / \mathrm{ml}$ but a much higher capacity than the former $(6500 \mu \mathrm{g} / \mathrm{g}$ liver). These uptake processes result in hepatic extraction ratios lying between 0.46 in monkeys and 0.97 in rats (Evans et al., 1973a).

Because of the high affinity of liver uptake, clearance is completely flow-dependent (Shand et al., 1973: Evans et al., 1973b; Anderson et al., 1978). Since, through its pharmacological properties, propranolol reduces cardiac output, and thereby liver blood flow, it may be expected that propranolol limits its own elimination. In fact, it has been shown that d-propranolol, the enantiomer which is devoid of betaadrenoceptor blocking properties (Howe and Shanks, 1968) and hence does not lower cardiac output, has a shorter half-life than the levo-isomer and the racemate in 
monkeys (Nies et al., 1973b) and man (George et al., 1972). It has been suggested (Shand, 1976) that d-propranolol would be handled differently from I-propranolol in the body. However, in an elegant study in which racemic propranolol was administered to dogs and the two stereo-isomers were determined separately, no difference in metabolic handling of the two was seen (Ehrsson, 1976).

From the above it may be expected that clearance is dose-dependent i.e. at high doses liver flow diminishes more than at lower doses and furthermore, liver uptake may become saturated. As already mentioned, in rats such a decrease of clearance has indeed been shown to occur with increasing dose (Street et al., 1977).

The relation between beta half-life, volume of distribution and clearance may be expressed as

$$
\mathrm{t} 1 / 2 \beta=0.693 \frac{V d \beta}{\text { clearance }}
$$

From the above-mentioned phenomena regarding volume of distribution and clearance, an increase in half-life with increasing doses can be expected. First of all, protein-binding may diminish at high concentrations, thus increasing volume of distribution. Furthermore, clearance may diminish as a consequence of saturation of liver uptake and lowering of cardiac output. This should result in prolonged beta-halflife. In fact, in rats Street and co-workers (1977) showed that increasing the dose from 1.5 to $7.5 \mathrm{mg} / \mathrm{kg}$ i.v. resulted in an $80 \%$ increase in beta-half-life, as a result from both increased $\operatorname{Vd} \beta$ and lowered clearance of the highest dose.

\section{ORALLY ADMINISTERED PROPRANOLOL.}

Upon oral ingestion propranolol is virtually completely absorbed. However, absorption is not the only factor determining the amount of a drug reaching the systemic circulation. Other processes may play a role.

From the discussions above it may be remembered that propranolol is extensively taken up by the liver. This process plays an important role in the fate of orally administered propranolol, since blood from the stomach and gut passes through the liver before entering the systemic circulation. Thus, propranolol is subject to a high degree of so-called first-pass elimination. This results in a bio-availability (i.e. the amount available for systemic distribution) of approximately $30 \%$ for propranolol (Johnsson and Reghàrd, 1976a).

Bio-availability has been the subject of much discussion. From saturation of high affinity low capacity liver uptake, a Michaelis-Menten-like kinetic pattern may be expected, i.e. increasing bio-availability with increasing dose, until at some point bioavailability will become constant. The first who reported this phenomenon were Shand and Rangno (1972). They noted that with doses between 40 and $160 \mathrm{mg}$ propranolol, there was a linear relationship between area under the plasma concentration time-curve (AUC) and dose, but with lower doses the ratio between AUC and dose became smaller. From their data they extrapolated to a "thresholddose" of $\mathbf{3 0} \mathrm{mg}$ which they stated to be necessary for any propranolol reaching the circulation following oral ingestion. This phenomenon has been challenged by Gomeni et al. (1977) who found a linear relationship between AUC and dose over a 
range of 10 to $40 \mathrm{mg}$ propranolol. It should, however, be noted that concentrations in plasma that are obtained with the lower doses approach detection-limits in both studies and small errors in concentration may result in huge errors in AUC.

Although the "threshold-dose" may be doubted, non-linearity of bio-availability is well-documented. It has been confirmed not only in patients (Walle et al., 1978) but also in isolated perfused rat livers (Evans et al., 1973b; Anderson et al., 1978). Furthermore, in a recent study by Walle and co-workers (1980) evidence for nonlinearity is contained. Although the authors did not find a difference in bio-availability for 20 and $80 \mathrm{mg}$ propranolol, they observed a decrease in the ratio between 4hydroxypropranolol and propranolol with increasing dose from 40 to $960 \mathrm{mg}$ daily. This probably reflects saturation of metabolic processes which are involved in presystemic clearance.

Recently the threshold-phenomenon has been questioned on the basis of pharmacodynamic evidence. Davies et al. $(1978,1979)$ reported physiological effects of repeated oral intake of $5 \mathrm{mg}$ propranolol (4 times with 8 hour intervals). Resting values of plasma renin activity, heart rate and blood pressure were reduced, as well as the effects of isoprenaline on these parameters.

Plasma-levels were found to be $4 \mathrm{ng} / \mathrm{ml}$ in samples, taken somewhere between 90 and $120 \mathrm{~min}$ after the last dose. It may, however, be that these effects result from actions of 4-hydroxy-propranolol which, as mentioned above, is formed in relatively large amounts at such low doses (Walle et al., 1980), thus although it is an interesting observation, these physiological data do not permit conclusions on the pharmacokinetics of propranolol.

Summarizing, it may be stated that bio-availability of oral propranolol is non-linear. However, an absolute threshold is not to be expected from theoretical and practical considerations. 
As has been discussed in this section first-pass clearance, distribution and elimination are all determined by high-rate processes like metabolism, proteinbinding and liver blood flow. This makes the pharmacokinetics of propranolol highly suspectible to inter- and intra-individual variations.

Ten- to twenty-fold inter-individual variation in plasma levels of propranolol following oral ingestion of the same dose have been reported (Chidsey et al., 1975; Esler et al., 1977; Lehtonen et al., 1977; Vervloet et al., 1977).

One study compared variation of plasma levels in patients following oral propranolol and compared it to variation in simultaneously administered $3 \mathrm{H}$-propranolol i.v. (Kornhauser et al., 1978). Their results show two-fold less variation in i.v. administered propranolol as compared to oral administration. This indicates that indeed a variable first-pass elimination is at least partly responsible for interindividual variation. In this context, an observation by Melander et al. (1977) may indicate that variation in this pre-systemic clearance is also a cause for intraindividual variation. These authors observed an increased bio-availability in their subjects if the drug was taken together with food. This phenomenon has been explained on the basis of changes in splanchnic blood flow which occur postprandially (McLean et al., 1978).

Besides the few factors cited above, a number of others have been recognized to cause changes in propranolol's pharmacokinetic behaviour. These have been excellently reviewed by Routledge and Shand (1979) and may all be related to the mechanisms which have been discussed here to be determining propranolol's pharmacokinetics. They will not be discussed further. It should, however, be noted that most of them are depending on factors like diet, disease, smoking-habits and genetic differences in metabolic capacities, which are not to be expected in the highly in-bred rat strains used in this and other animal-experimental studies. Differences caused by dose may be expected to persist.

1.3. The antihypertensive effect of propranolol: hemodynamic pattern of the response and proposed mechanisms of action.

Since the first reports by Prichard (1964) and Prichard and Gillam (1964) about resp. pronethalol's and propranolol's capability of lowering blood pressure, a large amount of research has been devoted to the hemodynamic effects underlying it.

A number of hypotheses have been proposed to explain the lowering of blood pressure, each focussing on one of the multiple actions of the drug in the cardiovascular system. However, it would probably be a simplification to suppose that the antihypertensive effect of propranolol (and more general of beta-adrenoceptor blockers) derives from only one of the many effects. This will be further discussed in this chapter, after attention has been paid to the hemodynamic effects of propranolol in man. 


\section{HEART RATE AND CARDIAC OUTPUT.}

Probably the most obvious effect of propranolol, both upon acute (intravenous) and chronic administration, is its bradycardic effect. This effect, which occurs during rest and exercise, is shared by all beta-adrenoceptor blocking drugs with the exception of those exhibiting partial agonist properties. The latter only have effects on exercise heart rate, leaving resting heart rate unaffected (Frishman and Silverman, 1979). The slowing of the heart derives largely from blockade of cardiac $\left(\beta_{1}\right)$ adrenoceptors. In patients treated with doses of $d$-propranolol comparable to those of the racemic drug, no reduction in heart rate could be detected (Waal-Manning, 1970; Rahn et al., 1974). A small degree of bradycardia has been obtained in anesthetized dogs, in which $5.25 \mathrm{mg} / \mathrm{kg}$ d-propranolol i.v. was needed to reduce heart rate by 20 beats $/ \mathrm{min}$, in contrast to the $0.25 \mathrm{mg} / \mathrm{kg}$ dl-propranolol which was needed for a heart rate reduction by 23 beats/min (Barrett, 1969). Similar observations were made in unanesthetized primates by Nies and co-workers (1973b) who reported $0.33 \mathrm{mg} / \mathrm{kg}$ dl-propranolol to be effective for eliciting bradycardia, whereas an equal dose of $d$ propranolol was not. This suggests some affinity of d-propranolol for betaadrenoceptors.

Since the reduction in heart rate is not accompanied by an increased stroke volume, it results in a diminished cardiac output as well. For propranolol a fall in cardiac output has been documented at rest and during exercise both after acute (Epstein et al., 1965; Ulrych et al., 1968; Johnsson et al., 1969; Sannerstedt et al., 1970; Tarazi and Dustan, 1972; Hansson, 1973; Hansson et al., 1974; Lund-Johansen, 1979; Conway, 1980) and chronic administration (Frohlich et al., 1968; Tarazi and Dustan, 1972; Hansson, 1973; Hansson et al., 1974; Lund-Johansen 1979). Depending upon dose a reduction of 13 to $25 \%$ is seen by aft investigators. From these studies it may be concluded that there is no return of cardiac output to control values during long-term therapy.

As suggested above, stroke volume does not increase, but rather a $4-10 \%$ decrease of this parameter is seen following acute administration of propranolol in the abovementioned studies. During long-term therapy the effect upon stroke volume disappears or even inverses (Frohlich et al., 1968; Hansson, 1973; Hansson et al., 1974); however, it does not quantitatively influence the effects of propranolol on cardiac output.

\section{EFFECTS ON BLOOD PRESSURE.}

Propranolol (as in fact all beta-adrenoceptor blocking drugs) has been shown to be an effective antihypertensive agent in hypertensive patients, although the effect is only modest (cf. Conway, 1980). In normotensive subjects a small but significant reduction of systolic (but not diastolic) pressure has been reported (LeWinter et al., $1975)$. There is a group of patients ( 30\%) which do not respond to beta-blockade with a lowering of blood pressure. This will be discussed more fully below.

For this moment, the most interesting is the rapidity of onset of the effect. What is obvious from all investigations, is that blood pressure does not fall concomitantly with cardiac output. In early studies it was said to take weeks to months to observe 
maximal effects (Prichard and Gillam, 1969; Tarazi and Dustan, 1972), but lately more acurate studies with atenolol, a cardio-selective beta-adrenoceptor blocking drug (Fitzgerald et al., 1978) and also with propranolol (Stumpe et al., 1976; Maling et al., 1979; Conway, 1980) have revealed a delay of only hours for an antihyperterisive effect to occur after acute dosage. It should, however, be mentioned that in the study of Stumpe et al. (1976) such a fast reduction of blood pressure was only seen in borderline hypertensives and not in established hypertension, although this may be a matter of dose. The dissociation between timing of reduction of cardiac output and blood pressure remains, however. This is also illustrated by the observation of Wilson et al. (1976) who reported the antihypertensive effect of propranolol to last for more than $24 \mathrm{~h}$, in spite of heart rate having returned to control values before.

\section{EFFECT ON PERIPHERAL VASCULAR RESISTANCE.}

From the above two paragraphs where a dissociation between cardiac output and blood pressure was discussed, it should be concluded that beta-adrenoceptor blockade influences peripheral vascular resistance. Acute administration of propranolol in man leads to increases in this parameter between 10 and $30 \%$ (Ulrych et al., 1968; Johnsson et al., 1969; Sannerstedt et al., 1976; Tarazi and Dustan, 1972; Hansson, 1973; Hansson et al., 1974). From a study in unanesthetized primates it may be concluded that the increase in resistance is equally distributed to all organs, with the exception of the brain, which is relatively spared (Nies et al., 1973b). This increase in resistance may have several causes. First of all it may derive from blockade of vascular beta 2 -adrenoceptors, stimulation of which causes vasodilation. This has, however, been shown to elicit variable effects in preparations using isolated perfused hindlimbs of rats (Rascher et al., 1978) or dogs (Sweet et al., 1979). In man JuhlinDanfelt and Aström (1979) recently confirmed the absence of direct effects of beta ${ }_{2}^{-}$ adrenoceptor blockade on peripheral vascular resistance in a set-up which was comparable to the isolated hind-limb preparation which is used in animals. Also in humans no direct effects on leg blood flow could be shown.

The results indicate, that these receptors do not substantially contribute to regulation of peripheral resistance under normal conditions. In a situation of stress or extreme exercise this situation may be different (Herwaarden, 1978), since under these conditions the adrenals release large amounts of adrenaline.

Further evidence for blockade of peripheral beta 2 -adrenoceptor blockade not being responsible for the increase in peripheral resistance comes from the fact that cardioselective ( $=$ beta $_{1}-$ ) adrenoceptor blocking drugs also increase peripheral resistance after acute administration (cf. Lysbo Svendsen, 1979).

Another possible mechanism could be an increase in sympathetic activity as a consequence of the decreased cardiac output. This is indicated by studies of the behaviour of plasma catecholamine levels in response to beta-adrenoceptor blockade. Immediately following injection of propranolol increases are seen in plasma noradrenaline (Benedict et al., 1977; Morganti et al., 1979) and adrenaline (Bonelli et al., 1979; Morganti et al., 1979). In the study of Bonelli, however, no evidence for an increased level of noradrenaline following acute propranolol was found. Taking plasma catecholamine levels as an index of sympathetic nervous 
activity, this would indeed indicate an increased activity in this parameter. This is contrary to findings in experimental animals, where direct measurement of nervous activity revealed a decreased firing rate of renal efferent newes (Friggi et al., 1977) after infusion of atenolol and of the splanchnic nerve after infusion of propranolol (Lewis and Haeusler, 1975) both in rabbits. It should, however, be noted that in both studies blood pressure dropped rapidly, making comparison with the slow response (as far as blood pressure is concerned) in man difficult. In fact, rabbits seem to be special in the rapidity of the response, which is not seen in other species. Assuming an increased sympathetic activity immediately following propranolol in man, it should, however, be studied what is the trigger for this increase. This will be discussed in this thesis.

During long-term therapy with beta-adrenoceptor blocking drugs, peripheral resistance has been shown to return to pre-treatment values, or to values just above (Frohlich et al., 1968; Tarazi and Dustan, 1972; Hansson, 1973; Hansson et al., 1974; Lund-Johansson, 1979). It is this return to lower resistance values that eventually leads to decreased blood pressure, since cardiac output remains low.

In this context it is of interest to take a closer look at the so-called non-responders, i.e. the group of hypertensive patients not responding to beta-blockade. Tarazi and Dustan (1972) and Hansson et al. (1974) both found that hemodynamic changes in non-responders were identical to those in responders with the exception of peripheral resistance which remained at a higher level in the non-responding group than in the responders.

It still is not clear what makes peripheral resistance return to control values. In it, undoubtedly one of the secrets of the antihypertensive activity of beta-adrenoceptor blocking.drugs is contained. Possible hypotheses for this will be discussed below.

\section{RENAL EFFECTS AND EFFECTS ON BODY FLUID VOLUMES.}

Renal effects may be subdivided in two parts. First of all beta-adrenoceptor blocking drugs have effects on renin release from the kidney. Secondly the overall hemodynamic changes may precipitate effects in the renal circulation and, via this, in fluid balance.

Renin is the first hormone in the sequence leading to angiotensin II, which is an extremely potent vasoconstrictor. Its release is stimulated amongst others through the sympathetic nervous system. Renin-release from the kidney is mediated by betaadrenoceptors. The nature of this receptor is still in discussion. Some beta ${ }^{-}$ adrenoceptor blocking drugs do not, or only slightly, reduce plasma renin activity (cf. Frishman and Silverman, 1979). Therefore, it has been suggested that it is a beta $2^{-}$ adrenoceptor. However, recently Gavras et al. (1979) reviewed clinical evidence for a beta $_{1}$-adrenoceptor-mediated release in man.

Thus, the exact nature of the beta-adrenoceptor mediating renin-release is still under discussion; for the actions of propranolol on plasma renin activity it does not matter. since this drug does not have specificity for beta ${ }_{1}$-or beta 2 -adrenoceptors. 
Upon acute administration propranolol lowers plasma renin activity within a short time, i.e. within an hour after acute administration in man as is shown by most authors (Hansson et al., 1974; Stokes et al., 1976; Stumpe et al., 1976; Sullivan et al., 1976; Morganti et al., 1979; Conway, 1980). Also in rabbits (Weber et al., 1974), dogs (Yum et al., 1977; Privitera et al., 1979) and SHR (Riley et al., 1976) reduction of plasma renin activity has been shown to be very rapid in onset. This is a first indication of a dissociation between the reduction in plasma renin activity and antihypertensive effect.

Nevertheless, a reduction of PRA has been suggested to be a primary mechanism for the lowering of blood pressure. This is based upon studies of Bühler et al. (1972, 1973,1975 ) who showed that the reduction of blood pressure in a group of patients with high or normal pre-treatment values of PRA was greater than that in a sub-group with low pre-treatment PRA. There was also a relationship between the degrees of reduction of PRA and blood pressure. These observations were confirmed by several others (Karlberg et al., 1976; Drayer et al., 1978; Vlachakis, 1980). Hollifield and coworkers (1976) noticed, however, that in their patients $160 \mathrm{mg}$ propranolol daily lowered blood pressure in high and normal renin hypertensives in a way related to the reduction of PRA. This dose was ineffective in low-renin patients. However, increment of the daily dose to $320-960 \mathrm{mg}$ caused an antihypertensive effect in all groups, which was independent of the reduction of PRA. Similar observations were made by others (Esler et al., 1977; Zweifler and Esler, 1977) whereas some authors could not find any relationship at all between PRA and blood pressure (Stokes et al., 1974; Bravo et al., 1975; Geyskes et al., 1975).

Further evidence for the fact that a reduction of PRA is not essential for the antihypertensive effect of beta-adrenoceptor blocking drugs in general comes from the fact that others than propranolol have no effect on PRA, as was shown for practolol (Esler, 1974), alprenolol (Gordon, 1976) and atenolol (Amery et al., 1974) or even increase PRA like pindolol (Stokes et al., 1974), yet their antihypertensive effectiveness is comparable to that of propranolol.

Thus, although changes in plasma renin activity may contribute to the ultimate antihypertensive effect of propranolol, it certainly does not explain why betaadrenoceptor blocking drugs in general cause a lowering of blood pressure.

The overall hemodynamic changes elicited by beta-adrenoceptor blockade, have consequences on renal circulation too. In fact, a reduction in renal plasma flow and glomerular filtration rate has been shown following propranolol (Schirmeister et al., 1966; Carriere, 1969; Nies et al., 1971; Ibsen and Sederberg-Olsen, 1973; Nies et al., 1973; Sullivan et al., 1976; Nomura et al., 1978; Bauer and Brooks, 1979; Falch et al., 1979; Hollenberg et al., 1979), whereas others reported the opposite, i.e. increased renal plasma flow (Carrara and Baines, 1976; Shibouta et al., 1979) without change in glomerular filtration rate. The same controversy exists for other beta-adrenoceptor blocking drugs. It should, however, be noted that the studies showing increases in the renal hemodynamic parameters were carried out in anesthetized animals, where damping of nervous reflexes may have played a role.

It may thus be concluded that beta-adrenoceptor blockade leads to either decreased or unchanged renal plasma flow and glomerular filtration rate, a possible decrease 
probably being related to the decrease in cardiac output (Sannerstedt and Conway. 1970; Nies et al., 1971; Bauer and Brooks, 1979).

Yet, beta-adrenoceptor blockade does not lead to an expansion of body fluid volumes, as should be expected in a situation with a primary reduced cardiac output, comparable to chronic heart failure. Plasma volume was even found to be decreased following acute (Julius et al., 1972) or long-term (Tarazi et al., 1971) administration, although other studies with propranolol (Sederberg-Olsen and Ibsen, 1972; Parving and Gyntelberg, 1973; Weidmann et al., 1976) and other beta-adrenoceptor blocking drugs like metoprolol (Rasmussen and Rasmussen, 1979) and atenolol (Amery et al., 1976) indicate no effect on plasma volume and possibly a slight increase in total extracellular fluid volume. Also no effect on total exchangeable body sodium and potassium has been found during propranolol therapy (Pedersen et al., 1979). Excretion of water and electrolytes is not only controlled by filtration, but probably a major control-mechanism is in reabsorption from the renal tubules. Under normal conditions water and sodium are reabsorbed for appr. $99 \%$ from the tubular fluid. Small changes in this process might have enormous consequences for body fluid volumes and through them on blood pressure. If beta-adrenoceptor blocking drugs influence tubular transport processes, it should be investigated through what factor(s) they possibly can do so.

First of all tubular reabsorption may be influenced by hormonal agents like angiotensin II, aldosterone and vasopressin. More important is, however, the observation that tubular function is also under sympathetic nervous control (for reviews: Di Bona, 1977, 1978). Antinatriuresis without change in overall renal hemodynamics may be elicited by sympathetic stimulation, resulting from both a baro-receptor reflex or a volume reflex mediated through volume-sensitive receptors in the left atrium (Di Bona, 1977, 1978; Kappagoda et al., 1979; Linden and Sreeharan, 1979). The exact nature of the adrenoceptor eventually mediating this response is not yet clear. An alpha-adrenergic component surely is in it (Di Bona, 1977,1978 ) but a possible beta-adrenoceptor involvement in this regulation-process cannot be excluded (Gill, 1979).

By influencing tubular reabsorption, through blockade of possible renal tubular betaadrenoceptors the above-mentioned absence of fluid-retention under circumstances of low cardiac output may be explained. This will be discussed in full extent in chapter 11 of this thesis.

\section{EFFECTS ON THE SYMPATHETIC NERVOUS SYSTEM.}

A drug's interference with the sympathetic nervous system control of blood pressure may be related to an action at one or more of several sites.

First of all there may be an action on the sensory units serving as an input for central nervous system integration-processes. Secondly these very integration-processes themselves may be influenced by interference with neurotransmission in the brain. This may both result in an increased or decreased outflow of nervous traffic to and/or beyond sympathetic ganglia. Finally there is a possibility of interference with synaps at the effector organ, i.e. a presynaptic effect. And although it is not really related to the activity of the sympathetic nervous system the stimulus-effector relationship may be changed. As stated, this latter is not to be related to activity but rather to the 
efficacy of the sympathetic nervous system.

The action of beta-adrenoceptor drugs at each of the levels mentioned, has been subject of extensive studies, which will be discussed here. In this discussion, data from animal-experiments are of extreme importance because of obvious experimental limitations encountered in man for this type of research.

Information about the magnitude of blood pressure reaches the brain from the baroreceptors, which are stretch-sensitive elements lying in the aortic arch and carotid sinusses. An increase in nervous activity in fibres originating from these receptors occurs, following an increase in blood pressure.

Resetting of the set-point of these baroreceptors to a lower "regulation-pressure" has been suggested to be the ultimate cause of the antihypertensive activity of propranolol (Prichard and Gillam, 1969). A direct effect of propranolol on afferent nerve traffic from these elements has been shown in two studies.

One study in cats (Tuttle and McLeary, 1978) revealed an increase in nerve activity derived from fibres which were identified as resulting from baroreceptors when the isolated carotid-sinusses were perfused with a solution containing $5 \mu \mathrm{g} / \mathrm{ml}$ propranolol. Both set-point and gain of the pressure-induced firing rates of the fibres were increased. Similar results were obtained in a comparable preparation in rabbits (Angell-James and Bobik, 1979). These latter authors also showed an increased baroreceptor afferent nerve-activity in renal hypertensive rabbits treated for 2-15 weeks with propranolol $(7 \mathrm{mg} / \mathrm{kg}$ i.m., twice daily) as compared to control renal hypertensive rabbits. In fact, the propranolol-treated animals more closely resembled normotensive untreated rabbits, both with regard to blood pressure and to baroreceptor-sensitivity.

Both authors discuss their results as being secondary to structural changes in the vessel-walls containing the baroreceptor-elements, although a more precise description of this phenomenon is not given. Furthermore, an apparent lack of both studies is the fact that d-propranolol was not tested, thus it is not clear whether the effects result from beta-adrenoceptor blockade or from local anesthetic properties of propranolol.

In man, only more indirect information about the baroreceptor reflex can be obtained. If the re-adjustment of the peripheral resistance results from decreased sympathetic tone, this may be interpreted as a result from resetting of the baroreceptors to a lower set-point. Cardiac effects will, of course, be obscured by the blockade of the (purely beta-adrenergic) components. Evidence for such a possibly reduced sympathetic vascular tone will be discussed below. Information about the gain of the baroreceptor reflex in man has been obtained by the technique introduced by Smyth et al. (1969) which is based upon correlation of the prolonging of the R-R-interval and increments of blood pressure seen upon injection of an alpha-adrenoceptor stimulant (phenylephrine).

Inconsistent results have been reported on the baroreceptor reflex in man during beta-adrenoceptor blockade. Pickering et al. (1972) found an increased sensitivity of the reflex in normotensives, both following acute and long-term propranolol.

This was confirmed in hypertensives for long-term therapy by Takeshita et al. (1978) and Hansson et al. (1974) although in the latter study (which used angiotensin II as a vasoconstricting agent) the effect did not reach statistical significance. Others have 
found no effect following acute propranolol (Simon et al., 1977), metoprolol or acebutolol (Watson et al., 1979), or long-term timolol (Simon et al., 1977) or propranolol (Krediet and Dunning, 1979; Watson et al., 1979) metoprolol and acebutolol (Watson et al., 1979). In conclusion, a contribution of increased baroreceptor activity to the effects observed in man is not yet clearly confirmed, however, this lack of confirmation may result from technical limitations. Using a modification of the technique of Smyth et al. (1969) we have carried out investigations into the baro-reflex sensitivity in spontaneoulsy hypertensive rats following propranolol, the results of which will be reported and discussed in this thesis.

From animal studies, evidence both in favour of and against an action of betaadrenoceptor blocking drugs within the central nervous system, contributing to the antihypertensive effects of these drugs, has been reported. Within the mammalian brain, interference with noradrenaline and dopamine turn-over have been reported (Fuxe et al., 1976a, b; Morinan and Leonard, 1977; Wiesel, 1977).

Also an interaction with GABA-ergic mechanisms has been suggested (Morinan and Leonard, 1977), whereas interaction with neurotransmission on serotoninergic snail neurons has also been shown (Cotrell and Cobett, 1978) although this latter was neither serotonin-specific nor stereo-selective. Evidence against involvement of central mono-aminergic mechanisms in the effects of propranolol has, however, also been obtained (Laverty and Taylor, 1968).

Direct evidence for beta-adrenoceptors involved in the central nervous system regulation of blood pressure has been thought to derive from animal studies in which propranolol was shown to be capable of lowering blood pressure, when introduced directly into the cerebral ventricles or the vertebral artery of either awake, or anesthetized experimental animals, like they were first performed in 1970 (Kelliher and Buckley, 1970). This first study showed an antihypertensive effect of $0.5 \mathrm{mg}$ propranolol in chloralose-anesthetized cats; $d$-propranolol proved to be equipotent to dl-propranolol in this study. Since this first report these results have been confirmed (Srivastava et al., 1973; Day and Roach, 1974; Reid et al., 1974; Day and Roach, 1975; Garvey and Ram, 1975; Myers et al, 1975a; b; Kelliher, 1976; Klevans et al., 1976; Sweet and Wenger, 1976; Sweet et al., 1976; Wepierre et al., 1978) but also denied (Offerhaus and van Zwieten, 1974; Nijkamp et al.,1979). Propranolol has been shown to be taken up rapidly and extensively into the brain of several species (Masuoka and Hansson, 1967; Laverty and Taylor, 1968; Hayes and Cooper, 1971; Levy et al., 1976; Schneck et al, 1977; Street et al., 1979) including man (Myers et al., 1975 b) Apart from this being an indirect indication for a possible action within the central nervous system, it is also an indication for the fact that once propranolol is injected into the brain, it will leak out very rapidly, as has in fact been shown in rabbits (Anderson et al., 1977). This should be taken into account in the interpretation of results. Circumstantial evidence against a central nervous system action comes from the fact that there are a number of beta-adrenoceptor blocking drugs which hardly penetrate into the brain (atenolol, sotalol, timolol) yet they do lower blood pressure in man. In this thesis results will be reported from studies in which both acute injections as well as long-term infusions of propranolol were done in SHR. There, further evidence against and in favour of a central nervous system action will be discussed in full detail. 
Changes in afferent sensitivity and/or central nervous system processing of the information should be reflected in a change, in this case diminishment, of efferent sympathetic nervous activity to result in effects.

The best possible way to assess efferent sympathetic nervous activity is undoubtedly the measurement of electrical activity in sympathetic fibres. This has been done both in conscious rabbits following propranolol (Lewis and Haeusler, 1975) and in anesthetized rabbits following atenolol (Friggi et al., 1977; Scott, 1978). In all studies a reduction of sympathetic nervous activity was observed, immediately following administration of beta-adrenoceptor blocking drugs. It should, however, be mentioned that in all studies blood pressure was lowered very rapidly, a phenomenon which is generally not observed in man, but as already mentioned above, this seems to be unique for rabbit. Another factor which is thought to be an index of efferent sympathetic nervous activity is the activity of catecholamine-synthetizing enzymes more specifically tyrosine-hydroxylase in sympathetic ganglia. Studies, again performed in animals, have shown a reduction in this activity following propranolol treatment in superior cervical ganglia and adrenal glands (Äblad et al., 1977; Raine and Chubb, 1977; Bhagat, 1978).

In man, the only measurable index which is believed to exist at this moment for sympathetic nervous activity is the level of plasma catecholamines which may be measured at rest or during physical or mental stress, thus providing an indirect impression of neural release of neurotransmitter.

Because apparent differences in acute and long-term effect of beta-adrenoceptor blocking drugs on blood pressure in man, this division should also be made with regard to the effects on plasma levels of catecholamines. Acute administration of propranolol has been shown uniformly to enhance the rise in plasma catecholamines induced by physical exercise (Irving et al., 1974; Lütold et al., 1976; Benedict et al., 1977; Palm and Grobecker, 1977; Hansen et al., 1978), although the effects of mental (calculation) stress are not influenced (Bonelli et al., 1979). Under resting conditions the effects are more variable. No effects were observed by several authors (Irving et al., 1974; Lütold et al., 1976; Palm and Grobecker, 1977; Bonelli et al., 1979). Increases in plasma noradrenaline and adrenaline were seen by others (Morganti et al., 1979); Benedict et al. (1979), Hansen et al. (1978) and Maling et al. (1979) only measured noradrenaline which was found to increase in the former two studies and not to change in the latter study following acute beta-adrenoceptor blockade with propranolol.

Long-term beta-adrenoceptor blockade during a 3-8 week's treatment of essential hypertensives with propranolol at rest increased both noradrenaline (Rahn et al., 1978; Vlachakis, 1979) and adrenaline (Rahn et al., 1978). Others could, however, not confirm this observation and reported unchanged noradrenaline-levels (Benedict et al., 1976; De Leeuw et al., 1977; Palm and Grobecker, 1977; Franco Morselli et al., 1978; Hamilton et al., 1978) or decreased levels for adrenaline (Franco Morselli et al., 1978). Similar disagreements exist for other beta-adrenoceptor blocking drugs. As in the acute studies, also after chronic administration of propranolol the increase in catecholamine-levels during physical exercise has been shown to be enhanced (Benedict et al., 1977; Palm and Grobecker, 1977; Rahn et al., 1978). 
Thus, assuming that plasma noradrenaline and adrenaline-levels provide an index for sympathetic nervous activity, this parameter should be concluded to increase, rather than decrease following acute and long-term propranolol therapy.

Although possible effects of propranolol on noradrenaline re-uptake (Avakian and Gillespie, 1968; Foo et al., 1968) and mono-amine-oxidase activity (Greef and Wagner, 1966) might be regarded to explain possible increases in plasma catecholamine-levels it should be noted that the levels needed to induce those effects are several orders of magnitude higher than those to obtain beta-blockade, which are in therapeutic ranges for obtaining an antihypertensive effect (Rahn et al, 1978).

From the above it should be concluded either that plasma-catecholamine levels do not accurately reflect sympathetic nervous activity in man, or that sympathetic nervous activity does not decrease under the influence of beta-adrenoceptor blockade. Finally a number of studies have been performed into nervous stimuluseffect relationship at the level of the peripheral vasculature. Following propranolol sympathetic stimulation has been reported to result in a decreased pressor response in the isolated perfused hind-limb of cats (Äblad et al., 1970) and dogs (Lokhandwala et al., 1976). A similar decreased effect of sympathetic stimulation has been reported for the cat nictating membrane (Eliash and Weinstock, 1971) and in isolated organ preparations like the isolate guinea-pig vas deferens (Mylecharane and Raper, 1970) and, interestingly, the portal vein of SHR (Ljung et al., 1975). This reduction in response occured in spite of unchanged (Mylecharane and Raper, 1970; Eliash and Weinstock, 1971; Ljung et al, 1975; Lokhandwala, 1976) or even increased (Äblad et al., 1970) sensitivity to exogenous noradrenaline, suggesting a pre-synaptic effect. However, increased responses to sympathetic nervous stimulation have been observed in the dog hind-limb (Dawes and Faulkner, 1975) and in DOCA-saline rats (Buñag, 1977) following propranolol. In the latter two studies there was also a greate sensitivity towards exogenously administered noradrenaline.

Similar results have been obtained with indirectly acting sympathomimetic amines (review Weinstock, 1976) also indicative for a pre-synaptic effect of propranolol. A pre-synaptic action has been proposed as a mechanism whereby beta-adrenoceptor blocking drugs lower blood pressure (Stjärne and Brundin, 1976).

If propranolol were to act presynaptically by a possible inhibition of stimulus-induced noradrenaline release, it would, however, be expected that this is reflected in decreased levels of circulating noradrenaline, which is, as discussed above, not observed in man. Thus, although there may be such an inhibition, it is not likely to play a role in the antihypertensive effect in man.

\subsection{Antihypertensive effects of propranolol in experimental hypertension.}

Probably part of the confusion existing about the antihypertensive mechanism of action of propranolol and other beta-adrenoceptor blocking drugs derives from the variety of results that have been reported from animal experiments. The species that have been used include rabbits, cats, dogs, monkeys and rats, as was recently reviewed by Buckingham and Hamilton (1979). Animals were either normotensive or hypertensive whereas a number of studies were carried out under anethesia for which 
different types of anesthetics have been used.

This chapter will focus on the possible antihypertensive effects in rats. For this there are two main reasons. First of all it is the most widely used animal in pharmalogical studies. This probably results from the fact is readily available, cheap and yet its dimensions allow a number of hemodynamic measurements. Secondly, in this animal species a good model for human essential hypertension has been developed, by selective in-breeding.

This model is known as the spontaneously hypertensive rat (SHR) or rather the Okamoto-SHR after the man who developed it (Okamoto and Aoki, 1963). Although since the first reports on this strain of rats a number of other strains have been developed that also possess this property, the Okamoto-strain is still the bestdocumented.

As stated above, hypertension in the Okamoto-SHR (that will referred to just as SHR in the rest of this thesis) resembles essential human hypertension.

At birth, the animals have a normal blood pressure as compared to their normotensive congeners, the Wistar-Kyoto rat. This remains so until some 6-8 weeks after birth, when a hypertension develops and stabilizes in some 4-6 weeks (review: Folkow and Hallbäck 1977).

This makes the SHR attractive for the study of antihypertensive agents and several of these have been shown to be active in this model (cf. Struyker-Boudier et al., 1980). Also beta-adrenoceptor blocking drugs have been tested in SHR, the results of which will be discussed here. They will be compared to studies in other types of experimental hypertension in rats.

A second limitation that will be made is, that this discussion will predominantly feature propranolol. It is the best documented beta-adrenoceptor blocking drug, and especially the availability of its non-beta-adrenoceptor blocking stereo-isomer (d-propranolol), as discussed in section 1.1., makes it attractive for mechanistic studies.

A popular approach for testing antihypertensive properties of beta-adrenoceptor blocking drugs is the attempt to prevent development of hypertension in rats. Table I.III summarizes results of this type of experiment with propranolol.

Although it probably does not contain all studies, it gives a general picture. It indicates that spontaneous hypertension may effectively be attenuated though not completely abolished if treatment commences soon after birth. Studies by Pfeffer et al. (1977) and Nishiyama et al. (1978) do not confirm this observation. In both studies however, blood pressure was measured in anesthetized animals which is in contrast to the other studies.

Thus, it may be an effect of the anesthetic that obscures an antihypertensive action, although both authors report reduced heart rate and cardiac output in their animals.

Also the development of DOCA-salt hypertension may be attenuated by propranolol over a wide dose range (see table I.III). Only one study by Takeda et al. (1975) could not confirm this. It may have been that the dose-regimen $(1 \times 100 \mathrm{mg} / \mathrm{kg}$ per day by gavage) has not been effective, however, it was effective to inhibit spontaneous hypertension in the same study. 

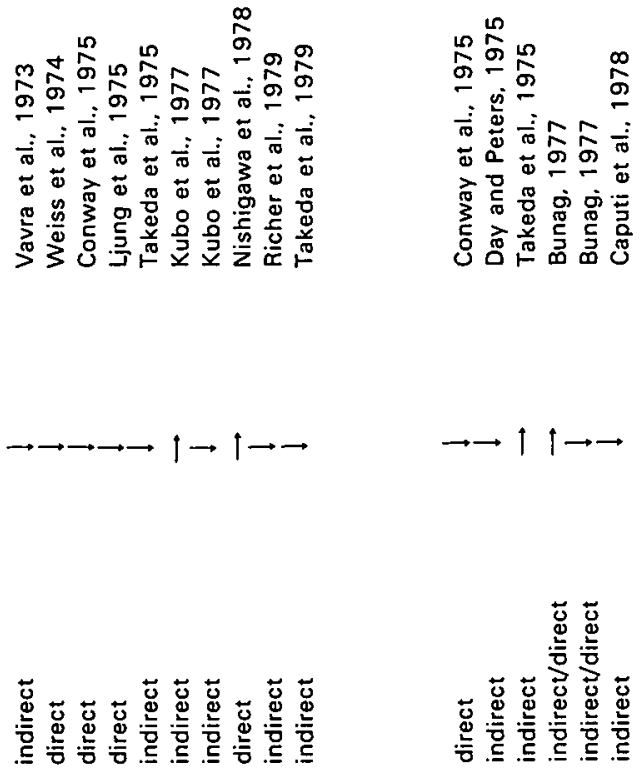

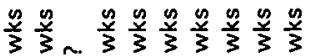

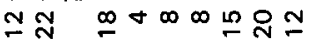
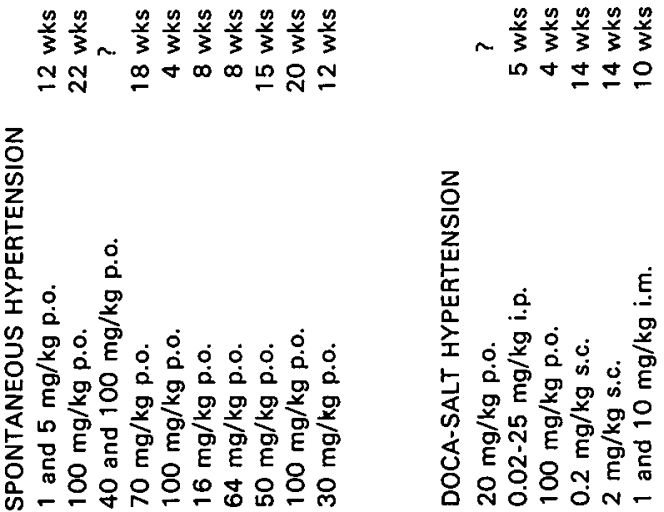

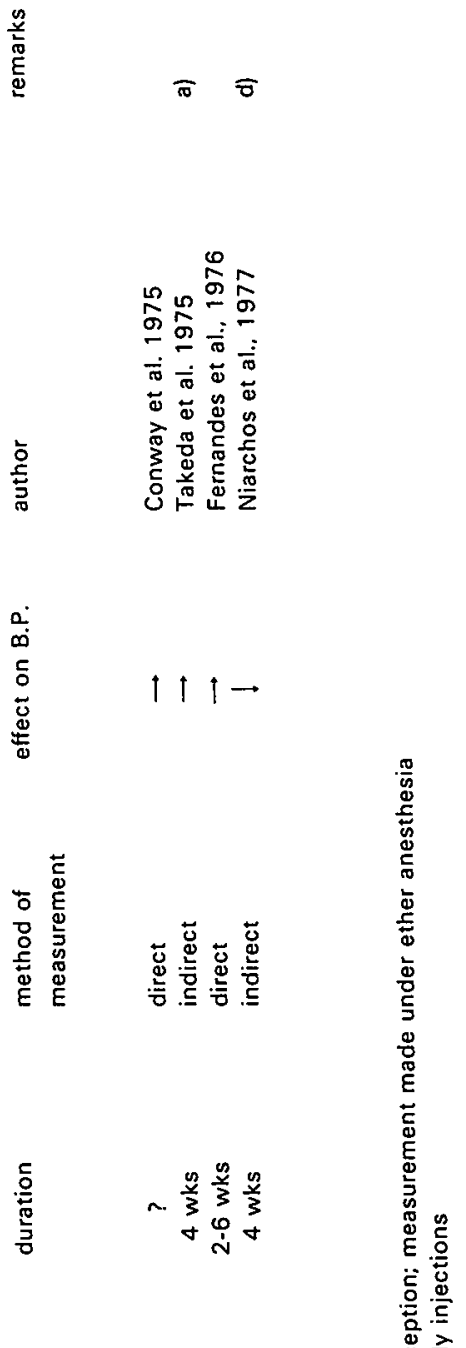

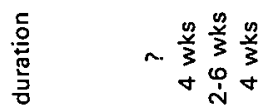

용 등

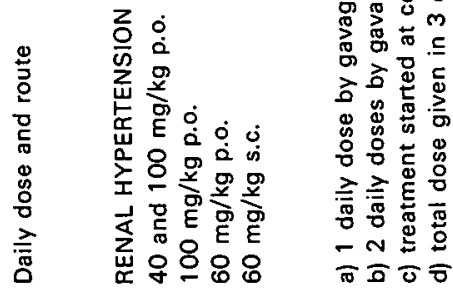


Renal hypertension (both 1 kidney and 2 kidney-models have been pooled in table I.III) seems to be resistant to beta-adrenoceptor blockade with propranolol. In this type of hypertension in rats only one study has reported the efficacy of propranolol in preventing it (Niarchos et al., 1977) although the effects were variable. The authors related the antihypertensive effect op propranolol in their (two-kidney renovascular hypertensive) model to a reduction in plasma renin activity. In renal hypertensive rabbits propranolol has been reported to be effective too (Angell-James and Bobik, 1979).

Prolonged administration of propranolol once hypertension has established in SHR has led to more variable results. These studies are summarized in table I.IV. Kubo and coworkers (1977) noted a reduction of blood pressure upon treatment with propranolol (64 mg/kg p.o.) for 12 weeks.

The reduction of systolic blood pressure was significant only after 7 weeks of administration and thereafter. Sweet et al. (1975) reported an antihypertensive effect already after $3-4$ days of administration of $20 \mathrm{mg} / \mathrm{kg} \mathrm{p.o.} \mathrm{The} \mathrm{main} \mathrm{difference} \mathrm{in} \mathrm{the}$ studies is in the method of blood pressure measurement which was direct in the study of Sweet and indirect in Kubo's.

A difference in sensitivity between the two methods is not a likely explanation for reported different results, because the $15-20 \mathrm{~mm} \mathrm{Hg}$ decrease in mean arterial pressure reported by Sweet and coworkers should be large enough to be accurately detectable by the more insensitive method of indirect blood pressure measurement, as is shown by the fact that the final reduction Kubo et al. (1977) report after 7-12 weeks treatment is of the same magnitude. It may, however, be that in the study of Kubo animals should accustom to the indirect once-a-week blood pressure measurement which requires restraint, in contrast to the direct method employed by Sweet et al. (1975). Such a non-familiarization with the blood pressure measurement might possibly also explain the lack of antihypertensive activity of propranolol in the studies of Forman and Mulrow (1974), Weiss et al. (1974; and Conway et al. (1975). In these studies blood pressure was either measured once weekly (Forman and Mulrow. 1974) or once at the end of the treatment period (Weiss et al., 1974; Conway et al., 1975).

Evidence for the importance of the method of measurement derives also from acute studies. Levy (1976) reported that repeated restraint of SHR for blood pressure measurement after a dose of $1 \mathrm{mg} / \mathrm{kg}$ propranolol s.c. Was lethal in most cases, whereas this effect was not observed after control-injections or a 10-fold lower dose. Thus, it seems that rats should either be unrestrained or trained for restraint to observe an antihypertensive effect.

The same inconsistent effects as discussed above for SHR have been reported for DOCA-salt hypertension in comparable experiments. Dusting and Rand (1974) noted an antihypertensive effect for low-dose $(0.4 \mathrm{mg} / \mathrm{kg}$. day) propranolol which disappeared at higher $(10 \mathrm{mg} / \mathrm{kg}$. day) doses. Buñag (1977) found, however, that 0.4 $\mathrm{mg} / \mathrm{kg}$. day was ineffective, whereas a 10 -fold higher dose did lower blood pressure after 3 days of treatment. The reason for this discrepancy cannot be explained by methodical differences since dose-regimen as well as method of blood pressure measurement were comparable. 
$\stackrel{2}{\stackrel{2}{\llcorner}}$

10

0

$\stackrel{+}{\frac{\pi}{\sigma}}$

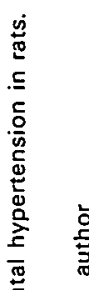

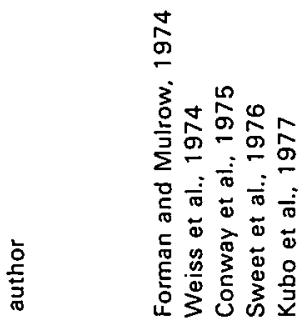

$2 \pi$

के क

ชั ฮั

$\stackrel{\infty}{\infty}:$

政会

त

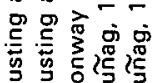

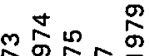

๙ัم

- $\div$ 。

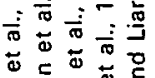

인

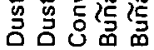

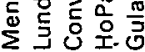

$-11 \rightarrow \rightarrow$

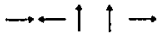

11111

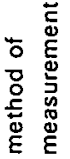

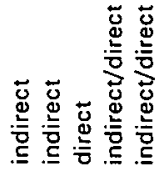

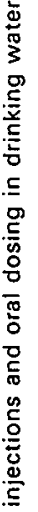

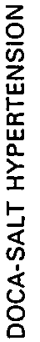

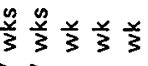

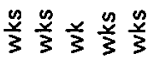

$\infty \cong-\dot{m} m$

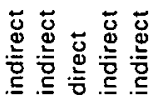


With regard to established renal hypertension no discussion exists on the actions of propranolol. Unanimously an ineffectiveness for propranolol has been reported in established renovascular hypertension.

Studies on the acute antihypertensive effects of propranolol in several types of experimentally hypertensive rats are summarized in table I.V. Amongst others, the length of time during which the effects on blood pressure were measured, as well as the time of maximal effect are contained in it. As was discussed in section 1.3 the antihypertensive effect in man takes some hours to develop. Yet a number of investigators probably did not have the patience to wait for such a time in their animal preparations. Thus, results should be interpreted carefully with regard to this aspect. Another factor which has been varied is the use (or abcense) of anesthetic. If used, the type of anesthetic has been included in the table. Again the method of blood pressure measurement is mentioned in the table.

As is seen from the table, administration of propranolol in SHR has been reported to be ineffective, hypertensive as well as antihypertensive.

In fact, the only authors observing a rapid lowering of blood pressure in conscious rats were Roba et al. (1972) upon $60 \mathrm{mg} / \mathrm{kg}$ propranolol p.o. and Davy et al. (1977) after 5 $\mathrm{mg} / \mathrm{kg}$ i.v. In the latter study this effect was seen within 5-15 min after the injection and was very moderate.

However, if animals were anesthetized with chloralose or pentobarbital profound reductions in blood pressure were observed which lasted throughout the $30 \mathrm{~min}$ experimental period (Davy et al., 1977). The most interesting observation in conscious SHR is probably that by Sweet and Wenger (1976), who reported an increase in blood.pressure immediately following injection of propranolol $0.03-0.3$ $\mathrm{mg} / \mathrm{kg} \mathrm{dl}$ - and $0.3 \mathrm{mg} / \mathrm{kg} \mathrm{d}$-propranolol into the lateral cerebral ventricles of conscious SHR which was, however, followed by a reduction in blood pressure which started somewhere between 6 and 24 hours after the injeciion, still being significant at the latter time. Intra-arterial injection of $0.3 \mathrm{mg} / \mathrm{kg}$ propranolol did not cause any effect at all.

Studies in DOCA-salt rats, renal hypertensive rats and rats with a neurogenic hypertension have led to similar inconsistency in results as those in SHR. In DOCAsalt hypertension Dusting and Rand (1974) found a s.c. dose of $0.2 \mathrm{mg} / \mathrm{kg}$ to be antihypertensive within 0.5 hour after administration. A higher dose $(5 \mathrm{mg} / \mathrm{kg} \mathrm{s.c.})$, however, caused a pressor effect. A comparable study by Buñag (1977), who used doses in the same range, did not confirm any of these results, although the latter authors stated no time-course.

Renal hypertensive rats also react with a pressor response (Nakao et al., 1975) or a lowering of blood pressure (Davy et al., 1977) immediately after the injection, whereas only one study is known on the effects in neurogenic hypertensive rats (Davy et al., 1977). This latter study was carried out under urethane-anesthesia, which rendered animals hypotensive rather than hypertensive, making the results hard to interpret.|

From the above it will be clear that no systematic study into the time-course of a possible antihypertensive effect has so far been done in hypertensive rats, including 
SHR, the best animal model for human essential hypertension. In conclusion, depending on experimental methods and on set-up, as well as dose, both hyper- and hypotensive responses have been obtained in experimental hypertension. Logically, the best method to study antihypertensives in animals, is in situations where they are used and effective in man too.

Thus, animals should not be anesthetized and restraint should only be used if it is inevitable. Furthermore, because of its close resemblance to human essential hypertension, spontaneous hypertension probably provides the best model. Finally, and this might be the most important point, one should not expect immediate blood pressure lowering effects; these do also not occur in human and hence, if such immediate effects are found, their relevance with regard to the effects in humans is questionable. 
$\frac{n}{\stackrel{2}{0}}$

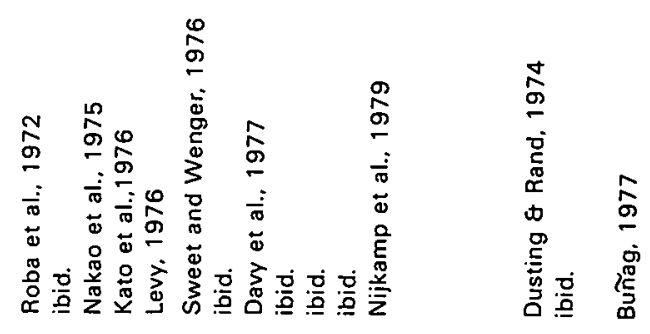

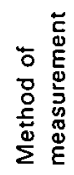

蓄<smiles>I[AlH]I</smiles>

|

m m

$\infty \oplus \sim$
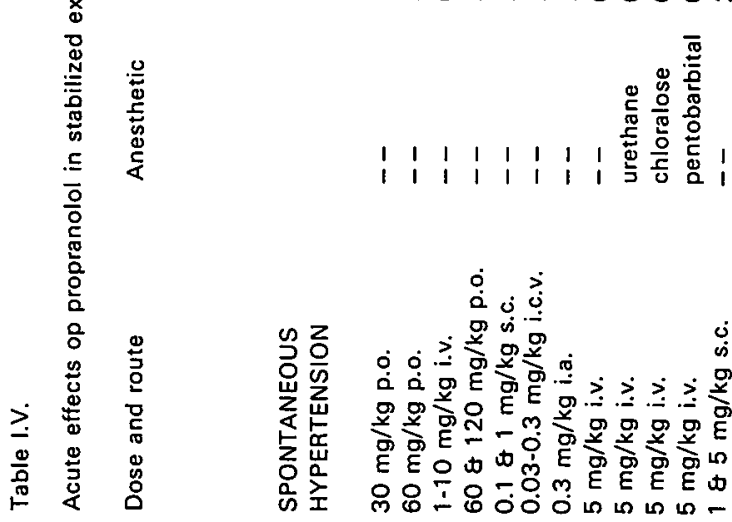

$\dot{0}$ i

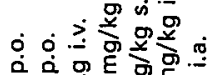

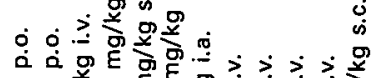

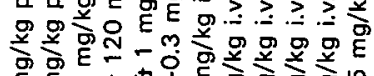

E E 0 w

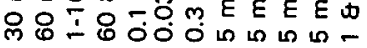

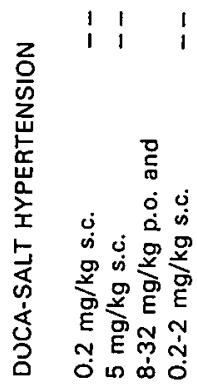




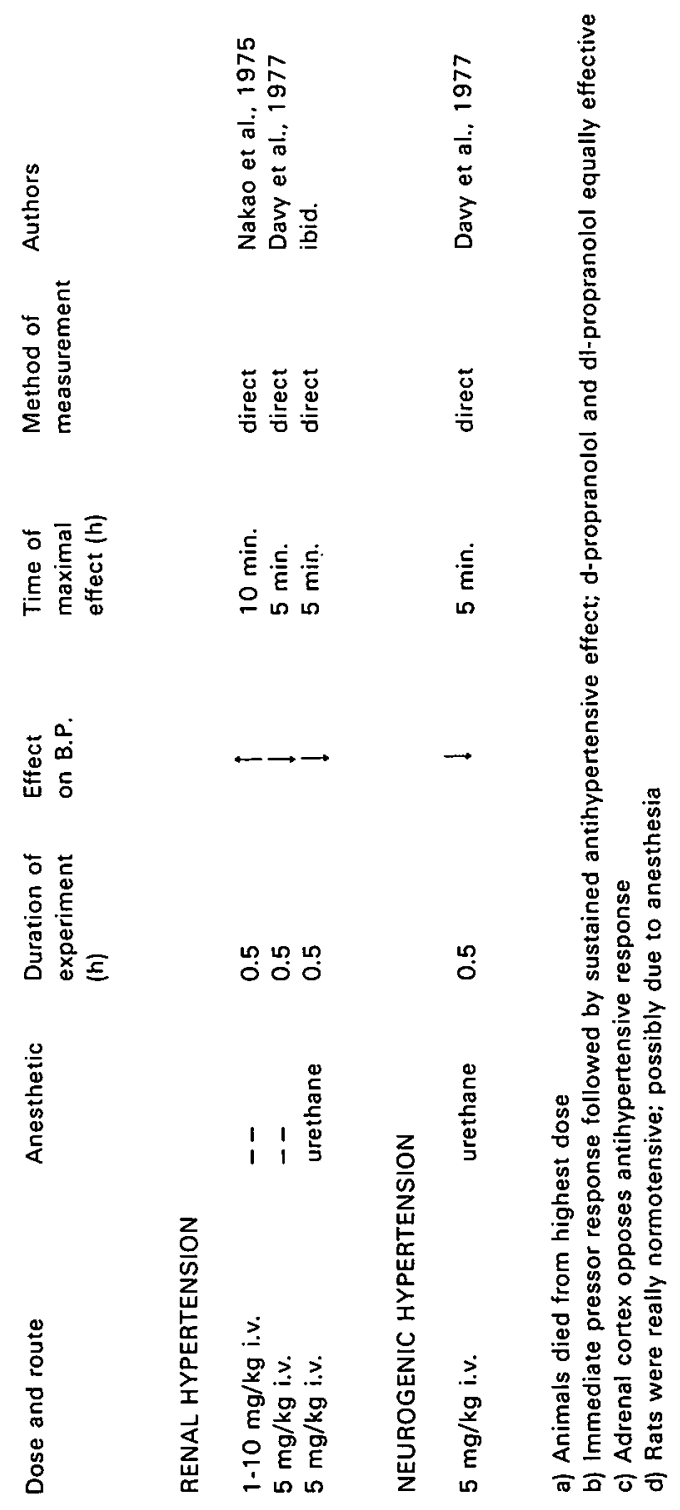




\subsection{The present thesis}

The apparent lack of understanding about the mechanism of action underlying the antihypertensive effect of beta-adrenoceptor blocking drugs may derive from several factors. First of all, it may indicate that drugs of this class share some unknown property that eventually causes the effect. As already discussed in section 1.1. this is very unlikely and it should be accepted that it is indeed the blockade of betaadrenoceptors that causes the antihypertensive effect. Alternatively, it may be that our knowledge of the role of beta-adrenoceptors in the control of blood pressure is incomplete. The third possibility is that we do know all about beta-adrenoceptor blockers and-blockade, but we do not have a complete insight in the changes that are brought about in the complex systems that regulates blood pressure by the primary effects resulting from beta-adrenoceptor blockade.

Although acute effects like the reduction of heart rate and cardiac output (see section 1.3.) are predictable from the blockade of cardiac beta-adrenoceptors, the ultimate antihypertensive effect occurring after some time, cannot be explained purely on the basis of the cardiac effect. It would probably be a gross simplification to assume that just one effect of a drug might be capable of throwing an extremely well-controlled system like that of blood pressure-regulation out of balance, which is, of course, what an antihypertensive agent does. Transient effects may be predictable on the basis of the primary pharmacological properties of an antihypertensive drug. In fact, they may also give us a clue to the ultimate mechanism of action. But also the physiological changes that are triggered by the primary effect, i.e. biological feed-back mechanisms, should be taken into account. These may become apparent immediately or after a prolonged period of time, during of after the administration of the drug.

Long-term changes, maintained by prolonged constant administration of the drug may give insight into such mechanisms. However, it should be understood that at some time a new equilibrium will establish, in which it may be impossible to identify all factors that contribute to it.

From the arguments mentioned above it is clear that in our view the problem of the mechanism of action of beta-adrenoceptor blocking drugs, and for antihypertensives in general, can only be solved by carefully studying changes that are brought about by acute as well as long-term administration of the drug. Special attention should be paid to the time-courses of any effects occurring. Transient and long-term effects should then both be considered and from that an understanding of the mechanism(s) of action may result.

The structure of the present thesis results from the philosophy above. After studying acute effects of propranolol in the first section of this thesis, the second part will go into the long-term changes that are brought about by propranolol in the spontaneously hypertensive rat. Both parts, in turn, consist of studies into the pharmacokinetics and the kinetics of hemodynamic, humoral and renal effects of propranolol in this species. 
Furthermore, special attention will be paid to a possible involvement of the central nervous system and nervous reflexes in the antihypertensive effect of propranolol. Finally, in the general discussion results from the acute and long-term experiments will be combined into a model which may explain the antihypertensive effect of betaadrenoceptor blocking drugs. 


\section{MATERIALS AND METHODS}

\subsection{Animals.}

In all experiments male adult SHR were used. Their body weights were between 250 and $350 \mathrm{gram}$. These animals may be regarded as stable hypertensive (Evenwel et al., 1979). The animals were derived from the Okamoto-Wistar strain (Okamoto and Aoki, 1963) and obtained through CPB, TNO Zeist, The Netherlands. In two studies (chapters 6 and 13) other rats were used, i.e. although they were derived from the same strain, they were purchased from another supplier (Blue Spruce Farms, Altamont, NY., USA). Normotensive rats were used in one study. These were derived from the Wistar-Kyoto strain, from which Okamoto-Wistar rats have been developed. Also these animals were purchased from CPB, TNO Zeist.

During most experiments the animals were housed separately in standard laboratory cages. In some studies it was necessary to house animals in metabolism cages. Two types were used. When quantitative sampling of radio-active urine and feces was necessary, metal cages (type SR-1, Ruco, Valkenswaard, The Netherlands) were used, which were smaller than those in which urinary excretion of water and sodium was the aim. These latter cages (type 1760. Techniplast, Buguggiate, Italy) were larger, and, more importantly, they permitted the animals to sense each other. This "social contact" was found to make animals much more quiet and at ease.

Normal food (Hope Farms, type RMH-TM) and tap water was allowed to all animals ad libitum. In one type of experiments rats ate sodium-free food, which was prepared by Dr. Morse of Hope Farms, Woerden, The Netherlands. This food was found to contain less than $0.03 \% \mathrm{Na}$, as determined by flame photometry.

\subsection{Measurement of blood pressure.}

\section{CATHETERS AND SURGERY.}

Effort was given to the development of a good method for direct measurement of blood pressure in rats. In the first experiments (see chapters 5 and 7) this was done through a catheter in a femoral artery. A simple PE- 50 catheter, filled with saline, was inserted into the right femoral artery through a small incision. The catheter was exteriorized in the groin after closing of the skin and animals were partially restrained in small restraining cages (Killian, 1973) for preventing them from biting the catheters.

After these first experiments methods were developed to allow direct measurement of blood pressure in freely moving rats. These will be discussed below.

\section{CAROTID ARTERY CATHETERS.}

Implantation of a catheter in a carotid artery for long-term measurement of blood pressure in rats was first described by Popovic and Popovic (1960). A catheter was constructed from a $4 \mathrm{~cm}$ piece of Silastic silicone-tubing (602-135) which was sealed 
to a $6 \mathrm{~cm}$ piece of $602-205$ Silastic tubing, using Dow Corning Medical Adhesive. Under light ether anesthesia a ventral incision was made in the neck and the left carotid artery was dissected free from surrounding tissue. The silicone catheter was inserted into it through a small hole which was cut in the artery. The catheter was secured to the vessel and exteriorized in the neck, between the shoulder-blades by guiding it through the neck muscles with a trocar. The catheter was filled with heparinized $(250 \mathrm{lU} / \mathrm{ml}) 0.9 \% \mathrm{NaCl}$ and closed with a small metal plug.

The catheter system described above functioned very well for short-term (up to 4 days) measurement of blood pressure in unrestrained rats. After 4 days the condition of a number of animals became worse, which, post mortem, proved to derive from infarctions in heart, brain and kidneys. Therefore, this simple method, which required minimal surgical stress, was used only in short-term experiments.

\section{ABDOMINAL AORTIC CATHETERS.}

In all other experiments blood pressure was measured from the abdominal aorta, for which two approaches were used. These will be described separately.

Cannulation of the abdominal aorta was performed in most experiments according to Browning et al. (1971). A catheter (see fig. 2.1) was constructed from a $9 \mathrm{~cm}$ piece of $P E-10$ tubing which was heat-sealed to a $12 \mathrm{~cm}$ piece of $P E 50$-tubing. Two small rims were made at the connection to facilitate securing of the catheter. On the other end of the PE 50-tubing a $1 \mathrm{~cm}$ piece of PE 100-tubing was heat-sealed. In this a $3 \mathrm{~mm}$ piece of stainless steel tubing was inserted to make it possible to slide a $3 \mathrm{~cm}$ piece of vinyltubing (Serva $\Pi$ T 63) over it. This latter piece was later to be exteriorized. The vinyltubing allows frequent clamping of the catheter without damaging it. Finally the PE 10-tubing was bent in an S-shape by dipping it into near-boiling water.

For implantation of the catheter described above, it was necessary to open the abdomen of the rats. This was done under light ether anesthesia through a $5 \mathrm{~cm}$ ventral midline incision. The intestines were carefully removed from the abdominal cavity and the abdominal aorta was dissected free from connective tissue over a length of $1 \mathrm{~cm}$ under the left renal artery. A small hole was made in the aorta with a 0.5 $\mathrm{mm}$ needle after clamping it and the PE 10-piece of the catheter was inserted downstream. The catheter was secured to the back-muscles with silk and guided through the muscles and s.c. to the neck where the vinyl-tubing was exteriorized.

The vinyl-tubing was sutured to the neck muscles. The catheter was filled with heparinized saline and closed with a small metal plug.

Alternatively, the abdominal aorta was cannulated by an approach through the left femoral artery. For this, a similar catheter as the one described above was constructed. Instead of bending the PE 10-tubing in an S-shape it was bent in a Jshape for this approach.

Under light ether anesthesia a small incision was made in the left groin and the femoral artery was freed from connective tissue. After clamping it, a small hole was 
cut in it and the PE 10-catheter was inserted. It was advanced for $4 \mathrm{~cm}$ into the artery, so that the tip was $\sim 1 \mathrm{~cm}$ below the left renal artery. The catheter was secured to the artery and to the leg-muscle with silk and guided s.c. to the neck where it was exteriorized. The catheter was filled with heparinized saline $(250 \mathrm{lU} / \mathrm{ml})$ and closed with a small metal plug.

The two methods described above for catheterization of the abdominal aorta proved to allow measurement of blood pressure over a prolonged period of time in most animals ( 7 days in $75 \%$ of the animals). The success-ratio for the abdominal approach was somewhat larger than that for the femoral artery approach $(65 \%$ vs. $75 \%)$.

Therefore, it was used in most experiments.

The condition of the animals was good, as judged from the fact that, besides a $3.5 \%$ weight-loss on the first day after surgery, they gained weight throughout the experiments.

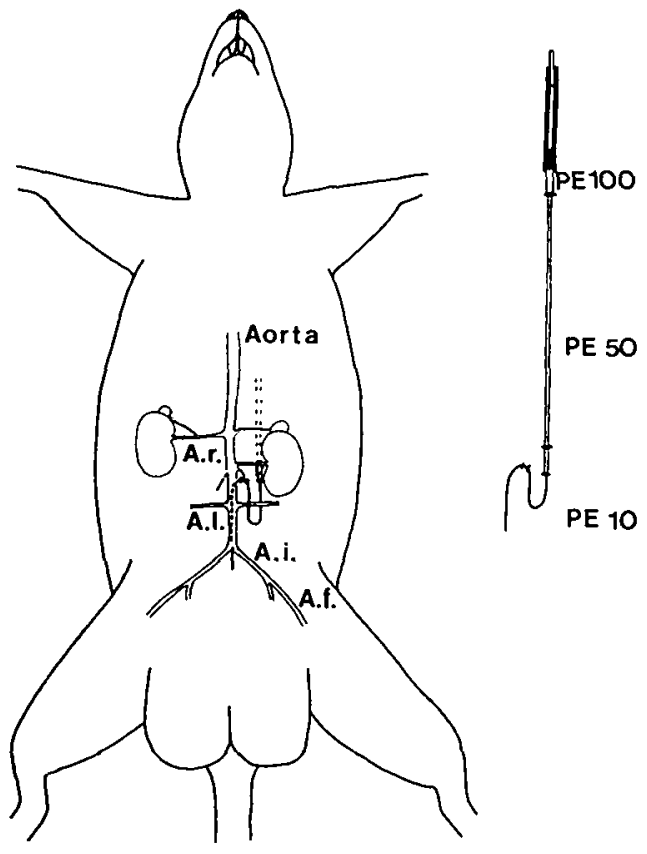

Figure 2.1. Drawing of the catheter system used for measurement of blood pressure from the abdominal aorta, projected on a schematic drawing of a rat. A.r.: Arteria renalis; A.I.: Arteria lumbalis; A.i.: Arteria iliaca; A.f.: Arteria femoralis. 


\section{MEASURING PROCEDURE.}

For measurement of blood pressure in unrestrained rats the animals were placed in glass experimental cages $(20 \times 20 \times 30 \mathrm{~cm})$. The arterial catheter was connected to a pressure-transducer (Central Technology Company, Inglewood, Cal., USA;

type CP 01). These transducers were calibrated daily, using a mercury manometer. The signal of the pressure transducer was recorded on paper. For this, either a Narco DMP-4B (Narco Bio-systems, Houston, Texas, USA), a Grass model 7 D-polygraph (Grass Instruments, Quincy, Mass., USA) or a Schwarzer-recorder model RS348 (Schwarzer GMBH, München, GFR) was used.

Heart rate was determined from pulsatile blood pressure using a Narco type 7302 biotachometer, the signal of which was also recorded. Mean arterial pressure (MAP) was obtained by low-pass filtering of the blood pressure signal.

\subsection{Measurement of venous pressure.}

\section{CATHETERS AND SURGERY.}

Central venous pressure was measured in unrestrained conscious SHR through a catheter in the vena cava. It was approached via the right femoral vein.

Under light ether anesthesia a small incision was made in the right groin.

The femoral vein was localized and dissected from surrounding tissues. It was slightly lifted with two silk sutures passed under it and a small hole was cut in the vessel through which a Silastic 602-175 -catheter was introduced. The catheter was advanced into the vessel for $9 \mathrm{~cm}$ which in $300 \mathrm{~g}$ rat locates the catheter-tip in the thorax between liver and heart. The localization of catheter-tips was checked post mortem.

The catheter was fixed to the vessel and the muscles in the groin and passed s.c. to the neck where it was exteriorized between the shoulder-blades. It was filled with heparinized saline $(250 \mathrm{lU} / \mathrm{ml}$ in $0.9 \% \mathrm{NaCl})$ and closed with a metal plug.

\section{MEASURING PROCEDURE.}

For measurement of venous pressure rats were transferred to glass experimental cages. The catheter was attached to a CTC-CP 01 pressure transducer (Central Technology Company, Inglewood, Cal., USA) which was placed at the level of the animal's heart when in normal position. The signal of the pressure transducer was recorded on a Grass Model 7D polygraph which was calibrated to give $0.5 \mathrm{~cm}$ pendeflection $/ \mathrm{mm} \mathrm{Hg}$, using a mercury manometer. The signal was filtered using a lowpass filter with a cut-off frequency of $0.5 \mathrm{~Hz}$. Readings were only taken with the animals in the normal position.

Using the method described above it was possible to measure venous pressure in unrestrained animals. Animals were used 1 day after surgery. 


\subsection{Measurement of cardiac output.}

\section{SURGERY.}

Cardiac output in unanesthetized animals was measured according to the method described by Smith and Hutchins (1979). In fact, a number of the experiments were carried out with invaluable assistance of Dr. Thomas L. Smith in the department of Dr. Thomas G. Coleman (Department of Physiology and Biophysics, University of Mississippi Medical School, Jackson, Miss. U.S.A.).

Cardiac output was measured as blood flow through the ascending aorta. For this, an electromagnetic flow-probe (Carolina Medical, King, NC., USA or Skalar, Delft, The Netherlands) was implanted around the aorta as follows.

The whole procedure was carried out under strict a-septic conditions. Animals were anesthetized with chloralhydrate $(100 \mathrm{mg} / \mathrm{kg}$ i.p.) or Nembutal (60 mg/kg i.p.). They were fixed on their back and the skin over the right third intercostal space was opened. The underlying muscle layers $(\mathrm{m}$. pectoralis profundus and $\mathrm{m}$. rectus abdominus) were dissected free and then cut with scissors. After this, the trachea was intubated and artificial ventilation was started using a Harvard Model 680 small animal respirator (Harvard, Millis, Mass., USA).

The frequency of the pump was set to 60 breaths/min and tidal volume was $2.5-3 \mathrm{ml}$. The thorax was opened by making a small hole in the intercostal muscles and pleurae using forceps. This hole was made approximately $4 \mathrm{~mm}$ lateral from the sternum. Under constant visual control it was then possible to carefully cut the intercostal muscles and pleurae over a distance of approximately $15 \mathrm{~mm}$ without damaging the lung. After this, a small sponge, which was cut from a sterile gauze $(\sim 10 \times 10 \mathrm{~mm})$ and had been soaked in $0.9 \% \mathrm{NaCl}$-solution, was introduced into the thorax to put the lung aside. A piece of silk-thread attached to the sponge allowed simple removal from the thorax at a later time.

Four threads (silk 3-0) were passed around the ribs at this stage of surgery. One was passed only around the fourth rib and was intended for fixation of the probe-cable. The other 3 served to close the thorax and were passed under the third and fourth rib.

After the threads were installed the ribs were spread using a miniature retractor. The thymus was carefully prepared free, after which the aorta could be seen. The aorta was carefully freed from all adventitia over a $3.4 \mathrm{~mm}$ distance and two threads were passed under it. The previously installed retractor and sponge were removed and by a light traction on the two threads under the aorta it was possible to slip the flow-probe over it. A slot-cover made of solid silicone-rubber was installed and the threads around the aorta removed.

The thorax was closed with the previously installed threads and the probe-cable was fixed to the ribs. The muscles which had been cut, were sutured separately using 5-0 silk. The probe-cable and-connector were guided to the neck. The cable was again secured to the deep muscle-layers just overlying the spinal cord and the skin was closed. 
Before closing the skin a drain was introduced into the thorax between the sixth and seventh right rib. Application of a negative pressure of $\sim 15 \mathrm{~cm}$ water served both to clear the thorax from fluids and to restore normal intra-thoracal pressure. Furthermore, at this stage a possible pneumo-thorax could be identified as such. After closing the skin (at the termination of surgery) the drain was removed from the thorax and the wound that it had made was closed at the same moment with the aid of a previously installed suture.

The success-ratio for the previously described surgery is well over $80 \%$. Failure is normally due to rupture of the ascending aorta which occurs between the second and third week after surgery. Incapsulation of the flow-probe (which is necessary for a stable flow-signal) is usually complete after the third day post-operatively. This then makes the animals suitable for cardiac output-measurement for 2-3 weeks. Stability of the preparation is illustrated in chapter 13 where control animals were measured over a period of 7 days.

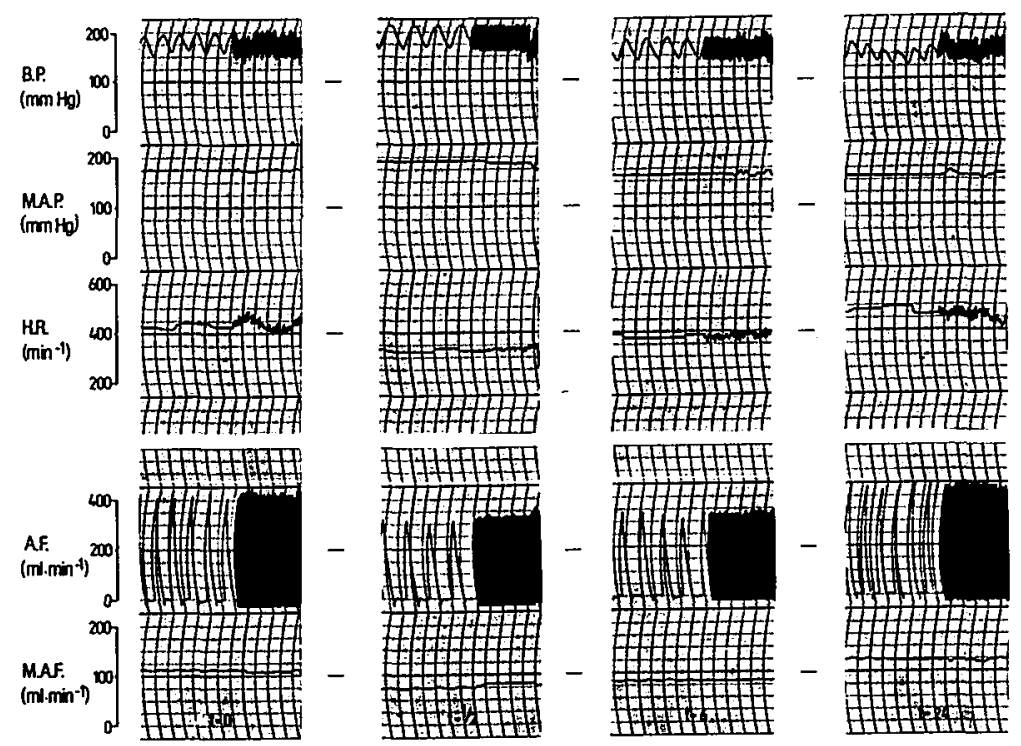

Figure 2.2. Typical registration of hemodynamic measurements as performed in the studies in chapter 6 . The registration was made 7 days post-operative in a conscious rat, injected with $5 \mathrm{mg} / \mathrm{kg}$ propranolol on time $t=0$. From top to bottom tracings represent pulsatile blood pressure (B.P.), mean arterial pressure (M.A.P.), heart rate (H.R.). pulsatile aorta flow (A.F.) and mean aorta flow (M.A.F.). Flow was measured on the ascending aorta. 
After recovery from surgery and implantation of a catheter in the abdominal aorta (see above) the animals were placed in glass experimental cages $(20 \times 20 \times 30 \mathrm{~cm})$. The flow-probe was connected to a flow-meter (Carolina Medical type 501D or Skalar model 506) and a ground (electrical zero) wire was either taped to the animal's tail or attached to a previously implanted silver wire which was passed s.c. together with the catheter at implantation of the latter. The flow-signal was then displayed on a Grass Model 7 D-polygraph. Zero-flow was taken to be the late horizontal part of diastole. This seems a good approximation for the probe was just above the heart.

A typical illustration from experiments in which cardiac output was measured is shown in fig. 2.2 .

\subsection{Measurement of plasma volume.}

\section{SURGERY.}

For measurement of plasma volume animals were equipped with a catheter in the abdominal aorta (see above: direct measurement of blood pressure) and a catheter in the right jugular vein (see below: intravenous injections).

Surgery was performed two days before the start of experiments.

\section{MEASURING PRODECURES.}

The method for measurement of plasma volume was developed and evaluated in our laboratory by Rob T. Evenwel. It consisted of injection of a known amount $(\sim 2-4 \mu \mathrm{Ci})$ of ${ }^{125}$ I-labelled serum albumin (IM $17 \mathrm{P}$, the Radiochemical Centre Ltd, Amersham, England) in a $50 \mu$ l volume of saline using a Hamilton micro-syringe. The (venous) catheter was flushed with $100 \mu \mathrm{l}$ saline containing $250 \mathrm{lU} / \mathrm{m} /$ heparin.

Twenty minutes after injection mixing was regarded to be complete and a first $100 \mu \mathrm{l}$ arterial blood sample was taken. Blood was centrifuged and 3 samples $(10 \mu l)$ of plasma were counted for radio-activity in a Packard gamma-counter.

For reproducibility of sample geometry in the counter the $10 \mu \mathrm{l}$-samples were pipetted into $1.0 \mathrm{ml}$ of water and thoroughly mixed on a vortex-mixer. To allow correction for disappearance of albumin from the circulation a second sample was taken and assuming first-order kinetics of disappearance extrapolation to the time of injection as well as forward-extrapolation was possible (Evenwel et al., to be published). If serial determinations of plasma volume were done, the proper corrections were made as described above and illustrated in figure 2.3.

\subsection{Injections in unrestrained SHR.}

All injections were given in sterile pyrogen-free solutions. The vehicle for injections is stated in the different studies. Subcutaneous injections, which do not require any special methods, were given in a $0.1 \mathrm{ml}$ volume between the shoulder-blades. 


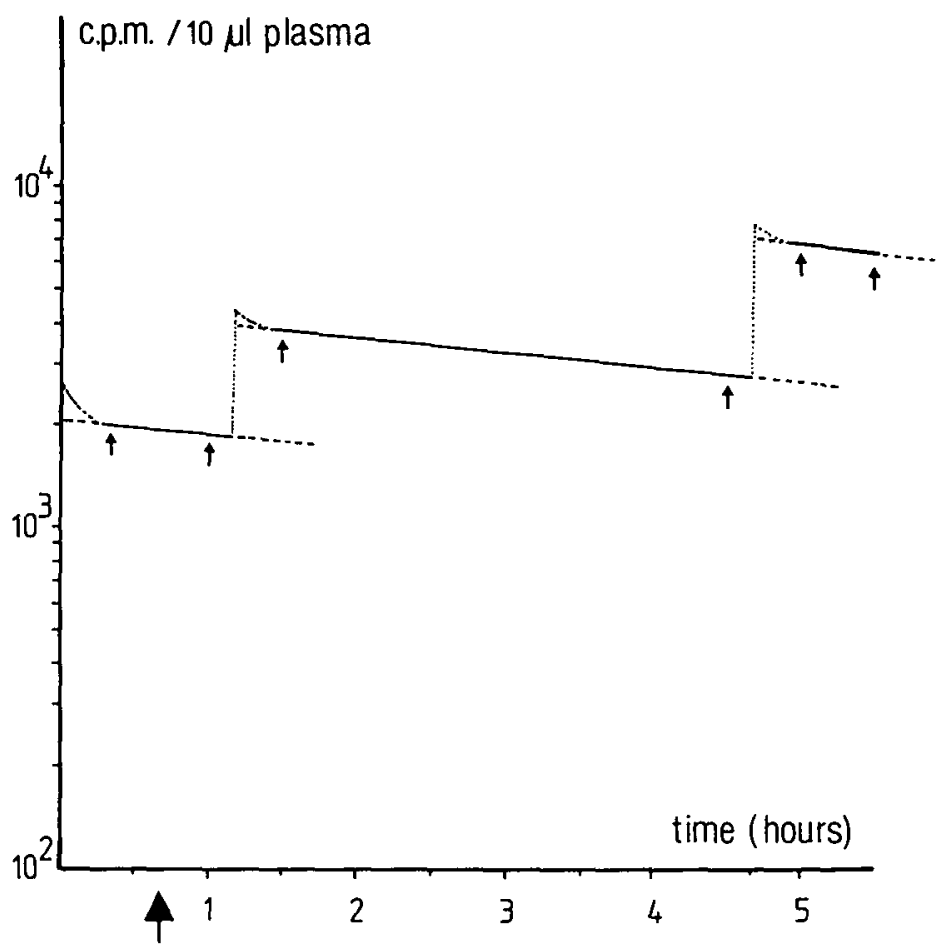

Figure 2.3. Theoretical curves for the disappearance of albumin from the circulation. Albumin-injections were (theoretically) given at times $t=0, t=70$ and $t=280 \mathrm{~min}$. The moments of blood sampling are indicated by the small arrows. Interrupted lines indicate extrapolations to the moment of injection. The large arrow indicates a theoretical (saline-) injection. For further explanation see section 2.5.

\subsubsection{Intravenous injections.}

\section{CATHETERS AND SURGERY.}

For intravenous injection in freely moving SHR a catheter $(3 \mathrm{~cm}$ of $602-135$ Silastic attached to a $4 \mathrm{~cm}$ piece of $602-205$ Silastic tubing) was implanted into the right jugular vein. Surgery was performed under light ether anesthesia. Through a $2 \mathrm{~cm}$ ventral mid-line incision in the neck the right jugular vein was localized and freed from surrounding tissue. A small hole was cut in it and the thin end of the catheter inserted into the vessel. The catheter was advanced for $3 \mathrm{~cm}$. This locates the tip of the catheter just above or in the right atrium. The catheter was fixed to the vessel and the neck muscles. The distal end was passed through the muscles to the back of the neck and exteriorized there. It was filled with $250 \mathrm{IU}$ heparin in $0.9 \% \mathrm{NaCl}$-solution and closed with a metal plug.

Catheters implanted as described, remain patent for more than 1 week in more than $90 \%$ of the animals. 
All injections were given in saline. The catheters were rinsed with $0.1 \cdot 0.2 \mathrm{ml}$ of saline to wash in the complete injectate. In the experiments in which baroreflexsensitivity was measured a $40 \mathrm{~cm}$ piece of PP-200 tubing was between animal and syringe. Both tubing and syringe were then filled with the solution to be injected. This allowed injections without the animals noticing.

\subsubsection{Intracerebroventricular injections}

\section{CANNULAS AND SURGERY}

Intracerebroventricular (i.c.v.) injections were given through a stainless steel cannula, implanted into the lateral cerebral ventricle under Nembutal-anesthesia $60 \mathrm{mg} / \mathrm{kg}$ i.p.) using standard stereotaxic techniques (see Struyker-Boudier, 1975). The cannula was fixed to the skull with jewellers screws and dental cement. Surgery was performed at least one week before experiments.

\section{INJECTIONS}

Injections were given in a $10 \mu \mathrm{l}$ volume of pyrogen-free sterile saline, using a Hamilton micro-syringe. The needle of this syringe was equipped with a small hub, allowing adjustment of the depth of injections (cf. Struyker-Boudier, 1975).

\subsection{INFUSIONS IN UNRESTRAINED RATS.}

\subsubsection{The osmotic minipump.}

For the infusion of propranolol in conscious unrestrained rats, a drug delivery system was needed that should meet three requirements:

- it should be small enough to be implanted in a rat

- it should give a prolonged, constant release of the drug

- it should be fit for local delivery of the drug, for instance in the brain. A system which answers to this description was found to be the ALZETTM osmotic minipump. A schematic drawing of this system is given in figure 2.4.

The group who designed the osmotic minipump originally has reviewed the essential features of this drug delivery system at several occasions in great detail (e.g. Yates et al., 1975; Theeuwes and Yum, 1976; Zaffaroni, 1978). Therefore only a brief description of the system will be given here.

The osmotic minipump consists of a $170 \mu \mathrm{l}$ collapsible reservoir surrounded by a sealed layer of an osmotic driving agent. The energy source is an inorganic salt that imbibes water, thus generating hydrostatic pressure on the reservoir and thereby displacing the drug solution contained in the latter through the delivery portal (see fig. 
2.4.B). The imbibement of water is controlled by a semi-permeable membrane. This membrane is a lamination of two cellulose-esters, the inner having a lower water permeability than the outer layer. The pumps are compatible with a large range of drug solvents ranging from distilled water to $50 \%$ DMSO in water.

The total dimensions of the osmotic minipump are given in figure 2.4.A.

In vivo testing of the system is included in chapter 12 of this thesis.

However, before testing the pumps in vivo, calibration of their pumping rate was carried out in vitro, using a propranolol-solution as a marker for release.

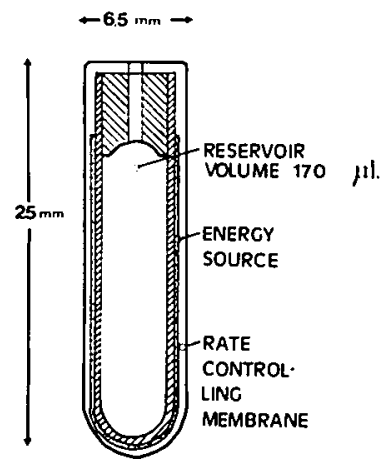

A

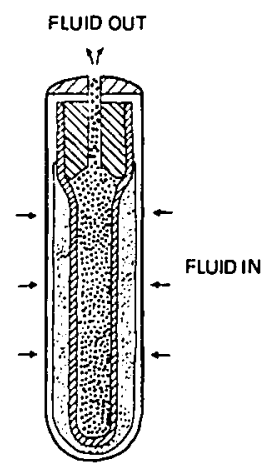

B

Figure 2.4. Schematic drawings of the ALZET osmotic minipump. Both dimensions (A) and its principle of operation (B) are shown.

\section{CALIBRATION OF OSMOTIC MINIPUMPS.}

Before using them in the animals the pumping rate of the osmotic minipumps was checked in vitro. Two batches of minipumps were used. Of each of these four were calibrated as described below.

Minipumps were filled with a propranolol-containing solution to which $\sim 5 \mathrm{Ci} / \mathrm{ml}^{3} \mathrm{H}$ propranolol (NET - 478, New England Nuclear) was added as tracer.

Minipumps thus filled were placed in a small glass tube containing $0.9 \% \mathrm{NaCl}$ solution. A $10 \mathrm{~cm}$ piece of PE-60 tubing was attached to the pump outlet. This tubing, which had previously been filled with the infusion-solution, was led into a second glass tube, containing $1.0 \mathrm{ml} 0.9 \% \mathrm{NaCl}$-solution. Tubes were sealed with laboratory film and placed at $37^{\circ} \mathrm{C}$. At $24 \mathrm{~h}$ intervals the tube containing the pump-outlet was changed. The amount of radioactivity pumped out, was determined by counting of a $0.5 \mathrm{~m}$ l sample of the $\mathrm{NaCl}$-solution in a Packard Tricarb scintillation counter using a commercial scintillation cocktail (Aquasol ${ }^{R}$, New England Nuclear). 
The results of calibration procedures are shown in fig. 2.5. for two batches, one (batch AR-C507) pumping at a rate of $0.59 \pm 0.02 \mu \mathrm{l} / \mathrm{hr}$, (mean \pm SD for 4 pumps), the other (batch 2627) having a rate of $0.91 \pm 0.05 \mu \mathrm{l} / \mathrm{hr}$ (mean \pm SD for 4 pumps).
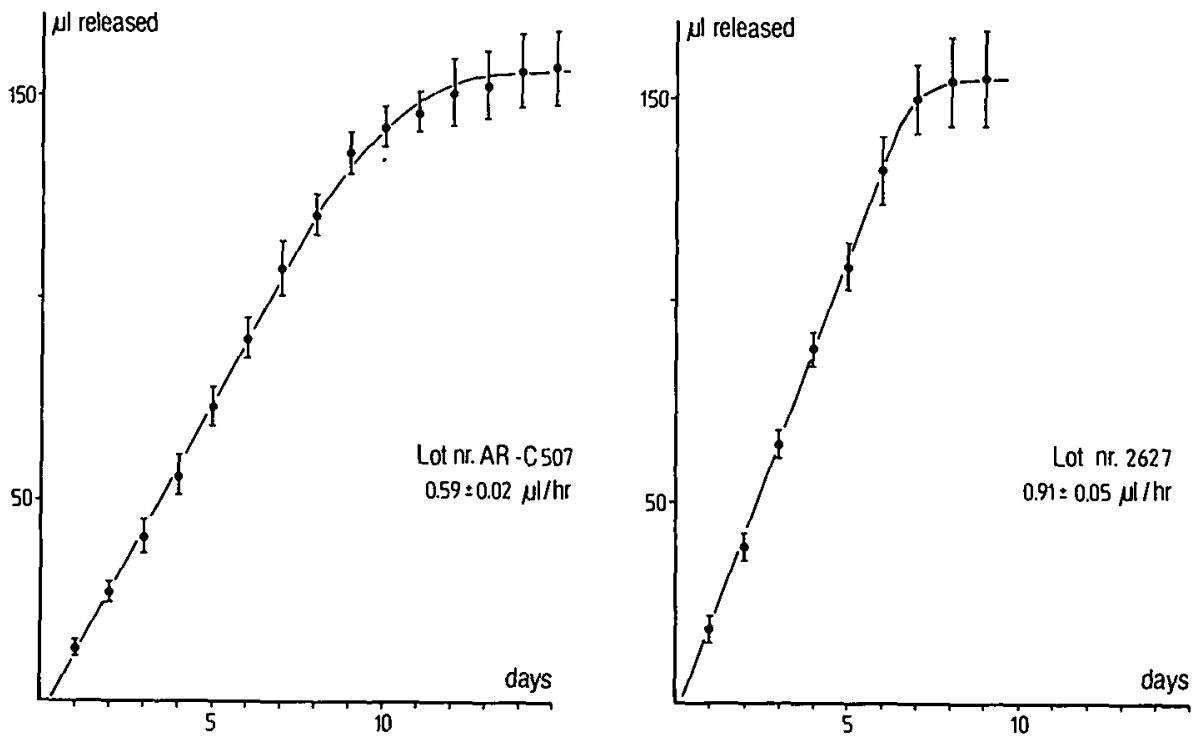

Figure 2.5. Calibration graphs for the two batches of osmotic minipumps used in the present studies. Each point represents the mean \pm SD for 4 pumps.

STABILITY OF PROPRANOLOL IN OSMOTIC MINIPUMPS.

Stability of propranolol in the osmotic minipumps was checked by thin layer chromatography of a sample of the fluid still present in a pump after 5 days of in vitro pumping. A chromatogram was developed in $0.2 \mathrm{M} \mathrm{NaCl} /$ acetone $(2: 1)$ as described below (see: "determination of propranolol in plasma"). The spot containing propranolol was scraped into a glass tube and eluted with ethanol. This was then counted for radio-activity in a Packard Tricarb scintillation counter. From the spot, more than $95 \%$ of the radio-activity applied to the plate could be recovered, indicating good stability of propranolol. 


\subsubsection{Subcutaneous intusions}

Subcutaneous infusions were given in unrestrained rats by implanting an osmotic minipump between the shoulder blades. This was done under light ether anesthesia. A small cut was made through the skin and the pump was simply slipped in. The wound was closed with 2 small wound clamps. The whole procedure took $\sim 2 \mathrm{~min}$, after which the animals were returned to their home-cages.

\subsubsection{Intracerebroventricular infusions}

By attachment of a special catheter to the osmotic minipumps it was possible to infuse drugs into the lateral cerebral ventricles during 1 week.

The catheter consisted of a small $(6-8 \mathrm{~mm})$ piece of $P E-60$ tubing which was heatsealed to a $10 \mathrm{~cm}$ piece of PE-10 tubing. A small rim was made at $6 \mathrm{~mm}$ from the opposite end of the PE-10 tubing to facilitate later attachment of the catheter to the skull. The PE-10 piece of the catheter was coiled 6 times by winding it around a stainless steel rod (O.D. $2 \mathrm{~mm}$ ) and dipping it into near-boiling water. The resulting spring later allowed free movement of the animals head, one end of the catheter attached to the skull, the other to the minipump which was between the shoulder blades.

Implantation of the i.c.v. catheter was performed at least one week before the start of the experiments. This was again done under Nembutal-anesthesia, using standard stereotaxic techniques. Because pumps were installed one week after implantation of the i.c.v. catheter, until then it was filled with infusion vehicle (an artificial cerebrospinal fluid according to Myers and Mora, 1977) and heat sealed. The whole catheter-system was subcutaneously.

Pumps were implanted under light ether anesthesia as described above. The i.c.v. catheter which was already between the shoulder-blades, was localized, the seal was cut off and the pump attached.

\subsubsection{Intra-arterial infusions}

In the studies reported in chapter 11 intra-arterial infusions were done. Animals had a catheter in the abdominal aorta for continuous measurement of blood pressure. Through this catheter infusions could be given at the same time using a CFS-Intraflo device (type CFS-06F) in the catheter system. For the infusions a Harvard type 975 syringe-infusion pump was used. The pump had been previously calibrated. 


\subsection{Quantitation of beta-adrenoceptor blockade}

Beta-adrenoceptor blockade was assessed by serial construction of dose-response curves for isoprenaline-induced tachycardia (beta ${ }_{1}$-adrenoceptors) and hypotension (beta ${ }^{-a d r e n o c e p t o r s) . ~ A n i m a l s ~ h a d ~ i n-d w e l l i n g ~ v e n o u s ~ a n d ~ a r t e r i a l ~ c a t h e t e r s ~(s e e ~}$ above). Isoprenaline was injected in doses from 0.003 to $30 \mu \mathrm{g} / \mathrm{kg}$.

Effects were measured and dose-response curves constructed. From these, $E_{50}$ values were determined by graphical analysis $\left(E_{50}\right.$ is the dose of agonist eliciting $50 \%$ of the maximal effect). Dose-response curves were constructed both before and at several times after the injection of propranolol or control-injections.

\subsection{Afferent denervation of baroreceptors}

\section{SURGERY.}

Surgical denervation of afferent baroreceptor fibres was accomplished according to Krieger (1964). Surgery was done under light ether anesthesia. It is illustrated in fig. 2.6.

Briefly, through a ventral mid-line incision in the neck the common carotid arteries and nerve-bundles travelling with them were localized. Vagal nerves and carotid arteries were separated from the sympathetic trunks and neuro-vascular sheaths after which a $1 \mathrm{~cm}$ piece of the latter two structures was resected bilaterally. Baroreceptor fibres from the aorta travelling with the recurrent laryngeal nerves were interrupted by resection of the superior laryngeal nerves. Carotid sinus baroreceptors were denervated by stripping the carotid bifurcations and their branches and painting the vessels with a $10 \%$ phenol-solution in ethanol. After that catheters were implanted into the right jugular vein and left carotid artery (see above).

Animals were housed separately after surgery.

Sham-operations consisted of a similar procedure, however, omitting resection of nerves and stripping and painting of the carotid bifurcations.

\section{TESTING OF DENERVATION.}

Presence of baroreflex activity in all animals was tested by intravenous injection of the alpha-adrenoceptor agonist phenylephrine.

This substance causes a vasoconstriction and a decrease in heart rate is elicited by the baroreflex. A total amount of 5-10 $\mathrm{gg} / \mathrm{kg}$ phenylephrine was injected, such that an increase in MAP greater than $50 \mathrm{~mm} \mathrm{Hg}$ was elicited. Baroreceptor denervation was regarded to be complete if heart rate did not drop by more than 20 beats $/ \mathrm{min}$ as a consequence of vasoconstriction. According to this criterium 15 out of 17 animals were regarded to be successfully denervated. The remaining two were not used in further experiments. In sham-operated animals 3 out of 18 did not have a baro-reflex according to this criterium. 


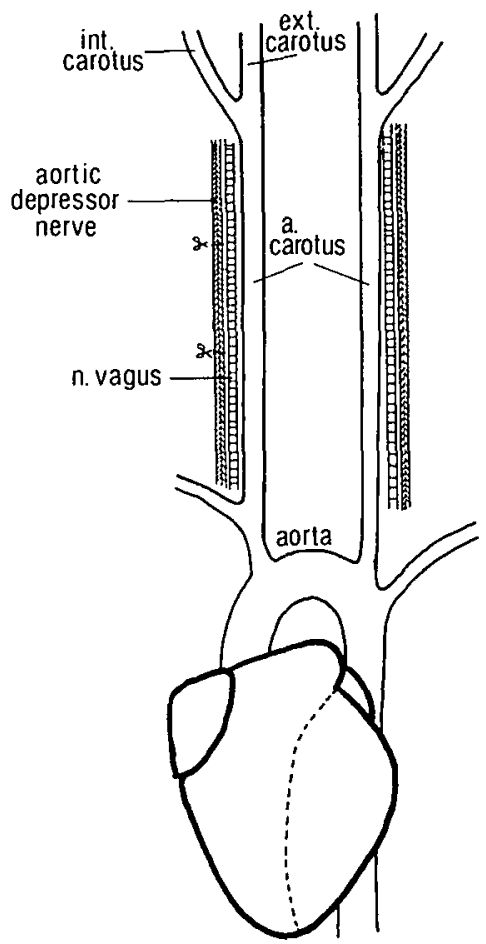

Figure 2.6. Schematic drawing of the ventral neck region in a rat, indicating the nervebundles that were cut for the afferent denervation of baroreceptors. The small scissors point to the places where nerves were dissected (see section 2.9.).

\subsection{Measurement of baroreflex sensitivity}

Baroreflex sensitivity was determined, using a modification of the technique of Smyth et al. (1968). These authors induced vasoconstriction in man by injection of phenylephrine (an alpha-adrenoceptor agonist) and measured systolic time-intervals during the resulting increase in blood pressure. Linear regression-analysis was carried out on systolic time-intervals and systolic blood pressure in the preceding heart-beat, the slope taken as a measure for baroreflex sensitivity.

For rats this technique cannot be used, because there is a delay of approximately 1 second in the reflex. In man this is a 1 heart-beat period. However, due to the high heart rate in rats, there is a delay of $5-7$ beats in the reflex. Therefore, a modification of the technique was used, which will be described and evaluated in full detail elsewhere (Struyker-Boudier et al., to be published). Briefly, it consisted of serial i.v. injections of phenylephrine. The maximal reduction of heart rate (HR) due to each increase in mean arterial pressure (MAP) was measured. Correlation between heart period $(H P=1 / H R)$ at the maximum of the effect and MAP, again at the maximal effect of the different injections, was calculated using standard linear regression analysis. 
The slope was taken as a measure for baroreflex sensitivity, if $r^{2}$ of regression $>0.8$ and $P<0.05$. Typical regression-lines obtained according to this method in an SHR and a WKy-rat are shown in figure 2.7.

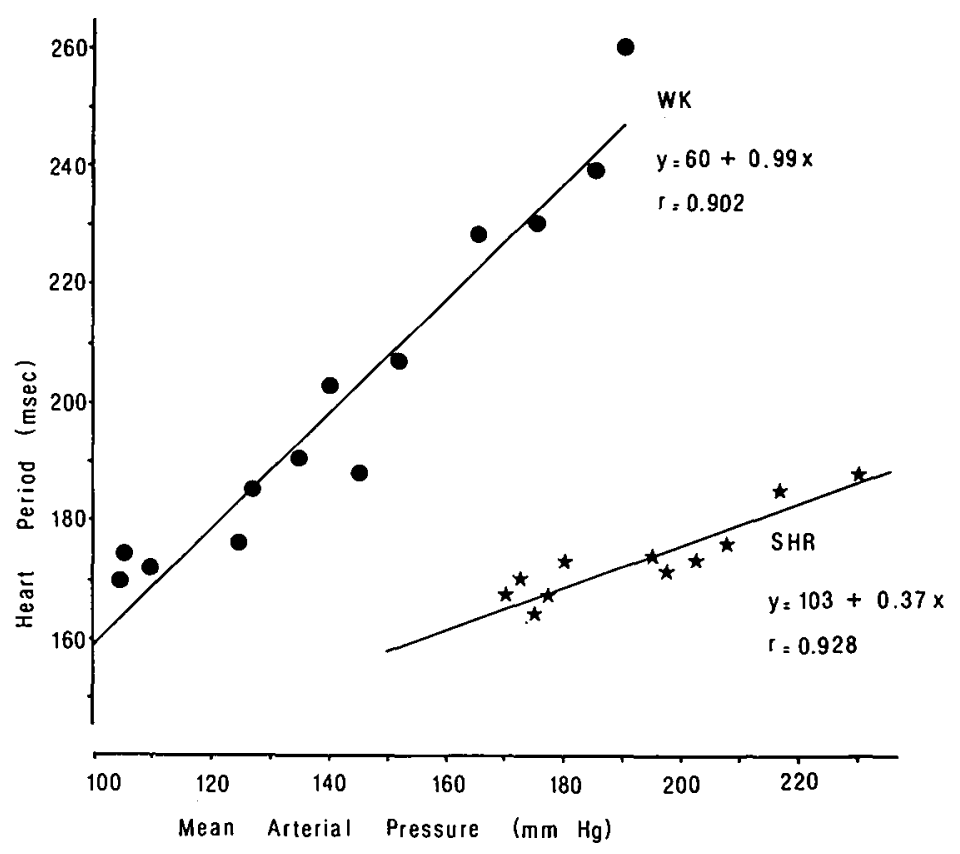

Figure 2.7. Typical regression lines for heart period (H.P.) vs. mean arterial pressure (M.A.P.) following intravenous phenylephrine. Lines were constructed according to the method in section 2.10 in a WKy-rat and a SHR.

\subsection{Measurement of urinary excretion of water and sodium}

To measure effects of propranolol on urinary excretion of water and sodium in conscious, unrestrained SHR, intake of water and sodium had to be carefully controlled. This was done by delivering a constant amount of water and sodium by intra-arterial infusion of a Ringer solution. This solution contained $9.0 \mathrm{~g} \mathrm{NaCl}, 0.20 \mathrm{~g}$ $\mathrm{KCl}$ and $0.20 \mathrm{~g} \mathrm{CaCl}_{2}$ per liter pyrogen-free distilled water. The $\mathrm{pH}$ was adjusted to 7.40 with a phosphate buffer. Infusions were started 24 hours before experiments begun.

Twenty-four $h$ before and during the experiments normal food was replaced by sodium-deplete food.

Excretion of water and sodium was measured in metabolism cages (Techniplast; see above). To accustom animals to their new environment they were housed in these cages for a period of at least one week preceding the experiments.

During the experimental period the outlets of the cages were connected to a LKB model 7000 Ultrorac $^{R}$ fraction collector which was set to change (pre-weighed) 
tubes every 60 minutes. Connections were made with silicone-tubing and a peristaltic pump was included in the system to ascertain constant flow of urine through the tubing.

Two days before the start of experiments rats were implanted with a catheter in the abdominal aorta for intra-arterial infusion and measurement of blood pressure (see above). After that they were placed in metabolism cages again.

Experiments started with a 24 hour run-in period during which Ringer's solution was infused at a constant rate of approximately $1.2 \mathrm{ml} /$ hour. This results in a fluid-intake of approximately $30 \mathrm{ml} /$ day and a sodium-intake of $\sim 4.5 \mathrm{meq} /$ day which is equivalent to the sodium-contents of $\sim 15$ grams normal food. These values may be regarded as normal for our SHR. From earlier studies (Struyker-Boudier et al., 1979) it is known that SHR reach equilibrium between intake and excretion of water and sodium within 6-8 hours after the start of infusions. To exclude any interference of run-in effects, a period of 16-18 hours was allowed for reaching equilibrium in the experiments reported in this thesis. Base-line values for water- and sodium-excretion were thus taken only during the last 6 hours before injections.

Tubes were re-weighed and the volume of urine calculated from the weight-increase assuming a specific gravity of $1 \mathrm{~g} / \mathrm{ml}$. Sodium concentration was measured in all samples with an Eppendorf flame-photometer using standard methods.

Once equilibrium was reached, rats were found to urinate reproducibly every 2 hours. Therefore, fractions from 2 successive hours were pooled. This results in reproducible and stable excretion patterns as is illustrated in control-experiments in this thesis. It was found impossible to recover $100 \%$ of the water and sodium infused from urine, as shown by base-line values in the studies reported in chapter 11 . Besides from fecal loss of water and sodium and loss of water through evaporation in breath, also the fact that large metabolism cages were used probably contributed to this loss. In an earlier study, where we used the smaller Ruco metabolism-cages (see above), urine was recovered for more than $80 \%$, once equilibrium was reached (Struyker-Boudier et al., 1979). However, because behaviour of rats was regarded to be less disturbed when animals were in the larger cages (which was necessary for cardiovascular measurements) these were preferred.

\subsection{Measurement of ${ }^{3} \mathrm{H}$-propranolol and its total metabolites in biological fluids and tissues.}

In the studies into the kinetics of propranolol in conscious SHR ${ }^{3} \mathrm{H}$-labelled dlpropranolol (New England Nuclear, NET-478) was used. Levels were determined in a number of fluids and tissue, i.e. urine, feces, plasma, erythrocytes, heart, lungs and kidneys. The brain was separated into brainstem, cerebellum, hypothalamus and cortex, the latter comprising all brain structures not mentioned before.

After weighing, tissues were homogenized in $10 \mathrm{ml} 0.9 \% \mathrm{NaCl}$ in water. Part of the homogenate was alkalinized ( $\mathrm{ph}>13$ with $10 \mathrm{~N} \mathrm{NaOH}$ and extracted with toluene/isoamylalcohol (1.5\%). After centrifugation the organic phase was transferred into a 
scintillation vial and counted for radio-activity in a Packard Tri-Carb scintillation counter after the addition of a commercial liquid scintillation-cocktail (Aquasol, New England Nuclear). Counts in this phase were regarded to derive from unchanged propranolol, as will be discussed below.

Another part of the homogenate was combusted quantitatively $\geqslant 99 \%$ ) in a Packard Model 306 Sample Oxidizer, and tritiated water thus formed was collected and the amount determined by liquid scintillation counting. All samples were corrected for quenching by internal standardization with ${ }^{3} \mathrm{H}$-toluene.

As stated before, the organic extract contained propranolol. Tritiated water derived from both unchanged propranolol and its total metabolites. By subtraction of counts of the amount of unchanged propranolol in the latter sample from the total, the amount of radio-activity from metabolites could be calculated. Metabolite concentrations are expressed as equivalents of propranolol i.e. the specific activity was assumed to be the same for metabolite and propranolol.

\section{TABLE 2.I.}

Specificity of the propranolol assay.

Tissue

Recovery

$($ mean\% $\pm S D, N=6)$
Identified as

propranolol $(\%, \mathrm{~N}=2)$

$\begin{array}{lll}\text { plasma } & 98 \pm 3 & 92-95 \\ \text { erythrocytes } & 94 \pm 3 & 92-93 \\ \text { heart } & 95 \pm 3 & 88-90 \\ \text { lungs } & 93 \pm 2 & 77-81 \\ \text { kidneys } & 92 \pm 3 & 86-91 \\ \text { liver } & 95 \pm 3 & 88-93 \\ \text { brain } & 98 \pm 6 & 91-91\end{array}$

Recovery is given as mean percentage of recovery of radiolabelled propranolol added to tissuehomogenates $(10-500 \mathrm{ng} / \mathrm{g})$. The second column represents the recovery of radioactivity from the spot containing propranolol after TLC; the percentage of radioactivity identified as propranolol compared to the total amounts of radioactivity applied to the TLC-plate is given for the two animals. 
In order to test the efficiency of the extraction procedure, known amounts of radiolabelled propranolol were added to six homogenates of each tissue to make up concentrations ranging from 10 to $500 \mathrm{ng} / \mathrm{g}$. Homogenates were extracted in the usual way and the amount of radio-activity in the heptane phase was measured by liquid scintillation counting. Since no dependency for recovery upon concentration was found, the data for different concentrations were pooled in table 2.I.

To test the specificity of the extraction procedure, two rats were implanted with an osmotic minipump containing dl-propranolol ( $1 \mathrm{mg} / \mathrm{kg}$. day) with a specific activity of $60 \mathrm{mCi} / \mathrm{mmol}$. On day 6 , the rats were killed and tissues mentioned above were taken out, weighed and homogenized in $0.9 \% \mathrm{NaCl}$. The homogenates were extracted with 1.5 volumes of $1.5 \%$ iso-amylalcohol in heptane after the addition of 0.025 volumes of $10 \mathrm{~N} \mathrm{NaOH}(\mathrm{pH}>13)$. To reduce lipid contents of the extract, which was necessary for chromatography, reextraction into an aqueous solution was carried out. The heptane phase was transferred to another glass and extracted twice with $3 \mathrm{ml}$ of $0.1 \mathrm{~N}$ $\mathrm{HCl}$. The acidic extracts were pooled and after addition of $200 \mu \mathrm{l}$ of $10 \mathrm{~N} \mathrm{NaOH}$ was reextracted into chloroform. After separation, the organic phase was taken to dryness under a gentle stream of nitrogen at room temperature. The residues were dissolved in $100 \mu \mathrm{l}$ of chloroform containing unlabelled propranolol $(10 \mu \mathrm{g} / \mathrm{ml})$ and $10 \mu \mathrm{l}$ were taken for liquid scintillation counting. Seventy microliters were then spotted on an F254-fluorescent silane-treated thin-layer chromatography (TLC) plate (Merck 5747) and chromatograms were developed in $0.2 \mathrm{M} \mathrm{NaCl}$-acetone (2:1) as described below (see section 2.13.).

After developing and drying of the plates, spots containing propranolol were visualized under ultraviolet light, marked and scraped into scintillation vials. Two milliliters of $0.1 \mathrm{~N} \mathrm{HCl}$ were added and the vials were shaken vigorously. Then $15 \mathrm{ml}$ of a commercial liquid scintillation cocktail (Aquasol, New England Nuclear) were added and the samples were counted for radio-activity. Quenching was corrected for by internal standardization.

Table 2.I shows the results of the experiments in which the recovery of propranolol, added to tissue homogenates, was tested. Lowest recovery was found from kidney homogenates, from which $92 \pm 3 \%$ (S.D., $N=6$ ) was recovered in the heptane phase. From all other tissues recovery was higher. Table 2.1 also shows the recovery of radio-activity from the TLC procedure. The carry-over of radio-activity through the reextraction steps was more than $90 \%$ for all samples. In the table, recovery has been expressed as percentage of the total radio-activity applied to the TLC plate. Lowest recovery was found from lungs $(77-81 \%)$ and highest from plasma (92-95\%). Since these recoveries were all approximately $80 \%$ or more, no corrections are made in the further text for tissue recoveries of propranolol. 


\subsection{Measurement of propranolol in plasma}

In co-operation with $\mathrm{Dr}$. $\mathrm{H}$. Thijssen a method was developed to measure the concentration of propranolol in small plasma samples, which will be described in full detail elsewhere.

Briefly, plasma $(0.1-1 \mathrm{ml})$ was alkalinized $(\mathrm{pH}>13)$ with $10 \mathrm{~N} \mathrm{NaOH}$ and extracted with $3 \mathrm{ml}$ heptane/2-pentanol (1.5\%) in a glass tube. After shaking and centrifugation, the organic layer was transferred to a new glass tube and taken to dryness under a gentle stream of nitrogen at $30^{\circ} \mathrm{C}$. This latter tube was then rinsed with $100 \mu \mathrm{l}$ chloroform. Two samples $(20 \mu \mathrm{l}$ and $60 \mu \mathrm{l}$ of the chloroform) were spotted on a $\mathrm{F} 254$ fluorescent silane-treated thin-layer chromatography (TLC) plate (Merck 5747). On the same TLC plate propranolol was spotted in known amounts, providing a calibration-line. Chromatograms were developed in $0.2 \mathrm{M} \mathrm{NaCl}$ /acetone (2:1) and wet plates were scanned for propranolol using a Shimadzu densitometer, set to measure emission at $350 \mathrm{~nm}$ caused by an excitation-wavelength of $292 \mathrm{~nm}$. The spots for calibration contained only propranolol and provided a reliable reference for localization of propranolol-spots in sample-extracts.

The lower limit of determination was $\sim 5 \mathrm{ng} / \mathrm{ml}$. Extraction-efficiency was $90 \%$ and reproducibility of the total assay was good as judged from the coefficient of variation of $10 \%(N=12)$ for intra-assay and $10 \%(N=7)$ for inter-assay variation.

Known propranolol-metabolites did not interfere with the assay. Besides having different fluorescence characteristics Rf-values were also different. In the chromatography system used, N-desisopropylpropranolol, propranololglycol and 4-hydroxypropranolol have Rf-values of $0.38,0.22$ and 0.46 , whereas propranolol has an Rfvalue of 0.31 .

\subsection{Measurement of plasma protein binding}

For determination of plasma protein binding, serum from 5 adult SHR was pooled. 0.5 $\mathrm{ml}$ fractions were taken and dialyzed in test-tubes at $37^{\circ} \mathrm{C}$ for 20 hours against $5 \mathrm{ml}$ of Sorenson buffer $\left(\mathrm{pH}=7.4\right.$.). To different test-tubes different amounts of ${ }^{3} \mathrm{H}$-labelled propranolol were added. At the end of the dialysis period aliquots of both buffer solution and serum were taken and counted for radioactivity. Quenching was corrected for by internal standardization, using a $3 \mathrm{H}$-toluene standard (New England Nuclear, NES-004). From known specific activity and d.p.m.'s, plasma concentrations (total) were calculated. The percentage of propranolol bound to plasma was calculated as:

$$
\left(1-\frac{\text { d.p.m./ml buffer }}{\text { d.p.m./ml plasma }}\right) \times 100
$$




\subsection{Determination of plasma renin activity}

Plasma renin activity was measured using a radio-immuno-assay, according to standard methods. Briefly, $50 \mu$ l plasma wre incubated at $37^{\circ} \mathrm{C}$ for 3 hours in the presence of $0.9 \mathrm{mg} / \mathrm{ml}$ phenantroline, $0.7 \mathrm{mg} / \mathrm{ml} \mathrm{Na} 2$ EDTA, $0.9 \mathrm{mg} / \mathrm{ml} 8$ hydroxyquinoline and $0.3 \mathrm{mg} / \mathrm{ml} \mathrm{BAL}$. The $\mathrm{pH}$ of the mixture was 6.0 .

Blanc samples, which allowed correction for endogenous angiotensin I (A-I), consisted of the same mixture but incubation was done at $0^{\circ} \mathrm{C}$.

After incubation angiotensins were extracted on a $A G 50 \mathrm{~W}-\mathrm{X} 4$ ion-exchange resin and washed with acid ( $10 \%$ acetic acid) and water. Angiotensins were then eluted with ammonia and diethylamine $(0.5 \mathrm{ml}$ each) and lyophilized. Samples were stored at $-70^{\circ} \mathrm{C}$ until further assayed. Losses during work-up were corrected for by addition of a small amount of ${ }^{125}$ /-angiotensin I (New England Nuclear, NEX-101) as a tracer after incubation.

Radio-immuno-assay was carried out according to standard procedures, using a commercial antiserum (New England Nuclear, NEA-022A) and ${ }^{125}$ I-angiotensin-I as a radio-ligand (New England, Nuclear, NEX-101). Plasma renin activity (PRA) was expressed as $\mathrm{ng} \mathrm{Al}$ generated per $\mathrm{ml}$ plasma per hour.

Intra- and inter-assay variation for the whole procedure were low, resp. $3 \%(\mathrm{~N}=5)$ and $4 \%(N=4)$. 
ONE DOSE STUDIES 


\section{PHARMACOKINETICS OF PROPRANOLOL AFTER A SINGLE SUBCUTANEOUS INJECTION IN CONSCIOUS SHR.}

\subsection{Introduction}

The pharmacokinetic properties of propranolol in man have been studied extensively, as was reviewed in section 1.2. For apparent experimental limitations, these studies have confined to plasma-kinetics. Only one study so far has dealt with kinetics of propranolol after acute injection in the species used in the present work, the spontaneously hypertensive rat (Forman and Mulrow, 1974). These authors only measured plasma levels at different times following injection of the drug. In several other experimental animal species like monkeys, dogs (Hayes and Cooper, 1971), normotensive rats (Laverty and Taylor, 1968; Schneck et al., 1977; Street et al., 1979) and mice (Masuoka and Hansson, 1967; Levy et al., 1976) plasma and tissue levels have been examined in extent. Since the antihypertensive effect of propranolol in man has been shown to be slow in onset and long-lasting, a possible slow penetration or retardation in tissues might give a clue to its site of antihypertensive action.

As stated above, no detailed information on the distribution of propranolol is available for the spontaneously hypertensive rat (SHR). Extrapolation of findings in other species seems hazardous. Propranolol is eliminated by the liver, its rate of elimination being dependent on liver blood-flow (Nies et al., 1973). Through its cardiovascular actions, that is reduction of cardiac output, propranolol might interfere with its own pharmacokinetics. In fact, Weiss et al. (1976) showed that the pharmacokinetic behaviour of propranolol in borderline hypertensive patients is different from that in permanent hypertensives. Differences could be explained entirely by different hemodynamic patterns.

Therefore, a detailed study of the distribution and elimination of propranolol was performed in the species under study. As in the rest of the studies rats were conscious and unrestrained. A fixed dose of $1 \mathrm{mg} / \mathrm{kg}$ was used and subcutaneous injection. which was also used in the cardiovascular studies, was chosen as the route of administration.

\subsection{Experimental protocol}

Animals and methods used in this study were described in chapter 2. Rats were implanted with a catheter in the right jugular vein to permit blood sampling.

Tritiated propranolol (NET-478, New England Nuclear) with a specific activity of approximately $20 \mathrm{mCi} / \mathrm{mmol}$ was injected subcutaneously (s.c.) in a dose of $1 \mathrm{mg} / \mathrm{kg}$. At maximally 4 points in time, separated by at least $30 \mathrm{~min}$, blood was drawn from the venous catheter $(0.2-0.5 \mathrm{ml})$. At different times after the administration of propranolol animals were killed by intravenous injection of an overdose of thiopental. They were bled immediately.

Heart, lungs, kidneys, brainstem, cerebellum, hypothalamus and the rest of the brain were taken out for the determination of propranolol and metabolite concentrations. 
The "rest of the brain" will be referred to furtheron as "cortex". The organs were dried and weighed. Thereafter they were transferred to glass tubes and homogenized in 10 $\mathrm{ml} 0.9 \% \mathrm{NaCl}$, using an Ultra Thurrax homogenizer.

Tritiated propranolol and its metabolites were determined according to the methods in section 2.12 .

Data are presented as means \pm 1 S.E.M. Curve fitting of the plasma propranolol concentration-time curves was done with the nonlinear least-square curve fitting program FARMFIT (Computer Centre of the Catholic University of Nijmegen). Relevant pharmacokinetic parameters were calculated according to standard procedures (cf. Gibaldi, 1977).

\subsection{Results}

\subsubsection{Plasma levels of propranolol as a function of time}

The plasma concentration-time profile of propranolol following a single s.c. injection of $1 \mathrm{mg} / \mathrm{kg}$ is shown in figure 3.1. In this figure data-points for different animals were pooled. No complete curves were obtained in single animals, because the rats were sacrificed at different times. The curve, drawn through the data-points, resulted from fitting of the individual data using a simple two-compartment open model, with an absorption phase.

The data reveal a very rapid uptake of propranolol in plasma the absorption half-life being approximately $1 \mathrm{~min}$. A maximal mean plasma level of $374 \pm 33 \mathrm{ng} / \mathrm{ml}(\mathrm{N}=10)$ was found $5 \mathrm{~min}$. after the injection. Absorption was followed by a biphasic decline of plasma levels. The early (alpha) phase had a half-life of $17 \mathrm{~min}$., whereas the half-life of the late (beta) phase was found to be $59 \mathrm{~min}$. Total body clearance, as calculated from the dose and the area under the curve, was $14 \mathrm{ml} / \mathrm{min}$.

\subsubsection{Tissue levels of propranolol as a function of time.}

Levels of propranolol in the tissues that were studied, are shown in figure 3.2., at different times following s.c. injection of $1 \mathrm{mg} / \mathrm{kg}$ propranolol. For comparison, plasma levels at these times are included in the figure. In all organs studied, maximal levels were observed $30 \mathrm{~min}$. after injection. Lungs reached the highest concentrations ( $10.4 \pm 15 \mu \mathrm{g} / \mathrm{g}, \mathrm{N}=5$ ) whereas in the other peripheral tissues studied i.e. heart and kidneys maximal levels were resp. $1.5 \pm 0.2 \mu \mathrm{g} / \mathrm{g}(\mathrm{N}=5)$ and $2.6 \pm 0.2 \mu \mathrm{g} / \mathrm{g}$ $(\mathrm{N}=5)$. These latter values are comparable to those in the brain areas studied, i.c. brainstem (1.27 $\pm 0.23 \mu \mathrm{g} / \mathrm{g}, N=5)$, cerebellum $(0.8 \pm 0.08 \mu \mathrm{g} / \mathrm{g}, \mathrm{N}=9$ ), hypothalamus (1.06 $\pm 0.16 \mu \mathrm{g} / \mathrm{g}, \mathrm{N}=5$ ) and cortex (0.90 $\pm 0.16 \mu \mathrm{g} / \mathrm{g}, \mathrm{N}=5)$. Plasma propranolol at $30 \mathrm{~min}$. after injection was $0.22 \pm 0.02 \mu \mathrm{g} / \mathrm{ml}(\mathrm{N}=10)$.

After the peak at $\mathbf{3 0} \mathrm{min}$. post injection, levels declined gradually and uniformly in all organs. Only in the lungs there was a slight irregularity, in that the concentration at 
$180 \mathrm{~min}$. was slightly higher than that at $90 \mathrm{~min}$. However, thereafter it declined again. At $360 \mathrm{~min}$. after the injection, the concentration in the lungs was still $0.08 \pm$ $0.02 \mu \mathrm{g} / \mathrm{g}$. In plasma it had declined to $1.4 \pm 0.1 \mathrm{ng} / \mathrm{ml}$, by that time. In all other tissues it was around $0.01 \mu \mathrm{g} / \mathrm{g}$.

From the data in figure 3.2. it can be concluded that no accumulation occurs in any of the tissues examined, since after $180 \mathrm{~min}$. post-injection the decline of the concentrations in all organs was equal to or greater than that in plasma.

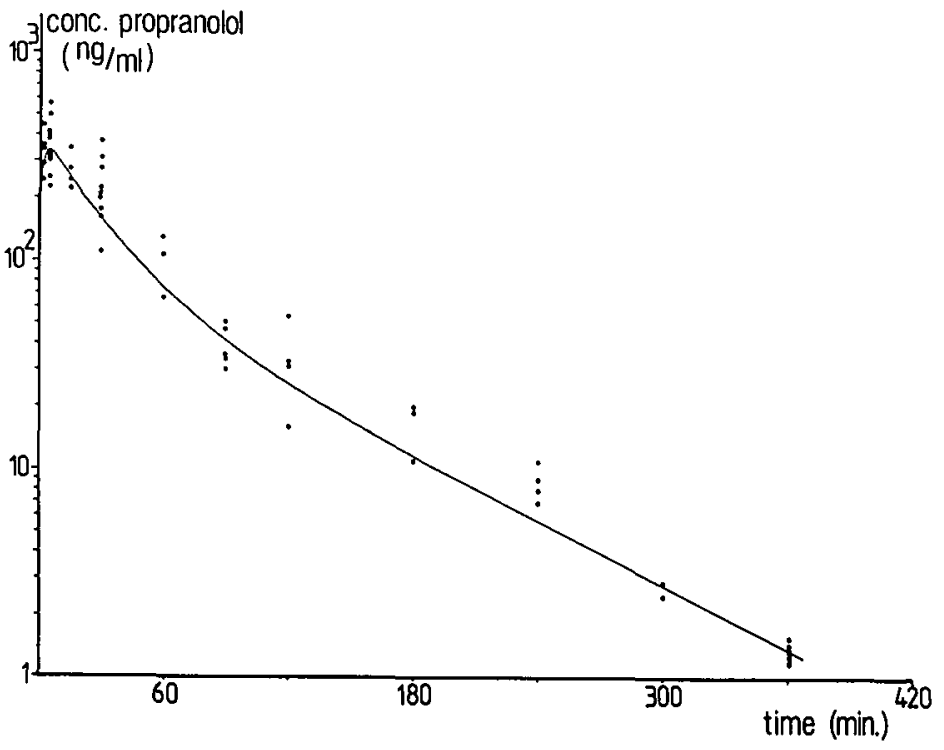

Figure 3.1. Plasma concentration-time profile for propranolol in SHR after s.c. injection of $1 \mathrm{mg} / \mathrm{kg}$ at time $t=0$. The curve was fitted for individual data using a two compartment open model with an absorption phase. 


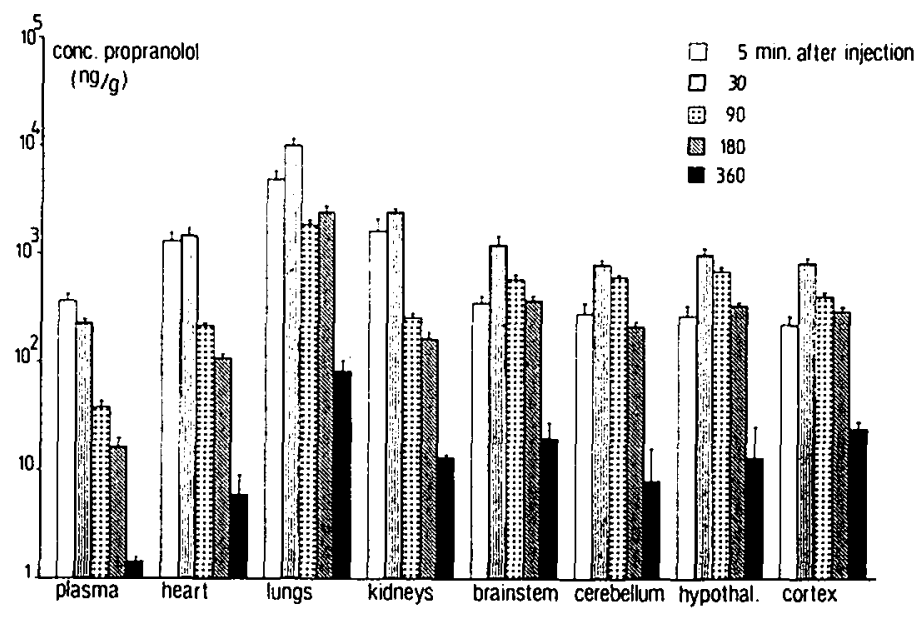

Figure 3.2. Propranolol levels in several tissues of SHR at 5, 30,90,180 and $360 \mathrm{~min}$. after s.c. injection of $1 \mathrm{mg} / \mathrm{kg}$. Each bar represents the mean of 3-8 animals with S.E.M. indicated.

\subsubsection{Tissue levels of total propranolol metabolites as a function of time.}

Figure 3.3 shows plasma and tissue-levels of total propranolol metabolites as a function of time, after injection of $1 \mathrm{mg} / \mathrm{kg}$ propranolol s.c. in plasma maximal concentrations were observed $90 \mathrm{~min}$. after the injection $(437 \pm 88 \mathrm{ng} / \mathrm{ml}, \mathrm{N}=5)$. Thereafter metabolite concentration declined, reaching a level of $38 \pm 20 \mathrm{ng} / \mathrm{ml}$ $(\mathrm{N}=5)$ at $6 \mathrm{~h}$ post-injection.

Into all tissues studied, propranolol metabolites were taken up rapidly and extensively. Maximal values were observed $30 \mathrm{~min}$. after the injection. Also here lungs reached the highest level $(6.0 \pm 2.0 \mu \mathrm{g} / \mathrm{g}, \mathrm{N}=5)$, whereas the lowest peakconcentration was found in cerebral cortex $(0.07 \pm 0.02 \mu \mathrm{g} / \mathrm{g}, \mathrm{N}=5)$. After $30 \mathrm{~min}$. metabolite concentration decreased, although not as regular as that observed for the mother-compound. It should, however, be stressed that total metabolite concentration represents a pool of metabolites, each having its own specific kinetic behaviour. 


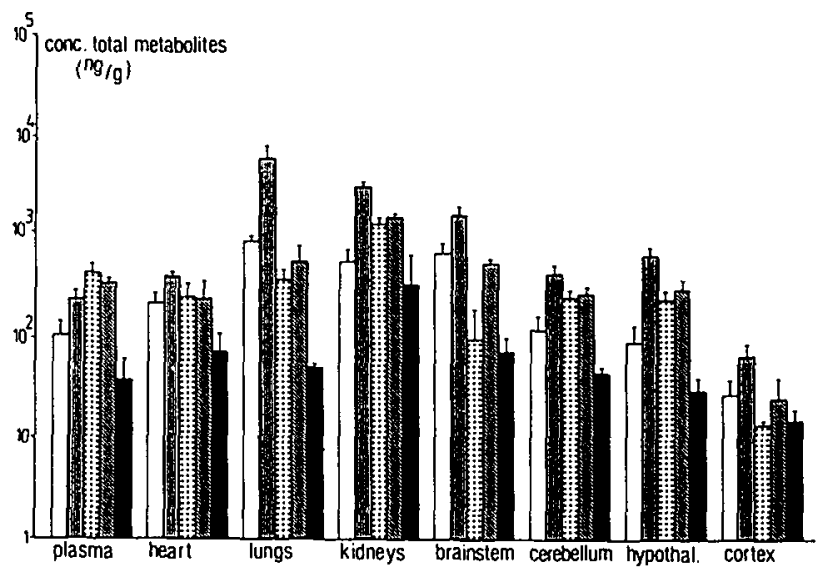

Figure 3.3. Total propranolol metabolite levels in several tissues of SHR at 5, 30, 90, 180 and $360 \mathrm{~min}$. after s. c. injection of $1 \mathrm{mg} / \mathrm{kg}$. Each bar represents the mean of $3-8$ animals with S.E.M. indicated.

\subsubsection{Relation between plasma concentration and protein binding of propranolol.}

Because the amount of propranolol available for tissue-penetration is only that part, which is not bound to plasma-proteins, it seemed necessary to investigate that plasma protein binding over the concentration-range encountered actually in plasma. Figure 3.4. shows the result of that study, in which serum of adult SHR was used. Plasma protein binding proved to be approximately $92 \%$ up to a total (=bound + unbound) concentration of about $100 \mathrm{ng} / \mathrm{ml}$. With higher concentrations binding diminished progressively, reaching a value of only $76 \%$ at the highest concentration tested $(345 \mathrm{ng} / \mathrm{ml})$.

\subsection{Discussion}

The data reported in this study show, that upon s.c. injection of $1 \mathrm{mg} / \mathrm{kg}$ in the conscious SHR propranolol appears in the blood-stream very rapidly (half-life of absorption $1 \mathrm{~min}$ ). Thereafter distribution and elimination processes take place (halflives of resp. 17 and $59 \mathrm{~min}$ ). This latter value is in reasonable agreement with the elimination half-life of $78 \mathrm{~min}$. as reported by Forman and Mulrow (1974). In normotensive rats values of $40 \mathrm{~min}$. (Shand et al., 1972), 63 and $108 \mathrm{~min}$. (Schneck et al., 1977) have been reported for intravenous propranolol in doses of resp. $2.5 \mathrm{mg} / \mathrm{kg}$, $1.5 \mathrm{mg} / \mathrm{kg}$ and $7.5 \mathrm{mg} / \mathrm{kg}$. So in this respect there seem to be no large differences with regard to strains. As compared to the beta half-life in man (2-6h; cf. section 1.2.) the half-life in rats is rather short. This may derive from the fact that clearance (as will be discussed below) is primarily determined by liver-flow, which in turn depends on cardiac output. This latter value in rats is $5-8$ times greater than that in man, when normalized for body weight. 
Clearance found in this study was $14 \mathrm{ml} / \mathrm{min}$. For a 300 grams SHR a cardiac output of appr. $120 \mathrm{ml} / \mathrm{min}$ may be expected (Smith and Hutchins, 1977; Coleman et al., 1980). Upon injection of $1 \mathrm{mg} / \mathrm{kg}$ propranolol this value will be reduced by some $10 \%-20 \%$ (see section 6.3.1). Under resting conditions in which approximately $13 \%$

(Yates and Hiley, 1979) to 19\% (Nishiyama et al., 1976) of cardiac output is distributed to the liver, liver-blood flow will be approximately $18 \mathrm{ml} / \mathrm{min}$ and plasma flow will be $\sim 11 \mathrm{ml} / \mathrm{min}$. for a 300 grams rat. Since in the rat hepatic clearance has been shown to be extremely effective (extraction-ratio 0.97 ) and dependent on blood flow, the clearance-value of $14 \mathrm{ml} / \mathrm{min}$ may be accounted for almost entirely by liverclearance. In normotensive rats clearance values from $19 \mathrm{ml} / \mathrm{min}$. (Schneck et al., 1977 ) to $28 \mathrm{ml} / \mathrm{min}$. (Evans et al., 1973) have been reported, so there is an indication for some extrahepatic clearance in the rat.

It should be stressed, that clearance and half-life reportedhere are only valid for the 1 $\mathrm{mg} / \mathrm{kg}$ dose in SHR. Higher doses will have a longer half-life with decreased clearance, lower doses may have a shorter half-life.

This was shown in rats by Schneck et al. (1977). Differences will be caused by several phenomena. First of all the high-affinity uptake mechanisms in liver have low capacity, therefore at high concentrations in plasma other binding-sites, possessing lower affinity but high capacity will be occupied thus clearance will diminish. Another factor which will result in a lowering of clearance is the fact that it depends on liver blood flow. Since propranolol decreases cardiac output in a dose-dependent manner (see section 6.3.) there will be a dose-dependent reduction of liver blood-flow, again diminishing clearance. If only clearance decreased, this would lead to an increase in beta half-life, distribution volume remaining unchanged. However, as was shown in this chapter protein binding of propranolol in plasma is concentration-dependent. Up to concentrations of $100 \mathrm{ng} / \mathrm{ml}$ approximately $92 \%$ is bound; this binding diminishes progressively at higher propranolol-levels. Since for tissue-distribution only unbound propranolol is available, this should lead to an increase in volume of distribution at higher doses, as was in fact shown by Schneck et al. (1977) in rats. This increase in volume of distribution again will influence half-life such, that the latter would increase even if clearance would be unaltered. Thus, 3 factors, each one depending on the others, will influence half-life of propranolol. Their interactions are too complex to make simple predictions in a quantitative way. Using data from kinetic and hemodynamic experiments from this thesis and literature, an attempt has been made to describe phenomena in a model, which will be discussed in an appendix to this thesis.

With regard to tissue distribution of propranolol the present results indicate a rapid and massive penetration of propranolol in all tissues examined. Maximal levels were observed $30 \mathrm{~min}$. after the injection in all organs, highest levels being reached at that time in lungs. Thereafter there was a steady decline of levels, which parallelled the disappearance from plasma. The distribution of propranolol after a single injection, has thus far been examined in mice (Masuoka and Hansson, 1967; Levy et al., 1976). rats (Hayes and Cooper, 1971; Schneck et al., 1977; Street et al., 1979) monkeys and dogs (Hayes and Cooper, 1971). In all species maximal organ-levels were reached between 15 and $60 \mathrm{~min}$. after the injection. All studies agree in the observation that lungs reach the highest levels. In an isolated lung-preparation Dollery and Junod 


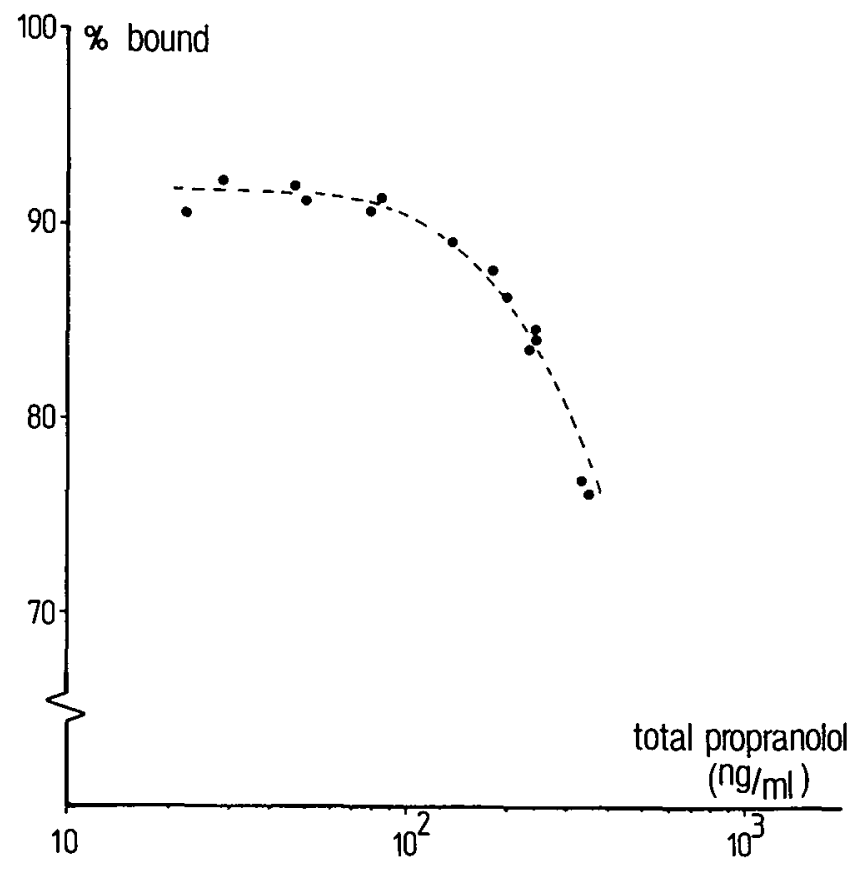

Figure 3.4. Plasma proteinbinding in SHR as determined by equilibrium dialysis. The percentage of propranolol bound (ordinate) is given as a function of total plasma propranolol concentration (abscissa).

(1976) showed that this results from binding of propranolol to at least two types of binding-sites. However, the exaxt nature of this binding still has to be clarified.

From the data reported in the study of Schneck et al. (1977) who studied the disposition of propranolol in normotensive rats it can be seen from tissue levels declining parallel to plasma that also in that species no retention occurs in any of the organs they studied. This is in agreement with our observations in SHR. However, in mice Levy et al. (1976) reported retention of propranolol in brain, lungs and heart. Although this may be caused by species-differences, the period of $2 \mathrm{~h}$ during which they measured levels may have been too short, resulting in interference of distribution-phenomena with elimination. Because of methodical aspects other studies into the disposition of propranolol (Masuoka and Hansson, 1967; Laverty and Taylor, 1968; Street et al., 1979) do not allow conclusions on this. These authors only measured total radio-activity in tissues. 
Propranolol metabolites are also taken up very rapidly by all tissues examined. Again lungs reach the highest levels, $0.5 \mathrm{~h}$ after the injection. The decline thereafter is not as gradual as that for propranolol. Probably this results from the fact that the pool of propranolol metabolites contains a number of substances, each with their own kinetic behaviour. Although it cannot be excluded that some metabolite is taken up slowly, the overall data do not suggest this.

Also retention does not seem to occur, again as judged from declines in plasma and tissue-levels after $3 \mathrm{~h}$. In conclusion, kinetic processes of uptake, distribution and elimination are all very rapid for propranolol in SHR. Tissue- and plasma-levels are all maximal around $30 \mathrm{~min}$. after the injections so any effects caused by simple drugreceptor interaction should be expected to occur rapidly too. 


\section{TIME-COURSE OF BETA-ADRENOCEPTOR BLOCKADE FOLLOWING A SINGLE SUBCUTANEOUS INJECTION OF PROPRANOLOL IN CONSCIOUS SHR}

\subsection{Introduction}

Prolonged beta-adrenoceptor blockade, i.e. even in the absence of any detectable drug in the plasma, could provide a possible explanation for the long duration of the antihypertensive effects of beta-adrenoceptor blocking drugs in man (see section 1.3.). From the preceding chapter it may be concluded, that propranolol rapidly disappears not only from plasma, but also from tissues. Taking tissue levels as a measure for the concentrations of the drug at receptor sites, one would expect its pharmacodynamic actions to diminish in relation to those concentrations, assuming drug-receptor interaction to be necessary for and correlated with any effect. However, tight binding of propranolol to certain sub-cellular structures might result in receptors still being occupied at times when plasma- or even tissue- levels are below dectection limits.

In man, several authors have reported a correlation between the logarithm of the plasma-propranolol concentration and inhibition of exercise-induced tachycardia or isoprenaline-induced tachycardia (see review Johnsson and Reghärd, 1976a). This latter observation could not be confirmed for orally administered propranolol (Coltart and Shand, 1970; Cuthbert and Collins, 1975) who speculated that propranololmetabolites, which they did not measure, possessed beta-adrenoceptor blocking capacities too, this disturbing correlation. Such metabolites might also be formed in SHR and, since no discrimination for single metabolites was made in the preceding chapter, could still cause beta-adrenoceptor blockade at times where, judging from plasma propranolol levels, it would no longer be expected. Furthermore a report by Sheppard and Burghardt (1978) showed that isoprenaline stimulated production of cyclic AMP in mouse thymus cells or rat erythrocytes could be reduced by preincubation of the cells with propranolol and that this reduction was retained even after several washings of the cell-suspensions, suggesting an irreversibility of betablockade.

Therefore, in this chapter results will be presented from investigations into the time course of cardiac (beta 1 ) and vascular ( beta $_{2}$ ) beta-adrenoceptor blockade after single s.c. injections of propranolol in the conscious SHR. No attempt was made to correlate beta-adrenoceptor blockade with plasma-levels of propranolol, but rather this investigation was undertaken to relate blockade to the ultimate cardiovascular effects that will be discribed in following chapters. 


\subsection{Experimental protocol}

Rats used in this study are the same as those in the "restrained" group in chapter 5. Methods for cannulation (of a femoral artery and vein) were described in chapter 2.

Serial injections of isoprenaline $(0.003-30 \mu \mathrm{g} / \mathrm{kg})$ were given at several points in time, i.e. 1 hour before and $0.5,1.5,3$ and 20 hours after the injection of saline or propranolol. The dose of isoprenaline was increased until maximal effects were reached.

Dose-response curves for isoprenaline-induced hypotension and tachycardia were constructed. The maximum of the effect of each dose was taken for this. From the curves $E_{50}$ was determined. This value was taken to be a measure for betaadrenoceptor blockade.

Data are expressed as means \pm S.E.M.. For statistical evaluation Student's t-test for unpaired observations was used.

\subsection{Results}

\subsubsection{Time-course of cardiac beta-adrenoceptor blockade}

The time-course of cardiac beta-adrenoceptor blockade in the total group of rats receiving resp. saline or propranolol in doses of $0.04,0.2,1$ and $5 \mathrm{mg} / \mathrm{kg}$ is shown in figure 4.1. Saline had no appreciable effects on isoprenaline-induced tachycardia. Propranolol caused a reduction of sensitivity for isoprenaline, the degree of reduction depending both on time after the injection and the dose of propranolol. Maximal betablockade was seen in all cases $0.5 \mathrm{~h}$ after injection of propranolol. For $1 \mathrm{mg} / \mathrm{kg}$ propranolol $E_{50}$ had increased by that time from $0.08 \pm 0.03 \mu \mathrm{g} / \mathrm{kg}$ to $0.68 \pm 0.06$ $\mu \mathrm{g} / \mathrm{kg}(\mathrm{N}=6)$. Thereafter beta-blockade gradually decreased, $E D_{50}$ in the $1 \mathrm{mg} / \mathrm{kg}$ group having values of $0.40 \pm 0.03 \mu \mathrm{g} / \mathrm{kg}$ and $0.15 \pm 0.03 \mu \mathrm{g} / \mathrm{kg}$ at $0.5 \mathrm{~h}$ and $3 \mathrm{~h}$ respectively. At $20 \mathrm{~h}$ post-injection $E_{50}$ 's were back at control-levels.

\subsubsection{Time-course of blockade of vascular beta-adrenoceptors.}

Mean $E D_{50}$-values for the groups are shown in figure 4.2. For isoprenaline-induced hypotension these were consistently higher than those observed for isoprenalineinduced tachycardia. Also the increase after propranolol was greater e.g. after 5 $\mathrm{mg} / \mathrm{kg} \mathrm{ED} 50$ for isoprenaline-induced hypotension increased approximately 300 -fold at $0.5 \mathrm{~h}$ after injection, whereas this increase for tachycardia was approximately 75 fold.

The time-course for inhibition of isoprenaline-induced hypotension was similar to that observed for tachycardia. Again the magnitude of the effect depended upon the dose of propranolol. Saline did not change $E D_{50}$ for isoprenaline-induced hypotension, and $0.05 \mathrm{mg} / \mathrm{kg}$ only increased it at $0.5 \mathrm{~h}$ after injection. All other doses of 


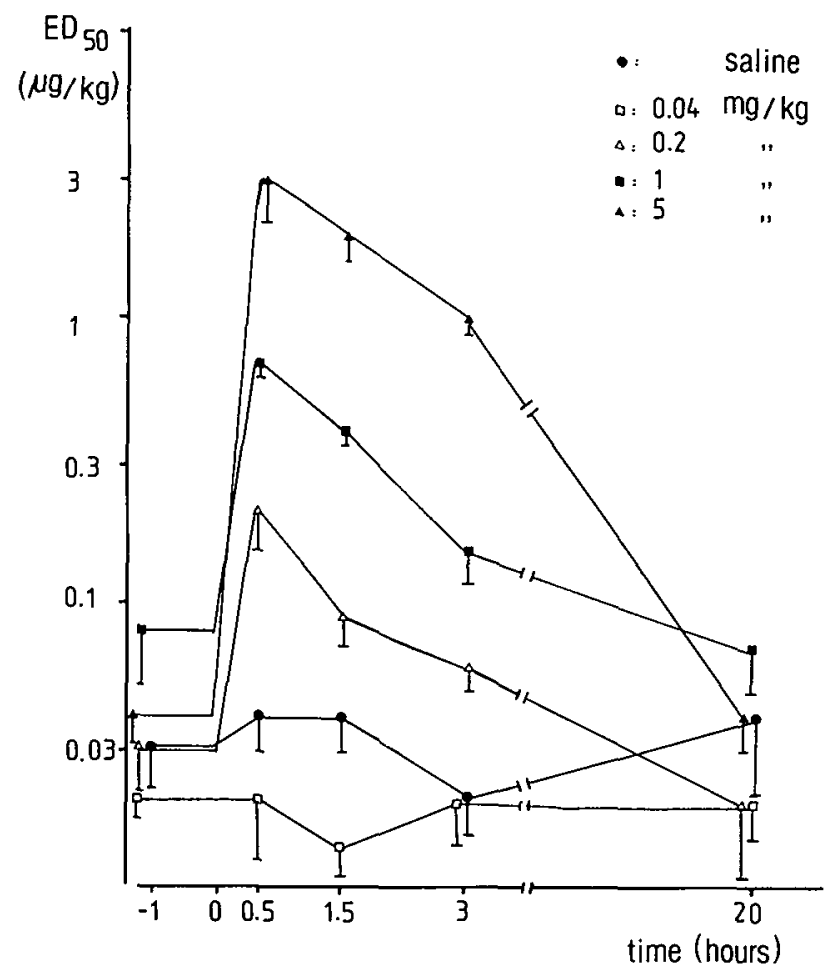

Figure 4.1. Time-course of the inhibition of isoprenaline-induced tachycardia produced by propranolol injected s.c. at time 0 . Each point represents the mean for 5 11 animals with S.E.M. indicated.

Symbols: ( $)$ saline controls; propranolol: ( $\square$ ) $0.04 \mathrm{mg} / \mathrm{kg} ;(\Delta) 0.2 \mathrm{mg} / \mathrm{kg}$; (D) $1 \mathrm{mg} / \mathrm{kg}$; ( A ) $5 \mathrm{mg} / \mathrm{kg}$.

propranolol clearly blocked vascular beta-receptors potently. Maximal ED 50 -values were also here seen $0.5 \mathrm{~h}$ after injection. Upon $1 \mathrm{mg} / \mathrm{kg} \mathrm{s.c.} \mathrm{it} \mathrm{increased} \mathrm{from} 0.10 \pm$ $0.02 \mu \mathrm{g} / \mathrm{kg}$ as a start-value, to $3.1 \pm 1.0 \mu \mathrm{g} / \mathrm{kg}$ by that time. Thereafter beta-blockade diminshed. For $1 \mathrm{mg} / \mathrm{kg}$ it was $1.3 \pm \mu \mathrm{g} / \mathrm{kg}$ and $0.58 \pm 0.18 \mu \mathrm{g} / \mathrm{kg}$ at $1.5 \mathrm{~h}$ and $3 \mathrm{~h}$ after injection. Twenty hours after propranolol $E_{50}$ 's were back at control levels. 


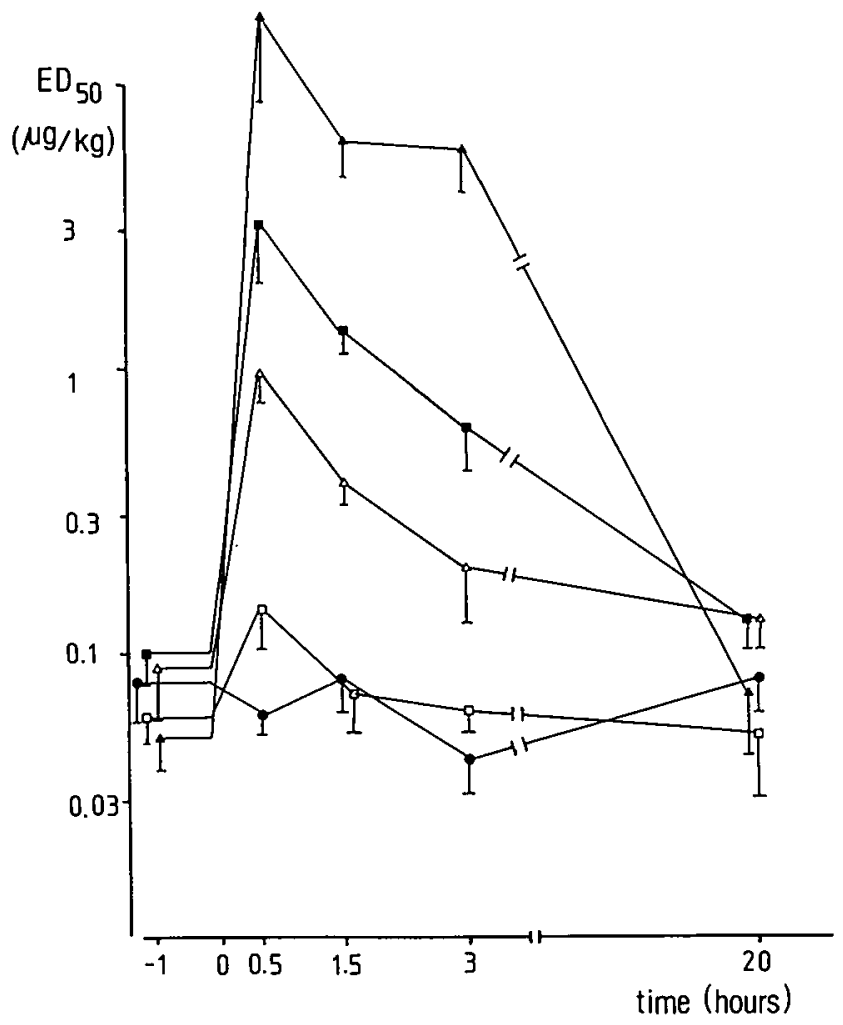

Figure 4.2. Time-course of the inhibition of isoprenaline-induced hypotension produced by propranolol injected s.c. at time 0 . Each point represents the mean for 5-11 animals with S.E.M. indicated.

Symbols: ( $\bullet$ ) saline controls; propranolol: $(\square) 0.04 \mathrm{mg} / \mathrm{kg}$; $\triangle 10.2 \mathrm{mg} / \mathrm{kg}$; ( 口 ) $1 \mathrm{mg} / \mathrm{kg}$; ( \ ) $5 \mathrm{mg} / \mathrm{kg}$. 


\subsection{Discussion}

As expected from the fact that propranolol is a non-selective beta-adrenoceptor blocking drug, both cardiac (beta ${ }_{1}$ ) and vascular (beta 2 ) responses to isoprenaline were inhibited by it. The degree of inhibition depended both upon the dose injected and time. The change in $\mathrm{ED}_{50}$-values for isoprenaline-induced hypotension was consistently greater than that for tachycardia. This might indicate a relatively greater affinity for beta 2 -adrenoceptors in SHR. In human and guinea-pig this has not been found (Harms, 1976). Another explanation might be that the hypotension induced by isoprenaline elicits a baroreceptor reflex, thus causing vagus-withdrawal from the heart. This would then lead to an over-estimation of the cardiac effects of isoprenaline, which could change with the degree of sympathetic blockade. This was not further investigated.

Maximum blockade of both vascular and cardiac beta-adrenoceptors was observed $0.5 \mathrm{~h}$ after the injection. Thereafter it diminished and $20 \mathrm{~h}$ post-injection no betaadrenoceptor blockade could be detected for any of the doses used. Plasma- and tissue-levels reported in the preceding chapter were also maximal at $0.5 \mathrm{~h}$ after the injection, declining thereafter. This suggests a correlation between the two phenomena. In fact, in man a direct relationship between the logarithm of plasmalevels of propranolol and isoprenaline- or exercise-induced tachycardia has been demonstrated by several authors (ct. section 1.3). However, some were not able to find a simple correlation between plasma-level and beta-adrenoceptor blockade when the drug was given orally (Coltart and Shand, 1970; Cuthbert and Collins, 1975). These authors speculated that formation of 4-hydroxy-propranolol interfered with concentration-effect relationships. This is a metabolite possessing betaadrenoceptor blocking properties comparable to those of the parent-drug (Fitzgerald and $O^{\prime}$ Donnel, 1971) and which is formed in detectable amounts only after oral ingestion of propranolol (Hayes and Cooper, 1970). Since in our studies the drug was administered subcutaneously it is not very probable that this metabolite is formed in considerable amounts, although neither the data from the preceding chapter, nor those presented here exclude the possibility. However, if it is formed, it does not cause prolonged beta-adrenoceptor blockade.

Sheppard and Burghardt (1978) reported that the inhibition of in vitro isoprenaline stimulated formation of cyclic AMP in mouse thymus-cells and rat-erythrocytes by propranolol was retained after several washings of the cell-suspensions. They concluded that there was a certain degree of irreversibility of beta-adrenoceptor blockade. Such phenomena could explain the long duration of antihypertensive effects reported in man. However, in our preparation for cardiac and vascular betaadrenoceptors no evidence for irreversible blockade was obtained, judged from the fact that $20 \mathrm{~h}$ after the injection no beta-adrenoceptor blockade could be shown.

In conclusion, blockade of cardiac and vascular beta-adrenoceptors was found to be occurring rapidly reaching maxima $0.5 \mathrm{~h}$ after injection, diminishing thereafter. Furthermore the degree of blockade depended upon the dose of propranolol injected. 


\section{EFFECTS OF A SINGLE SUBCUTANEOUS INJECTION OF PROPRANOLOL ON BLOOD PRESSURE AND HEART RATE IN CONSCIOUS SHR.}

\subsection{Introduction.}

In chapter 1 (section 1.4) literature concerning studies into the antihypertensive effectiveness in spontaneously hypertensive rats was reviewed. Only few authors have been able to detect an antihypertensive response to propranolol in this animal model. In awake animals only Roba et al. (1972) and Sweet and Wenger (1976) reported such an effect. In both studies it took between 2 and 20 hours before the effect was observed, although the latter authors only saw the effect after administration of propranolol into the cerebral ventricles. All other studies report propranolol to be ineffective or even to cause a rise in blood pressure. As was discussed in section 1.4 this discrepancy may be explained from methodical differences as well as the fact that most experiments were of short duration, so a late antihypertensive effect may have been over-looked.

After reporting on the pharmacokinetics and the kinetics of beta-adrenoceptor blockade in the preceding chapters, this chapter will deal on the kinetics of cardiovascular responses, i.e. the kinetics of the effects of propranolol on blood pressure and heart rate in conscious SHR. For this it seemed necessary to measure these paramaters for a prolonged period of time after the administration of the drug. Furthermore, the influence of restraining the animals, which is often done in experiments of this type, was investigated by comparing effects in partially restrained and fully unrestrained animals.

\subsection{Experimental protocols}

In restrained rats blood pressure was measured through an indwelling catheter in the femoral artery (PE 50). In unrestrained rats it was measured either in the abdominal aorta or the left common carotid artery. All experiments were started between 11:00 and 12:00 a.m. to exclude interference of circadian rhythm. Experiments in restrained rats were started 2-3 hours after termination of anesthesia. After determination of base-line values for MAP and HR injections were given in an $0.1 \mathrm{ml}$ volume of saline. MAP and HR were monitored continuously for another 20 hours.

Data used for comparison between restrained and unrestrained rats were derived from studies included in the following chapters. Unless there are special reasons for not doing so, in these chapters reference will be made to the present chapter.

Blood pressure in freely moving rats was measured while animals were in glass experimental cages or metabolism cages. Rats were used 1-3 days after surgery. Also here injections were given in $0.1 \mathrm{ml}$ saline. In most unrestrained animals blood pressure and heart rate were not measured continuously. In animals injected with 1 $\mathrm{mg} / \mathrm{kg}$ propranolol measurements were interrupted at 4 hours after injection. Animals 
were re-connected 20 hours after injection.

In most other animals measurements were not made between 8 and 12 hours and 12 and 20 hours after injection.

Data are presented as means \pm S.E.M.. Base-line values were determined from 6 consecutive readings during the last $30 \mathrm{~min}$ before injection.

Significances in differences in effects between groups were calculated using Student's t-test for unpaired observations. Differences were regarded to be statistically significant if $P<0.05$.

\subsection{Results}

\subsubsection{Effects on heart rate}

Base-line values for heart rate (HR) are summarized in table 5.I. In restrained rats it was between 427 and 478 beats/min. In unrestrained rats HR was consistently lower, ranging from 321 to 416 beats $/ \mathrm{min}$.

\section{Table 5.I.}

Base-line values for mean arterial pressure and heart rate in the rats in this chapter.

Restrained rats

N

- saline

- $0.04 \mathrm{mg} / \mathrm{kg}$ propranolol

$-0.2 \mathrm{mg} / \mathrm{kg}$ propranolol

- $1 \mathrm{mg} / \mathrm{kg}$ propranolol

- $5 \mathrm{mg} / \mathrm{kg}$ propranolol

\section{Unrestrained rats}

N

- saline

$-0.2 \mathrm{mg} / \mathrm{kg}$ propranolol

- $1 \mathrm{mg} / \mathrm{kg}$ propranolol

$-5 \mathrm{mg} / \mathrm{kg}$ propranolol
6

5

6

11

8 MAP (mm Hg) HR (beats/min)

$158 \pm 10$

$477 \pm 14$

$158 \pm 5$

$478 \pm 16$

$148 \pm 3$

$473 \pm 8$

$153 \pm 7$

$444 \pm 13$

$169 \pm 5$

$427 \pm 19$

Data are presented as means \pm 1 S.E.M. 


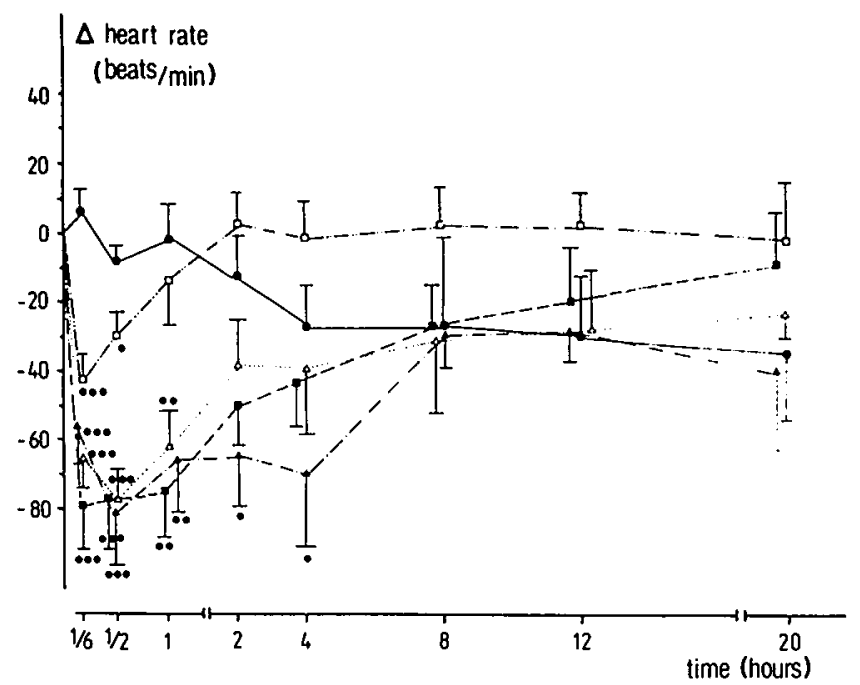

Figure 5.1. Effects of s.c. injection of saline ( $\bullet$ ) or propranolol at doses of 0.04 $\mathrm{mg} / \mathrm{kg}(\square), 0.2 \mathrm{mg} / \mathrm{kg}(\Delta), 1 \mathrm{mg} / \mathrm{kg}$ ( $)$ ) and $5 \mathrm{mg} / \mathrm{kg}$ ( $\Delta$ ) on heart rate in restrained SHR. Each point represents the mean of 5-11 animals with S.E.M. indicated. Significance of the difference to saline controls:

$\bullet:$ P <0.05; • •: P <0.01; • • : P < 0.001 .

In restrained rats HR slowly dropped by $15-30$ beats/min in the first $4 \mathrm{~h}$ following injection of saline (see fig. 5.1). Thereafter HR remained stable. Propranolol caused an immediate bradycardia. The magnitude of this effect depended both upon dose and time after the injection. Maximal bradycardia was observed 10-30 min after s.c. injection of propranolol in restrained SHR. This maximal bradycardia was not significantly different after s.c. injection of $0.2 \mathrm{mg} / \mathrm{kg}(-77 \pm 9$ beats $/ \mathrm{min} ; \mathrm{N}=6)$ and higher doses of $1 \mathrm{mg} / \mathrm{kg}(-79 \pm 13$ beats $/ \mathrm{min} ; \mathrm{N}=11)$ or $5 \mathrm{mg} / \mathrm{kg}(-80 \pm 16$ beats $/ \mathrm{min}$; $\mathrm{N}=8$ ). However, the duration of the effect tended to increase with the dose of propranolol. Depending upon dose, bradycardia lasted for $1-4 \mathrm{~h}$. Thereafter HR was at control levels.

The effects of injections on HR in unrestrained SHR are shown in fig. 5.3. After injection of saline HR hardly showed any variation, a maximal effect of $-10 \pm 5$ beats $/ \mathrm{min}$ ( $\mathrm{N}=31$ ) being seen $2 \mathrm{~h}$ post-injection. Injection of 1 or $5 \mathrm{mg} / \mathrm{kg}$ propranolol caused a bradycardia which was comparable to that seen in restrained rats. Maximal bradycardia was seen around $30 \mathrm{~min}$ after injection and was $-65 \pm 9$ beats $/ \mathrm{min}$ $(\mathrm{N}=13)$ and $-82 \pm 7$ beats $/ \mathrm{min}(\mathrm{N}=50)$ in the 1 and $5 \mathrm{mg} / \mathrm{kg}$ groups resp. Thereafter it gradually returned to control-values. Four hours post-injection it was no longer significantly different from control in the $1 \mathrm{mg} / \mathrm{kg}$ group, but in the $5 \mathrm{mg} / \mathrm{kg}$ group it was still significantly reduced until $\sim 6$ hours after injection. Injection of $0.2 \mathrm{mg} / \mathrm{kg}$ propranolol caused only a slight (insignificant) reduction of HR. 


\subsubsection{Effects on blood presssure}

Base-line values for mean arterial pressure (MAP) were comparable in restrained and unrestrained rats (see table 5.1 ). It ranged from 146 to $169 \mathrm{~mm} \mathrm{Hg}$.

Injection of saline in both groups of rats only caused slight variations in MAP (figs. 5.2 and 5.4). After propranolol two distinct phases in the effects on MAP could be recognized. During the first two hours it did not change or increased slightly. After 5 $\mathrm{mg} / \mathrm{kg}$ propranolol the increase was significant as compared to the appropriate controls in both restrained ( $+18 \pm 2 \mathrm{~mm} \mathrm{Hg} ; \mathrm{N}=8, \mathrm{P}<0.01$ ) and unrestrained rats $(+13 \pm 1 \mathrm{~mm} \mathrm{Hg} ; \mathrm{N}=50, \mathrm{P}<0.001)$.

After two hours MAP began to decrease. In restrained rats MAP was lowered significantly by $0.2-5 \mathrm{mg} / \mathrm{kg}$ propranolol at 4 hours after injection. Maximal effects were, however, not observed until 8-12 hours after injection. By that time $5 \mathrm{mg} / \mathrm{kg}$ propranolol had lowered MAP by $58 \pm 17 \mathrm{~mm} \mathrm{Hg}(\mathrm{N}=8, \mathrm{P}<0.01)$. Injection of 0.2 $\mathrm{mg} / \mathrm{kg}$ and $1 \mathrm{mg} / \mathrm{kg}$ propranolol caused a maximal reduction of MAP at 8 hours $(-38 \pm$ $12 \mathrm{~mm} \mathrm{Hg}$ and $-43 \pm 6 \mathrm{~mm} \mathrm{Hg}$ resp.).

Twenty hours after injection MAP was still lowered in the three groups. The magnitude of the response by that time was the same for all three. The lowest dose of $0.04 \mathrm{mg} / \mathrm{kg}$ propranolol did not have any effect on MAP.

In unrestrained rats MAP was decreased significantly at 4 hours after injection of 1 $\mathrm{mg} / \mathrm{kg}$ propranolol $(-17 \pm 1 \mathrm{~mm} \mathrm{Hg} ; \mathrm{N}=13, \mathrm{P}<0.01)$ and $5 \mathrm{mg} / \mathrm{kg}(-16 \pm 2 \mathrm{~mm} \mathrm{Hg}$; $\mathrm{N}=50, \mathrm{P}<0.001$ ) whereas in these animals $0.2 \mathrm{mg} / \mathrm{kg}$ propranolol was ineffective. In the $5 \mathrm{mg} / \mathrm{kg}$ group, where MAP and HR were measured until 8 hours and also at 12 hours post-injection, MAP was found not to fall further in the period between 4 and 20

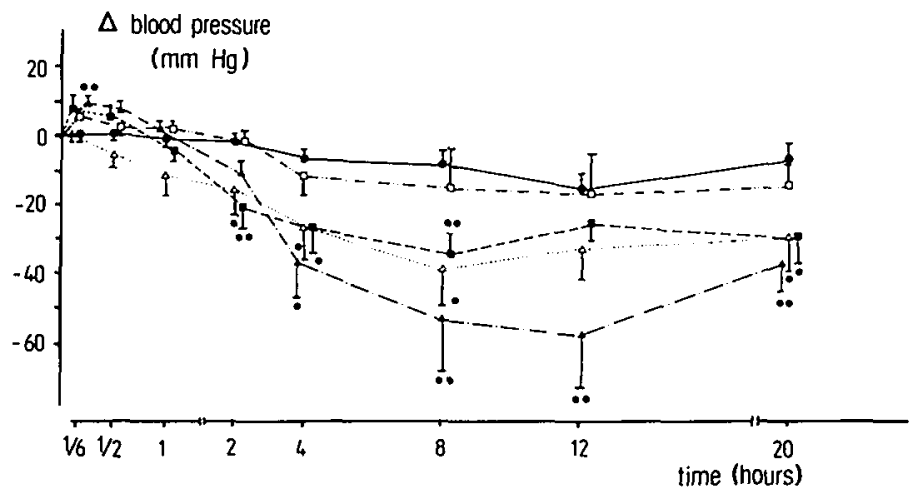

Figure 5.2. Effects of s.c. injection of saline ( ) or propranolol at doses of 0.04 $\mathrm{mg} / \mathrm{kg}(\square) .0 .2 \mathrm{mg} / \mathrm{kg}(\Delta), 1 \mathrm{mg} / \mathrm{kg}(\square)$ and $5 \mathrm{mg} / \mathrm{kg}$ ( $\Delta$ ) on mean arterial blood pressure in restrained SHR. Each point represents the mean of 5-11 animals with S.E.M. indicated. Significance of the difference to saline controls:

- : $P<0.05$; $\bullet: P<0.01$. 
hours after injection. In both the $1 \mathrm{mg} / \mathrm{kg}$ group and the animals injected with $5 \mathrm{mg} / \mathrm{kg}$ propranolol MAP was still significantly reduced at 20 hours after injection. Although at this time MAP was reduced slightly more in the $5 \mathrm{mg} / \mathrm{kg}$ group $(-21 \pm 3 \mathrm{~mm} \mathrm{Hg})$ than in the $1 \mathrm{mg} / \mathrm{kg}$ group $(-16 \pm 4 \mathrm{~mm} \mathrm{Hg})$, the difference was not significant. The reductions in MAP in unrestrained rats were smaller than those observed in restrained animals (cf. figs. 5.2 and 5.4).

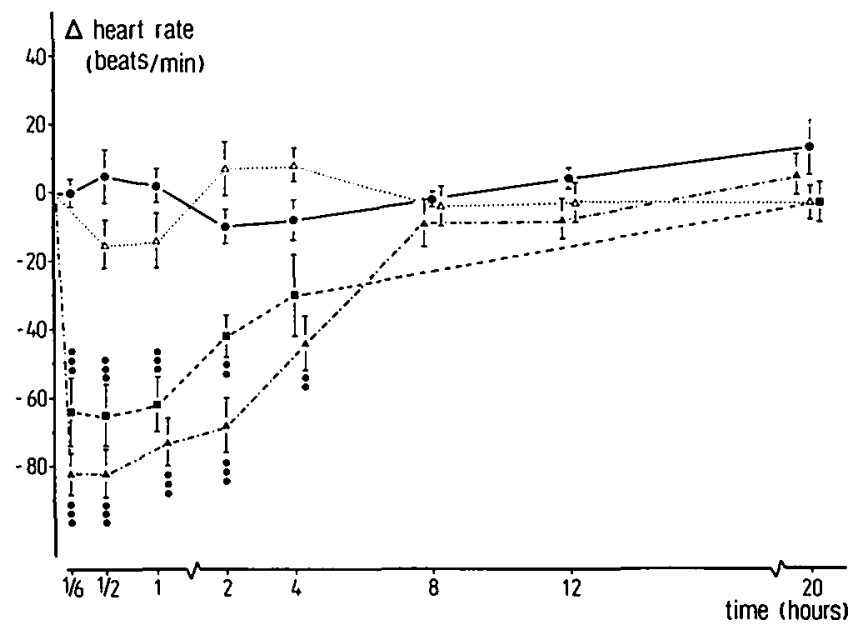

Figure 5.3. Effects of s.c. injection of saline ( ) or propranolol at doses of $0.2 \mathrm{mg} / \mathrm{kg}$ $(\Delta), 1 \mathrm{mg} / \mathrm{kg}(\boldsymbol{\Delta})$ and $5 \mathrm{mg} / \mathrm{kg}(\Delta)$ ) on heart rate in unrestrained SHR. Each point represents the mean of 12-50 animals with S.E.M. indicated.

Significance of the difference to saline controls:

$\bullet: \mathrm{P}<0.05 ; \bullet \bullet: \mathrm{P}<0.01 ; \bullet \bullet: \mathrm{P}<0.001$.

\subsection{Discussion}

Effects of propranolol in restrained and unrestrained rats were qualitatively but not quantitatively similar. Immediately after injection, propranolol caused a profound bradycardia. In restrained rats maximal effects after $0.2 \mathrm{~kg} / \mathrm{mg}, 1 \mathrm{mg} / \mathrm{kg}$ and $5 \mathrm{mg} / \mathrm{kg}$ propranolol did not differ, whereas the duration of the effect clearly increased with the dose. In unrestrained rats $0.2 \mathrm{mg} / \mathrm{kg}$ was found to be ineffective, whereas both maximal effect and duration of effect increased with dose in rats injected with 1 $\mathrm{mg} / \mathrm{kg}$ or $5 \mathrm{mg} / \mathrm{kg}$ propranolol.

The bradycardic effect has been reported in all species examined, including man. It 
probably results from both blockade of cardiac beta-adrenergic receptors and a direct cardio-depression. This may be concluded from the fact that in isolated atrial preparations, which of course do not have a sympathetic drive, propranolol induces a slowing of spontaneous contractions (cf. Yamamoto et al., 1975).

The rapidity of the onset and disappearance of bradycardia was to be expected from pharmacokinetics and kinetics of beta-adrenoceptor blockade in SHR (see chapters 3 and 4$)$ and the arguments discussed above. For the response on blood pressure, however, a totally different time-course is found. Two distinct phases can be observed. At first blood pressure tends to increase. A significant increase is seen only with the highest dose of $5 \mathrm{mg} / \mathrm{kg}$. This effect, which lasts about $1.5-2 \mathrm{~h}$ is in fact the only effect on blood pressure in rats which has been documented extensively thus far for peripherally administered propranolol (Sekiya et al., 1974; Nakao et al., 1975; Yamamoto et al., 1975; Kato et al., 1976; Levy, 1976). Nakao et al. (1975) showed that this pressor response can be diminished by pretreatment of the animals with hexamethonium, which is a ganglion blocker. Also adrenalectomy inhibited the rise in blood pressure. Therefore, it may be concluded that the pressor effect results from over-activation of the sympathetic nervous system. A possible action of propranolol in the central nervous system causing the increase in blood pressure will be discussed in chapter 7. After 2-4 hours MAP began to reach values below control, an effect which lasted for at least $20 \mathrm{~h}$.

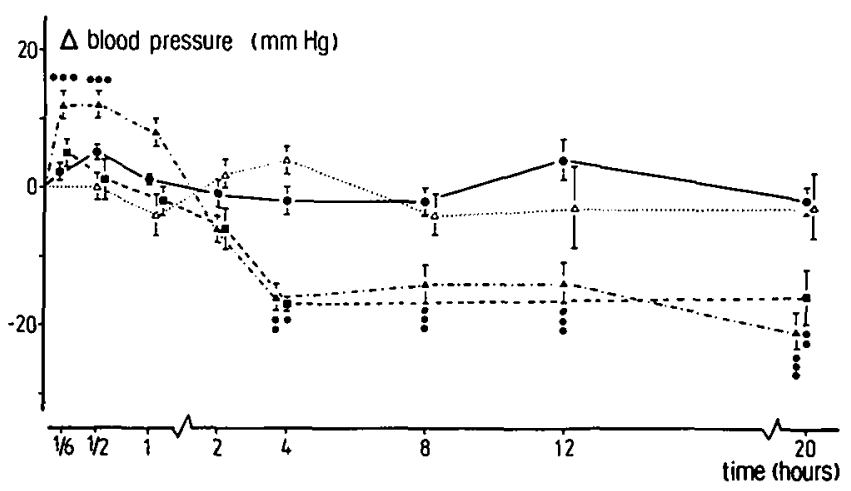

Figure 5.4. Effects of s.c. injection of saline ( ) or propranolol at doses of $0.2 \mathrm{mg} / \mathrm{kg}$ $(\Delta), 1 \mathrm{mg} / \mathrm{kg}(\boldsymbol{\omega})$ and $5 \mathrm{mg} / \mathrm{kg}(\Delta)$ on mean arterial blood pressure in unrestrained SHR. Each point represents the mean of $12-50$ animals with S.E.M. indicated. Significance of the difference to saline controls: $\bullet: P<0.05 ; \bullet \bullet: P$ $<0.01$ : • : $P<0.001$. 
In another series of experiments, which will be reported in chapter 9, blood pressure was measured again 48 hours post-injection and was found to have returned to control values by that time. The fact that the blood pressure fall occurred only with a delay of some hours may be the reason for other investigators "over-looking" the antihypertensive effect, because in most cases measurements were stopped after $2 \mathrm{~h}$. Sweet and Wenger (1976) found in their SHR that MAP fell with a similar delay, however, only after intracerebroventricular (i.c.v.) injection. Intra-arterial injections were not found to be effective. In the light of chapter 7 this cannot be understood. There it will be shown that i.c.v. injection of propranolol can be fully compared to s.c. injection.

Davy et al. (1977) reported dl-propranolol in a dose of $5 \mathrm{mg} / \mathrm{kg}$ to induce an antihypertensive effect within 5-15 min after intravenous injection. Probably this is an artifact, caused by a residual effect of the rather large dose of $300 \mathrm{mg} / \mathrm{kg}$ chloralhydrate which was given 90-105 min before the experiments, although the authors claim that by that time certain reflexes had reappeared. However, circulatory reflexes, like the baroreceptor reflex, may still have been depressed. As will be shown in chapter 8 of this thesis, this may greatly influence the effects of propranolol.

Such a residual effect of anesthesia may have been present in our restrained rats too. In these animals the time-course of the response was found to be approximately similar to that in the unrestrained rats, however, the magnitude of the effect was much larger. Also restraint (or rather adaptation to restraint) may, of course, have contributed to this. Because we felt that effects obtained from unrestrained animals are more representative for those in man, further experiments (with one exception. see chapter 7) were all done in fully unrestrained rats. In fact, the blood pressure and heart rate data for unrestrained animals in this chapter were derived from studies in later chapters. Reference will be made properly.

The late antihypertensive effect reported here for propranolol in conscious SHR is similar to the late blood pressure-lowering action of acute administration of atenolol (Fitzgerald, 1978) and propranolol (Stumpe et al., 1976; Maling et al., 1979; Conway, 1980 ) in man, although Stumpe and co-workers (1976) only found this effect in borderline hypertensive patients and not in patients with a stabilized hypertension. This may, however, have been a matter of dosage. The nature of the effect in SHR cannot be understood from pharmacokinetics of the drug (chapter 3 ). Also the timecourse of beta-adrenoceptor-blockade (chapter 4 ) is totally different from that of the anithypertensive effect. Therefore, the studies in the following chapters were undertaken to systematically investigate what hemodynamic, humoral, renal and nervous factors contribute to the late blood pressure-lowering action. 


\section{FURTHER CHARACTERIZATION OF THE HEMODYNAMIC EFFECTS OF A SINGLE SUBCUTANEOUS INJECTION OF PROPRANOLOL IN CONSCIOUS SHR.}

\subsection{Introduction}

In the preceding chapter it was concluded that blood pressure in conscious SHR does not fall immediately upon injection of propranolol in spite of an instantaneous and profound decrease in heart rate. Although a reduction of heart rate does not necessarily lead to a diminished cardiac output because of a possible concomitant increase in stroke volume, such a reduction of cardiac output has in fact been shown in man by numerous authors (cf. section 1.3.). In rats, however, such experiments have been hard to perform for technical reasons.

Davy et al. (1977) used thermodilution for repeated ( 2 times) measurement of cardiac output and could not demonstrate a change of this parameter in SHR after propranolol. These authors, however, only measured changes at the time of maximal reduction of blood pressure, which they found to occur within $15 \mathrm{~min}$ after the injection of propranolol. As was discussed in the preceding chapter this may have resulted from a residual action of the anesthetic, which was given 1.5-2 $\mathrm{h}$ before the experiments.

In the present study we wanted to investigate the complete time-course of hemodynamics during the first $20 \mathrm{~h}$ after propranolol in conscious, unrestrained SHR. As a method for measurement of cardiac output a recently developed technique was chosen, which permits continuous registration of this parameter by electromagnetic flow-metry (Smith and Hutchins, 1979).

Part of the experiments in this chapter were carried out during a stay of the author in the Department of Physiology and Biophysics of the University of Mississippi Medical School (Jackson, Miss., USA). For their invaluable help in the performance of these experiments, Dr. Thomas G. Coleman and Dr. Thomas L. Smith are gratefully acknowledged.

\subsection{Experimental protocol}

Methods for implantation of flow-probes and abdominal aorta-catheters, which was done 2-4 days before experiments, were described in chapter 2 .

For measurement of blood pressure and cardiac output rats were placed in normal glass experimental cages $(20 \times 20 \times 30 \mathrm{~cm})$. After a stabilization period of 1 hour an injection of saline $(\mathrm{N}=7), 1 \mathrm{mg} / \mathrm{kg}$ propranolol $(\mathrm{N}=4)$ or $5 \mathrm{mg} / \mathrm{kg}$ propranolol $(\mathrm{N}=8)$ was given s.c. In animals injected with saline and $5 \mathrm{mg} / \mathrm{kg}$ propranolol hemodynamics were monitored continuously during the first 8 hours after the injection. Furthermore measurements were made at 12 and 20 hours post-injection. in rats injected with $1 \mathrm{mg} / \mathrm{kg}$ propranolol hemodynamics were monitored continuously during the first 4 hours after injection and furthermore at 20 hours. 
응 त्:

$+1+1$

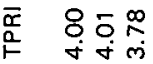

$\omega m$

$+1+H$

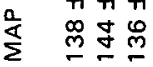

이 $10 \mathrm{~m}$

$\infty \infty$

$+1+1+1$

$\sim \infty$ in

\ $\quad \infty \underset{\infty}{\infty} \infty$

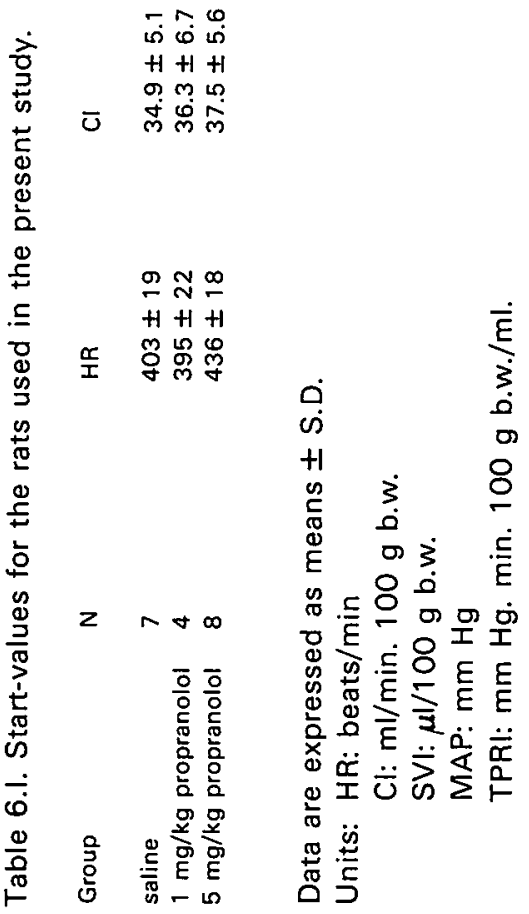


Cardiac output was normalized for body weight and is expressed as $\mathrm{ml} / \mathrm{min} .100 \mathrm{~g}$ b.w. (body weight). This value will be referred to as cardiac index (CI). From MAP and $\mathrm{Cl}$ it was possible to calculate the total peripheral resistance index (TPRI $=\mathrm{MAP} / \mathrm{Cl}$; units: $\mathrm{mm} \mathrm{Hg}$. $\min .100 \mathrm{~g} \mathrm{b.w.} / \mathrm{ml})$. Furthermore, from $\mathrm{Cl}$ and $\mathrm{HR}$ calculation of stroke volume index was possible (SVI $=\mathrm{Cl} / \mathrm{HR}$; units: $\mu \mathrm{l} / 100 \mathrm{~g} \mathrm{b.w.)}$.

Groups were compared using Student's t-test for unpaired observations. Differences were regarded to be statistically significant if $P<0.05$.

\subsection{Results}

Effects on blood pressure and heart rate have been included in the preceding chapter. Since the effects in the animals were fully comparable to those of the (unrestrained) group as a whole, these data have not been included in this chapter.

\subsubsection{Effects on cardiac index.}

Cardiac index ranged from 34.9 to $37.5 \mathrm{ml} / \mathrm{min} .100 \mathrm{~g} \mathrm{b.w.} \mathrm{(cf.} \mathrm{table} \mathrm{6.1.).} \mathrm{As} \mathrm{is} \mathrm{shown}$ in figure 6.1. there was little fluctuation in this parameter following the injection of saline. Propranolol in a dose of $5 \mathrm{mg} / \mathrm{kg}$ reduced cardiac index maximally by $10.8 \pm$ $1.2 \mathrm{ml} / \mathrm{min} .100 \mathrm{~g} \mathrm{~b} . \mathrm{w}$. between 60 and $90 \mathrm{~min}$ after injection (figure 6.1.). Following this dose cardiac index remained decreased until $12 \mathrm{~h}$ after injection. At $20 \mathrm{~h}$ postinjection this parameter had returned to control values.

One $\mathrm{mg} / \mathrm{kg}$ propranolol also decreased cardiac index, a maximal reduction of $8.9 \pm$ $0.6 \mathrm{ml} / \mathrm{min} .100 \mathrm{~g} \mathrm{~b} . \mathrm{w}$. being observed at $30 \mathrm{~min}$ post-injection. This effect was no longer present at $4 \mathrm{~h}$ after injection (figure 6.1.).

\subsubsection{Effects on stroke volume index}

Stroke volume index in our rats, as calculated from $\mathrm{HR}$ and $\mathrm{Cl}$, was between 88.2 and $93.0 \mu \mathrm{l} / 100 \mathrm{~g} \mathrm{b.w}$. (cf. table 6.1.). Saline did not influence it (figure 6.2.). Five $\mathrm{mg} / \mathrm{kg}$ propranolol caused a small transient increase $(5.6 \pm 3.5 \mu \mathrm{l} / 100 \mathrm{~g} \mathrm{~b} . \mathrm{w}$.) in stroke volume index. Thereafter it decreased a maximal reduction of $10 \pm 2.9 \mu \mathrm{l} / 100 \mathrm{~g}$ b.w. $(P>0.05)$ being obsenved at $2 \mathrm{~h}$ after the injection. It remained slightly lowered throughout the further experimental period, although it was (with the exception of the one point at $1 \mathrm{~h}$ post-injection; see figure 6.2) never reduced significantly.

Injection of $1 \mathrm{mg} / \mathrm{kg}$ propranolol did not cause the transient increase in stroke volume. Only the reduction described above for $5 \mathrm{mg} / \mathrm{kg}$ was seen, although the effect was smaller (figure 6.2.).

\subsubsection{Effects on total peripheral resistance index}

The start-value for total peripheral resistance index (TPRI) which was calculated from MAP and $\mathrm{Cl}$ was between 3.78 and $4.01 \mathrm{~mm} \mathrm{Hg}$. $\mathrm{min} .100 \mathrm{~g} \mathrm{b.w.} / \mathrm{ml}$. (cf. table 6.1.). In saline-injected rats TPRI remained at control-levels throughout the $20 \mathrm{~h}$ experimental period (see fig. 6.3.). Injection of 1 and $5 \mathrm{mg} / \mathrm{kg}$ propranolol caused an 


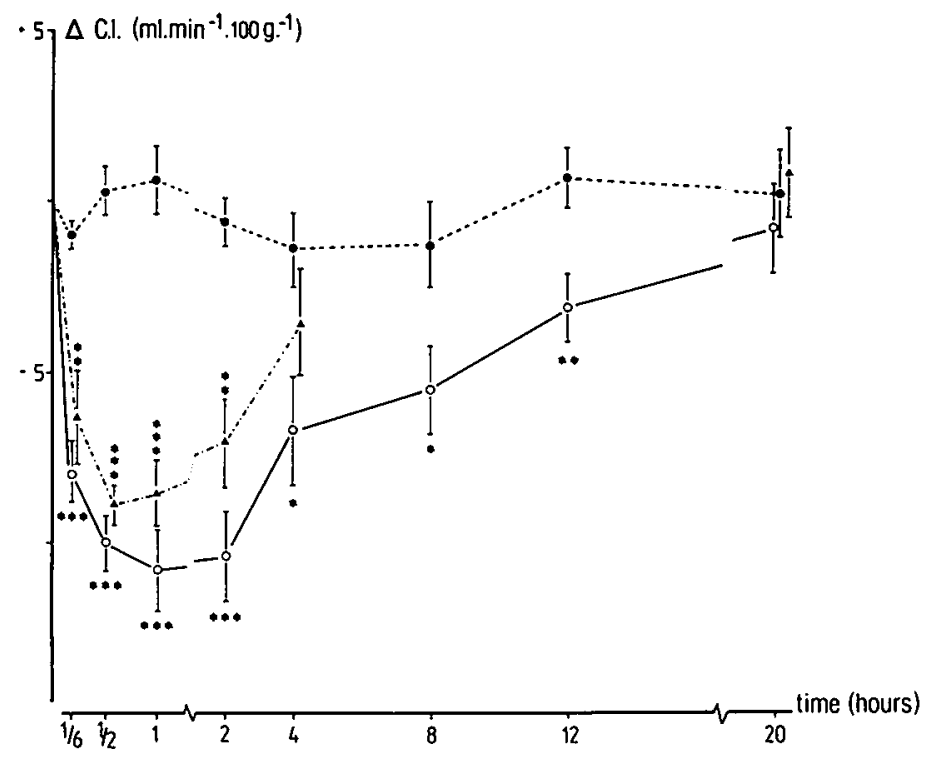

Figure 6.1. Changes (mean \pm S.E.M.) in cardiac index following saline $(\bullet: N=7$ ), $1 \mathrm{mg} / \mathrm{kg}$ propranolol $(\boldsymbol{\Delta} ; \mathrm{N}=4)$ or $5 \mathrm{mg} / \mathrm{kg}$ propranolol $(\mathrm{O} ; \mathrm{N}=8)$ in conscious SHR. Significances in the differences between propranolol- and saline-induced effects: $*: \mathrm{P}<0.05 ; \quad * *: \mathrm{P}<0.01 ; \quad * * *: \mathrm{P}<0.001$.

immediate tremendous increase in TPRI which was maximal between 0.5 and $1 \mathrm{~h}$ after injection $(1.95 \pm 0.27 \mathrm{~mm} \mathrm{Hg}$. $\mathrm{min} .100 \mathrm{~g} \mathrm{~b} . w . / \mathrm{ml}$ in the $5 \mathrm{mg} / \mathrm{kg}$ group). This increase (which was a $51 \%$ increase as compared to control-values) was followed by a return of TPRI to control-values which were reached between 2 and $4 \mathrm{~h}$ after injection. It remained there throughout the further experimental period with the exception of $20 \mathrm{~h}$ post-injection when it was in fact, besides blood pressure, the only parameter which was below control-values, although it only just reached statistical significance $(P<0.05)$.

Comparison of the effects following 1 and $5 \mathrm{mg} / \mathrm{kg}$ propranolol revealed again a smaller though similar response in the former group, at least during the first $4 \mathrm{~h}$ (see fig. 6.3.). Twenty hours after injection the reduction of TPRI in the $1 \mathrm{mg} / \mathrm{kg}$ group was similar to that observed in the $5 \mathrm{mg} / \mathrm{kg}$ group. 


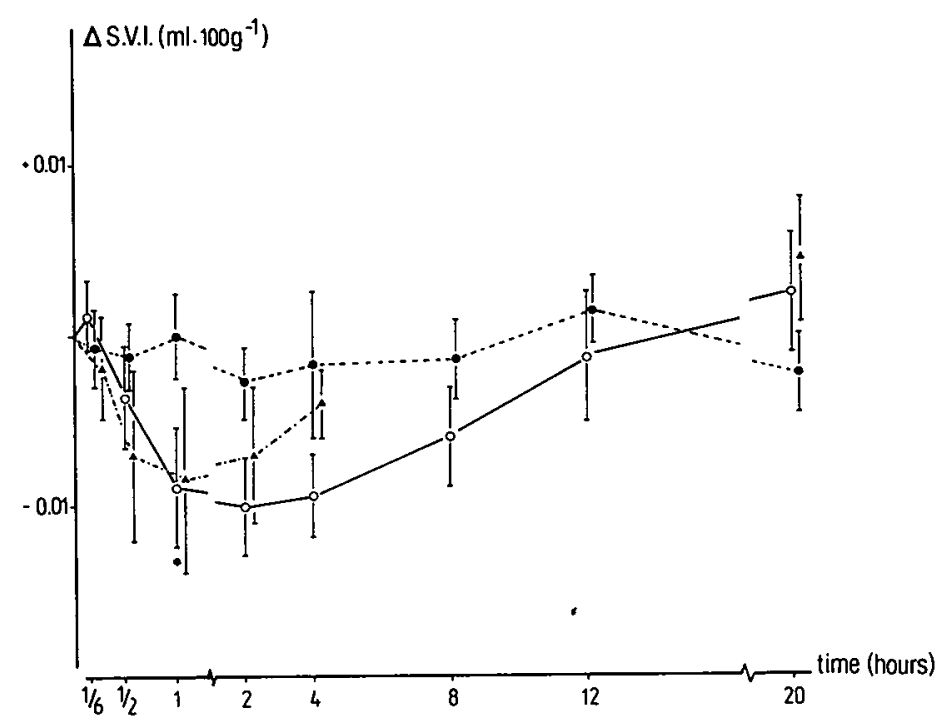

Figure 6.2. Changes (mean \pm S.E.M.) in stroke volume index following saline ( ; $\mathrm{N}=7$ ), $1 \mathrm{mg} / \mathrm{kg}$ propranolol $(\Lambda ; \mathrm{N}=4)$ or $5 \mathrm{mg} / \mathrm{kg}$ propranolol $(\mathrm{O} ; \mathrm{N}=8$ ) in conscious SHR.

For further explanation: see figure 6.1.

\subsection{Discussion}

In this study the effects of propranolol on hemodynamics in the conscious unrestrained SHR were investigated. Along with heart rate, cardiac output falls immediately upon s.c. injection of 1 and $5 \mathrm{mg} / \mathrm{kg}$ propranolol. Because of a slight initial increase in stroke volume following $5 \mathrm{mg} / \mathrm{kg}$ propranolol, which was followed by a prolonged decrease in this parameter, heart rate and cardiac output do not exactly parallel. In fact, whereas heart rate was only depressed significantly during the first $4 \mathrm{~h}$ following injection, cardiac output remains significantly below control during 12 hours.

In spite of the drastic reduction of cardiac output, blood pressure does not change because of a concomitant increase in peripheral resistance. Some 2-3 hours after injection of propranolol peripheral resistance had almost returned to control-values, although, it was still slightly elevated. The still existing diminishment of cardiac output at that time is then the cause of a net reduction of blood pressure. All values gradually return to control-levels with the exception of blood pressure which remains reduced until $20 \mathrm{~h}$ post-injection. This is due to a reduction of peripheral resistance and not to changes in cardiac output. 
The immediate reduction of heart rate and cardiac output upon injection of propranolol in man is well-documented (Ulrych et al., 1968; Tarazi and Dustan, 1972; Hansson, 1973). These authors also found an increased total peripheral resistance which prevented blood pressure to fall during the first few hours following injection. In SHR Davy et al. (1977) could not find a significant reduction in either cardiac output or peripheral resistance, whereas blood pressure did fall within $15 \mathrm{~min}$ after the injection of propranolol (5 mg/kg i.v.). With the method they used (thermodilution) they could, however, not measure cardiac output continuously. Furthermore, the method has a number of error sources which are less in the present method of electromagnetic flow-metry.

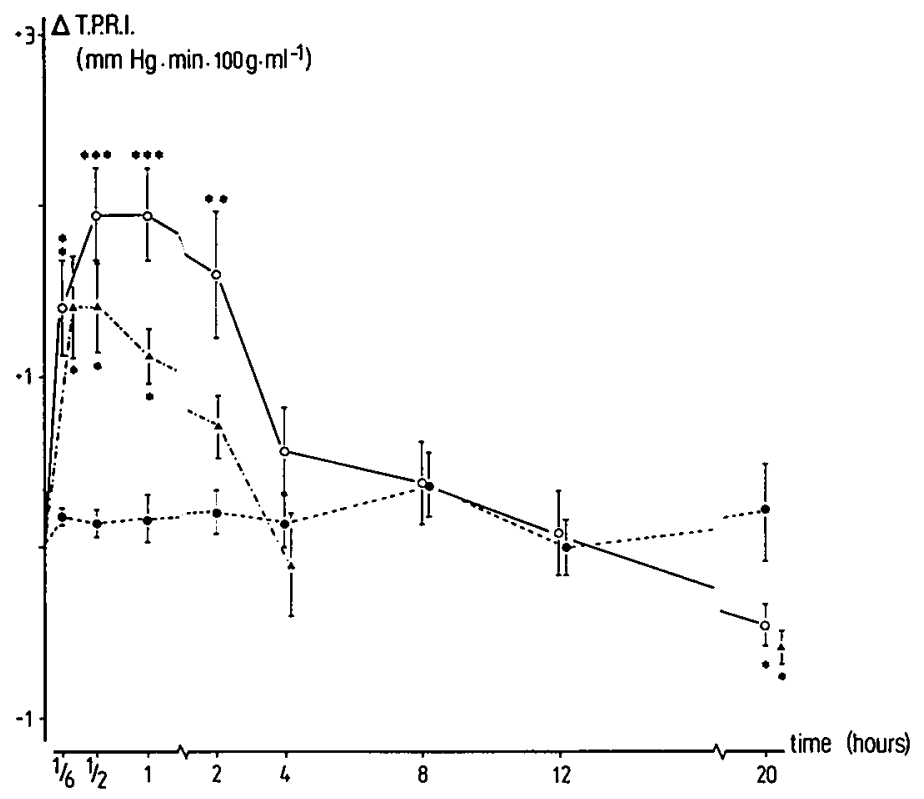

Figure 6.3. Changes (mean \pm S.E.M.) in total peripheral resistance index following saline ( $: N=7), 1 \mathrm{mg} / \mathrm{kg}$ propranolol $(\Lambda ; N=4)$ or $5 \mathrm{mg} / \mathrm{kg}$ propranolol $(O ; N=8)$ in conscious SHR.

For further explanation: see figure 6.1 .

The origin of the increased peripheral resistance is not yet clear. It may be thought to results from a reflex-mediated sympathetic activation since, as was discussed in section 1.3., in man most authors reported an increase in plasma catecholamine levels. This will be investigated further in chapter 8 of this thesis.

After some $1-2$ hours peripheral resistance begins to return to control-values although cardiac output remains diminished, resulting from both decreased heart rate and stroke volume. This may indicate a wearing off of the triggered reflex. Eventually, 2-8 $\mathrm{h}$ after the injection blood pressure is reduced. Up to $12 \mathrm{~h}$ after injection this may be explained by depressed cardiac output and almost adjusted peripheral resistance. 
However, $20 \mathrm{~h}$ after injection cardiac output has fully returned to control levels or slightly above. Since blood pressure is still reduced at that time, this antihypertensive effect should result from lowered peripheral resistance. The magnitude of this is only small as is antihypertensive effect. It seems to occur both after $5 \mathrm{mg} / \mathrm{kg}$ and the lower dose of $1 \mathrm{mg} / \mathrm{kg}$ propranolol, although the latter dose was only injected in 4 animals.

Statistical comparison of TPRI-values at $20 \mathrm{~h}$ post-injection (using Student's t-test) reveales a significance at the $5 \%$-level for both the $1 \mathrm{mg} / \mathrm{kg}$ and $5 \mathrm{mg} / \mathrm{kg}$ propranolol groups.

In man, long-term treatment of hypertension with beta-adrenoceptor blocking drugs results in slightly elevated or normal values of peripheral resistance (LundJohansen, 1979). A reduction to values below control does not occur during longterm therapy. However, the time-course of hemodynamics following a single injection of proranolol in man has never been monitored as we did here in rats. Thus, it not clear whether the effect we observed in this study may be compared to the effect of the same treatment in man.

In the following chapters an attempt will be made to analyse mechanisms underlying the effects reported here. Involvement of hormonal, fluid-dynamic and nervous mechanisms will be investigated and discussed. 


\section{EFFECTS OF SINGLE INTRACEREBROVENTRICULAR INJECTIONS OF PROPRANOLOL IN CONSCIOUS SHR}

\subsection{Introduction}

As was already stated in chapter 1 (section 1.3) the site of action of propranolol has been suggested to be in the central nervous system (CNS). For other antihypertensives like clonidine (Kobinger, 1967; Schmitt et al., 1967; Struyker-Boudier, 1975) and alpha-methyldopa (Henning and van Zwieten, 1968; Henning and Rubenson, 1971; Struyker-Boudier et al., 1975) such an action within the CNS has been confirmed. Techniques that are currently used for studies into a possible CNSsite of action include injections of substances into the vertebral artery, the cerebral ventricles or localized brain structures of experimental animals (for review see van Zwieten, 1975).

In chapter 3 it was shown, that propranolol rapidly penetrates into the brain of SHR. This would be in agreement with the proposed CNS-site of action. It should, however, be recognized that a substance which rapidly diffuses into a tissue will just as rapidly diffuse out of it, unless binding to the tissue occurs. For propranolol in rabbits and dogs it has in fact been shown that leakage from the cerebrospinal fluid to the peripheral blood-stream occurs rapidly and extensively upon i.c.v. injection of the substance (Anderson et al., 1977; Mouillé et al., 1977). This makes the validity of this technique questionable.

Nevertheless a great number of authors have concluded for the site of antihypertensive action of propranolol in the CNS in the basis of such experiments in cats, dogs and rats (Kelliher and Buckley, 1970; Day and Roach, 1973; Reid et al., 1974; Day and Roach, 1975; Garvey and Ram, 1975; Myers et al., 1975a, b; Kelliher, 1976; Klevans et al., 1976; Sweet and Wenger, 1976; Sweet et al., 1976; Wépierre et al., 1978; Privitera et al., 1979). Others have not been able to confirm this in similar experiments (Offerhaus and van Zwieten, 1974; Nijkamp et al., 1979).

In this study we investigated the possible involvement of the CNS in the antihypertensive action of propranolol in conscious SHR, using the convential technique of a bolus injection into the lateral cerebral ventricles of the animals. Not only did we measure possible cardiovascular effects, but also an attempt was made to verify leakage of propranolol to the peripheral blood-stream, both on the basis op plasma level measurements and peripheral beta-adrenergic receptor blockade.

\subsection{Experimental protocols}

Methods used in this study have been described in chapter 2 . The protocols were the same as those in chapters 3,4 and 5 (for restrained animals).

The proper analysis-methods from the previous chapters $(3,4$ and 5$)$ were used in this chapter. 


\subsection{Results}

\subsubsection{Peripheral beta-adrenoceptor blockade}

Mean $E_{50}$-values for isoprenaline-induced hypotension for the groups were between 0.06 and $0.09 \mu \mathrm{g} / \mathrm{kg}$, whereas it was between 0.04 and $0.09 \mu \mathrm{g} / \mathrm{kg}$ for isoprenaline-induced tachycardia. The effects of a single i.c.v. injection of saline, 0.2 $\mathrm{mg} / \mathrm{kg}$ and $1 \mathrm{mg} / \mathrm{kg}$ propranolol on isoprenaline-induced tachycardia and hypotension are shown in fig. 7.1.

Blockade of cardiac (beta 1 ) and vascular (beta 2 ) beta-adrenoceptors developed rapidly upon injection of both 0.2 and $1 \mathrm{mg} / \mathrm{kg}$ propranolol. Maximal ED $50^{\text {-values }}$ were found $0.5 \mathrm{~h}$ after the injection. At this time $E D_{50}$ for isoprenaline-induced hypotension had reached a value of $2.8 \pm 0.7 \mu \mathrm{g} / \mathrm{kg}(\mathrm{N}=6)$ which is comparable to the $E_{50}$-value for this parameter following s.c. administration of the same dose $13.1 \pm$ $1.2 \mu \mathrm{g} / \mathrm{kg}, \mathrm{N}=11$; see chapter 4). Also inhibition of isoprenaline-induced tachycardia was maximal at that time and again $\mathrm{ED}_{50}$-values after i.c.v. $(0.6 \pm 0.1 \mu \mathrm{g} / \mathrm{kg})$ and s.c. $(0.7 \pm 0.1 \mu \mathrm{g} / \mathrm{kg})$ administration were equal. After the initial peak, beta-adrenoceptor blockade slowly disappeared and was no longer present 20 hours after the injections.

As is seen from fig. 7.1, the same results were obtained for an i.c.v. injection of 0.2 $\mathrm{mg} / \mathrm{kg}$, although, as expected, the magnitude of the effect was smaller.
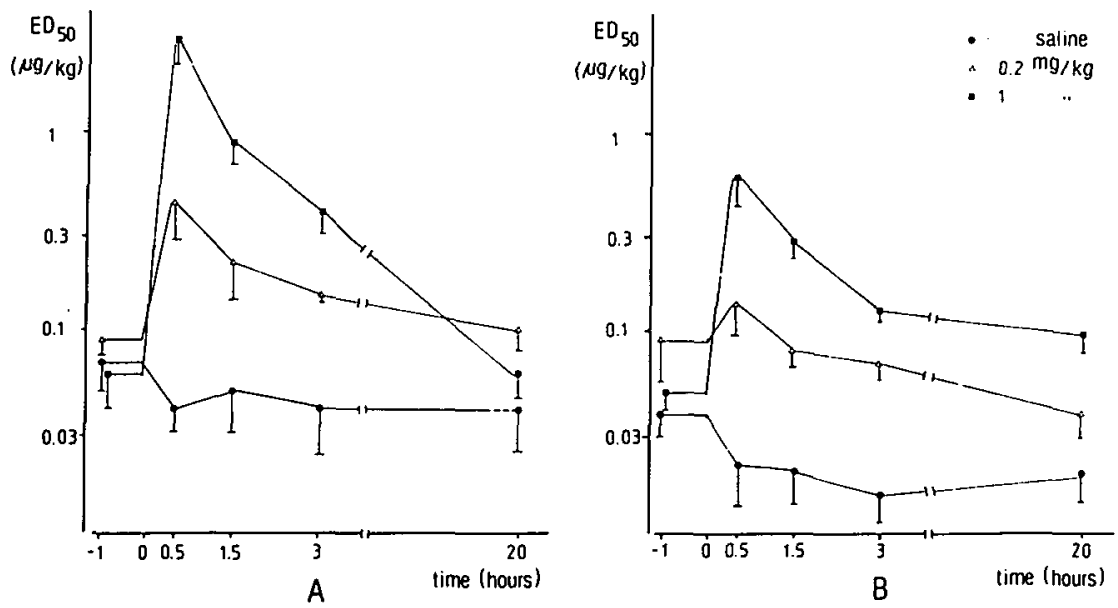

Figure 7.1. Time-course for the inhibition of isoprenaline-induced hypotension (A) and tachycardia (B) produced by propranolol injected i.c.v. at time 0 . Each point represents the mean for 6-10 animals with S.E.M. indicated.

Symbols: ( ) saline controls; propranolol: $(\Delta) 0.2 \mathrm{mg} / \mathrm{kg}$; $11 \mathrm{mg} / \mathrm{kg}$. 


\subsubsection{Plasma concentration-time profile}

The results from the measurements of plasma propranolol-concentrations following i.c.v. injection of $1 \mathrm{mg} / \mathrm{kg}$ propranolol are shown in fig. 7.2.

The individual curves were fitted for a two-compartment open model.

Pharmacokinetic parameters derived from this are summarized in table 7.I. together with the results from the s.c. injected animals as taken from chapter 4.

The appearance of propranolol in plasma was so rapid that a mean maximal level of $573 \pm 47 \mathrm{ng} / \mathrm{ml}$ was observed already $2 \mathrm{~min}$ after the injection. Since this point was the first one measured, no absorption phase could be recognized. Plasma levels declined bi-phasically. The half-life of the alpha-phase was $13 \mathrm{~min}$ whereas the late (beta) phase had a half-life of $80 \mathrm{~min}$. These values are comparable to those after s.c. injection ( $\mathrm{t}_{1 / 2} \mathrm{a} / \mathrm{pha}=17 \mathrm{~min} ; \mathrm{t}_{1 / 2}$ beta $\left.=59 \mathrm{~min}\right)$. Total body clearance was calculated to be $15 \mathrm{ml} / \mathrm{min}$ which is also similar to that, found following s.c. injection of the same dose $(14 \mathrm{ml} / \mathrm{min})$.

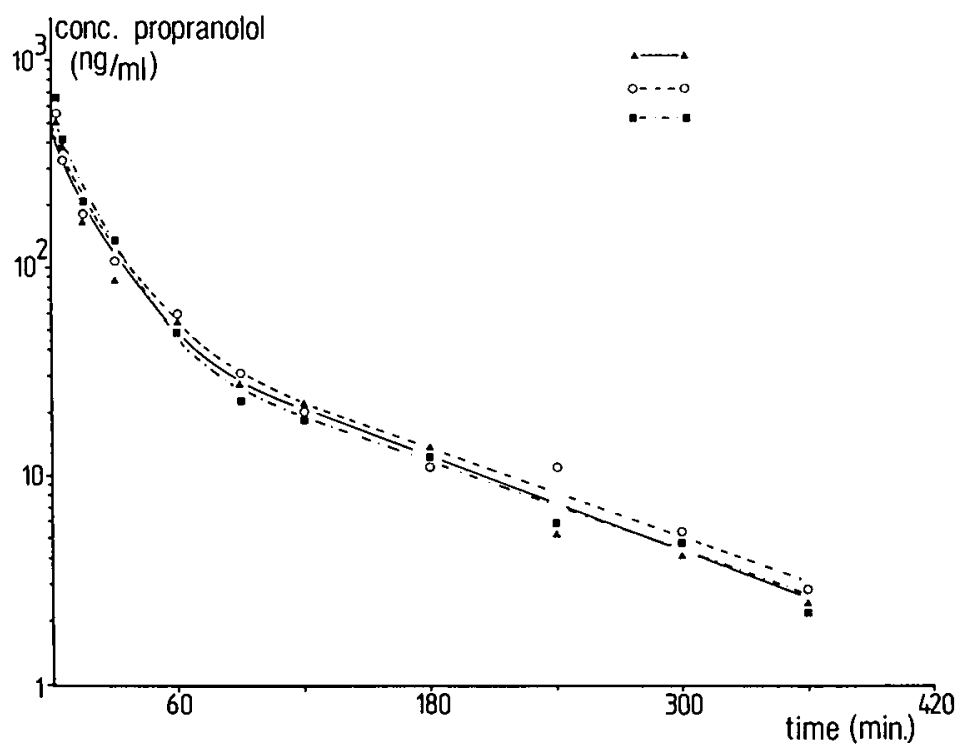

Figure 7.2. Plasma concentration-time profile for propranolol in 3 different SHR after i.c.v. injection of $1 \mathrm{mg} / \mathrm{kg}$ at time $t=0$. The curves were fitted using a twocompartment open model. Different symbols were used for the 3 rats. 


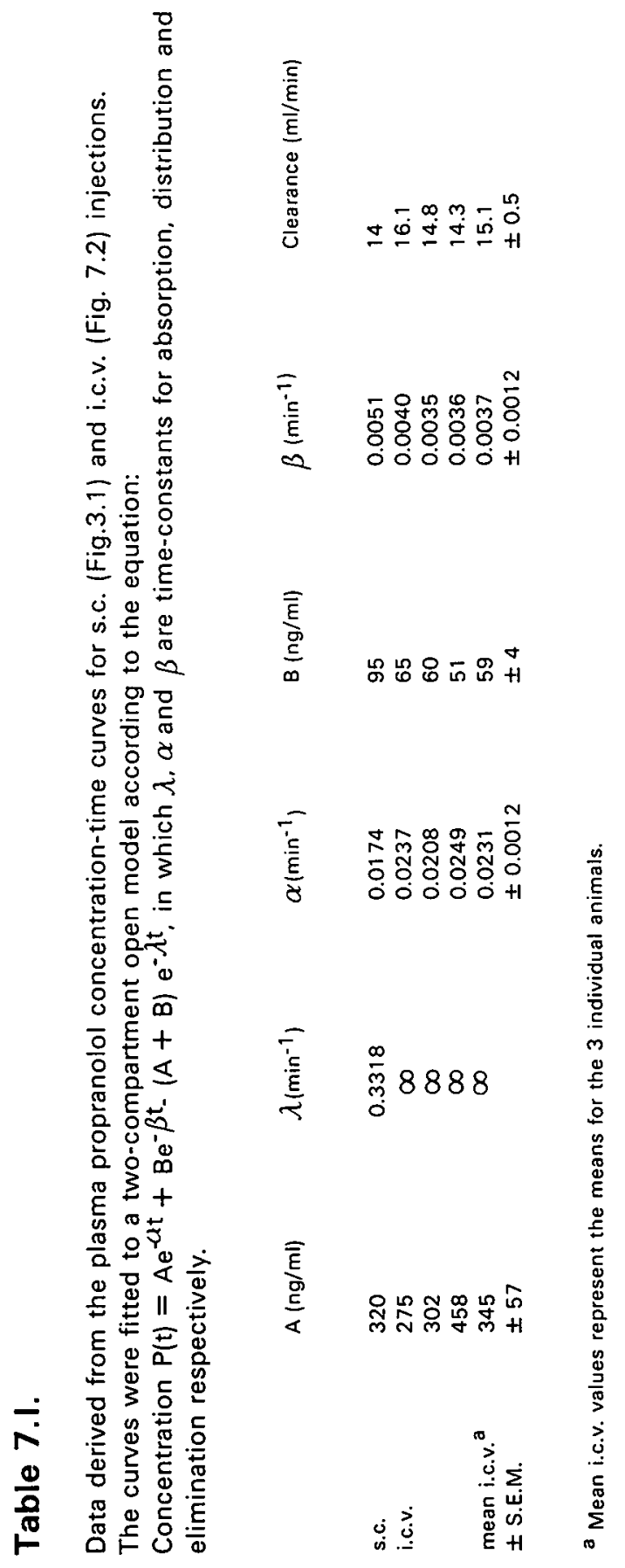




\subsubsection{Effects on heart rate}

Mean heart rates in the groups at time $t=0$ ranged from 427 to 450 beats $/ \mathrm{min}$. The effects of i.c.v. injection of saline and propranolol on heart rate (HR) are summarized in fig. 7.3. In the first 4 hours following saline HR slowly dropped 15-30 beats/min. Thereafter it remained relatively stable throughout the further experimental period. All doses of propranolol reduced HR, the duration and magnitude of the effect depending on the dose. As compared to saline controls, $0.04 \mathrm{mg} / \mathrm{kg}$ propranolol i.c.v. reduced HR significantly by $40 \pm 8$ beats $/ \mathrm{min}(\mathrm{N}=6 ; \mathrm{P}<0.001)$ at $10 \mathrm{~min}$ after the injection.

Twenty minutes later it was no longer significantly reduced. On the other hand, 1 $\mathrm{mg} / \mathrm{kg}$ i.c.v. reduced heart rate maximally at $30 \mathrm{~min}$ after the injection by $78 \pm 18$ beats/min ( $N=6: P<0.001)$ which is fully comparable to the $79 \pm 13$ beats $/ \mathrm{min}$ reduction observed following s.c. administation of the same dose. Two hours after the injection of $1 \mathrm{mg} / \mathrm{kg}$ i.c.v. HR was no longer reduced.

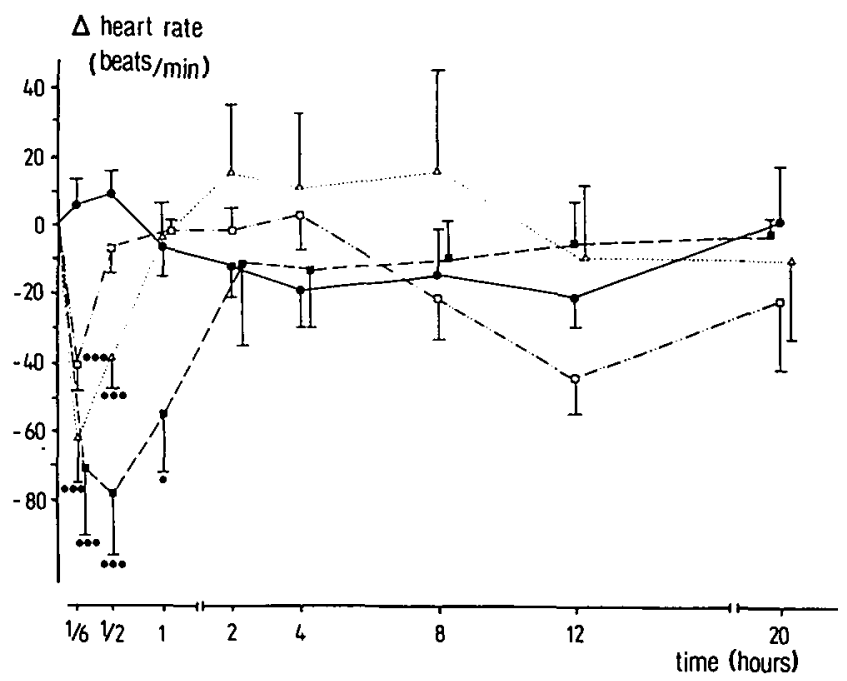

Figure 7.3. Effects of i.c.v. injection of saline ( - ) or propranolol at doses of 0.04 $\mathrm{mg} / \mathrm{kg}(\square), 0.2 \mathrm{mg} / \mathrm{kg}(\Delta)$ and $1 \mathrm{mg} / \mathrm{kg}(\square)$ on heart rate in SHR. Each point represents the mean of 6-10 animals with S.E.M. indicated. Significance of the difference to saline controls: $\bullet: \mathrm{P}<0.05 ; \bullet \bullet: \mathrm{P}<0.001$. 


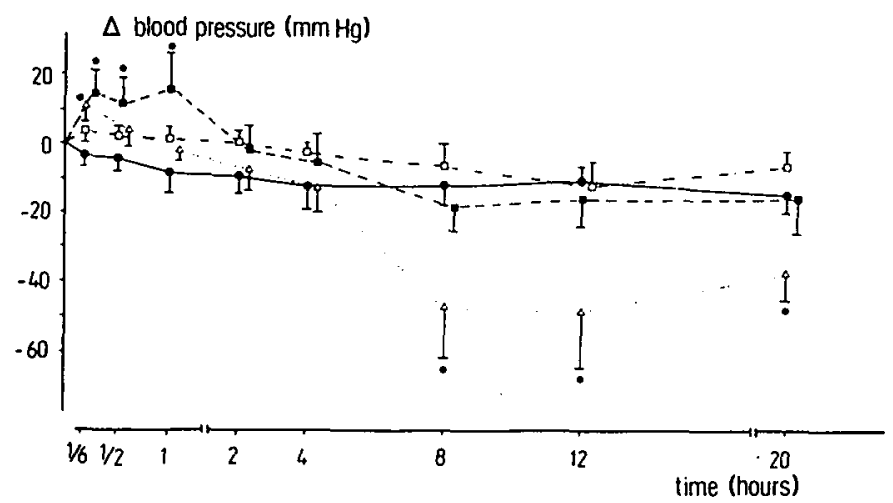

Figure 7.4. Effects of i.c.v. injection of saline ( $\bullet$ ) or propranolol at doses of 0.04 $\mathrm{mg} / \mathrm{kg}(\square) .0 .2 \mathrm{mg} / \mathrm{kg}(\Delta)$ and $1 \mathrm{mg} / \mathrm{kg}(\square)$ on mean arterial blood pressure in SHR. Each point represents the mean of 6-10 animals with S.E.M. indicated. Significance of the difference to saline controls: $\bullet P<0.05$.

\subsubsection{Effects on blood pressure}

Mean start-values for mean arterial pressure (MAP) for the groups were between 142 and $168 \mathrm{~mm} \mathrm{Hg}$.

The effects of a single i.c.v. injection of saline or propranolol on MAP are shown in fig. 7.4. Following saline there was only a slight decrease of MAP throughout the experiment. Injection of propranolol $(0.04-1 \mathrm{mg} / \mathrm{kg})$ induced a transient increase in MAP. Both after 0.2 and $1 \mathrm{mg} / \mathrm{kg}$ propranolol i.c.v. this increase reached statistical significance as compared to saline controls. The highest dose increased MAP by $16 \pm$ $10 \mathrm{~mm} \mathrm{Hg}(\mathrm{N}=6 ; \mathrm{P}<0.05)$ and this effect persisted for 1 hour.

After the initial pressor phase MAP returned to control levels and remained unchanged throughout the experimental period in the groups receiving the lowest $(0.04 \mathrm{mg} / \mathrm{kg})$ and the highest dose $(1 \mathrm{mg} / \mathrm{kg})$. In the group which was injected with $0.2 \mathrm{mg} / \mathrm{kg}$ propranolol blood pressure did, however, decrease to values below control.

The decrease was maximal at 12 hours after the injection $(48 \pm 17 \mathrm{~mm} \mathrm{Hg}, \mathrm{N}=6$; $P<0.05)$ and persisted for 20 hours after injection.

\subsection{Discussion}

The results presented in this chapter indicate that i.c.v. injected propranolol leaks rapidly and extensively from the cerebrospinal fluid to the peripheral blood stream, which confirms the observations by Mouille et al. (1977) in dogs and those of Anderson et al. (1977) in rabbits. This may be concluded especially from the plasmalevels following i.c.v. injection as well as the rapidity and extent to which blockade of cardiac and vascular beta-adrenoceptors occurs. Furthermore, the data on the reduction of heart rate support these observations. 
With regard to leakage of propranolol to the peripheral blood stream in experimental animals, the cat may be an exception. Day and Roach (1974) did not find an inhibition of tachycardia following i.v. injections of isoprenaline but they did observe blockade of the tachycardia following i.c.v. isoprenaline. Thus, there may be speciesdifferences although the nature of such differences is hard to understand. It certainly is not a general feature in the cat since for i.c.v. injected prazosin it has been shown that this substance does leak out of the feline brain (Roach et al., 1978).

The observations on the effects of propranolol on heart rate in experimental animals are controversial with regard to the site where it may be elicited. Sweet and Wenger (1976) reported bradycardia following $0.3 \mathrm{mg} / \mathrm{kg}$ intra-arterially but not after i.c.v. administration of the drug in conscious SHR. In contrast, Garvey and Ram (1975) only observed bradycardia after $0.03-0.3 \mathrm{mg} / \mathrm{kg}$ propranolol in anesthetized cats and dogs if it was administered into the CNS. Our data clearly show that in conscious SHR the reduction of $H R$ is independent of the route of administration. It suggests that bradycardia results from blockade of cardiac beta-adrenoceptors, although a small contribution of a CNS-effect cannot be excluded.

The effects of i.c.v. injected propranolol on blood pressure are more complex. Upon s.c. injection of propranolol a dose of $5 \mathrm{mg} / \mathrm{kg}$ elicited a significant increase in MAP (see section 5.2). However, if injected i.c.v. only $0.2 \mathrm{mg} / \mathrm{kg}$ is needed to observe this response and this effect is even more pronounced and longer-lasting following 1 $\mathrm{mg} / \mathrm{kg}$ i.c.v. This confirms observations for i.c.v. injected propranolol in normotensive cats (Day and Roach, 1974), rabbits (Reid et al., 1974) and SHR (Sweet and Wenger, 1976). Thus, is seems attractive to speculate that the increase in MAP results from an action within the CNS. Both a local anesthetic effect (Reid et al., 1974) and a specific effect on CNS beta-adrenoceptors (Sweet et al., 1976) have been put forward as an explanation. This was not further investigated in this study.

Both 0.04 and $0.2 \mathrm{mg} / \mathrm{kg}$ propranolol have effects on MAP which are comparable for s.c. and i.c.v. administration, i.e. $0.2 \mathrm{mg} / \mathrm{kg}$ does and $0.04 \mathrm{mg} / \mathrm{kg}$ does not lower MAP with a delay of some hours in this and the former study (chapter 5). As was already stated in section 5.4 the magnitude of the effects in these studies (where animals had to be slightly restrained and experiments were started shortly after termination of anesthesia) was greater than those in the later studies in which unrestrained animals were used. However, since the experiments in the two studies which have been compared in this chapter were identical, this will not influence possible conclusions on a central or peripheral site of action.

The highest (1 $\mathrm{mg} / \mathrm{kg}$ ) dose of i.c.v. propranolol behaved differently from the same amount administered s.c. in that it did not lower MAP but only gave an extensive initial rise. This may result from sustained high CNS-levels which (as discussed above) tend to increase blood pressure. Such a CNS-induced rise in MAP might obscure or even counteract a late reduction of blood pressure.

Although long-term i.c.v. infusion of high doses of propranolol does not cause a pressor effect, neither counteracts a reduction of MAP (see chapters 13 and 14) the 
bolus which is introduced in the brain in the present experiments may cause effects which are quite different from those during infusion, with which a gradual build-up of levels is achieved.

In conclusion, the experiments in this chapter do not allow discrimination between a peripheral or CNS-site of action, because of methodical shortcomings. Both after s.c. and i.c.v. injection high brain levels are reached and also plasma kinetics do not differ. Thus, it is impossible to draw conclusions on the site of antihypertensive action of propranolol. Application of another method which allows such studies during longterm experiments will be presented later in this thesis (chapters 13 and 14). 


\section{THE BARORECEPTOR REFLEX FOLLOWING A SINGLE SUBCUTANEOUS INJECTION OF PROPRANOLOL IN CONSCIOUS SHR.}

\subsection{Introduction}

This chapter deals with the possible involvement of the baroreceptor reflex in the acute hemodynamic effects of propranolol. Such an involvement may be manifold. First of all an activation of the baroreceptors could explain the lack of immediate antihypertensive activity of propranolol, i.e. the increase in peripheral resistance may result from sympathetic activation, triggered by the baroreceptors. Furthermore, besides providing a possible mechanism to explain why beta-adrenoceptor blockade does not lower blood pressure immediately it has been put forward as a possible explanation for the contrary, i.e. the ultimate capability of propranolol lowering blood pressure by alteration of overall sensitivity, as has been discussed extensively in section 1.3. of this thesis.

The purpose of the present chapter is to further investigate these possible involvements, a problem for which different experimental approaches had to be chosen. For the first problem, the prevention of an immediate antihypertensive response, the acute effects of propranolol on blood pressure and heart rate in intact animals were compared to those in rats in which afferent connections from the baroreceptors were surgically interrupted. To investigate a change in overall sensitivity of the barorecptor reflex, a modification of the method of Smyth et al. (1969) was employed, as described in section 2.10 .

To be able to relate possible changes in baroreflex sensitivity to effects on blood pressure, these were also checked in the normotensive congeners of our SHR, the Wistar-Kyoto rat.

\subsection{Experimental protocols}

For determination of the effects of propranolol in baroreceptor-denervated and shamoperated rats the animals were transferred to glass experimental cages $(20 \times 20 \times 30$ $\mathrm{cm}$ ) in which they were allowed to move freely after connection of the arterial catheter to a pressure transducer. Blood pressure and heart rate were recorded.

After a 1-2 hour stabilizing period base-line values for MAP and HR were obtained from 6 consecutive readings during the last $30 \mathrm{~min}$ of this period.

After that, animals were randomly injected with saline or 1 or $5 \mathrm{mg} / \mathrm{kg}$ dl-propranolol s.c. MAP and HR were recorded for 3 more hours.

For the experiments in which sensitivity of the baroreceptor-reflex was determined, a similar procedure was used. After obtaining base-line values for MAP and HR a series of phenylephrine injections were given intravenously for determination of base-line BRS. This procedure normally took approximately 0.5 hour. After another $0.5 \mathrm{~h}$ period 
a s.c. injection of saline or propranolol $(5 \mathrm{mg} / \mathrm{kg})$ was given. MAP and HR were recorded for another $3 \mathrm{~h}$ and furthermore $20 \mathrm{~h}$ after the injection. BRS was redetermined $0.5 \mathrm{~h}, 2 \mathrm{~h}$ and $20 \mathrm{~h}$ after injections. Again, these determinations took 0.5 h.

\section{DATA-ANALYSIS}

Baroreflex-sensitivity was calculated as the slope of the line obtained by plotting maximal effects on heart period (HP) against those on MAP, elicited by consecutive phenylephrine-injections. If a linear regression-analysis revealed a correlationcoefficient $\left(r^{2}\right)$ greater than 0.80 and if $P<0.05$, data were used for further analysis. Typical regression-lines for a Wky-rat and SHR were shown in fig. 2.7. For details, see section 2.10 .

In both types of experiments, groups were compared, using Student's t-test for unpaired observations. Differences were regarded to be statistically significant if $P<0.05$.

\subsection{Results}

\subsubsection{Modification of effects by afferent denervation of baroreceptors}

Resting-values of mean arterial pressure (MAP) and heart rate (HR) in baroreceptordenervated and sham-operated rats, as determined in a 1 hour period preceding injections, were not different as is shown in table 8.1. for measurements made at days 2 and 4 after surgery.

Effects of injections of propranolol ( 1 and $5 \mathrm{mg} / \mathrm{kg}$ ) on MAP and HR during the first 3 hours after injection are shown in fig. 8.1. and 8.2. Effects of saline which was injected in 7 denervated and 9 sham-operated animals are not contained in the figure. In denervated animals only minimal changes, average of $3 \mathrm{~mm} \mathrm{Hg}$, were seen in MAP. In sham-operated animals MAP increased by $5 \pm 3 \mathrm{~mm} \mathrm{Hg}$ during the first 10 min after injection of saline, after which it returned to and stayed at control levels.

As in intact animals (see chapters 4 and 5), propranolol decreased HR in shamoperated and denervated animals (fig. 8.1.). Maximal bradycardia following both 1 $\mathrm{mg} / \mathrm{kg}$ (in 8 denervated and 9 sham-operated animals) and $5 \mathrm{mg} / \mathrm{kg}$ propranolol (in 7 denervated and 7 sham-operated animals) was observed around 30 min after injection. Mean reductions in HR at this time were $89 \pm 12$ beats $/ \mathrm{min}$ and $68 \pm 11$ beats $/ \mathrm{min}$ following s.c. injections of $1 \mathrm{mg} / \mathrm{kg}$ in denervated and sham-operated rats respectively, whereas, in the same order, $5 \mathrm{mg} / \mathrm{kg}$ propranolol induced reductions in HR of $136 \pm 14$ beats $/ \mathrm{min}$ and $97 \pm 14$ beats $/ \mathrm{min}$ at this time. As compared with Student's t-test the difference in effects on HR following $5 \mathrm{mg} / \mathrm{kg}$ in both groups was statistically significant $(P<0.05)$ at this time, as it was throughout the 3 hour experimental period. Although the effects of $1 \mathrm{mg} / \mathrm{kg}$ propranolol were greater in denervated than in sham-operated SHR at all points where it was measured, it did not achieve statistical significance at any of these points. 


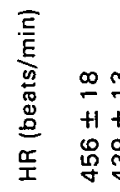

$\begin{array}{ll}\text { I } & \\ E & \infty 10 \\ E & +1+1 \\ a & 0 \pm \\ \Sigma & \square\end{array}$

$z r$ 은

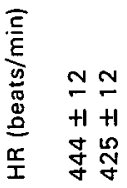

홈

tH

这吉思

든

哇

范

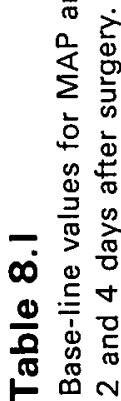

$m$
+1
$\stackrel{m}{7}$
$\stackrel{m}{7}$

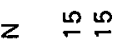

离
E $\infty \infty$

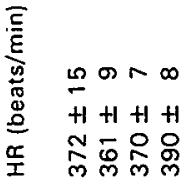

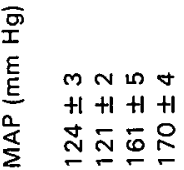

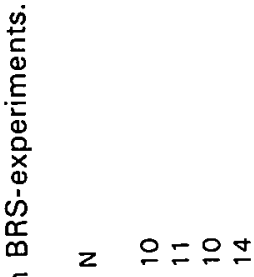

$\therefore$

롱

$\sum$ 


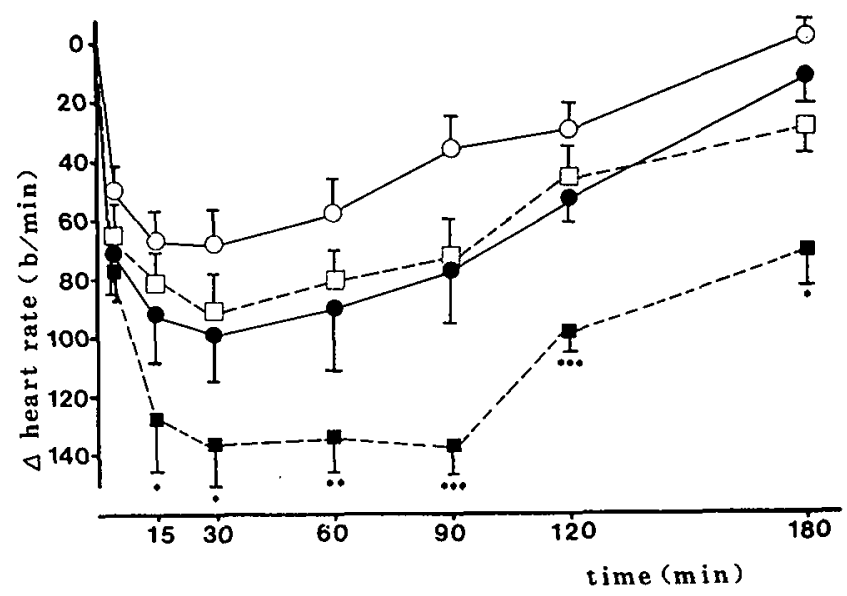

Figure 8.1. Effects of s.c. injection of $1 \mathrm{mg} / \mathrm{kg}$ propranolol on heart rate in shamoperated (O;N=9) and baroreceptor-denervated SHR (0; $N=8)$ and $5 \mathrm{mg} / \mathrm{kg}$ propranolol in sham-operated $(\mathrm{D} ; \mathrm{N}=7)$ and baroreceptor-denervated animals

$(\boldsymbol{\square} ; \mathrm{N}=7$ ).

Each point represents mean \pm S.E.M. Significance in the differences between shamoperated and denervated SHR: $*: \mathrm{P}<0.05 ; * *: \mathrm{P}<0.01 ; * * *: \mathrm{P}<0.001)$.

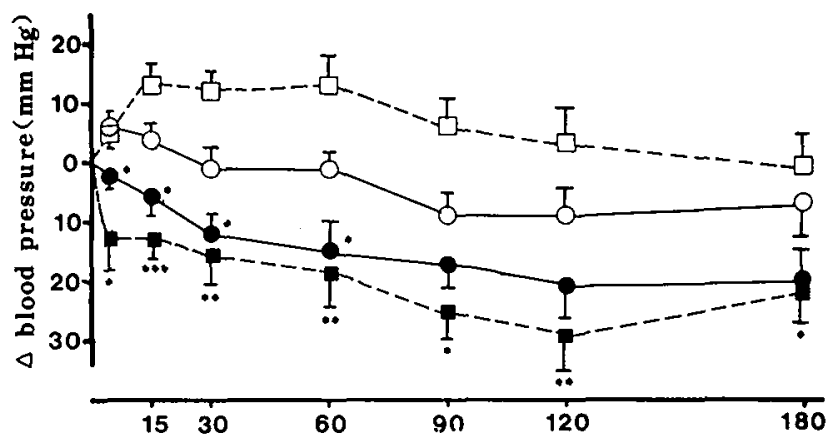

Figure 8.2. Effects of s.c. injection of $1 \mathrm{mg} / \mathrm{kg}$ and $5 \mathrm{mg} / \mathrm{kg}$ propranolol on mean arterial pressure in sham-operated and baroreceptor-denervated SHR.

For explanation of symbols: see fig. 8.1. 
Effects of 1 and $5 \mathrm{mg} / \mathrm{kg}$ propranolol on MAP in sham-operated and denervated animals are shown in fig. 8.2 . Both 1 and $5 \mathrm{mg} / \mathrm{kg}$ propranolol tended to increase MAP in sham-operated animals. After $5 \mathrm{mg} / \mathrm{kg}$ the increase was significant $(P<0.05)$ as compared to effects in saline-injected sham-operated animals $(N=9)$ between 15 and 60 min after injection. Over the further 3 hour period MAP did not attain values that were lower than those in saline-injected animals and were slightly above or below control

In denervated SHR, neither 1 nor $5 \mathrm{mg} / \mathrm{kg}$ propranolol increased blood pressure. On the contrary, MAP dropped immediately, this effect being significant $(P<0.05)$ as compared to effects in sham-operated animals already 5 min after the injection. Pressure gradually fell further and reached a minimum around 2 hours post-injection, where it had been reduced by $21 \pm 6 \mathrm{~mm} \mathrm{Hg}$ or $29 \pm 8 \mathrm{~mm} \mathrm{Hg}$ in animals injected with 1 and $5 \mathrm{mg} / \mathrm{kg}$ propranolol respectively.

\subsubsection{Propranolol and baroreflex sensitivity}

\section{EFFECTS OF PROPRANOLOL ON MAP AND HR IN WKY-RATS}

Base-line values for MAP and HR in groups of WKy-rats and $S H R$ are summarized in table 8.II. MAP in SHR was resp. $161 \pm 5 \mathrm{~mm} \mathrm{Hg}(\mathrm{N}=10)$ and $170 \pm 4 \mathrm{~mm} \mathrm{Hg}(\mathrm{N}=14)$ in saline and propranolol injected animals. In WKy-rats these values were $124 \pm 3$ $\mathrm{mm} \mathrm{Hg}(\mathrm{N}=10)$ and $121 \pm 2 \mathrm{~mm} \mathrm{Hg}(\mathrm{N}=11)$ resp.. HR-values ranged from $361 \pm 9$ beats $/ \mathrm{min}$ in the $5 \mathrm{mg} / \mathrm{kg}$ propranolol WKy-group and $390 \pm 8$ beats $/ \mathrm{min}$ in the same SHR-group. The difference between those two values was marginally $(P<0.05)$ significant.

Effects of propranolol on MAP and HR in SHK have been shown in chapter 5 . Effects of saline and propranolol on MAP and HR in WKy-rats are shown in fig. 8.3. Saline caused only small transient effects on MAP and HR. As in SHR, propranolol caused an immediate reduction in HR which was maximally $-47 \pm 7$ beats/min around 1.5 hours after injection in WKy-rats. Thereafter, it returned to control values. Twenty hours after injections it was no longer reduced.

MAP increased immediately after injection of propranolol. This increase was maximal 5 min after injection ( $+10 \pm 2 \mathrm{~mm} \mathrm{Hg}$ ). Thereafter, it declined and at 2 and 4 hours it was significantly reduced (see fig. 8.3.). As in SHR, the reduction of MAP persisted for 20 hours, at which time it was reduced by $24 \pm 2 \mathrm{~mm} \mathrm{Hg}$.

\section{EFFECTS OF PROPRANOLOL ON BAROREFLEX SENSITIVITY (BRS)}

For the groups of animals base-line values for BRS in saline- and propranolol-injected SHR were resp. $0.38 \pm 0.05$ and $0.41 \pm 0.03 \mathrm{msec} / \mathrm{mm} \mathrm{Hg}$ whereas in WKy-rats these values were $0.80 \pm 0.12$ and $0.89 \pm 0.04 \mathrm{msec} / \mathrm{mm} \mathrm{Hg}$ (cf. table 8.II). These values, together with the effects of injections are shown in fig. 8.4. As is shown there, BRS remained consistently lower in SHR as compared to WKyrats.

In all groups of rats BRS tended to increase, although the changes within groups were not statistically significant (as compared with a paired Student's t-test). Furthermore, there were no differences between the effects caused by saline and propranolol, thus, propranolol did not change BRS as compared to control rats. 

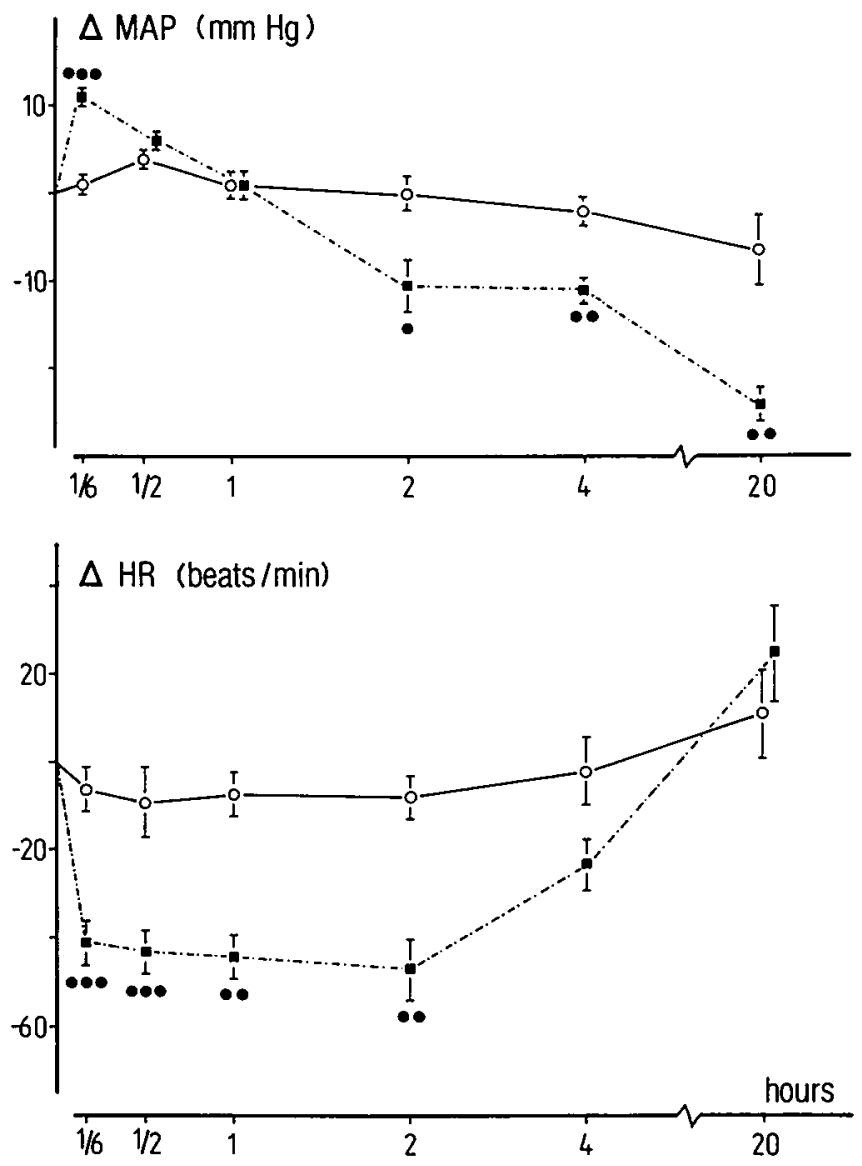

Figure 8.3. Effects of a single s.c. injection of saline $(\mathrm{O} ; \mathrm{N}=10)$ and $5 \mathrm{mg} / \mathrm{kg}$ propranolol ( $\mathbf{Q} N=11$ ) on heart rate (HR) and mean arterial pressure (MAP) in Wistar-Kyoto rats. Significance in the difference between saline- and propranololinjected animals: $\bullet: P<0.05 ; \bullet: P<0.01 ; \bullet \bullet: P<0.001)$.

\subsection{Discussion}

\section{DENERVATION STUDY}

Successful denervation of baroreceptors according to Krieger (1964) was accomplished in 15 out of 17 rats as judged from an absence of reflex-bradycardia to the increased blood pressure following intravenous injection of phenylephrine. 
In these animals cardiovascular effects of s.c. injected propranolol were compared to those in sham-operated rats.

The pattern of the effects on HR in sham-operated and denervated SHR was similar to that in intact SHR, i.e. a pronounced bradycardia was observed immediately after injection. It lasted for 1.5 - 3 hours, depending upon dose.

The bradycardia seen in denervated animals was, however, more pronounced than in sham-operated animals. This indicates an inhibitory role for the baroreceptors with regard to the reduction of $H R$ in the latter group. This may occur either through sympathetic stimulation or through withdrawal of vagal activity.

Since following s.c. injection of 1 and $5 \mathrm{mg} / \mathrm{kg}$ propranolol beta-adrenoceptors are blocked in a competitive way, a tremendous increase in sympathetic activity could still have effects on the heart. However, judging from increased $E D_{50}$-values for isoprenaline-induced tachycardia which greatly increases following these doses of propranolol, this is not likely, although it cannot be excluded. Vagal withdrawal, also resulting in a relatively increased $H R$, is a more likely explanation for bradycardia being less in sham-operated animals than in denervated animals.

In previous chapters we have shown that in intact, conscious SHR as in man (see section 1.3.) propranolol does not lower blood pressure during the first 3-4 hours after injection. Similar effects were seen here in sham-operated animals. The highest dose of $5 \mathrm{mg} / \mathrm{kg}$ propranolol even increased blood pressure, as was also shown in intact animals. In denervated SHR blood pressure fell immediately. The decrease in MAP, as compared to effects in sham-operated rats, was significant already $5 \mathrm{~min}$ after injection and it remained greater throughout the 3 hour experimental period. Thus, from this it may be concluded that in non-denervated rats baroreceptors antagonize the hypotensive effect of propranolol. This is in agreement with studies of Davy et al. (1977) and Montastruc and Montastruc (1979) in neurogenically hypertensive rats and dogs respectively. Neurogenic hypertension was induced by de-afferentation of baroreceptors and in these animals propranolol was found to have an immediate blood pressure lowering effect, as in our SHR. Another observation by Lisander and Nilsson (1978) also confirms these findings. Those authors showed that the resistance of the muscle vasculature in cats, as measured in a vascularly isolated calfmuscle which was perfused by donor-cats, increased following propranololadministration. This could be abolished by constant-pressure perfusion of the carotid-sinuses. The latter study in the isolated calf-muscle, of which innervation was intact, clearly shows that the increase in vascular resistance is of neural origin. This was also suggested in man where plasma-catecholamine levels were found to increase immediately after administration of propranolol (Irving et al., 1974; Lütold et al., 1976; Benedict et al., 1977; Palm and Grobecker, 1977; Hansen et al., 1978; Morganti et al., 1979).

Thus, from the above it seems that the increase in peripheral resistance which is seen immediately after administration of propranolol (see chapter 5) results from a baroreceptor-triggered increase in sympathetic nervous activity.

However, as was shown in chapter 5 of this thesis, the decrease in cardiac output in SHR following propranolol almost parallels the reduction in heart rate during the first few hours after injection. In the rats used in the present study, this would mean that 

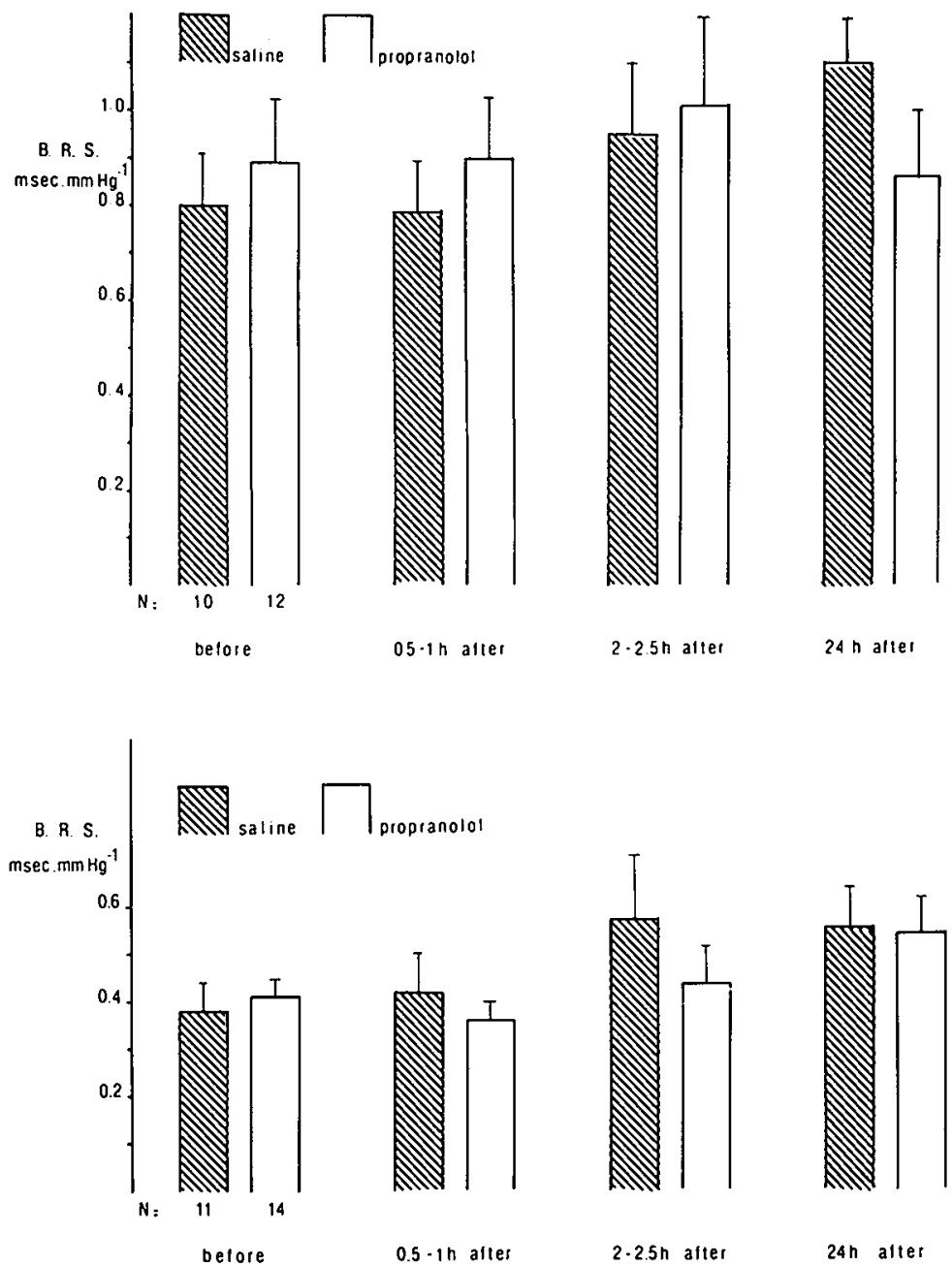

Figure 8.4. Effects of a single s.c. injection of saline and $5 \mathrm{mg} / \mathrm{kg}$ propranolol on baroreflex-sensitivity (BRS) in conscious WKy-rats (upper panel) and SHR (lower panel). Each column represents mean \pm S.E.M. for each group.

maximal reduction of cardiac output would occur between 30 and $90 \mathrm{~min}$ after injection. Since the reduction of cardiac output in this study is not counteracted by a reflex-increase in peripheral resistance from baroreceptor activation, maximal effects on blood pressure would be expected to occur at that time too.

This is, however, not so. Thus, it should be concluded that other mechanisms are also involved. These may include increased vascular tone as a consequence of blockade of vascular beta 2 -adrenoceptors or an action within the central nervous system where we have shown propranolol to act hypertensive rather than hypotensive (see chapter 
7). The former possibility is not a likely one, as may be concluded from studies in isolated perfused hind-quarters of rats (Rascher et al., 1978) and dogs (Sweet et al., 1979) as well as the above-cited study of Lisander and Nilsson (1978) where propranolol was shown to have little direct vascular effects (see also section 1.3.). The possibility of specific or a-specific CNS-effects, like shown in chapter 7, may, however, explain why blood pressure does not parallel heart rate in baroreceptordenervated SHR.

\section{BAROREFLEX-SENSITIVITY STUDY}

The slope of the baroreceptor-reflex was tested in hypertensive and normotensive rats at several times after propranolol and saline. This was done using a modification of the method of Smyth et al. (1969).

Cardiovascular responses to propranolol in SHR were reported in chapter 5 . In this study the effects in WKy-rats were shown to be similar to those in hypertensive animals. In normotensive man, propranolol has been shown to lower blood pressure too (LeWinter et al., 1975).

Baroreflex-sensitivity was consistently lower in SHR as compared to normotensive WKy-rats. Similar observations have been made in hypertensive man (Bristow et al., 1969; Gribbin et al., 1971). These studies showed a decrease of baroreflex-sensitivity in man as a consequence of both higher age and blood pressure. Using suction of the neck-region as a way for stimulating the carotid baroreceptors Bevegård et al. (1977) could, however, not find any difference in the slope of the response in normotensive and hypertensive patients. The latter technique allows measurement of responses of both blood pressure and heart rate, whereas with the former technique only heart rate responses can be measured. Also in the study by Bevegård et al. (1977) the heart rate response was blunted by hypertension.

Propranolol did not affect the sensitivity of the baroreflex in WKy-rats and SHR. BRS increased slightly, though not significantly, during the experiments.

This increase was similar in propranolol - and control-rats and may reflect adaptation of the animals to the experimental procedure.

In man, acute injection of propranolol has been shown to increase BRS (Pickering et al., 1972) but others, using propranolol (Simon et al., 1977), metoprolol and acebutolol (Watson et al., 1979) have not been able to confirm the observation, as is also indicated by our results. Similar discrepancy exists with regard to the effects of chronic beta-adrenoceptor blocking treatment. Several authors reported an increase in BRS (Pickering et al., 1972; Hansson et al., 1974; Takeshita et al., 1978) whereas others found no change (Bevegård et al., 1977; Simon et al., 1977; Krediet and Dunning, 1979; Watson et al., 1979). Differences in results may derive from technical shortcomings which have recently been discussed extensively (Karemaker, 1980). This study showed that results from experiments, using the technique as introduced Smyth et al. (1969) should be interpreted with extreme care. 
A possible increase in baroreceptor-reflex slope by propranolol has been suggested to result from a direct effect of the drug on stretch-sensitive elements in aortic and carotid regions of cats (Tuttle and McCleary, 1978) and rabbits (Angell-James and Bobik, 1979). These experiments were performed in isolated perfused aortic-carotid regions and direct recording of nerve-fibres was used for assessment of BRS. Tuttle and McCleary (1978) used a concentration of $5 \mu \mathrm{g} / \mathrm{ml}$ propranolol in the perfusate, although Angell-James and Bobik (1979) used lower concentrations. Neither of the studies did, however, take possible local anesthetic effects of dl-propranolol into account and d-propranolol was not tested. Thus, these results should be regarded with care.

The present study shows that an increase in baroreflex-sensitivity does not occur following propranolol. Thus, this hypothesis cannot be used to explain the hemodynamic effects observed in our rats, and probably also in man. The technique, as used in this study, does, however, only permit conclusions on the slope of the response of baroreceptor-stimulation. The set-point, around which the reflex is regulating, cannot be measured. Prichard and Gillam (1969) suggested a re-setting of the baroreceptor reflex to explain the anithypertensive effect in man. This should, however, not necessarily be a direct action of the drug in the reflex-arc.

The baroreflex has been shown to be active only in short-term blood pressure regulation (Guyton and Coleman, 1969; Guyton et al., 1970). Thus, it will adapt to the (long-term) hemodynamic changes that are brought about by the drug. From this, it should be concluded that any drug that is capable of lowering blood pressure during long-term therapy causes a re-setting, or better, an adaptation of the baroreflex to the new situation.

The fact that blood pressure is lowered for hours after injection of propranolol without signs of reflex tachycardia, even at a time where beta-adrenoceptor blockade is no longer evident (see chapter 2), may be interpreted as adaptation of baroreceptors to another blood pressure regulation-level. This is, as shown above, not accompanied by a change in sensitivity. 


\section{EFFECTS OF A SINGLE INJECTION OF PROPRANOLOL ON PLASMA RENIN ACTIVITY IN CONSCIOUS, UNRESTRAINED SHR.}

\subsection{Introduction}

As was discussed in the introduction to this thesis (section 1.3.) a contribution of the renin-angiotensin system to the antihypertensive effect of beta-adrenoceptor blocking drugs in man has been put forward by some authors, although it was denied by others. The time-course of the antihypertensive effect in our animal model, as shown in the preceding chapters, closely resembles that observed in man. There is no immediate reduction of blood pressure, although cardiac output decreases immediately after the injection of propranolol in conscious SHR. Blood pressure falls with a delay of some hours, remaining lowered for more than 20 hours after the injection. In this chapter a possible relation between the late antihypertensive effect of propranolol in conscious SHR and a reduction of plasma renin activity was investigated.

\subsection{Experimental protocol}

The effects of saline and $5 \mathrm{mg} / \mathrm{kg} \mathrm{dl}$-propranolol on blood pressure (MAP), heart rate (HR) and plasma renin activity (PRA) were compared within one group of 7 SHR. Control- and propranolol-injections in these rats were given in a random sequence with a period of 2 days in between. The $0.2 \mathrm{mg} / \mathrm{kg}$ dl-propranolol-dose was tested in a separate group of 6 SHR.

On the experimental day rats were placed in glass containers $(20 \times 20 \times 30 \mathrm{~cm})$. The heparinized saline was drawn from the catheter, after which it was connected to a CTC-CP 01 pressure transducer. Blood was flushed out of the catheter with normal (non-heparinized) physiological saline.

After a stabilization-period of 1 hour during which MAP and HR were recorded (Grass Polygraph. Model 7D), $1.0 \mathrm{ml}$ of blood was drawn from the catheter without disturbing the animals. Blood was replaced by $1.0 \mathrm{ml} 0.9 \% \mathrm{NaCl}$-solution.

Then a s.c. injection of $0.9 \% \mathrm{NaCl}(0.1 \mathrm{ml})$ or dl-propranolol $(0.2$ or $5 \mathrm{mg} / \mathrm{kg}$ in $0.1 \mathrm{ml}$ physiological saline) was given. Recording of MAP and HR were continued and one hour after the injection another $1.0 \mathrm{ml}$ blood sample was taken. which was again replaced by $1.0 \mathrm{ml}$ physiological saline. The catheters were then filled with heparinized saline $(250 \mathrm{lU} / \mathrm{ml})$ and closed. After this the animals were transferred to their home cages.

Twenty to 24 hours after the injections the animals were placed in the glass cages again and MAP and HR were recorded as on the first day. After a period of 1 hour the last $1.0 \mathrm{ml}$ blood sample was taken. 
Data on MAP and HR have been included in chapter 3 (for unrestrained rats).

Data are expressed as means \pm S.E.M. Effects in rats that received $5 \mathrm{mg} / \mathrm{kg} \mathrm{dl-}$ propranolol were compared to those in saline-injected animals using Student's t-test for paired observations, whereas for comparison of the effects of $0.2 \mathrm{mg} / \mathrm{kg} \mathrm{dl}-$ propranolol and saline the same test for unpaired observation was used.

\section{TABLE 9.I.}

Composition of the experimental groups from this chapter.

\begin{tabular}{|c|c|c|c|}
\hline Group & $N \operatorname{MAP}(\mathrm{mm} \mathrm{Hg})$ & HR (beats/min) & PRA (ng Al/ml.h) \\
\hline rol & $7^{*} 144 \pm 3$ & $381 \pm 10$ & $7.8 \pm 1.3$ \\
\hline $0.2 \mathrm{mg} / \mathrm{kg}$ propranolol & $6151 \pm 7$ & $357 \pm 12$ & $6.1 \pm 1.5$ \\
\hline $5 \mathrm{mg} / \mathrm{kg}$ propranolol & $7^{*} 146 \pm 8$ & $386 \pm 10$ & $10.4 \pm 1.7$ \\
\hline
\end{tabular}

* Animals in control- and $5 \mathrm{mg} / \mathrm{kg}$ propranolol-group were the same; they were injected with saline or propranolol in random order (see experimental protocol).

\subsection{Results}

As seen in table 9.I starting-values for PRA varied from $6.1 \pm 1.5 \mathrm{ng} \mathrm{Al} / \mathrm{ml} . \mathrm{h}$ to 10.4 $\pm 1.7 \mathrm{ng} \mathrm{Al} / \mathrm{ml}$. $\mathrm{h}$ in the $0.2 \mathrm{mg} / \mathrm{kg}$ and $5 \mathrm{mg} / \mathrm{kg}$ propranolol-groups respectively. Inter-group differences were not statistically significant.

Both in the control-group and the group injected with $0.2 \mathrm{mg} / \mathrm{kg}$ propranolol PRA tended to increase during the 24 hour experimental period. It had increased by $2.3 \pm$ $1.7 \mathrm{ng} \mathrm{Al} / \mathrm{ml} . \mathrm{h}$ and $1.9 \pm 1.3 \mathrm{ng} \mathrm{Al} / \mathrm{ml} . \mathrm{h}$. one hour following the injection of saline resp. $0.2 \mathrm{mg} / \mathrm{kg}$ propranolol. In the blood sample taken $24 \mathrm{~h}$ after the injections it had risen by resp. $4.7 \pm 1.1 \mathrm{ng} \mathrm{Al} / \mathrm{ml}$. $h$ and $3.4 \pm 1.6 \mathrm{ng} \mathrm{Al} / \mathrm{ml} . \mathrm{h}$ in the two groups. The difference is not statistically significant $(P>0.05)$.

Following injection of $5 \mathrm{mg} / \mathrm{kg}$ propranolol PRA fell by $7.5 \pm 1.3 \mathrm{ng} \mathrm{Al} / \mathrm{ml}$. h at 1 hour after the injection ( $P<0.001$ as compared to controls). Twenty-four hours after the injection it was still slightly lowered $(-1.1 \pm 2.0 \mathrm{ng} \mathrm{Al} / \mathrm{ml} . \mathrm{h})$ although this was no longer statistically significant as compared to controls $(P>0.05)$. These effects are shown in fig. 9.1 .

\subsection{Discussion}

The results from this study indicate that PRA is reduced by $65 \%$ at 1 hour following the s.c. injections of $5 \mathrm{mg} / \mathrm{kg}$ propranolol in conscious SHR. Neither control-injections nor injection of $0.2 \mathrm{mg} / \mathrm{kg}$ propranolol caused any change in this parameter. Twentyfour hours after injection PRA was back to control-values in all 3 groups.

The rapid reduction of PRA in our rats by propranolol confirms the findings of others in rabbits (Weber et al., 1974), dogs (Yun et al., 1977; Privitera et al., 1979), SHR (Riley et al., 1976), hypertensive patients (Stokes et al., 1976; Sullivan et al., 1976; Conway, 


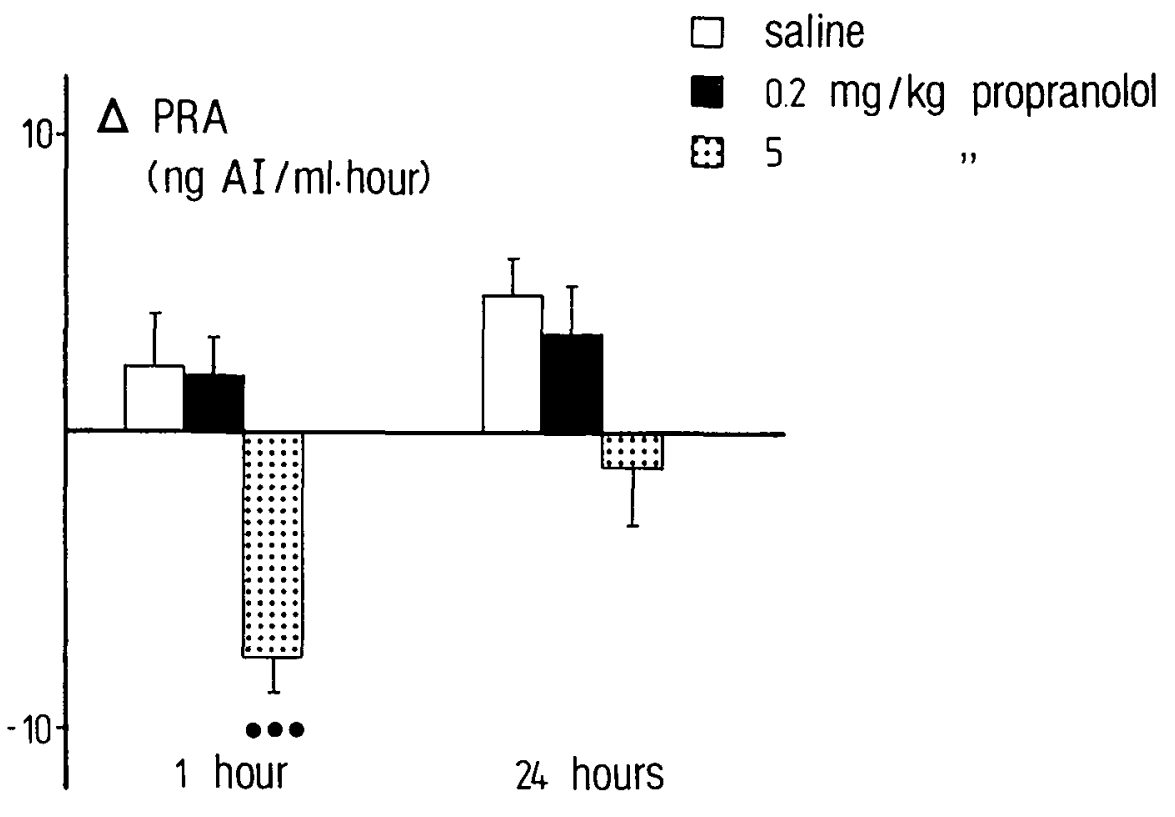

Figure 9.1. Mean ( \pm S.E.M.) changes in plasma renin activity at 1 and 24 hours after the subcutaneous injection of saline, $0.2 \mathrm{mg} / \mathrm{kg}$ and $5 \mathrm{mg} / \mathrm{kg}$ propranolol in conscious SHR. 1 $\cdots$ : $P<0.001$ as compared to controls).

1980) and borderline hypertensives (Stumpe et al., 1976). This latter group did, however, not detect such a rapid fall in PRA in patients with a stabilized hypertension. In dogs (Yun et al., 1977) and borderline hypertensives (Stumpe et al., 1976) the fall in PRA was accompanied by a reduction in blood pressure. In the other studies it was not found, although Riley et al. (1976) did not measure blood pressue.

Our results indicate clearly that in SHR there is a dissociation between PRA-lowering and antihypertensive actions of propranolol. One hour following injection of $5 \mathrm{mg} / \mathrm{kg}$ propranolol PRA is lowered drastically, whereas at that time blood pressure is increased, rather than decreased. On the other hand, 24 hours following injection of propranolol an antihypertensive effect is present, although by that time PRA is no longer reduced. Thus, we have no indication for an involvement of the reninangiotensin system in the antihypertensive action of a single injection of propranolol in SHR. 
The reduction of PRA following propranolol is generally believed to result from blockade of intra-renal beta-adrenoceptors mediating its release (see section 1.3.). Evidence comes, amongst others, from experiments in which d-propranolol proved to be incapable of lowering PRA (Weber et al., 1974; Weinberger, 1975). In our experiments both $0.2 \mathrm{mg} / \mathrm{kg}$ and $5 \mathrm{mg} / \mathrm{kg}$ propranolol caused bradycardia, although only the latter lowered PRA.

Possibly the $0.2 \mathrm{mg} / \mathrm{kg}$ dose was too low to block renal beta-adrenoceptors. Another explanation may be that a lowering of renal blood flow, which occurs following propranolol (cf. section 1.3.), stimulates renin-release (Guyton, 1976). In the case of the lower dose this may effectively counteract the reduction which is the consequence of beta-adrenoceptor blockade, whereas the latter effect may override the former when $5 \mathrm{mg} / \mathrm{kg}$ propranolol is given. However, no definite conclusions on this may be drawn from our experiments.

In conclusion we have not obtained evidence that the kinetics of the blood pressure reduction occurring in SHR after a single s.c. injection of propranolol is possibly related to the kinetics of the reduction of plasma renin activity. 


\section{EFFECTS OF A SINGLE SUBCUTANEOUS INJECTION OF PROPRANOLOL ON PLASMA VOLUME IN CONSCIOUS SHR.}

\subsection{Introduction}

Acute administration of propranolol lowers cardiac output in humans (see section 1.3 of this thesis) and also in our animal model (see chapter 6). The resulting situation is comparable to an acute cardiac failure. Oliguria following acute heart failure is well documented. Fluid retention will lead to a return of cardiac output to normal (prefailure) values, by increasing venous filling pressure (Guyton et al., 1973).

The effects of propranolol on body fluid volumes in man have only been studied extensively in long-term treatment. Tarazi et al. (1971) reported a decrease of plasma volume in patients with oral propranolol therapy. Others could, however, not confirm this observation (Sederberg-Olson and Ibsen, 1972; Parving and Gyntelberg, 1973; Weidman et al., 1976). These authors did not find a detectable change in plasma volume. Leth and Ibsen (1976) reported a decrease in the ratio between plasma volume and extracellular volume, which was explained by an increase of extracellular volume, rather than a decreased plasma volume.

Acute intravenous administration of propranolol to normotensive and borderline hypertensive subjects has been reported to induce an immediate reduction of plasma volume (Julius et al., 1972). In that study, venous pressure was found to increase following propranolol and this made the investigators propose that increased venous tone would lead to increased capillary fluid transport.

In this chapter the effects of a single injection of propranolol on plasma volume and venous pressure were examined in the conscious unrestrained SHR.

\subsection{Experimental protocols}

Plasma volume was measured as described in section 2.5 , while the animals were in their home-cages. The protocol used for the serial determinations of plasma volume was illustrated in fig. 2.3. Plasma volume was determined three times in each animal. Albumin-injections were done $30 \mathrm{~min}$ before the s.c. injection of either dl-propranolol $(5 \mathrm{mg} / \mathrm{kg}$ ) or saline $(0.1 \mathrm{ml})$ and furthermore $50 \mathrm{~min}$ and $260 \mathrm{~min}$ after propranolol-or control-injections. On the first and second occasion $\sim 2 \mu \mathrm{Ci}$ of labelled albumin were injected in a $50 \mu$ volume, using a Hamilton microliter syringe. On the third occasion $\sim 4 \mu \mathrm{Ci}$ were injected in a $100 \mu \mathrm{l}$ volume, using the same Hamilton microliter syringe. After each albumin injection, the catheter was flushed with $0.1 \mathrm{ml}$ of $0.9 \% \mathrm{NaCl}$. Details of the technique have been given in section 2.5.

Venous pressure was measured using the catheter described in section 2.3. The animals were allowed to move freely in $20 \times 20 \times 30 \mathrm{~cm}$ glass experimental cages. The catheter was attached to a miniature pressure transducer. Care was taken to place the transducer at the same height as where the catheter-tip was supposed to be located. 
Because the animals could move freely, they had to be guarded constantly and a score was made of the animals behaviour, with special reference to rearing. Only measurements obtained in periods in which the animals exhibited a normal pose were evaluated. After the experiments the correct placement of the catheter-tip was verified.

After a 1 hour equilibration period a s.c. injection of $0.1 \mathrm{ml} 0.9 \% \mathrm{NaCl}$ or dlpropranolol $(5 \mathrm{mg} / \mathrm{kg})$ was given. Venous pressure was measured for $30 \mathrm{~min}$ following control-injections and for one hour following propranolol.

Data obtained from control and propranolol-injected animals were compared using Student's t-test for unpaired observations. Differences were regarded to be statistically significant at $P$ values $<0.05$.

\subsection{Results}

\subsubsection{Effects on plasma volume}

The results from the repeated measurements of plasma volumes in SHR are summarized in figure 10.1. Starting volume for 12 propranolol-injected animals was $11.7 \pm 0.4 \mathrm{ml}$ whereas for 8 saline-injected rats it was $10.9 \pm 0.5 \mathrm{ml}$ (mean \pm S.E.M.). These values do not differ significantly.

Effects of injections on plasma volume are shown in figure 10.1.

Fifty minutes after the propranolol-injection plasma volume was $10.7 \pm 0.4 \mathrm{ml}$., which is a reduction of $8.0 \pm 2.3 \%$. As compared to saline-induced changes (an insignificant increase of $3.3 \pm 2.8 \%$ ) this reduction was significant with a $P<0.01$. Four hours after the injections differences were no longer significant $(P>0.05)$.

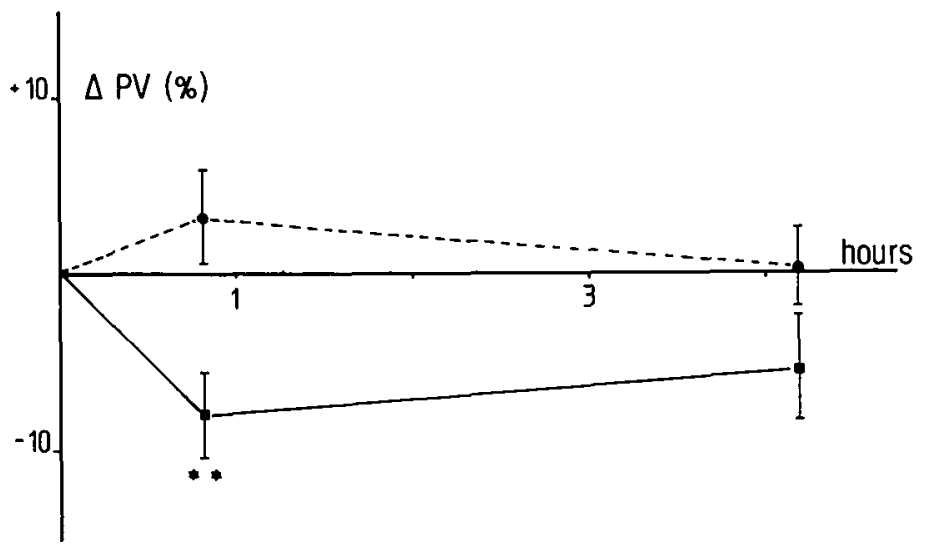

Figure 10.1. Effect of a single s.c. injection of saline ( $; \mathrm{N}=8)$ or $5 \mathrm{mg} / \mathrm{kg}$ propranolol ( $; \mathrm{N}=12$ ) on plasma volume in conscious, unrestrained SHR. Points represent means \pm S.E.M. for the groups.

**: Significant difference $(P<0.01)$ between propranolol-injected and control rats. 


\subsubsection{Effects on venous pressure}

Fig. 10.2 shows the effect of saline and propranolol on venous pressure in conscious unrestrained SHR. The mean value for venous pressure at time 0 was $0.7 \pm 0.5 \mathrm{~mm} \mathrm{Hg}$ and was identical before saline- and propranolol-injections.

The maximal effect of propranolol on venous pressure was observed 5 min after the injection (+0.5 $\pm 0.4 \mathrm{~mm} \mathrm{Hg}, \mathrm{N}=7)$. This increase in venous pressure was not different from the maximal effect of control-injections ( $+0.1 \pm 0.2 \mathrm{~mm} \mathrm{Hg}, \mathrm{N}=7$ ).

During the periods venous pressure was measured, it was not significantly different for saline or propranolol.

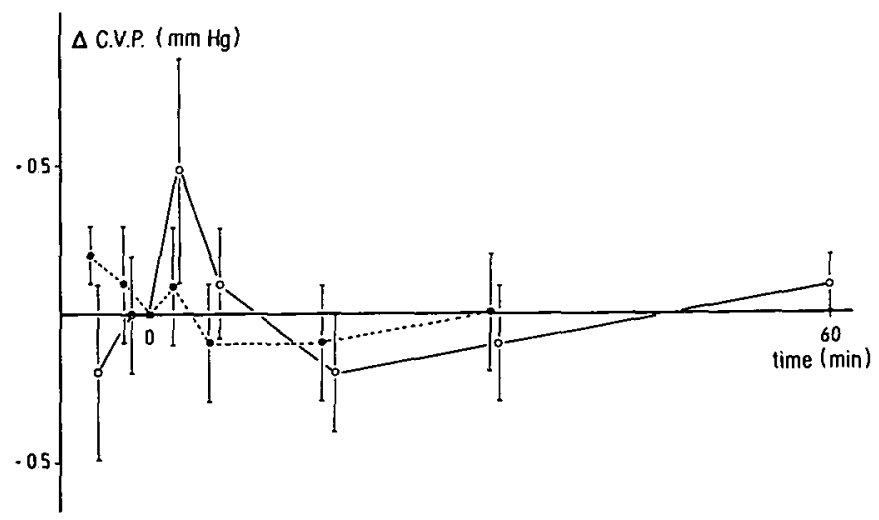

Figure 10.2. Changes (mean \pm S.E.M.) in central venous (CVP) following a single s.c. injection of saline $(O ; N=7)$ or $5 \mathrm{mg} / \mathrm{kg}$ propranolol $(\bullet ; N=7)$ in conscious, unrestrained SHR.

\subsubsection{Discussion}

Immediately following the injection of $5 \mathrm{mg} / \mathrm{kg}$ propranolol, plasma volume was reduced by $8 \%$ in conscious SHR. This confirms the findings of Julius et al. (1972) who found a $13 \%$ reduction of plasma volume already $10 \mathrm{~min}$ after $0.2 \mathrm{mg} / \mathrm{kg}$ propranolol injected intravenously in human normotensive and borderline hypertensive subjects.

Propranolol when injected systemically leads to an immediate decrease in cardiac output in man (cf. section 1.3) and also in conscious SHR (see chapter 6 of this thesis). Blood pressure does, however, not fall for some hours following the injection, a delay which is caused by activation of baroreceptors (see chapter 8 ). This baroreceptoractivation, leading to an enormous increase in total peripheral resistance may not only affect resistance vessels, but also the venous side of the circulation which also possesses sympathetic innervation that may be activated in the course of the baroreflex (Guyton, 1976). 
An increase in venous tone might lead to an increased capillary filtration of fluid which, in turn, can explain the decrease in plasma volume observed in this study and in man (Julius et al., 1972). In this study, however, no evidence for an increase in venous pressure could be obtained. Assuming venous pressure to be determined by both filling and compliance of the venous system, a net decrease in the latter should be assumed to explain the constant venous pressure in spite of an $8 \%$ decrease in filling. This might reflect a baroreceptor-mediated sympathetic activation.

After the initial decrease in plasma volume, it returns to control values very rapidly. In fact, 4 hours after injection of saline and propranolol no significant difference was detectable anymore. This should indicate a "refilling" of the circulation from the extravascular space. In fact, after the initial peak in baroreceptor activity, this reflex seems to gradually diminish its activity, as reflected by a gradual return of peripheral resistance to control levels. Thus, since venous filling had diminished in the early phase, which is however compensated by a decreased venous compliance as a consequence of baroreceptor-mediated increased sympathetic nervous activity, the result of the latter returning to control values should mean a net decrease of venous tone. Since this will inevitably lead to diminished capillary fluid transport or even a transport into the vascular system (Guyton, 1976) plasma volume will return to a normal value at the expense of the (relatively large) extra-vascular fluid volume.

In conclusion, acute administration of $5 \mathrm{mg} / \mathrm{kg}$ propranolol in conscious SHR leads to a contraction of plasma volume, which is not associated with an increased venous tone. The duration of the effect on plasma volume is only short and indicates that a reduction of it will not, by itself, contribute to the blood pressure reduction, which occurs at a time where plasma volume is back to control values. 


\section{EFFECTS OF A SINGLE INJECTION OF PROPRANOLOL ON URINARY EXCRETION OF WATER AND SODIUM IN CONSCIOUS SHR.}

\subsection{Introduction}

During long-term therapy with beta-adrenoceptor blocking drugs cardiac output remains depressed (see section 1.3). With regard to this, the situation may be compared to cardiac failure. However, patients that suffer from that disease restore normal cardiac output through retention of fluid and thereby increased venous pressure. Although there is a group of hypertensive patients who do indeed develop circulatory congestion upon therapy with beta-adrenoceptor blocking drugs, this does not occur in most.

As reviewed in section 1.3 of this thesis, renal function has been reported to diminish, with regard to renal plasma flow and glomerular filtration rate, upon acute or longterm beta-adrenoceptor blocking therapy. These parameters are, however, hard to measure is conscious unrestrained rats, because they require a constant urine flow. Therefore, in this chapter the most physiological approach was chosen to measure renal function i.e. the excretion of water and sodium were measured directly in rats which were extremely well-balanced with regard to water- and salt-intake.

The purpose of this study was to investigate whether acute administration of propranolol has any effect on urinary excretion of water and sodium. A possible increase in these parameters might not only explain the change in plasma volume reported in the preceding chapter, but also the absence of water- and sodiumretention during long-term beta-adrenoceptor blockade.

\subsection{Experimental protocol}

Urinary excretion of water and sodium were measured as described in full detail in section 2.11. Sodium- and water-balance were created and maintained by a constant infusion of a Ringer's solution. Only sodium-depleted food was allowed.

SHR normally achieve equilibrium between in- and output of water and sodium within 6-8 hours (Struyker-Boudier et al., 1979). To be sure that this equilibrium was reached, animals were infused for 24 hours before any injection of either $0.1 \mathrm{ml}$ Ringer's solution ( $N=6$ ) or propranolol in a dose of $0.2 \mathrm{mg} / \mathrm{kg}(\mathrm{N}=6)$ or $5 \mathrm{mg} / \mathrm{kg}$ $(N=14)$ was given through the arterial catheter. The latter was done to prevent excitation of the animals. Mean arterial pressure and heart rate were measured throughout the infusion-periods.

For evaluation of urine-data only those obtained during the last 6 hours before injection and 20 hours after injection were used. Data are expressed as mean \pm S.E.M. unless indicated otherwise. Data were analyzed using Student's t-test for unpaired observations. 


\subsection{Results}

Base-line values for MAP and $\mathrm{HR}$ are contained in table 11.1. MAP ranged from $133 \pm$ $7 \mathrm{~mm} \mathrm{Hg}$ (mean \pm S.D.; $\mathrm{N}=6$ ) to $150 \pm 19 \mathrm{~mm} \mathrm{Hg}$ ( $\mathrm{N}=6$ ). HR was between $284 \pm 13$ beats $/ \mathrm{min}(\mathrm{N}=6)$ and $334 \pm 53$ beats $/ \mathrm{min}(\mathrm{N}=6)$.

Recoveries of urine in the 3 groups of rats, expressed as percentage of fluid infused, were between $51 \pm 19 \%$ and $67 \pm 38 \%$. Recovery of sodium was somewhat greater, ranging from $58 \pm 34 \%$ to $71 \pm 24 \%$. These values represent means ( \pm S.D.) of 3 consecutive $2 \mathrm{~h}$ periods before injection.

TABLE 11.I Base line values for MAP, HR, water- and sodium-excretion. For MAP and HR mean values ( \pm SD) during the last 2 hours of stabilization are stated, whereas for Uv and UvNa mean values $( \pm S D)$ during the last $6 \mathrm{~h}$ before injection are given.

\begin{tabular}{|c|c|c|c|c|c|}
\hline Group & $N$ & $\begin{array}{l}\text { MAP } \\
(\mathrm{mm} \mathrm{Hg})\end{array}$ & $\begin{array}{l}\text { HR } \\
\text { (beats/min) }\end{array}$ & $\begin{array}{l}\text { Uv } \\
\text { (\% infused) }\end{array}$ & $\begin{array}{l}\text { UvNa } \\
\text { (\% infused) }\end{array}$ \\
\hline salin & 6 & $133 \pm 7$ & $334 \pm 53$ & $67 \pm 38$ & $71 \pm 26$ \\
\hline propranolol $0.2 \mathrm{mg} / \mathrm{kg}$ & 6 & $150 \pm 19$ & $284 \pm 34$ & $51 \pm 19$ & $69 \pm 24$ \\
\hline propranolol $5 \mathrm{mg} / \mathrm{kg}$ & 14 & $142 \pm 16$ & $329 \pm 38$ & $64 \pm 35$ & $58 \pm 34$ \\
\hline
\end{tabular}

\section{EFFECTS ON URINARY EXCRETION OF WATER AND SODIUM}

Intra-arterial injection of Ringer $(0.1 \mathrm{ml})$ had only small effects on excretion of water and sodium. The lowest excretion of water (UV) occurred between 12 and 14 hours after injections ( $56 \pm 13 \%$, mean \pm S.E.M.) whereas it was highest between 8 and 10 hours $(98 \pm 54 \%)$. Maximal and minimal sodium-excretions were seen in this group from 8-10 hours ( $94 \pm 29 \%)$ and 4-6 hours $(54 \pm 13 \%)$ respectively. These effects are shown in fig. 11.1 . Both 0.2 and $5 \mathrm{mg} / \mathrm{kg}$ propranolol caused an immediate increase in water-excretion. During the first two hours after injections Uv was $112 \pm 18 \%$ resp. $189 \pm 26 \%$ in the $0.2 \mathrm{mg} / \mathrm{kg}$ and $5 \mathrm{mg} / \mathrm{kg}$ propranolol-group vs. $85 \pm 15 \%$ in controlanimals. The difference between control-rats and rats injected with $5 \mathrm{mg} / \mathrm{kg}$ propranolol was statistically significant $(P<0.01)$. Thereafter UV was back at preinjection values in the $5 \mathrm{mg} / \mathrm{kg}$-group, whereas it remained slightly elevated in the 0.2 $\mathrm{mg} / \mathrm{kg}$-group. Minimal fluid excretion was observed between 16 and 18 hours after injection $153 \pm 15 \%$ resp. $52 \pm 7 \%$ in animals injected with 0.2 and $5 \mathrm{mg} / \mathrm{kg}$ propranolol).

Urinary sodium-excretion (UvNa) also increased following propranolol. Five $\mathrm{mg} / \mathrm{kg}$ caused a sodium-excretion of $150 \pm 22 \%$ during the first $2 \mathrm{~h}$ period after injection. This excretion was significantly different from that in control animals $177 \pm 24 \%$, $P$ $<0.05$ ). After the initial peak-effect UvNa was back at control-levels. Injection of 0.2 $\mathrm{mg} / \mathrm{kg}$ propranolol caused a peak sodium-excretion during the first 2 hours after injection (125 $\pm 18 \%)$. Again this effect was not significantly different from control. Lowest sodium-excretions were seen from $12-14 \mathrm{~h}$ after $5 \mathrm{mg} / \mathrm{kg}(55 \pm 10 \%)$ and $16-$ $18 \mathrm{~h}$ after $0.2 \mathrm{mg} / \mathrm{kg}$ propranolol $(61 \pm 17 \%)$. 

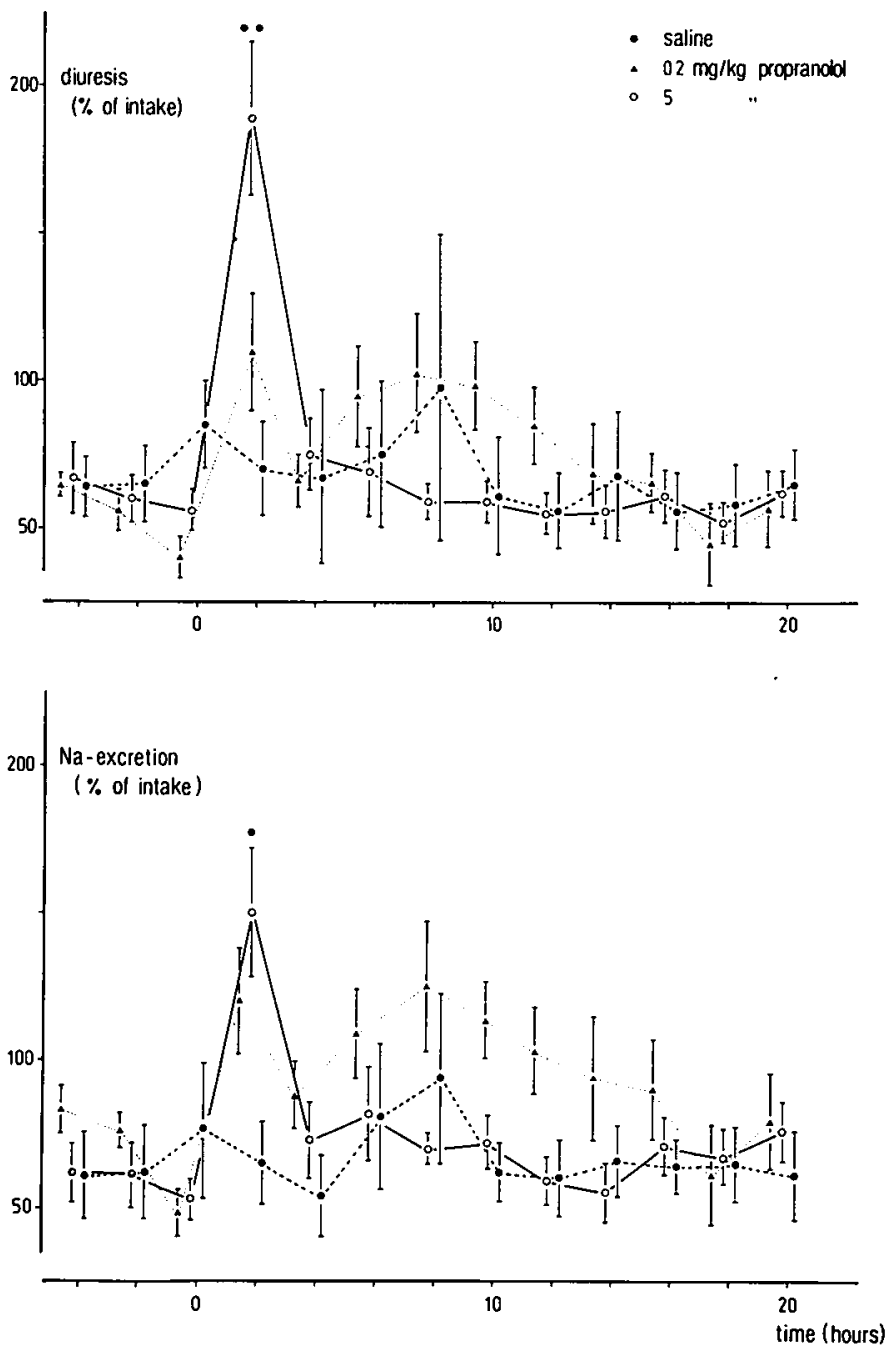

Figure 11.1. Effect of a single injection of saline $(\bullet ; \mathrm{N}=6) .0 .2 \mathrm{mg} / \mathrm{kg}$ propranolol ( $\boldsymbol{A} ; \mathrm{N}=6$ ) and $5 \mathrm{mg} / \mathrm{kg}$ propranolol ( $\mathrm{O} ; \mathrm{N}=14$ ) on urinary excretion of water (Uv) and sodium (UVNa) in conscious SHR. The arrow marks the time of injection. Significance in the difference with control animals in the same period: $\bullet: P<0.05$; - : $P<0.01$. 


\subsection{Discussion}

In this study SHR were carefully balanced with regard to water-and sodium-intake and excretion. This was achieved by a constant infusion of a Ringer's solution at a rate of $1.2 \mathrm{ml} / \mathrm{h}$. The net-intake thus was approximately $30 \mathrm{ml} /$ day, which may be regarded as normal for adult SHR. The excretion-values for both water and sodium were low, i.e. only $51-67 \%$ of the amounts infused were recovered from the collection-system during the run-in period. The reason for this low recovery is probably not caused by a retention in the animals but rather adhesion to the cages and collecting-system should be regarded as the cause for it. From an earlier study, in which small metal metabolism cages were used, we know that normally adult SHR excrete more than $80 \%$ of the water and sodium infused similarly as in the present study (StruykerBoudier et al., 1979) within 6-8 hours after the start of the infusion.

To make sure that equilibrium was reached, we waited for 24 hours after the start of infusions before experiments were begun and only urine-samples collected later than 16-18 hours after the start of the infusions were used for evaluation. As was shown in this chapter, recovery of urine was reproducible and, more important, it was constant over the $20 \mathrm{~h}$ experimental period in control animals.

Five $\mathrm{mg} / \mathrm{kg}$ propranolol caused an immediate significant increase in sodium-and water-excretion, which was not seen after control-injections and $0.2 \mathrm{mg} / \mathrm{kg}$ propranolol. This phenomenon has been reported before in normotensive anesthetized (Carrara and Baines, 1976; Shibouta et al., 1979) and conscious rats (Chan and Poorvin, 1979). Other studies in this species revealed an increased sodium-excretion with no effect on diuresis in awake (Lees, 1968) and anesthetized rats (Greven, 1974). In contrast to the effects of beta-adrenoceptor blockade, isoproterenol-induced stimulation of beta-adrenoceptors has been shown to cause anti-diuresis and -natriuresis in rats (Lees, 1968; Greven, 1974; Shibouta et al., 1978). It should, however, be noted that water-loaded rats were used in all studies.

Depending upon methods stimulation of renal beta-adrenoceptors with isoprenaline in dogs has caused a decrease (Heidenreich et al., 1969; Schrier et al., 1972), an increase (Gill and Casper, 1971) or no change (Blendis et al., 1972; Stein et al., 1972) in water- and sodium-excretion. Propranolol decreased sodium-excretion in dogs (Nies et al., 1971; Nomura et al., 1978), an effect which the authors related to the decrease in cardiac output, caused by propranolol.

Also in man beta-adrenoceptor blockade has been shown to interfere with urinary function. This is reflected by a reversal of the diurnal excretion pattern for sodium resulting in increased nocturnal sodium-excretion (Epstein and Braunwald, 1966; Rahn et al., 1968). No clearcut effects on total daily sodium-excretion were, however, observed in most patients (Epstein and Braunwald, 1966).

Beta-adrenoceptor blockade may be expected to be capable of influencing renal function in several ways. Both renal blood flow (RBF) and glomerular filtration rate (GFR) may decrease as a consequence of cardiac effects of beta-adrenoceptor blockade as well as the concomitant increase in sympathetic nerve activity (chapter 8 ) leading to afferent arteriolar constriction. This has in fact been shown to occur both after acute and chronic administration of propranolol in all species (Schirmeister et 
al., 1966; Nies et al., 1971, Ibsen and Sederberg-Olsen, 1973; Nomura et al., 1978; Bauer and Brooks, 1979). In two studies in anesthetized water-loaded rats RBF was increased by propranolol (Carrara and Baines, 1976; Shibouta et al., 1979) and no effects on GFR were found. Greven (1974) reported also no change in total kidney GFR but there was an increase in GFR of superficial nephrons which was probably caused by a redistribution of RBF from deep to cortical nephrons. Thus, if any effects of GFR on water- and sodium-excretion should be expected, it would be more likely to decrease instead of increasing as was shown in the present study. Therefore, other effects may play a role.

Renal sympathectomy leads to increased sodium- and water-excretion in rats. This effect is not associated with any changes in GFR or RBF (Bencsath et al., 1979). These authors showed that renal sympathectomy causes a decrease in proximal tubular sodium reabsorption with a slightly increased distal tubular resorption. Similar effects have been reported to result from depression of renal nervous activity by increased left atrial pressure (Di Bona, 1977; Di Bona et al., 1977; Kappagoda et al., 1979).

Stimulation of renal nerves either directly or by increased baroreceptor activity elicits increases in tubular reabsorption of water and sodium (Di Bona, 1977; Di Bona et al., 1977; Colindres et al., 1978). The latter effect may be blocked by phenoxybenzamine (Di Bona, 1977) indicating alpha-adrenoceptor-involvement in the effect. No studies on the effect of beta-adrenoceptor blockade are known. Thus, it may be concluded that renal sympathetic nervous activity has an inhibitory effect on water- and sodiumexcretion and consequently blockade of a possible beta-adrenergic component may lead to an increased diuresis and natriuresis by reducing tubular reabsorption.

Besides an influence via beta-adrenoceptors in the kidney, also hormonal changes may be induced that influence tubular reabsorption. Candidate substances may be vasopressin, aldosterone and angiotensin. Vasopressin, which is an antidiuretic hormone, is probably not involved in the effects seen in this study, since also in Brattelboro rats, which have no vasopressin because of hereditary diabetes insipidus, a diuretic response is caused by propranolol (Levi et al., 1971). In dogs a diuretic response to isoprenaline has been suggested to result from inhibition of vasopressinrelease from the pituitary (Schrier et al., 1972). Thus, inhibition of vasopressinrelease is not a likely explanation of the effects seen in this chapter. A reduction of plasma renin activity and consequently a decrease in angiotensin II and aldosterone might be an alternative explanation. However, blockade of angiotensin II receptors with saralasin has been shown to decrease urine flow in rats, rather than increasing it (Carrara and Baines, 1976). From animal experiments no detailed data on a possible involvement of aldosterone in the diuretic response are available. Following acute administration of propranolol in man plasma aldosterone-levels were, however. reported to be unchanged (Stumpe et al., 1976).

Thus, involvement of the sympathetic nervous system in the effects reported in this study is a likely explanation. Five $\mathrm{mg} / \mathrm{kg}$ propranolol increased sodium- and waterexcretion during the first two hours following injection; thereafter it was normal. It should, however, be noted that after the first 2-hour period MAP was lowered, which by itself should lower diuresis (Guyton, 1976). Thus, during this period there is a 
relative diuresis left. The same relative diuresis occurs in man where, although blood pressure and cardiac output are depressed, no retention of fluid occurs (Epstein and Braunwald, 1966; Rahn et al., 1968).

In conclusion it was shown, that propranolol increases urinary water- and sodiumexcretion. Although in this study GFR and RBF could not be measured, changes in these parameters may be expected from literature to predict the opposite effect, suggesting interference of propranolol with tubular function. 
LONG-TERM STUDIES 


\section{DISPOSITION OF PROPRANOLOL AND ITS TOTAL METABOLITES FOLLOWING LONG-TERM INFUSION: SUBCUTANEOUS VS. INTRACEREBROVENTRICULAR INFUSION.}

\subsection{Introduction}

In chapters 3 and 7 we studied the pharmacokinetics of propranolol after a single subcutaneous (s.c.) resp. intracerebroventricular (i.c.v.) injection in the SHR. It was found there, that after s.c. injection propranolol reached very high concentrations in all tissues studied. After i.c.v. injection, propranolol appeared immediately in plasma, indicating rapid and massive leakage to the peripheral blood-stream. This latter observation made conclusions on a possible CNS-action (using bolus-injections) impossible.

In this study we investigated the disposition of propranolol and its total metabolites during continuous infusion. For that, we used the ALZET TM osmotic minipump as a zero-order drug delivery system in unrestrained animals (see section 2.7.1.). The purpose of the study was three-fold. First of all we wanted to investigate whether it is possible to create and maintain a steady-state for propranolol and its total metabolites during a 6-day infusion of the drug. Furthermore, we wanted to study the distribution of propranolol and its metabolites in the body after a s.c. infusion, to see if the drug cumulates in any tissue. Finally, we compared the distribution of propranolol and its total metabolites after a 6-day s.c. and i.c.v. infusion. This was done to investigate whether it was possible to achieve relatively high brain levels upon i.c.v. infusion as compared to s.c. infusion. If so, then the long-term i.c.v. infusion might be used to investigate a possible CNS-site of action of the drug with regard to its antihypertensive effect.

\subsection{Experimental protocol}

All animals were equipped with a catheter in the left jugular vein to permit repeated blood sampling (see section 2.6.1.). Catheters were implanted one day prior to the start of the infusion.

Animals that were to receive i.c.v. infusions, were implanted with a special catheter in the lateral cerebral ventricle (see section 2.7.3.) at least one week before the start of the experiments.

Osmotic minipumps (batch AR-C507) were filled with ${ }^{3} \mathrm{H}$-labelled propranolol. Propranolol was infused s.c. at a rate of $1 \mathrm{mg} / \mathrm{kg}$.day in 5 rats, whereas the same amount was infused i.c.v. also in 5 animals. Five other rats received $0.01 \mathrm{mg} / \mathrm{kg}$. day i.c.v. Specific activity was $3.3 \mathrm{mCi} / \mathrm{mmol}$ in the case of infusions of $1 \mathrm{mg} / \mathrm{kg}$.day, whereas it was $330 \mathrm{mCi} / \mathrm{mmol}$ in the $0.01 \mathrm{mg} / \mathrm{kg}$. day group.

After implantation of osmotic minipumps for s.c. (section 2.7.2.) or i.c.v. infusion (section 2.7.3.) animals were housed separately in metabolism cages (type SR1, 


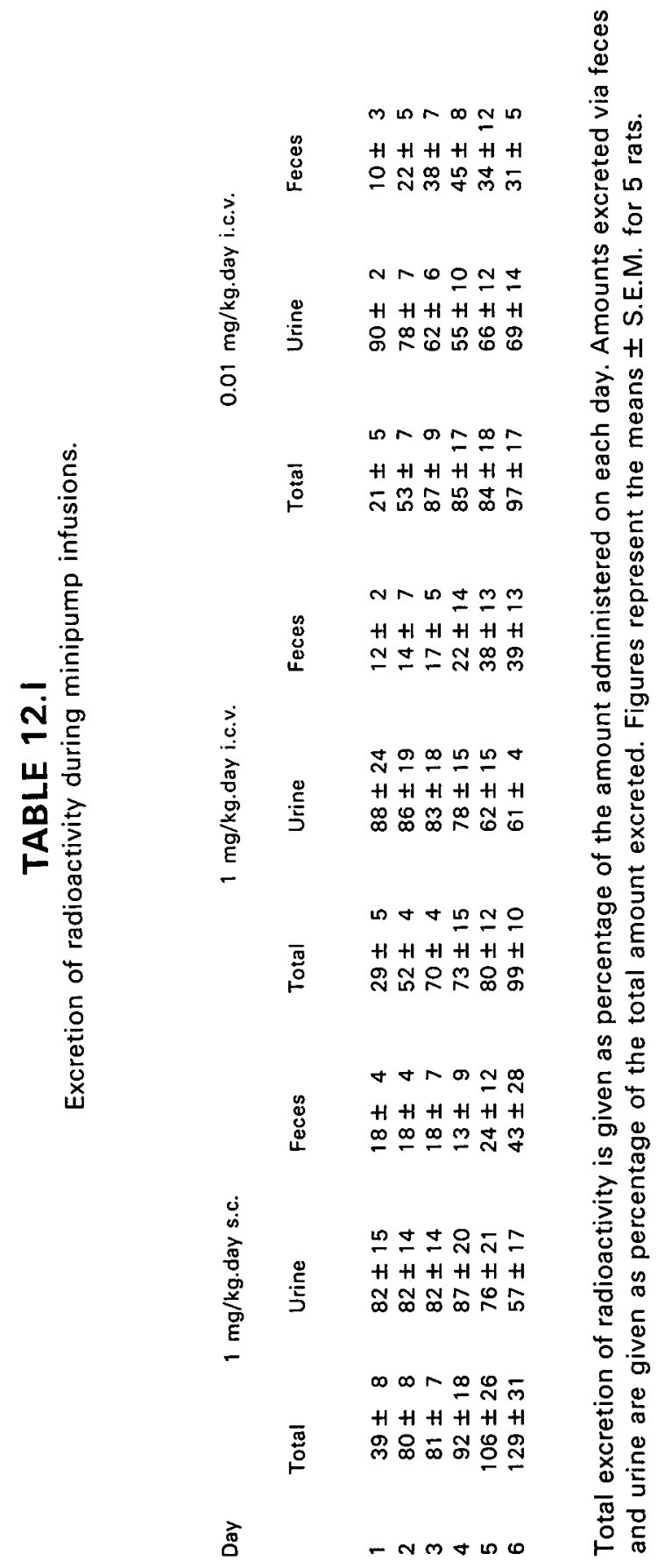


Ruco; section 2.1.) to allow separate sampling of urine and feces.

Urine and feces were collected every 24 hours. On days 1.3 and 6 after the start of the infusions blood was drawn from the venous catheter. Finally, on day 6 , between 10:00 and 12:00 a.m., the animals were killed with an intravenous over-dose of thiopental and tissues were taken out for determination of propranolol and its total metabolites, as described in section 2.12. For determination of propranolol and its metabolites in erythrocytes, cells were lysed by addition of $5 \mathrm{ml}$ distilled water to 0.5 $\mathrm{ml}$ erythrocytes.

Data are presented as means \pm S.E.M. Significances were calculated using Student's t-test.
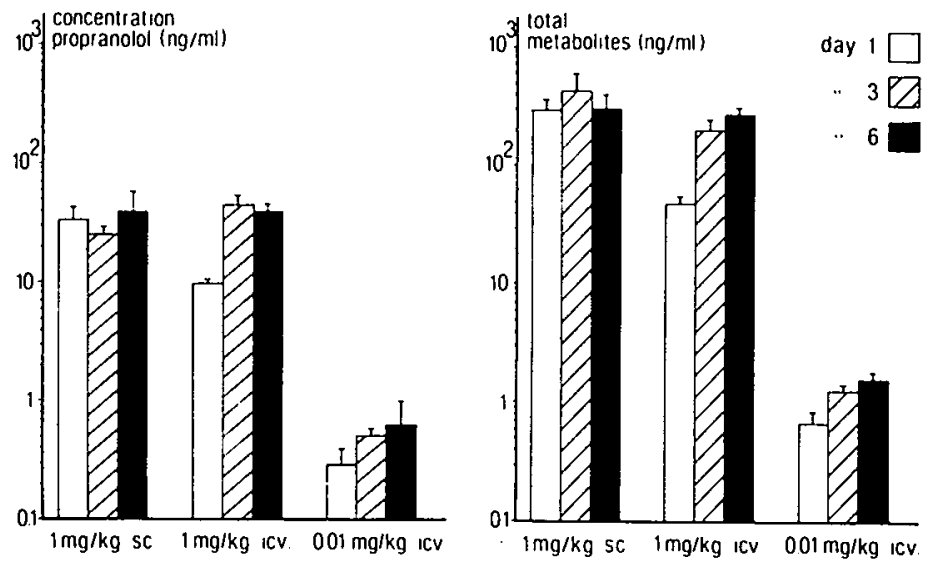

Figure 12.1. Plasma concentrations of propranolol and its total metabolites on days 1,3 and 6 after the start of the respective infusion procedures.

Each bar represents the mean \pm S.E.M. for 5 rats.

\subsection{Results}

\subsubsection{Excretion of propranolol and its metabolites}

Excretion of total radio-activity - expressed as percentage of the amount infused each day - is given in table 12.l. At the end of the first day only $21-39 \%$ of the dose infused that day was excreted. During subcutaneous infusion $80 \%$ or more is excreted from the second day on. During i.c.v. infusion the excretion on the second day only amounted to $53 \pm 7 \%$ and $52 \pm 4 \%$ for the $0.01 \mathrm{mg} / \mathrm{kg}$.day respectively $1 \mathrm{mg} / \mathrm{kg}$.day dose. After day 2 more than $70 \%$ of the amount infused daily is excreted. 
In table 12.1. total excretion is specified for excretion via urine and feces. Both urinary and fecal radioactivity almost exclusively represent propranolol metabolites, since less than $2 \%$ of radioactivity was heptane extractable. Relative excretion via the feces is only $10-20 \%$ during the first $2-4$ days. However, fecal excretion accounts for $24-43 \%$ of total excretion during the last 2 days.

\subsubsection{Plasma levels during long-term infusion}

Plasma concentrations of propranolol and its metabolites on days 1,3 and 6 are shown in figure 12.1. During subcutaneous infusion of $1 \mathrm{mg} / \mathrm{kg}$. day plasma levels of both propranolol $(33 \pm 9,25 \pm 3$ and $39 \pm 21 \mathrm{ng} / \mathrm{ml})$ and total metabolites $(290 \pm 70$. $418 \pm 165$ and $300 \pm 106 \mathrm{ng} / \mathrm{ml}$ ) did not differ significantly on respectively day 1,3 and 6. During i.c.v. infusion with $1 \mathrm{mg} / \mathrm{kg}$.day plasma levels of propranolol $(9 \pm 1$ $\mathrm{ng} / \mathrm{ml}$ ) and total metabolites $(46 \pm 8 \mathrm{ng} / \mathrm{ml})$ on the first day were significantly lower $(\mathrm{P}<0.01)$ than those on days 3 and 6 (propranolol: $44 \pm 10$ and $39 \pm 8 \mathrm{ng} / \mathrm{ml}$; total metabolites: $202 \pm 52$ and $263 \pm 29 \mathrm{ng} / \mathrm{ml}$ ). Also during i.c.v. infusion with 0.01 $\mathrm{mg} / \mathrm{kg}$. day lower levels of propranolol $(0.30 \pm 0.10 \mathrm{ng} / \mathrm{ml})$ and total metabolites $(0.65 \pm 0.19 \mathrm{ng} / \mathrm{ml})$ were observed on the first day than on days 3 and 6 (propranolol: $0.53 \pm 0.03$ and $0.64 \pm 0.36 \mathrm{ng} / \mathrm{ml}$; total metabolites: $1.26 \pm 0.14$ and $1.58 \pm 0.15$ $\mathrm{ng} / \mathrm{ml}$ ). These differences, however, do not reach a statistically significant level. Steady-state plasma levels of propranolol and total metabolites do not depend upon the route of administration, as indicated by the fact that no statistically significant differences were found between plasma concentrations of propranolol or total metabolites during subcutaneous and i.c.v. infusions of $1 \mathrm{mg} / \mathrm{kg}$.day on days 3 and 6 . Plasma concentrations of propranolol and total metabolites during the i.c.v. infusion of $0.01 \mathrm{mg} / \mathrm{kg}$. day were only $0.01 \cdot 0.02$ times those during $\geq 1 \mathrm{mg} / \mathrm{kg}$.day infusion (figure 12.1.).

\subsubsection{Disposition of propranolol its total metabolites}

Figure 12.2. shows the organ distribution of propranolol after a 6 day subcutaneous infusion of $1 \mathrm{mg} / \mathrm{kg}$.day. Highest concentrations were found in the lungs $(206 \pm 73$ $\mathrm{ng} / \mathrm{g}$ ). This concentration is 5.3 times higher than that in plasma. Lowest concentrations were found in erythrocytes $(14 \pm 7 \mathrm{ng} / \mathrm{g})$.

In all other tissues examined, propranolol concentrations were close to that in plasma.

I.c.v. infusion of $1 \mathrm{mg} / \mathrm{kg}$.day produced propranolol concentrations in peripheral organs that did not differ significantly from those found after subcutaneous infusion of the same dose (figures 12.3. and 12.5.). In plasma propranolol concentration was 39 $\pm 8 \mathrm{ng} / \mathrm{ml}$ during i.c.v. infusion and $39 \pm 12 \mathrm{ng} / \mathrm{ml}$ during subcutaneous administration.

In other tissues these values were respectively: erythrocytes $11 \pm 2$ and $14 \pm 7 \mathrm{ng} / \mathrm{g}$; heart: $60 \pm 7$ and $42 \pm 14 \mathrm{ng} / \mathrm{g}$; lungs: $274 \pm 35$ and $206 \pm 73 \mathrm{ng} / \mathrm{g}$; liver: $36 \pm 7$ and 


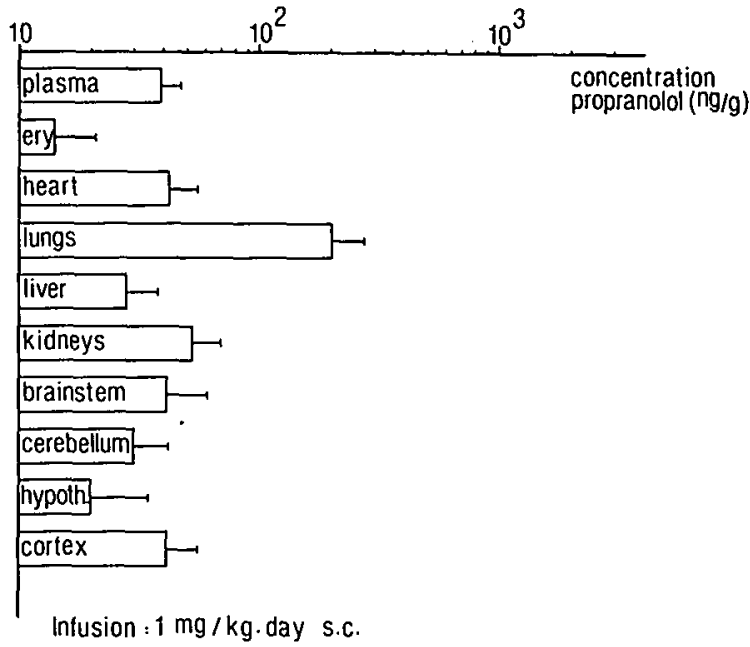

Figure 12.2. Tissue distribution of propranolol following a 6 day subcutaneous infusion with $1 \mathrm{mg} / \mathrm{kg}$. day propranolol. Each bar represents the mean \pm S.E.M. for 5 rats. Abbreviations used: ery. $=$ erythrocytes; hypoth. $=$ hypothalamus.

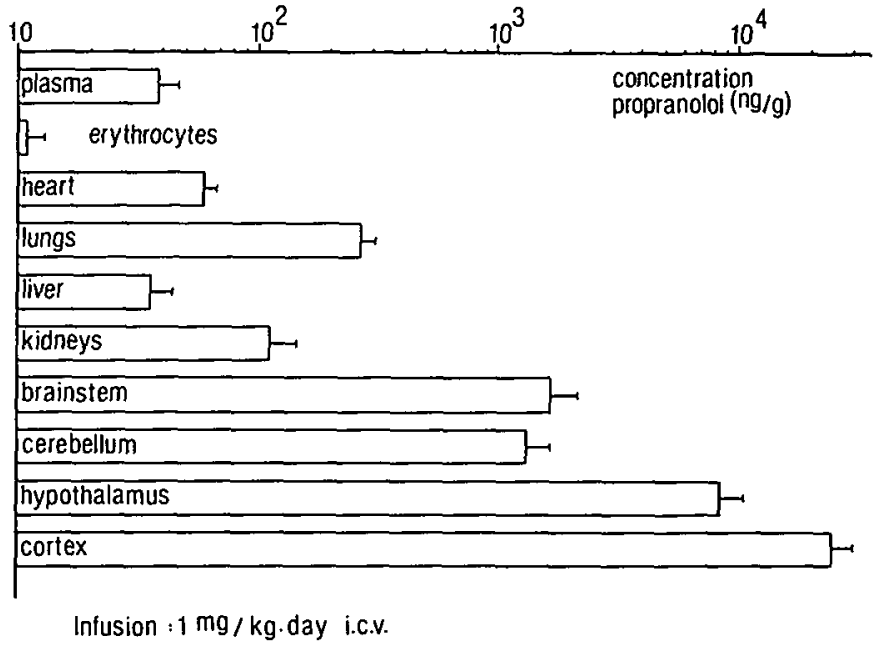

Figure 12.3. Tissue distribution of propranolol following a 6 day i.c.v. infusion with 1 $\mathrm{mg} / \mathrm{kg}$. day propranolol. Each bar represents the mean \pm S.E.M. for 5 rats. 
$28 \pm 10 \mathrm{ng} / \mathrm{g} ;$ kidneys: $117 \pm 31$ and $54 \pm 16 \mathrm{ng} / \mathrm{g}$. In contrast, brain concentrations of propranolol reached values 41 (brainstem) to 569 (cortex) times higher after i.c.v. infusion. Highest concentrations were reached in the hypothalamus $(8653 \pm 2511$ $\mathrm{ng} / \mathrm{g})$ and cortex $(24446 \pm 9147 \mathrm{ng} / \mathrm{g})$, which agrees with the location of these structures close to the ventricular system.

Following i.c.v. infusion of $0.01 \mathrm{mg} / \mathrm{kg}$.day, peripheral concentrations as measured in in plasma $(0.64 \pm 0.36 \mathrm{ng} / \mathrm{ml})$, erythrocytes $(0.18 \pm 0.09 \mathrm{ng} / \mathrm{g})$ and heart $(0.72 \pm 0.20$ $\mathrm{ng} / \mathrm{g}$ ) were only $0.005-0.02$ times those following i.c.v. or subcutaneous infusion with $1 \mathrm{mg} / \mathrm{kg}$.day (figures 12.4 and 12.6 ).

Brain concentrations varied from $20 \pm 6 \mathrm{ng} / \mathrm{g}$ in brainstem to $235 \pm 44 \mathrm{ng} / \mathrm{g}$ in cortex (figure 12.4.). These concentrations are similar to those obtained after subcutaneous infusion of $1 \mathrm{mg} / \mathrm{kg}$.day (figure 12.6).

Total metabolite concentrations are given in table 12.II. The distribution pattern of these metabolites is difficult to interpret, since total metabolites represent a pool of different metabolites, of which the relative amounts may differ per tissue.

Concentrations of total metabolites in peripheral organs as well as the CNS did not differ significantly $(P>0.05$ for all organs) following subcutaneous or i.c.v. infusion with $1 \mathrm{mg} / \mathrm{kg}$.day (table 12.11 and figure 12.5). Following i.c.v. infusion with 0.01 $\mathrm{mg} / \mathrm{kg}$.day total metabolite concentrations in peripheral tissues were only 0.003 0.005 those during subcutaneous infusion of $1 \mathrm{mg} / \mathrm{kg}$. day (table 12.11 and figure 12.6). In brain, however, slightly higher concentrations were found $(0.015-0.09$ times those after $1 \mathrm{mg} / \mathrm{kg}$.day subcutaneously).

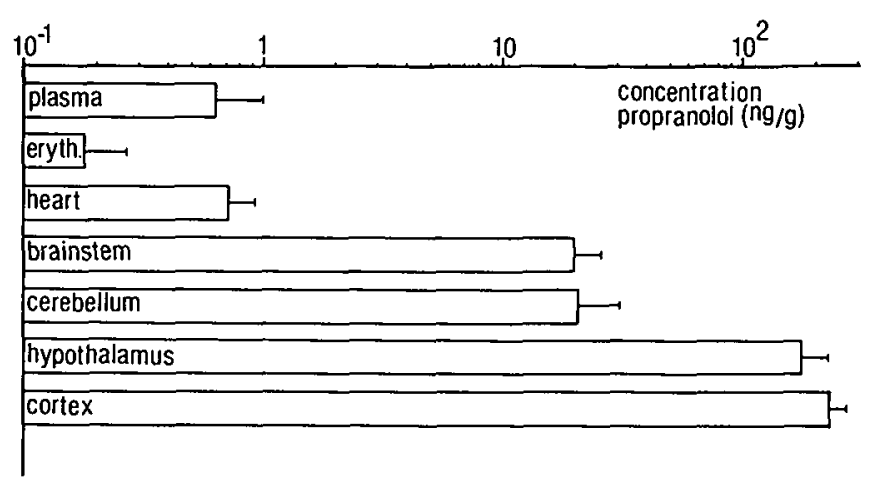

Infusion : $0.01 \mathrm{mg} / \mathrm{kg}$.day i.c.v.

Figure 12.4. Tissue distribution of propranolol following a 6 day i.c.v. infusion with $0.01 \mathrm{mg} / \mathrm{kg}$. day propranolol. Each bar represents the mean \pm S.E.M. for 5 rats. Abbrevation used: eryth. $=$ erythrocytes. 


\section{TABLE 12.11}

Steady-state tissue levels of propranolol metabolites.

$1 \mathrm{mg} / \mathrm{kg}$.day s.c. $\quad 1 \mathrm{mg} / \mathrm{kg}$.day i.c.v. $\quad 0.01 \mathrm{mg} / \mathrm{kg}$. day i.c.v.

$\begin{array}{lrrl}\text { plasma } & 300 \pm 106 & 263 \pm 29 & 1.58 \pm 0.15 \\ \text { erythrocytes } & 401 \pm 132 & 213 \pm 35 & 1.92 \pm 0.23 \\ \text { heart } & 429 \pm 132 & 163 \pm 18 & 1.20 \pm 0.22 \\ \text { lungs } & 367 \pm 87 & 237 \pm 54 & \text { n.d. }{ }^{a} \\ \text { liver } & 2620 \pm 250 & 2098 \pm 128 & \text { n.d. } \\ \text { kidneys } & 2600 \pm 270 & 1988 \pm 207 & \text { n.d. } \\ \text { brainstem } & 871 \pm 173 & 506 \pm 121 & 13 \pm 5 \\ \text { cerebellum } & 446 \pm 80 & 471 \pm 154 & 33 \pm 11 \\ \text { hypothalamus } & 722 \pm 180 & 415 \pm 128 & 44 \pm 23 \\ \text { cortex } & 261 \pm 109 & 417 \pm 243 & 24 \pm 7\end{array}$

Total propranolol metabolite levels ( $\mathrm{ng} / \mathrm{g}$ ) after a 6 day continuous infusion with propranolol $1 \mathrm{mg} / \mathrm{kg}$.day (subcutaneous and i.c.v.) and $0.01 \mathrm{mg} / \mathrm{kg}$.day (i.c.v.).

Means \pm S.E.M. are given for 5 rats.

a n.d.: not determined.

\subsection{Discussion}

Both excretion data and plasma levels of propranolol and its metabolites found in this study indicate that a steady-state can be built up and maintained with osmotic minipumps for continuous release of propranolol. Repeated determinations of plasma levels of propranolol and its metabolites in particular indicate a good steady-state. Excretion data may be less well fit for evaluation of the kinetics of building up a steady-state, since fecal excretion of propranolol metabolites is slow in onset. Data in table 12.1 show a relatively fast and high fecal excretion in rats receiving $0.01 \mathrm{mg} / \mathrm{kg}$. day. Fecal excretion of radioactivity was delayed much more pronounced in rats infused with $1 \mathrm{mg} / \mathrm{kg}$. day.

This may have resulted from the fact that SHR receiving $1 \mathrm{mg} / \mathrm{kg}$. day did not produce many stools during the early infusion-period. It is not clear whether this is a propranolol-related effect. Interestingly, Hayes and Cooper (1971) also found that after a single subcutaneous injection of propranolol $(1 \mathrm{mg} / \mathrm{kg})$ in rats no fecal excretion occurred during the first 24 hours in which urinary excretion was high. Only after 48-72 hours significant amounts were excreted via the feces. Similar to our results Hayes and Cooper (1971) found that in rats propranolol is excreted completely metabolized for some $70 \%$ via the urine and $30 \%$ via the feces. 


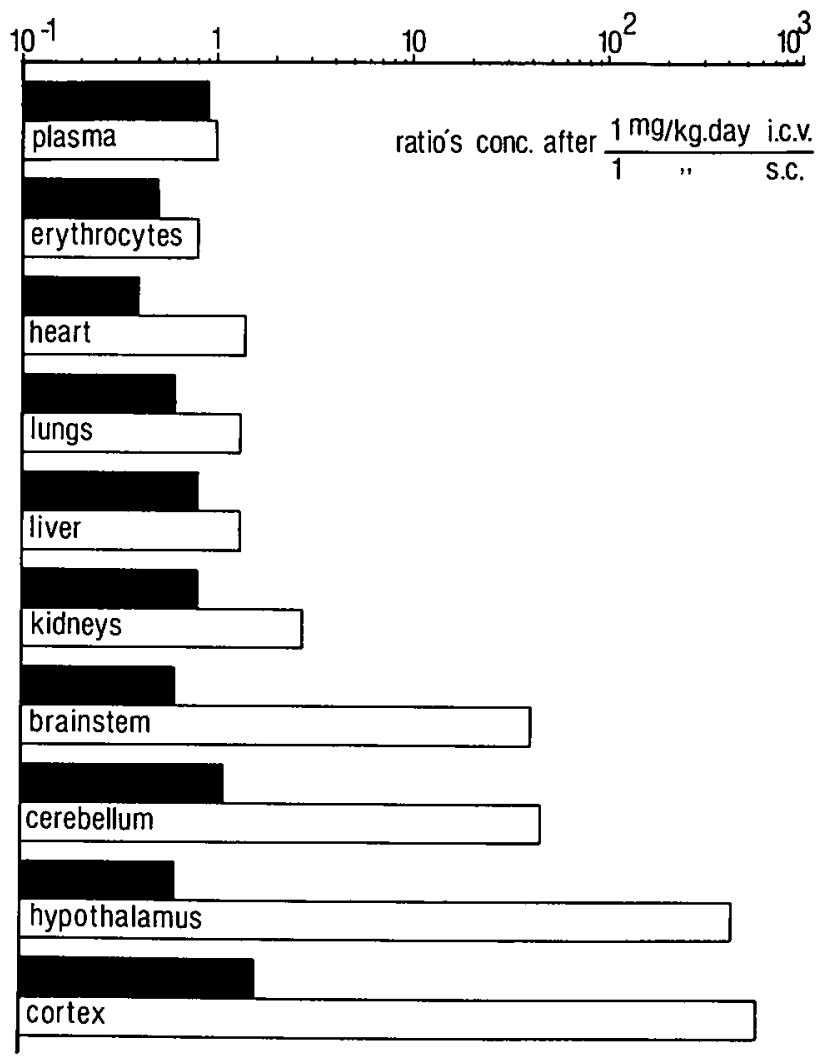

Figure 12.5. Concentrations of propranolol (open bars) and its total metabolites (closed bars) following a 6 day infusion of $1 \mathrm{mg} / \mathrm{kg}$.day i.c.v. divided by the concentrations in the same tissues after $1 \mathrm{mg} / \mathrm{kg}$. day subcutaneously for 6 days.

Plasma levels of propranolol and its metabolites indicate that upon subcutaneous infusion a steady-state is reached in plasma already with in one day after implantation of the minipumps. This agrees with the rapid uptake and relatively short plasma elimination half-life of $\sim 60$ minutes for propranolol after subcutaneous injection in the SHR (chapter 3).

During i.c.v. infusion steady-state is reached somewhat later. This may be explained by the fact, that in case of an i.c.v. infusion propranolol is introduced directly into a deep compartment. On the basis of the results during subcutaneous infusion, the high concentrations reached in brain after i.c.v. infusion are not expected to result from specific binding.

The data from the experiments in which $1 \mathrm{mg} / \mathrm{kg}$.day was infused subcutaneously indicate that propranolol does not accumulate in the CNS of SHR. 
This is in contrast with the studies in humans by Myers et al. (1975b) who found that after prolonged infusion of d-propranolol $(2.10 \mathrm{mg} / \mathrm{kg}$.day) 3-to 35-fold higher concentrations were found in brain. Also after an acute administration of propranolol in experimental animals CNS concentrations can reach values much higher than those in plasma (Laverty and Taylor, 1968; Hayes and Cooper, 1971; Myers et al., 1975b; chapter 3).

This discrepancy may be due to concentration-dependent protein-binding of propranolol in plasma. As indicated by equilibrium dialysis experiments, propranolol binds for $92 \%$ to rat plasma proteins over a concentration range of $0-100 \mathrm{ng} / \mathrm{ml}$. However, at higher plasma concentrations, binding diminishes progressively, reaching a value of $75 \%$ binding at $300 \mathrm{ng} / \mathrm{ml}$ (see chapter 3 ). These differences in binding greatly affect the possibility for propranolol to penetrate into tissues (Evans and Shand, 1973). Garvey and Ram (1975a) studied tissue distribution of propranolol in normotensive rats and SHR after repeated oral or subcutaneous administration of propranolol ( 7.5 respectively $5 \mathrm{mg} / \mathrm{kg}$. day for 14 days). After chronic oral treatment these authors also found brain concentrations equal to those in plasma, whereas following repeated subcutaneous injections, brain concentrations were 10-30 fold higher (Garvey and Ram, 1975a). However, in contrast to the oral treatment in which propranolol was given continuously via the drinking water, chronic subcutaneous treatment was established by one daily injection of the total dose (Garvey and Ram, 1975a). Since with this latter approach a true steady-state cannot be reached for a drug with a relatively short half-life, it is hard to compare these data with ours.

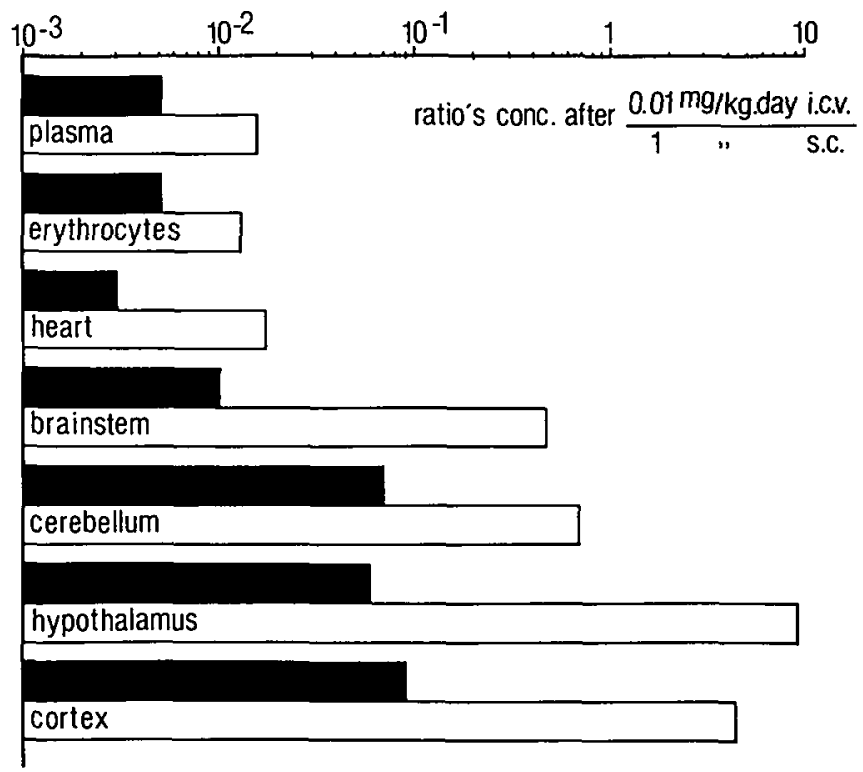

Figure 12.6. Concentrations of propranolol (open bars) and its total metabolites (closed bars) following a 6 day infusion of $0.01 \mathrm{mg} / \mathrm{kg}$. day i.c.v. divided by the concentrations reached in the same tissues after a $1 \mathrm{mg} / \mathrm{kg}$.day subcutaneous infusion for 6 days. 
A final result from this study is that steady-state concentrations of propranolol in peripheral tissues like plasma, erythrocytes, heart, lungs, liver and kidneys are independent of the route of administration in the dose we used $(1 \mathrm{mg} / \mathrm{kg}$.day).

However, when using equal doses, i.c.v. infusion results in brain concentrations approximately one hundred-fold higher than subcutaneous infusion of propranolol. In fact, i.c.v. infusion with a dose 100 times lower produced brain propranolol concentrations in the same order of magnitude as those obtained with a subcutaneous infusion of $1 \mathrm{mg} / \mathrm{kg}$.day.

Total metabolite concentrations in peripheral tissues as well as the CNS do not differ significantly during subcutaneous or i.c.v. infusion with $1 \mathrm{mg} / \mathrm{kg}$. day, indicating that metabolism takes place outside the CNS. Following i.c.v. infusion with the low dose of $0.01 \mathrm{mg} / \mathrm{kg}$. day CNS metabolite concentration is relatively higher. It remains to be established whether this indicates that the CNS is capable of metabolizing small amounts of propranolol. Such a low extent of metabolism might be masked in the CNS of rats infused with the high dose by the bulk of metabolites which are undoubtedly of peripheral origin.

In conclusion, the infusion method described in this study allows selective long-term perfusion of the CNS with propranolol. This approach may be of great value in further delineating a role of the CNS in the cardiovascular actions of propranolol. So far, such studies have only been performed on the basis of bolus injections or short-term infusions of propranolol into the vertebral arteries (Offerhaus and van Zwieten, 1974), the cerebral ventricles (Kelliher and Buckley, 1970; Reid et al., 1974; Sweet and Wenger, 1976) or directly into brain tissue (Garvey and Ram, 1975b).

A clear disadvantage of these methods is that the major part of the dose applied, leaks out of the CNS (chapter 7) and that only acute mechanisms of action of propranolol can be considered with these methods.

Since the acute hemodynamic effects of propranolol differ markedly from the chronic ones (Tarazi and Dustan, 1972; Hansson et al., 1974), conclusions on the involvement of the CNS in the long-term cardiovascular actions of propranolol require chronic selective perfusion methods. 


\section{HEMODYNAMIC EFFECTS OF LONG-TERM SUBCUTANEOUS INFUSION OF PROPRANOLOL IN CONSCIOUS SHR}

\subsection{Introduction}

Upon long-term treatment with propranolol in man blood pressure remains lowered as a consequence of reduced cardiac output. Peripheral resistance increases strongly upon acute administration, but during chronic treatment it returns to control values or just above.

In the previous chapter we described kinetic experiments which were performed with osmotic minipumps. From the results it seems that with the aid of these minipumps a steady-state may be built up and maintained for propranolol in SHR. During s.c. infusion of $1 \mathrm{mg} / \mathrm{kg}$.day plasma levels are around $40 \mathrm{ng} / \mathrm{ml}$.

In the present study we investigated cardiovascular effects of long-term s.c. infusion of propranolol in conscious SHR. Besides effects on blood pressure and heart rate we measured cardiac output in a number of animals. The aim was to find out effective dose and to characterize possible long-term effects.

\subsection{Experimental protocol}

Experiments were started the day after implantation of the catheters. Each day mean arterial pressure (MAP), heart rate $(\mathrm{HR})$ and cardiac index $(\mathrm{Cl})$ were recorded during a 2-hour experimental period. Animals were fully unrestrained in glass experimental cages $(20 \times 20 \times 30 \mathrm{~cm})$. Daily values were obtained as the average of 6 readings during the last $30 \mathrm{~min}$ of measurement.

If MAP was above $125 \mathrm{~mm} \mathrm{Hg}$ on the first two days and hemodynamic values did not differ by more than $10 \%$ on both occasions, rats were used for further experiments and were randomly assigned to one of the experimental groups.

Hemodynamics were monitored for another 5 days. After the last measurement a blood sample was obtained for determination of propranolol levels in a number of animals (see section 2.13.).

Infusions were given using osmotic minipumps (Batch nr. AR-C507 or 02627).

Dl-propranolol was dissolved in $0.9 \% \mathrm{NaCl}$ containing ascorbic acid $(0.1 \mathrm{mg} / \mathrm{ml})$.

The concentration of propranolol was such that animals received $1 \mathrm{mg} / \mathrm{kg}$. day $(\mathrm{N}=8)$ or $5 \mathrm{mg} / \mathrm{kg}$.day $(\mathrm{N}=24)$. Control infusions were given in 27 animals.

From MAP, $\mathrm{HR}$ and $\mathrm{Cl}$ the values of $\mathrm{TPRI}(=\mathrm{MAP} / \mathrm{Cl})$ and $\mathrm{SVI}(=\mathrm{Cl} / \mathrm{HR})$ were calculated.

Data are expressed as means \pm S.E.M. unless stated otherwise. Data from groups were compared using Student's t-test for unpaired observations. 


\subsection{Results}

Basal values for the animals infused with saline, $1 \mathrm{mg} / \mathrm{kg}$.day and $5 \mathrm{mg} / \mathrm{kg}$.day propranolol are shown in table 13.I. During the course of this study saline was infused in 27 animals and $5 \mathrm{mg} / \mathrm{kg}$. day propranolol was given s.c. in 24 SHR.

Eight animals received $1 \mathrm{mg} / \mathrm{kg}$. day propranolol. Mean arterial pressure in the groups ranged from $147 \pm 14 \mathrm{~mm} \mathrm{Hg}$ (means $\pm S . D . ; \mathrm{N}=27$ ) to $155 \pm 11 \mathrm{~mm} \mathrm{Hg}$ $(N=8)$ whereas $H R$ ranged from $385 \pm 25$ beats $/ \mathrm{min}(N=8)$ to $399 \pm 49$ beats $/ \mathrm{min}$ $(\mathrm{N}=24)$ (see table 13.1). Hemodynamic characterization was done in 6 animals infused with saline and 9 animals that received $5 \mathrm{mg} / \mathrm{kg}$.day propranolol. Cardiac index in these respective groups were $35.8 \pm 4.5$ and $40.9 \pm 4.3 \mathrm{ml} / \mathrm{min} .100 \mathrm{~g} \mathrm{b.w}$. Values for TPRI were $4.31 \pm 0.52$ and $3.67 \pm 0.49 \mathrm{~mm} \mathrm{Hg}$. $\mathrm{min} .100 \mathrm{~g} \mathrm{b.w.} / \mathrm{ml}$ and SVI was $0.92 \pm 0.08$ and $0.99 \pm 0.07 \mathrm{ml} / 100 \mathrm{~g} \mathrm{b.w}$. respectively. There were no statistically significant differences between groups.

\section{TABLE 13.I}

Composition of the experimental groups infused s.c. Data are expressed as means \pm S.D.

The number of animals in each group is given in parentheses.

$\begin{array}{llll} & \text { saline } & 1 \mathrm{mg} / \mathrm{kg} . \text { day } & 5 \mathrm{mg} / \mathrm{kg} . \text { day } \\ \text { MAP (mm Hg) } & 147 \pm 14(27) & 155 \pm 11(8) & 147 \pm 9(24) \\ \text { HR (beats/min) } & 397 \pm 55(27) & 385 \pm 25(8) & 399 \pm 49(24) \\ \mathrm{Cl}(\mathrm{ml} / \mathrm{min} .100 \mathrm{~g} \mathrm{b.w.)} & 35.8 \pm 4.5(6) & - & 40.9 \pm 4.3(9) \\ \text { TPRI (mm Hg. min. } 100 \mathrm{~g} \mathrm{b.w./ml)} & 4.31 \pm 0.52(6) & - & 3.67 \pm 0.49(9) \\ \text { SVI (ml/100 g b.w.) } & 0.92 \pm 0.08(6) & - & 0.99 \pm 0.07(9)\end{array}$

\subsubsection{Effects on heart rate}

Fig. 13.1 summarizes effects on HR. In control animals HR was stable, a maximal change of $29 \pm 14$ beats $/ \mathrm{min}$ was seen on the 5 th day of infusion. Infusion of $5 \mathrm{mg} / \mathrm{kg}$. day propranolol invariably decreased HR. On the first day already this bradycardia was significant by $36 \pm 7$ beats/min ( $P<0.001$ as compared to controls).

During the rest of the experimental period the reduction in HR was significant $(P<0.001)$ around 60 beats/min; a maximal effect was seen on the fifth day of infusion (-67 \pm 9 beats $/ \mathrm{min})$. One $\mathrm{mg} / \mathrm{kg}$.day propranolol did not have any significant effects on HR. At first it tended to decrease ( $-19 \pm 9$ beats/min on the first day) but later on it was around or even above base-line values. 


\subsubsection{Effects on blood pressure}

The effects of infusions on MAP are shown in fig. 13.2. During infusion with saline MAP tended to increase slightly. A maximal increase was seen on the 4 th day of infusion ( $4 \pm 4 \mathrm{~mm} \mathrm{Hg}$ ). In the group of SHR infused with $5 \mathrm{mg} / \mathrm{kg}$. day propranolol no significant reduction in MAP was seen on the first day of infusion.

However, from the second day of infusion throughout the further experimental period it was lowered in a highly significant manner. A maximal reduction of MAP was seen on the 4 th day of infusion $(-15 \pm 3 \mathrm{~mm} \mathrm{Hg} ; P<0.001$ as compared to controls). As before for HR, $1 \mathrm{mg} / \mathrm{kg}$.day propranolol did not have any effect on MAP.

\subsubsection{Effects on cardiac index}

The effects of infusion of saline $(\mathrm{N}=6)$ or $5 \mathrm{mg} / \mathrm{kg}$. day propranolol $(\mathrm{N}=9)$ on $\mathrm{Cl}$ are shown in fig. 13.3. Control-infusions did hardly affect $\mathrm{Cl}$. A maximal effect was present on the third day of infusion (+ $1.8 \pm 1.6 \mathrm{ml} / \mathrm{min} .100 \mathrm{~g} \mathrm{~b} . \mathrm{w}$.).

Infusion of propranolol ( $5 \mathrm{mg} / \mathrm{kg}$. day) invariably decreased $\mathrm{Cl}$. A maximal decrease was seen on the second day of infusion $(-9.1 \pm 0.6 \mathrm{ml} / \mathrm{min}$. $100 \mathrm{~g} \mathrm{b.w.:P}<0.001$ as compared to controls). It remained significantly depressed $(P<0.001)$ throughout the experimental period. No tendency of return to control-values could be detected.

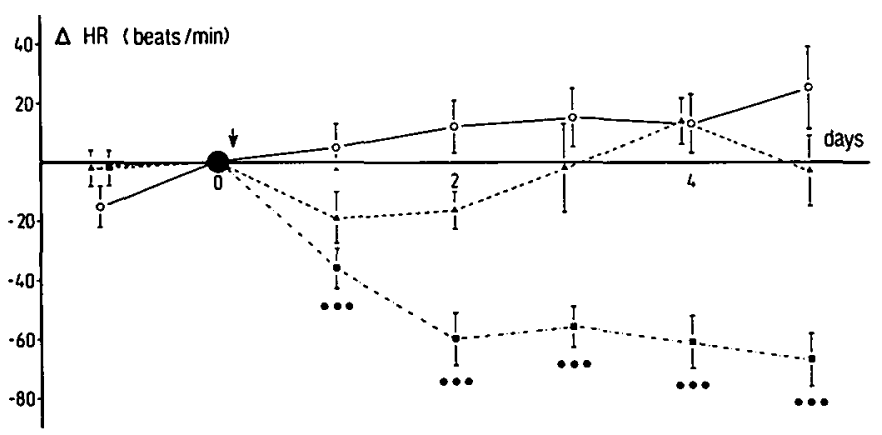

Figure 13.1. Changes (mean \pm S.E.M.) in heart rate during a five day s.c. infusion of saline $(O ; N=27)$, or propranolol in doses of $1 \mathrm{mg} / \mathrm{kg}$.day $(\Delta ; N=8)$ or $5 \mathrm{mg} / \mathrm{kg}$. day ( $\square ; \mathrm{N}=24$ ) in conscious, unrestrained SHR. Osmotic minipumps were implanted after the second measurement (see arrow). Significance in the difference with control rats: $\bullet \bullet: \mathrm{P}<0.001$. 


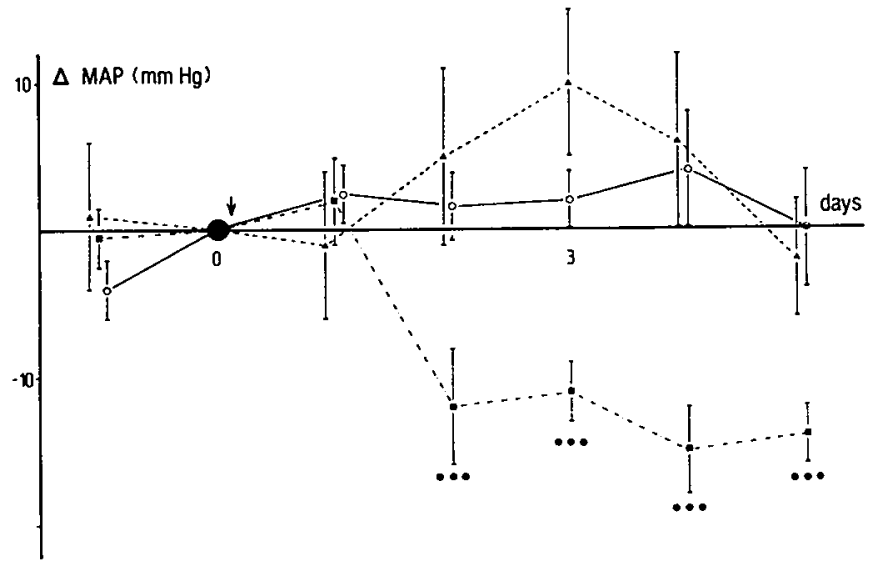

Figure 13.2. Changes in mean arterial pressure in rats infused s.c. with saline, 1 $\mathrm{mg} / \mathrm{kg}$. day or $5 \mathrm{mg} / \mathrm{kg}$.day propranolol. For explanation of symbols: see figure 13.1 . Significance in the difference with controls:

$\bullet: \mathrm{P}<0.05 ; \bullet \bullet: \mathrm{P}<0.01 ; \bullet \bullet: \mathrm{P}<0.001$.

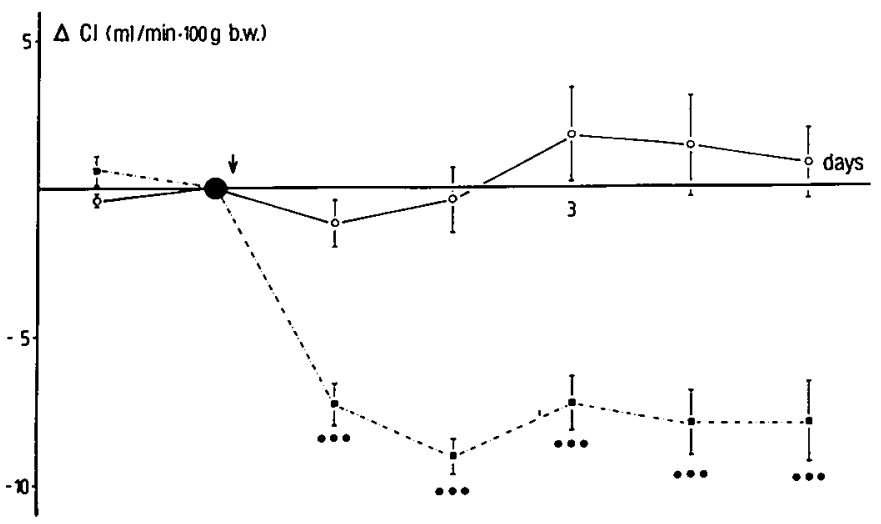

Figure 13.3. Effect (mean \pm S.E.M.) of s.c. infusion of saline $(O ; N=6)$ or $5 \mathrm{mg} / \mathrm{kg}$.day propranolol ( $\mathbf{\square} ; \mathrm{N}=9$ ) on cardiac index in conscious, unrestrained SHR. Significance in the difference with controls:

$\bullet: \mathrm{P}<0.05 ; \bullet: \mathrm{P}<0.01 ; \bullet \bullet: \mathrm{P}<0.001$. 
These are summarized in fig. 13.4. Effects on SVI were small and variable in both groups. In control animals it fluctuated around base-line values, a maximal effect of $+0.05 \pm 0.02 \mathrm{ml} / 100 \mathrm{~g} \mathrm{~b} . w$. being observed on the third day of infusion.

Propranolol tended to decrease SVI, although the effects were significant only on the first three days of infusion when it was reduced maximally by $0.08 \pm 0.02 \mathrm{ml} / 100 \mathrm{~g}$ b.w. ( $P<0.05$ as compared to control animals).

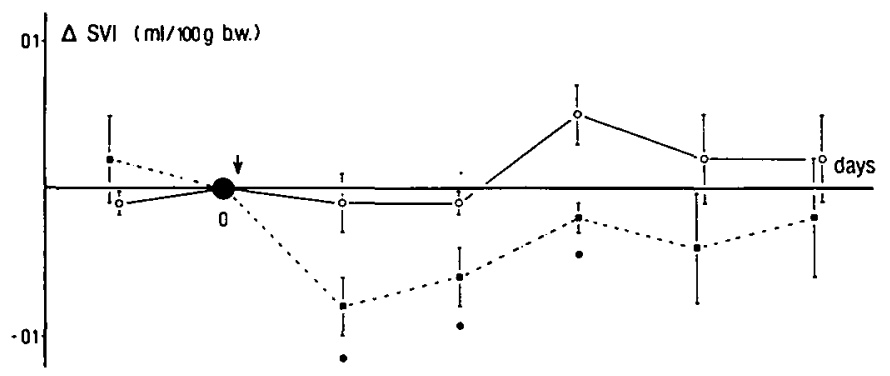

Figure 13.4. Effect (mean \pm S.E.M.) of s.c. infusion of saline or $5 \mathrm{mg} / \mathrm{kg}$.day propranolol on stroke volume index in conscious, unrestrained SHR. For explanation of symbols: see fig. 13.3.

\subsubsection{Effects on total peripheral resistance index}

Effects on TPRI are summarized in fig. 13.5. On the first day of infusion this parameter was increased in both groups, although the effect of $5 \mathrm{mg} / \mathrm{kg}$. day propranolol was greater than that of saline-infusion $(+1.01 \pm 0.21 \mathrm{vs} .+0.27 \pm 0.29 \mathrm{~mm} \mathrm{Hg} . \mathrm{min} .100$ $\mathrm{g}$ b.w./ml; $P$ in the difference $<0.05)$. In control animals TPRI was around base-line values throughout the further experimental period. In contrast, the group infused with propranolol maintained a significantly increased TPRI. It was still elevated by $0.64 \pm$ $0.17 \mathrm{~mm} \mathrm{Hg}$. min. $100 \mathrm{~g} \mathrm{~b} . w . / \mathrm{ml}(\mathrm{P}<0.05$ as compared to control) on the fifth day of infusions.

\subsubsection{Plasma propranolol levels}

Plasma levels of propranolol on the fifth day of infusion were determined in all animals infused with $1 \mathrm{mg} / \mathrm{kg}$.day $(\mathrm{N}=8)$ and in 8 animals which received $5 \mathrm{mg} / \mathrm{kg}$.day. In animals infused with $1 \mathrm{mg} / \mathrm{kg}$. day plasma propranolol was $22 \pm 10 \mathrm{ng} / \mathrm{ml}$ and in those infused with $5 \mathrm{mg} / \mathrm{kg}$. day it was $99 \pm 25 \mathrm{ng} / \mathrm{ml}$. 


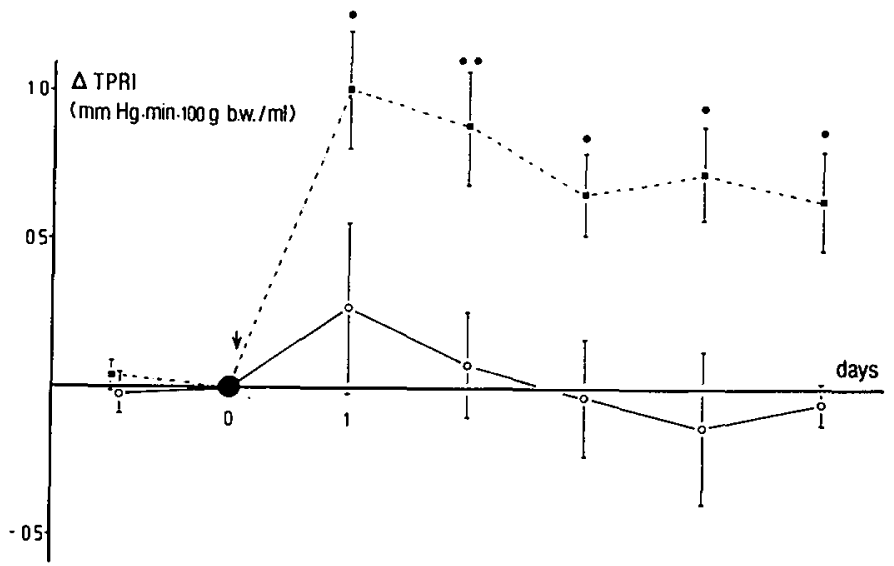

Figure 13.5. Effect (mean \pm S.E.M.) of s.c. infusion of saline or $5 \mathrm{mg} / \mathrm{kg}$.day propranolol on total peripheral resistance index in conscious, unrestrained SHR. For explanation of symbols: see fig. 13.3.

\subsection{Discussion}

The present data indicate that s.c. infusion of saline or $1 \mathrm{mg} / \mathrm{kg}$.day propranolol does not influence blood pressure and heart rate in conscious, unrestrained SHR.

However, a reduction of MAP is seen upon infusion of $5 \mathrm{mg} / \mathrm{kg}$.day, although this reduction is seen only from the second day of infusion on. Other parameters measured in this study had changed already on the first day of infusion.

Infusion of $5 \mathrm{mg} / \mathrm{kg}$ propranolol was associated with a fall in heart rate which was significant on all days. On the second and later days the reduction in heart rate was somewhat larger than on the first day. Stroke volume slightly decreased and this, together with the reduction in heart rate, resulted in a decreased cardiac output throughout the experimental period.

Also this parameter seemed to further decrease after the first day of infusion.

Total peripheral resistance increased during infusion of $5 \mathrm{mg} / \mathrm{kg}$ propranolol.

The increase was highest during the first two days of infusion and diminished thereafter. However, after three days of infusion TPR was constant and was still significantly elevated on the fifth day of infusion. In not one of the animals a net reduction of TPR was observed during infusion of propranolol.

The observation that propranolol lowers blood pressure and heart rate upon longterm administration of the drug in SHR confirms the findings of Sweet et al. (1976) and Kubo et al. (1977). 
The former group gave 5 or $20 \mathrm{mg} / \mathrm{kg}$ in one daily oral dose, whereas Kubo and coworkers gave $64 \mathrm{mg} / \mathrm{kg}$.day propranolol in the drinking water. None of these authors measured plasma propranolol-levels. In our study we found a plasma-propranololconcentration of $\sim 100 \mathrm{ng} / \mathrm{ml}$ upon infusion of $5 \mathrm{mg} / \mathrm{kg}$.day. This level is in the range which may be regarded as therapeutic in man (Esler et al., 1977).

Several authors have not been able to demonstrate a reduction of blood pressure during administration of $5-100 \mathrm{mg} / \mathrm{kg}$.day propranolol in SHR (Forman and Mulrow, 1974; Weiss et al., 1974; Conway et al., 1975). The major difference between these studies and the ones mentioned above (including the present study) is of experimental nature, as was already discussed in section 1.4 of this thesis. It seems that if blood pressure is measured only once at the end of the experiment or with large ( 2 weeks) intervals no effect is seen, or even an increased blood pressure. This suggests that animals are not accustomed to the measuring-procedure, which may interfere with the results.

The pattern of hemodynamic changes during infusion of propranolol in SHR has never been studied before. It does, however, closely resemble changes seen in man during long-term administration, consisting of a long-term reduction of cardiac output, whereas peripheral resistance first increased sharply but later returned to values just above, or at control values (Frohlich et al., 1968; Tarazi and Dustan, 1972; Hansson. 1973). For other beta-blockers, similar results have been obtained. Thus, the reduction in MAP depends upon a reduction of cardiac output with a return of peripheral resistance to a value which is lower than that seen immediately after the administration of the drug. The reason for the adaptation of peripheral resistance probably is a re-setting of the baro-receptors to the lowered blood pressure and cardiac output. In a previous study (chapter 8 ) we showed that the early lack of antihypertensive activity of propranolol results from activation of the baroreflex and it is generally accepted that the reflex resets to the prevailing situation between $6 \mathrm{~h}$ (Purdy and Ashbrook, 1978) and $48 \mathrm{~h}$ (Salgado and Krieger, 1978) after induction of a change in hemodynamics. More striking, however, is the fact that cardiac output remains lowered. A reduction of cardiac output resulting from cardiac failure normally is compensated through an increase in venous pressure and thereby mean circulatory filling pressure. Propranolol does, however, seem to be capable to lower cardiac output for a prolonged period of time and from the results prensented in this chapter it seems that the reduction of blood pressure depends on it.

In conclusion propranolol, infused in a dose of $5 \mathrm{mg} / \mathrm{kg}$ day, lowers blood pressure through a reduction of cardiac output, leaving peripheral resistance somewhat elevated. In the following chapters the mechanisms underlying changes in these parameters will be investigated further, as has been done in the first part of this thesis for acute effects. 


\section{EFFECTS OF LONG-TERM \\ INTRACEREBROVENTRICULAR INFUSION OF \\ PROPRANOLOL ON BLOOD PRESSURE AND HEART RATE IN CONSCIOUS SHR.}

\subsection{Introduction}

A site of action within the central nervous system (CNS) has been attributed to several antihypertensive agents, e.g. clonidine (Kobinger, 1967; Schmitt et al., 1967; Struyker-Boudier et al., 1975), $\alpha$-methyldopa (Henning and van Zwieten, 1968; Henning and Rubenson, 1971; Heise and Kroneberg, 1972; Struyker-Boudier et al., 1975 ) and $\beta$-adrenoceptor blocking drugs like propranolol (Kelliher and Buckley, 1970; Day and Roach, 1974; Reid et al., 1974; Garvey and Ram, 1975b; Sweet and Wenger, 1976). Techniques currently used for the study of a possible site of action of drugs within the CNS of experimental animals include injection via the vertebral artery, administration into the cerebral ventricles or cisterna magna or application to localized, brain structures by micro-injection (van Zwieten, 1975). However, these techniques require large boluses of drugs to be applied to the CNS. Furthermore, once the injection has been given, the drug may leak rapidly out of the brain into the peripheral bloodstream as has recently been shown for propranolol in rabbits (Anderson et al., 1977) and rats (chapter 7 of this thesis) and for prazosin in cats (Roach et al., 1978). This makes interpretation of results extremely difficult.

Moreover, these techniques are only suited for the study of acute effects, since repeated administration is hard to achieve unless restraint or anesthesia is used. For $\beta$-adrenoceptor blocking drugs like propranolol, the long-term cardiovascular effects have been shown to differ from the acute effects (Tarazi and Dustan, 1972; Hansson et al., 1974). Thus, for the analysis of the mechanism of action of this class of drugs, study of the long-term effects seems most important.

In chapter 12 we reported that long-term infusion of low doses of propranolol into the cerebral ventricles of freely moving spontaneously hypertensive rats (SHR), using ALZET osmotic minipumps leads to a steady-state in which the ratio between brain: plasma concentration is approximately one hundred, whereas upon subcutaneous (s.c.) infusion this ratio is near unity. In a separate study (chapter 13) we reported that upon s.c. infusion of $5 \mathrm{mg} / \mathrm{kg}$.day a significant long-term lowering of blood pressure in SHR was found, lower dosages being ineffective. In this study we compared the effects of s.c. and i.c.v. infused propranolol on blood pressure and heart rate in conscious, unrestrained SHR.

\subsection{Experimental protocol}

Animals were implanted with a special catheter in the lateral cerebral ventricle at least one week before the start of experiments (see section 2.7.3.). After surgery they were housed separately. 
One day before the start of measurements a catheter was implanted into the abdominal aorta (see section 2.2.) under light ether anesthesia.

The protocol for measurement of blood pressure and heart rate, as well as dataanalysis, were identical to those in chapter 13.

All i.c.v. infusions were given in an artificial cerebrospinal fluid (aCSF) according to Myers and Mora (1977).

\subsection{Results}

Table 14.I summarizes values for MAP and HR on day 0 for the different experimental groups. HR ranged from $394 \pm 11$ beats $/ \mathrm{min},(N=7)$ to $425 \pm 10$ beats $/ \mathrm{min}(\mathrm{N}=8)$. No statistically significant differences between these values were found. MAP ranged from $142 \pm 6 \mathrm{~mm} \mathrm{Hg}(\mathrm{N}=7)$ to $159 \pm 5 \mathrm{~mm} \mathrm{Hg}(\mathrm{N}=6)$.

Again, there were no statistically significant differences between the groups.

TABLE 14.I Composition of the experimental groups (MAP and HR on day 0).

Group

$0.01 \mathrm{mg} / \mathrm{kg}$. day dl-propranolol

$0.1 \mathrm{mg} / \mathrm{kg}$. day dl-propranolol

$1 \mathrm{mg} / \mathrm{kg}$. day dl-propranolol

$1 \mathrm{mg} / \mathrm{kg}$. day dl-propranolol

$5 \mathrm{mg} / \mathrm{kg}$. day dl-propranolol aCSF

\subsubsection{Effects on heart rate}

The effects of the infusions on HR are shown in fig. 14.1 A and 14.2A. Artificial CSF tended to increase HR slightly during the first 3 days of infusion. This increase was maximal on day $2(25 \pm 15$ beats $/ \mathrm{min}$ ) and the effect had disappeared after day 3 . A somewhat greater increase in HR was seen upon infusion of $0.01 \mathrm{mg} / \mathrm{kg}$. day, reaching a maximum of $50 \pm 17$ beats/min on day 4 . However, this effect was not significantly different from that of aCSF.

Dl-propranolol in doses of $1 \mathrm{mg} / \mathrm{kg}$. day and $5 \mathrm{mg} / \mathrm{kg}$. day decreased HR.

These decreases were significantly different from control changes already on the first day of infusion. Maximal decreases were observed on the 4 th day of infusions in both groups. $1 \mathrm{mg} / \mathrm{kg}$. day decreased HR by $46 \pm 11$ beats $/ \mathrm{min}$ ( $P<0.05$ as compared to controls) and the decrease seen in rats receiving $5 \mathrm{mg} / \mathrm{kg}$. day was $59 \pm 16$ beats $/ \mathrm{min}$ $(\mathrm{P}<0.01$.$) .$

D-propranolol decreased $H R$ slightly with a maximal effect after 4 days of infusion (28 \pm 8 beats $/ \mathrm{min}, \mathrm{P}<0.05$ as compared to controls). 

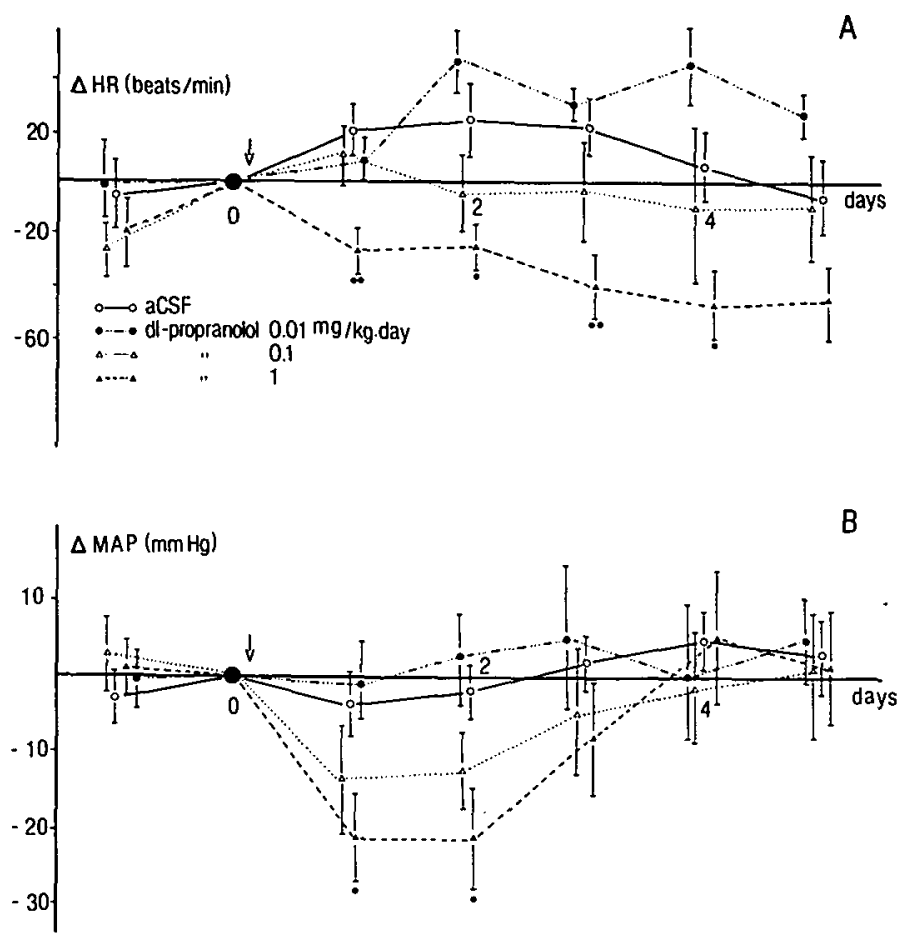

Figure 14.1.: Effects of i.c.v. infusion of aCSF and dl-propranolol in doses of $0.01,0.1$ and $1 \mathrm{mg} / \mathrm{kg}$. day on HR (14.1A) and MAP (14.1B) in conscious unrestrained SHR. Each point represents the mean for 7-11 animals with S.E.M. indicated. Arrows indicate the moment of implantation of the minipumps.

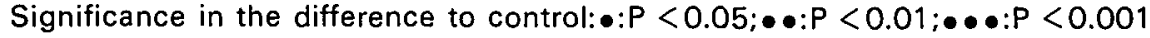

\subsubsection{Effects on blood pressure}

Fig. 14.1 B and 14.2B show the effects of infusion of propranolol on MAP in SHR. Vehicle and $0.01 \mathrm{mg} / \mathrm{kg}$. day caused only minor changes in MAP $(<5 \mathrm{~mm} \mathrm{Hg})$. In rats infused with $0.1 \mathrm{mg} / \mathrm{kg}$. day MAP was decreased slightly, but insignificantly. Infusion of $1 \mathrm{mg} / \mathrm{kg}$. day lowered MAP significantly during the first 2 days of infusion $(-21 \pm 7 \mathrm{~mm} \mathrm{Hg}, \mathrm{P}<0.05$ as compared to controls). The effect disappeared thereafter. Dl-propranolol in a dose of $5 \mathrm{mg} / \mathrm{kg}$. day lowered MAP only with a delay of one day. On the second day of the infusion it was lowered by $26 \pm 5 \mathrm{~mm} \mathrm{Hg}(\mathrm{P}<0.01$ as compared to controls). It remained significantly beneath control-levels throughout the rest of the infusion period. D-propranolol in a dose of $5 \mathrm{mg} / \mathrm{kg}$. day i.c.v. had, except for minor fluctuations, no effect on MAP. 


\subsubsection{Plasma propranolol levels}

Plasma propranolol levels are summarized in table 14.11 . In rats receiving 0.01 or 0.1 $\mathrm{mg} / \mathrm{kg}$.day plasma propranolol-levels, as determined after the last measurement, were below detection limits. Infusion of $1 \mathrm{mg} / \mathrm{kg}$. day dl-propranolol gave rise to plasma-levels of $38 \pm 5 \mathrm{ng} / \mathrm{ml}$. Five $\mathrm{mg} / \mathrm{kg}$. day dl-propranolol and d-propranolol resulted in plasma-levels of resp. $132 \pm 43 \mathrm{ng} / \mathrm{ml}$ and $84 \pm 13 \mathrm{ng} / \mathrm{ml}$.
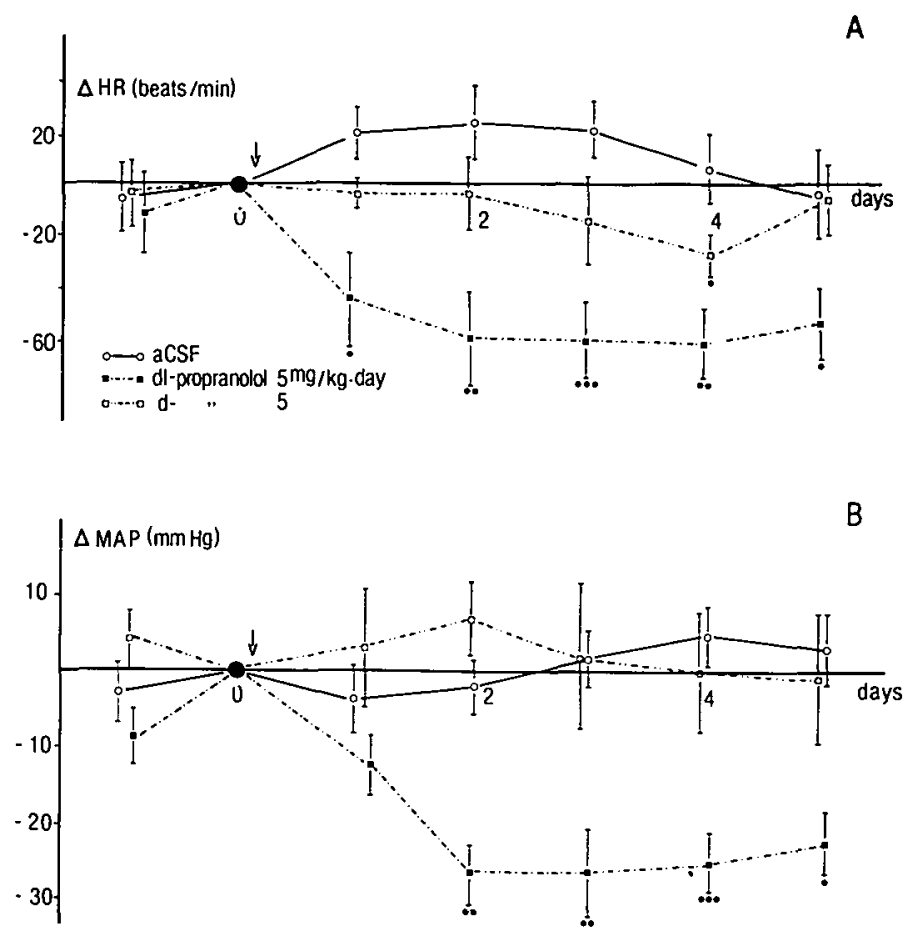

Figure 14.2.: Effects of i.c.v. infusion of aCSF, $5 \mathrm{mg} / \mathrm{kg}$. day dl-propranolol and 5 $\mathrm{mg} / \mathrm{kg}$. day d-propranolol on HR (14.2A) and MAP (14.2B) in conscious unrestrained SHR. Each point represents the mean for $6-8$ animals with S.E.M. indicated. Arrows indicate the moment of implantation of the minipumps.

Significance in the difference to control: $\bullet: P<0.05 ; \bullet \bullet: P<0.01 ; \bullet \bullet \bullet: P<0.001$ 


\subsection{Discussion}

In the present study we used long-term low-dose infusion of propranolol into the cerebral ventricles of conscious SHR to investigate whether the chronic antihypertensive effect we reported in chapter 13 for propranolol in this species derives from an action within the CNS. Upon i.c.v. infusion of $\mathrm{dl}$-propranolol in a dose of $5 \mathrm{mg} / \mathrm{kg}$. day $H R$ was lowered already on the first day and it remained depressed throughout the whole five day experimental period. This dose lowered MAP from the second day on. Also this parameter remained significantly reduced throughout the experimental period. Dl-propranolol in a dose of $1 \mathrm{mg} / \mathrm{kg}$. day lowered HR significantly during the first 4 days of infusion. On the 5 th day this effect was no longer present. This dose of dl-propranolol when given i.c.v. lowered MAP only on the first 2 days of the infusion. Thereafter MAP was back at control levels. Infusion of 0.01 or $0.1 \mathrm{mg} / \mathrm{kg}$. day did not cause any cardiovascular effects. Thus, $5 \mathrm{mg} / \mathrm{kg}$. day is needed to induce a long-term antihypertensive effect in conscious SHR upon i.c.v. infusion, lower doses only cause transient effects or none at all.

In chapter 13 we showed that for a blood pressure-lowering effect of s.c. infused dlpropranolol $5 \mathrm{mg} / \mathrm{kg}$. day was effective. When infused by that route, $5 \mathrm{mg} / \mathrm{kg}$. day significantly reduced MAP by $16 \pm 3 \mathrm{~mm} \mathrm{Hg}$ and HR by $68 \pm 13 \mathrm{beats} / \mathrm{min}$. The timecourse of the effects was similar to that reported in this study for $5 \mathrm{mg} / \mathrm{kg}$. day i.c.v. Lower doses, when infused s.c., had no effects on HR and MAP. Thus, to induce comparable effects on MAP both routes of administration require the same dose of propranolol (5 mg/kg . day) to be infused. Bradycardia, however, is observed upon i.c.v. infusion of $1 \mathrm{mg} / \mathrm{kg}$. day, whereas upon s.c. administration this dose was ineffective (chapter 13).

TABLE 14.II Plasma levels of propranolol on day 5 of the infusions.

\section{Group}

$0.01 \mathrm{mg} / \mathrm{kg}$. day dl-propranolol

$0.1 \mathrm{mg} / \mathrm{kg}$. day dl-propranolol

$1 \mathrm{mg} / \mathrm{kg}$. day dl-propranolol

$5 \mathrm{mg} / \mathrm{kg}$. day dl-propranolol

$5 \mathrm{mg} / \mathrm{kg}$. day d-propranolol level ( $\mathrm{ng} / \mathrm{ml}$ )

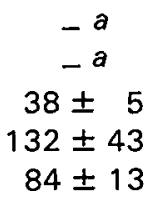

a Below detection limits.

We have previously shown, that the distribution of dl-propranolol in SHR is different for the two routes of administration (chapter 12). As reported there, plasma levels did not differ for s.c. $(39 \pm 12 \mathrm{ng} / \mathrm{ml})$ and i.c.v. $(39 \pm 8 \mathrm{ng} / \mathrm{ml})$ infused dl-propranolol in a dose of $1 \mathrm{mg} / \mathrm{kg}$. day. The plasma levels found in this study for 1 and $5 \mathrm{mg} / \mathrm{kg}$. day i.c.v. were resp. $38 \pm 5 \mathrm{ng} / \mathrm{ml}$ and $132 \pm 43 \mathrm{ng} / \mathrm{ml}$. These values are comparable to the values of $22 \pm 10 \mathrm{ng} / \mathrm{ml}$ and $99 \pm 25 \mathrm{ng} / \mathrm{ml}$ for s.c. infusion of resp. 1 and $5 \mathrm{mg} / \mathrm{kg}$ . day (chapter 13). However, the ratio between CNS concentrations and plasma concentrations are approximately 100 for i.c.v. infused dl-propranolol, whereas upon s.c. infusion this ratio is near unity. Thus, if the antihypertensive effect of dl- 
propranolol in conscious SHR would be caused by an action within the CNS, a dose of 0.01 to $0.1 \mathrm{mg} / \mathrm{kg}$. day when infused i.c.v. should have been effective as compared to the dose of $5 \mathrm{mg} / \mathrm{kg}$. day that lowers MAP upon s.c. infusion. The results presented here do, however, not contain any evidence for this, suggesting that there is a peripheral rather than central site of antihypertensive action for dl-propranolol in conscious SHR. A contribution of the CNS to the bradycardia observed after infusion of dl-propranolol cannot be ruied out, because of the lower dose required for this effect upon i.c.v. infusion.

For the study of possible CNS effects of propranolol until now only high-dose infusions or bolus injections into the vertebral arteries or the cerebral ventricles have been used. Results from such studies are difficult to interpret since rapid and massive leakage of propranolol from the brain to the peripheral bloodstream has been shown to occur upon vertebral artery administration in cats (Offerhaus and van Zwieten, 1974) as well as after i.c.v. injection in rabbits (Anderson et al., 1977) and SHR (chapter 7).

Another disadvantage of the above-mentioned methods is, that after bolus injections enormous CNS-concentrations will be reached and besides beta-adrenoceptor blockade, a-specific effects are to be expected. In fact, Bousquet et al. (1978) concluded that in anesthetized cats the blood pressure-lowering activity of betaadrenoceptor blocking drugs, applied to the surface of the brainstem, depended upon their local anesthetic potency, rather, than their beta blocking properties. Several other authors have shown that different modes of acute central application of relatively high doses result in a-specific effects in anesthetized cats (Kelliher and Buckley, 1970; Offerhaus and van Zwieten, 1974; Klevans et al., 1976; Bousquet et al., 1978), rabbits (Myers et al.,1975b) and in conscious SHR (Sweet and Wenger, 1976) since d-propranolol in their animals lowered blood pressure too. This enantiomer is practically devoid of beta-adrenoceptor blocking properties (Howe and Shanks, 1966). Moreover, this isomer does not lower blood pressure in hypertensive patients (Waal-Manning, 1970; Rahn et al., 1974). In our experiments $5 \mathrm{mg} / \mathrm{kg}$. day d-propranolol did not cause effects on MAP, indicating that upon continuous lowdose infusion a-specific effects do not occur. Plasma levels after i.c.v. infusion of $d-$ propranolol were somewhat lower than those after infusion of the same dose $(5$ $\mathrm{mg} / \mathrm{kg}$. day) of the racemate. This confirms findings in man (George et al., 1972), monkeys (Nies et al., 1973) and rabbits (Myers et al., 1975b) and is probably caused by the fact that dl-propranolol by lowering cardiac output (chapter 13), reduces liver blood-flow, thus limiting its own elimination. Since d-propranolol is not a betaadrenoceptor blocking drug it will not cause these effects and will be eliminated faster. In our experiments higher doses of d-propranolol were not infused, because of the limited solubility of the drug and the fixed pumping rate of the minipumps.

DI-propranolol when infused either s.c. (chapter 13) or i.c.v. in a dose of $5 \mathrm{mg} / \mathrm{kg}$. day reduces blood pressure with a delay of 1 day, whereas bradycardic effects can be observed already on the first day of infusion. In man, a delay for the antihypertensive effects of propranolol has also been reported. Although there is an immediate reduction of cardiac output, a concomitant increase in peripheral resistance prevents 
blood pressure from falling during the first hours to days in man (Tarazi and Dustan, 1972; Hansson et al, 1974) and SHR (chapter 13).

Thus, any immediate effects on blood pressure as have been reported in previous studies (Offerhaus and van Zwieten, 1974; Reid et al., 1974; Day and Roach, 1975; Garvey and Ram, 1975b; Klevans et al., 1976) may have been caused by a different mechanism of action than the long-term effect observed in daily medical practice.

It may be concluded from the present study, that in conscious SHR, propranolol does not lower blood pressure through a direct action within the CNS. Earlier conclusions on such a central effect may have been artifacts of the experimental techniques used by others and have probably resulted from a-specific actions of the drug. Attention should be paid to peripheral actions like reduced cardiac output and possible intrarenal effects to explain the long-term antihypertensive actions of the drug. 


\section{EFFECT OF LONG-TERM INFUSION OF PROPRANOLOL ON PLASMA RENIN ACTIVITY IN CONSCIOUS, UNRESTRAINED SHR.}

\subsection{Introduction}

As was discussed in section 1.3 of this thesis a reduction of plasma renin activity (PRA) has been proposed as a mechanism through which beta-adrenoceptor blocking drugs lower blood pressure. Evidence from studies in man both in favour and against that hypothesis, have been discussed.

In rats the effect of beta-adrenoceptor blocking drugs on PRA is not very well documented. Depending upon the model of hypertension, beta-adrenoceptor blockade has been shown to have no effect or lower PRA in rats. It should, however, be noted that most studies have been done in DOCA-saline and renovascular hypertensive rats, two types of hypertension in which PRA is augmented.

The present study was done to investigate whether effects of propranolol on PRA possibly contribute to the antihypertensive action of long-term low-dose propranolol, as reported in chapter 13 of this thesis.

\subsection{Experimental protocol}

Animals were equipped with a catheter in the abdominal aorta. Experiments started one day after surgery.

Each day, on the same time (between 1 and 3 p.m.) to avoid interference of circadian rhythm with the experiments, rats were placed in experimental cages and the catheter was connected to a pressure transducer. Blood pressure and heart rate were measured during a 1-hour period, the averages of which were taken for evaluation.

If MAP was above $125 \mathrm{~mm} \mathrm{Hg}$ on the first two days and MAP and HR did not differ by more than $10 \%$, a blood sample was taken at the end of the second measuringsession. Blood was drawn via the catheter-system used for blood pressure measurement, without disturbing the animals. One $\mathrm{ml}$ of blood was taken and immediately transferred to ice-cooled glass tubes containing $1.5 \mathrm{mg} \mathrm{Na}{ }_{2}$ EDTA and $0.175 \mathrm{mg}$ o-phenantroline. Blood was centrifuged and plasma thus obtained was stored at $-25^{\circ} \mathrm{C}$ until assayed.

After sampling of blood animals were implanted s.c. with an osmotic minipump containing either saline or propranolol in a concentration such that animals received $5 \mathrm{mg} / \mathrm{kg}$.day. Assignment to groups was at random.

Blood pressure and heart rate were measured for five more days, whereas blood samples were taken 1 and 4 days after the implantation of pumps.

Data are expressed as mean \pm S.E.M., unless indicated otherwise. Effects in the two groups were compared using Student's t-test for unpaired observations. 


\subsection{Results}

The effects of infusions on MAP and HR have been included in the groups in chapter 13 of this thesis.

Plasma renin activity (PRA) on the day before the infusion-start was indentical in the two groups. In the saline-group it was $8.6 \pm 4.6 \mathrm{ng} \mathrm{Al} / \mathrm{ml}$. $\mathrm{h}$ (mean $\pm \mathrm{SD} ; \mathrm{N}=11$ ) whereas it was $7.7 \pm 3.2 \mathrm{ng} \mathrm{Al} / \mathrm{ml}$. $\mathrm{h}$ (mean $\pm \mathrm{SD} ; \mathrm{N}=7$ ) in the group infused with propranolol.

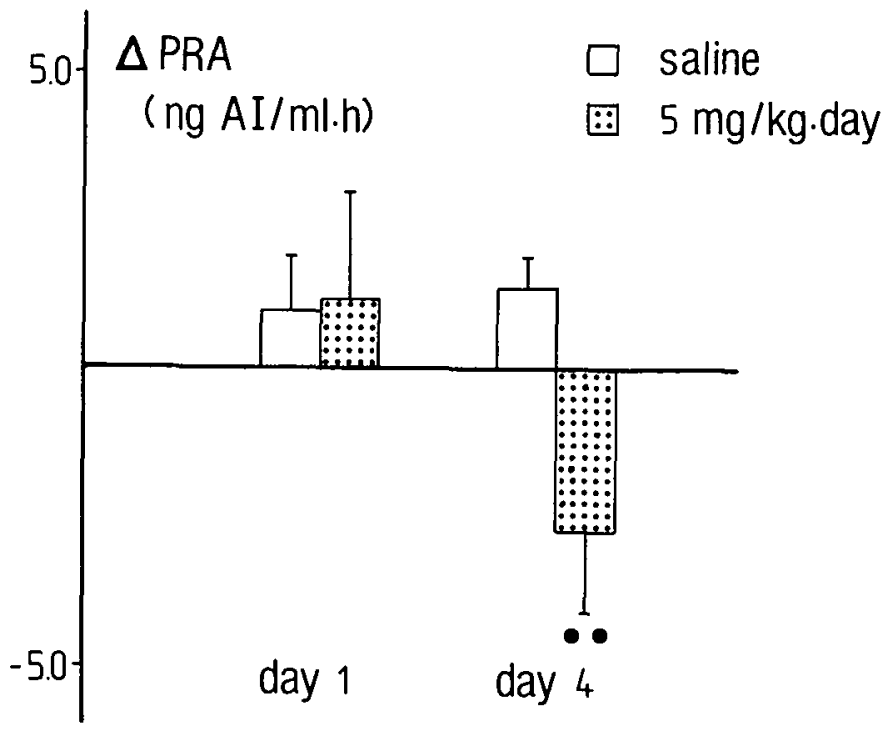

Figure 15.1. Change (mean \pm S.E.M.) in PRA during a 5-day s.c. infusion of saline $(\mathrm{N}=11$ ) or $5 \mathrm{mg} / \mathrm{kg}$.day propranolol $(\mathrm{N}=7)$ in conscious, unrestrained SHR.

Significance in the difference: $\bullet: P<0.01$.

Effects of infusions on PRA are shown in fig. 15.1. In both groups PRA tended to increase on the first day of infusion. This increase was identical in both groups $1+1.0$ $\pm 0.9 \mathrm{ng} \mathrm{Al} / \mathrm{ml}$. h resp. $+1.2 \pm 1.8 \mathrm{ng} \mathrm{Al} / \mathrm{ml}$. $\mathrm{h}$ in saline- and propranolol-infused animals). This increase was still present after 4 days of infusion in the saline-group $1+$ $1.4 \pm 0.5 \mathrm{ng} \mathrm{Al} / \mathrm{ml}$. $\mathrm{h}$ ), whereas by that time propranolol had caused a net decrease in PRA (-2.7 $\pm 1.4 \mathrm{ng} \mathrm{Al} / \mathrm{ml}$. h). The difference between groups was statistically significant $(P<0.01)$. 


\subsection{Discussion}

Propranolol infused in a dose of $5 \mathrm{mg} / \mathrm{kg}$. day in conscious unrestrained SHR causes a a decrease in blood pressure and heart rate. In the present study it was investigated whether a reduction of PRA contributes to the effect on blood pressure.

PRA was increased slightly in both groups on the first day of infusion and increased further in saline-infused animals. The reason for this is not clear.

Food- and water-intake appeared to be normal, although it was not quantitated. Possibly repeated blood sampling increases PRA.

Propranolol caused a significant net decrease of PRA on the fourth day of infusion. These results are in conflict with those of Forman and Mulrow (1974) who treated SHR with propranolol in doses between 2 and $18 \mathrm{mg} / \mathrm{kg}$ daily for 16 days. Part of the propranolol was given intramuscularly divided over two doses and the other part was administered via the drinking water. In their study, animals were killed by decapitation 1 or 16 hours after the last injection and blood collected from the trunk. No effects of propranolol on PRA whatsoever were found. These authors, who measured blood pressure and heart rate once weekly by the tail-cuff method, also found no reduction of blood pressure, whereas heart rate was reduced one hour but not sixteen hours after injections of propranolol. The latter indicates that betaadrenoceptors were not blocked consistently, which might interfere with their observations. Furthermore, the stressful decapitation may have caused the discrepancy between their results and ours.

In section 1.3 of this thesis it was discussed that, although the significance of this effect for the antihypertensive action may be doubted, most beta-adrenoceptor blocking agents reduce PRA in man. Exceptions to this are drugs like pindolol (Stokes et al., 1974), practolol (Esler, 1974), alprenolol (Gordon, 1976) and possibly atenolol (Amery et al., 1974). The latter is a beta-adrenoceptor blocking drug with greater affinity for beta 1 -than for beta ${ }_{2}$-adrenoceptors whereas the others possess intrinsic sympathomimetic activity (see table 1.l). Thus, these properties may interfere with the reduction of PRA.

In experimental hypertension in rats the reports have been conflicting.

Propranolol reduced plasma renin activity in DOCA/saline rats (Caputi et al., 1978) and in two-kidney renovascular hypertensive rats (Niarchos et al., 1977; Gulati and Liard, 1979), although the latter observation could not be confirmed by others (Leenen and Ackerman, 1976). Plasma renin concentration does not seem to be affected in two-kidney (Fernandes et al., 1976; 1977; Ho Pak et al., 1977) and onekidney renovascular hypertension (Ho Pak et al., 1977). It should be noted that both in DOCA/saline hypertension and two-kidney renovascular hypertension plasma renin levels are strongly elevated and probably contribute to the development of hypertension. However, no relationship seems to exist between antihypertensive effects (if present) and effects on PRA in the above-cited studies. This suggests that, as in man, reduction of PRA is not crucial for the antihypertensive activity of propranolol. 
The absence of a reduction of PRA on the first day of infusion probably results from the same phenomenon that increases TPR, i.e. the increase in sympathetic nerve activity. This increased nerve activity, which normally may be expected to increase PRA is blocked in a competitive way by propranolol. The net result is an unchanged PRA.

Our experiments do not exclude an involvement of PRA in the antihypertensive effect of propranolol in SHR. In fact, on the first day neither MAP nor PRA were reduced, whereas both were below control on the fourth day of infusion. The delayed antihypertensive effect was characterized hemodynamically as a result from a slight further decrease of cardiac output on day 4 as compared to day 1 and also a diminished increase of TPR on day 4 , again as compared to day 1 of infusions. Thus, possibly the reduction of PRA contributes to this latter effect on TPR, although it should be noted that resistance remains increased, so reduction of PRA does not cause a net decrease of peripheral resistance.

In conclusion, PRA may play a role in the re-adjustment of peripheral resistance which occurs during long-term infusion of propranolol in conscious, unrestrained SHR. 


\section{EFFECT OF LONG-TERM INFUSION OF PROPRANOLOL ON PLASMA VOLUME IN CONSCIOUS, UNRESTRAINED SHR.}

\subsection{Introduction}

In chapter 10 of this thesis an acute injection of propranolol in conscious SHR was shown to result in a transient reduction of plasma volume. It was probably caused by a peak-diuresis that was shown to occur following an acute injection of $5 \mathrm{mg} / \mathrm{kg}$ propranolol.

Long-term reduction of cardiac output an blood pressure will be compensated through an increase in filling of the vascular system, as is seen in cardiac failure. As was discussed in section 1.3 of this thesis, this does not occur in man during longterm treatment with beta-adrenoceptor blocking drugs. In this study the effect of long-term infusion of an antihypertensive dose of propranolol on plasma volume of SHR was investigated.

\subsection{Experimental protocol}

Rats were implanted with catheters in the right jugular vein and the abdominal aorta via the left femoral artery to allow repeated injection resp. sampling of blood. After that they were housed separately. Two days were allowed for recovery, before plasma volume was determined for the first time. Thereafter, rats were implanted with an osmotic minipump containing either saline or propranolol in a concentration such, that the animals received $5 \mathrm{mg} / \mathrm{kg}$. day. Plasma volume was again determined on the day after the start of the infusion and 4 days after the start of the infusion.

Plasma volume was determined according to the methods described in section 2.5 by injection of radio-iodinated albumin. For injections on day 1 and day 4 after the start of infusions proper corrections for residual radio-activity from earlier injections were made by taking blood samples before injection of a new tracer.

Plasma volume was not normalized for body weight, because for rats which weigh more than 200 grams (as used in this study) no relation exists between plasma volume and body weight (Evenwel et al., to be published).

Results are expressed as means \pm S.E.M., unless indicated otherwise. Differences between control and propranolol-infused animals were compared using Student's t-test for unpaired observations. 


\subsection{Results}

The composition of the groups with regard to their body weights and plasma volumes on the day before the start of infusion is shown in table 16.I. Saline rats weighed 263 $\pm 19 \mathrm{~g}$ (mean \pm S.D. 8 rats) vs. $256 \pm 22 \mathrm{~g}(\mathrm{~N}=9)$ for propranolol-infused rats. Also plasma volumes were identical $(9.6 \pm 0.9 \mathrm{ml}$ and $9.5 \pm 0.8 \mathrm{ml}$ resp.).

Table 16.I Composition of the groups used for serial determinations of plasma volume.

$\begin{array}{llll} & \text { N } & \text { Body weight }(\mathrm{g}) & \text { Plasma volume }(\mathrm{ml}) \\ \text { controls } & 8 & 263 \pm 19 & 9.6 \pm 0.9 \\ \text { propranolol-infused } & 9 & 256 \pm 22 & 9.5 \pm 0.8\end{array}$

Data represent means \pm S.D.

Effects of control- and propranolol-infusions are shown in figure 16.1. On the first day of infusion no change in plasma volume had occurred in either of the groups. Both showed a small $(0.1-0.2 \mathrm{ml})$ reduction of plasma volume, which was not significant. On the fourth day of infusion (i.e. at the third occasion where it was measured) plasma volume was slightly increased in both groups to an equal extent $(+1.4 \pm 0.3 \mathrm{ml}$ in control rats vs. $+1.3 \pm 0.2 \mathrm{ml}$ in propranolol-infused rats).

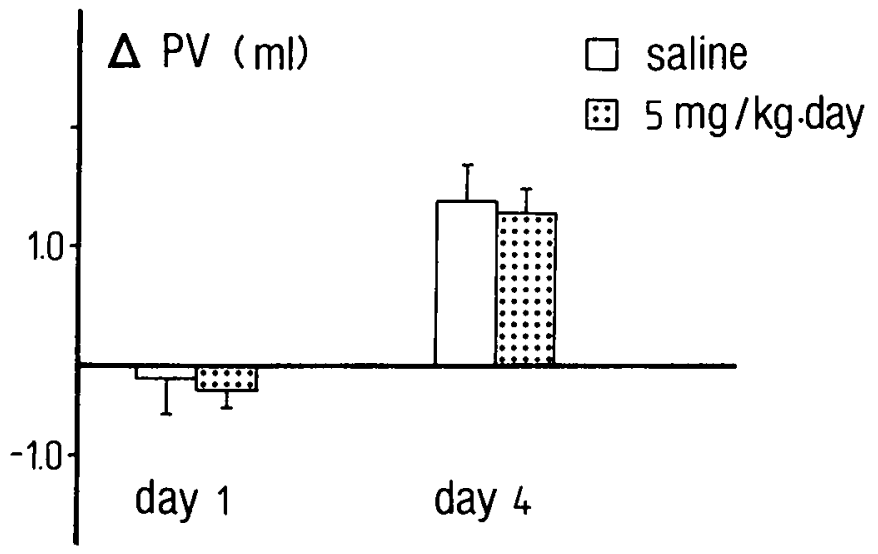

Figure 16.1. Changes (mean \pm S.E.M.) in plasma volume during a four-day s.c. infusion of saline $(\mathrm{N}=8)$ or $5 \mathrm{mg} / \mathrm{kg}$.day propranolol $(\mathrm{N}=9)$ in conscious, unrestrained SHR. 


\subsection{Discussion}

The present results do not indicate any long-term effect of propranolol on plasma volume (PV) in SHR. Although PV had increased on day 4 of the infusion this increase was also seen in the control group and may result from a relative underestimation of this parameter on the first days. This may in turn result from surgery.

Ohter authors who have studied the behaviour of plasma volume in spontaneously hypertensive rats during chronic administration of propranolol have reported an increased (Pessina et al., 1976) or decreased (Lee, 1975) plasma volume.

The daily doses used were $5 \mathrm{mg} / \mathrm{kg}$ and $300 \mathrm{mg} / \mathrm{kg}$ resp. in the two studies and treatment lasted for 10 days in the first study, whereas in the latter study it was not specified. The difference in results may be explained by the fact that two different strains of genetically hypertensive rats were used.

In man, long-term treatment with propranolol has been shown to reduce plasma volume in one study (Tarazi et al., 1971). In conflict with this are studies which do not report any change in plasma volume during propranolol-therapy (Sederberg-Olsen and Ibsen, 1972; Ibsen and Sederberg-OIsen, 1973; Parving and Gyntelberg, 1973; Weidmann et al., 1976). Sederberg-Olsen and Ibsen (1972) did find a small increase in extracellular fluid volume. This observation was confirmed for metoprolol (Rasmussen and Rasmussen, 1979). Interestingly, these latter authors detected a group of patients which did not respond to beta-adrenoceptor blockade and found a five times higher increase in extracellular fluid volume in non-responding patients as compared to responders. Furthermore, addition of a diuretic to metoprolol did reduce both blood pressure and extracellular fluid volume in non-responding patients. Also for atenolol non-responding patients were characterized as patients developing circulatory congestion (Reybrouck et al., 1979). In this study the lack of response was found to be assiociated with a strongly increased stroke volume which compensated the reduction of cardiac frequency.

Normally, all antihypertensive agents may be expected to cause an increase in extracellular fluid volume as a consequence of reduced renal perfusion pressure (Finnerty, 1971). The only two classes of antihypertensives which do not increase plasma volume are diuretics and beta-adrenoceptor blocking drugs. For diuretics this undoubtedly results from their intra-renal action.

For beta-adrenoceptor blocking drugs the reason for the lack of increase in plasma volume is not known. In the following chapter this will be discussed in relation to intra-renal effects as shown in chapter 11. 


\section{GENERAL DISCUSSION AND CONCLUSIONS}

\subsection{Pharmacokinetics of propranolol in SHR.}

In this thesis the kinetics of distribution and elimination of propranolol in SHR were studied both after a single subcutaneous (s.c.) and intracerebroventricular injection as well as after long-term infusion via either of these routes. Several observations deserve further attention:

1. During long-term s.c. infusion organ levels of propranolol are equal to those in plasma (with the exception of levels in lungs).

2. Following a single s.c. injection of propranolol, the drug reaches extremely high levels in all tissues, again as compared to plasma.

3. A single i.c.v. injection of propranolol results in plasma levels comparable to those after s.c. injection of the same amount, indicating rapid and massive leakage of propranolol to the peripheral blood-stream.

4. Upon long-term i.c.v. infusion, propranolol reaches brain levels which are approximately 100 -fold higher than those in plasma.

The finding that following s.c. infusion of propranolol the level in plasma (central compartment) and tissues (second compartment) are equal (chapter 12), may be expected on the basis of a simple two-compartment open model, assuming that binding in either of the compartments is of equal magnitude (see appendix 1). An exception to the above mentioned observation were lungs, and interestingly, these have been shown to contain active binding-sites (Dollery and Junod, 1976). Plasma protein-binding for propranolol was $92 \%$ at plasma levels reached during infusion of $1 \mathrm{mg} / \mathrm{kg}$. day. Thus, tissue-binding should be of the same magnitude, because in steady-state the free concentrations in all compartments must be equal.

Following a single subcutaneous injection of propranolol, extremely high tissuelevels are reached, as compared to those in plasma (chapter 8 ). Normally, again on the basis of a two-compartment open model, it is to be expected that concentrations in the second compartment are higher than those in the central compartment once distribution is complete. However, the maximal level reached in the second compartment will not become higher than the maximal level ever reached in the central compartment. Only a high binding in the second compartment, as compared to that in the central compartment, may explain that phenomenon. Binding to tissues was shown not to occur, at least not to a degree higher than that in plasma following long-term s.c. infusion. However, it was shown that at plasma levels higher than 100 $\mathrm{ng} / \mathrm{ml}$ plasma protein-binding diminishes progressively (chapter 3 ). Assuming that saturation of tissue-binding does not occur, this may explain the apparent discrepancy between results from acute and long-term studies.

A theoretical implication of the saturation of plasma protein-binding would be, that the distribution volume of the drug must increase with dose, if uptake into plasma is rapid enough to saturate the binding. This was in fact shown following i.v. injection in rats (Schneck et al., 1977). 
A single i.c.v. injection of $1 \mathrm{mg} / \mathrm{kg}$ propranolol results in a plasma concentration-time curve which is comparable to that observed after s.c. administration of the same dose (chapter 7). From the reasoning above this is to be expected, since propranolol does not bind excessively to brain tissue. With regard to diffusion into plasma, the depot applied to the brain behaves the same as that under the skin, if administered s.c.

This is also illustrated by the fact that during i.c.v. infusion of propranolol plasma levels are identical to those following s.c. infusion. Brain levels are, however, much higher than plasma levels, during i.c.v. infusion. Mathematically this can be described as follows.

In a two-compartment open model where infusion is into the second compartment and elimination takes place only from the central compartment, processes may essentially be described by two differential equations:

$$
\begin{aligned}
& V_{I I} \cdot \frac{d C_{l I}}{d t}=Q-K_{21} C_{1 I}+K_{12} C_{l} \\
& V_{l} \cdot \frac{d C_{l}}{d t}=-K_{12} C_{l}+K_{21} c_{I I}-K_{e l} c_{l}
\end{aligned}
$$

where

$V_{1}, V_{11}=$ volume of the central resp. second compartment.

$C_{1}, C_{\|}=$drug concentration in the central resp. second compartment.

$\mathrm{Q}=$ infusion rate.

$\mathrm{K}_{12}, \mathrm{~K}_{21}=$ clearance from the central to the second compartment and vice versa $\left(K_{12}=K_{21}\right.$, by definition).

$\mathrm{K}_{\mathrm{el}}=$ total body clearance.

In a steady-state $\frac{d C_{\mid}}{d t}$ and $\frac{d C_{\mid 1}}{d t}$

are zero and $Q=C_{l}$. $K_{e l}$ by definition.

The differential equations then derive to 


$$
c_{I I}=\frac{K_{21}+K_{e l}}{K_{21} \cdot K_{e l}} \cdot \mathrm{Q}
$$

and

$$
\frac{c_{11}}{c_{1}}=\frac{k_{21}+k_{e l}}{k_{21}}
$$

Thus, the ratio between the concentrations in the second compartment and the central compartment depends upon the ratio between $\mathrm{K}_{\mathrm{el}}$ and $\mathrm{K}_{21}$, if $\mathrm{K}_{21}$ is small as compared to $\mathrm{K}_{\mathrm{el}}$. For propranolol $\mathrm{K}_{\mathrm{el}}$ was shown to be approximately equal to liver blood-flow. When infused into the brain, $\mathrm{K}_{21}$ cannot be greater than blood-flow through the brain. From these considerations, brain levels may be expected to be much higher than plasma levels, upon i.c.v. infusion, since liver blood-flow is much higher than brain blood-flow.

The pharmacokinetics of propranolol in SHR will be described quantitatively in computer-simulations in appendix I. There, a model based upon physiological parameters will be presented.

\subsection{Acute hemodynamic effects of propranolol in SHR.}

This thesis was divided into two parts, the first one dealing with hemodynamic effects of propranolol in SHR following a single injection, whereas the second part was devoted to the study of long-term effects. Because the dynamics of the effects were different (cf. chapters 6 and 13), the acute and long-term effects will be discussed separately, before presenting an integrated hypothesis on propranolol's mode of antihypertensive action.

Propranolol, when given in a single s.c. dose of $1-5 \mathrm{mg} / \mathrm{kg}$ in SHR, reduces blood pressure (chapter 5). The time-course of this effect is comparable to that observed in man after administration of propranolol (Stumpe et al., 1976; Maling et al., 1979; Conway, 1980) and atenolol (Fitzgerald et al., 1978).

MAP is reduced with a delay of $2-4$ hours. The antihypertensive effect observed in our study is in conflict with observations of other authors (see table 1.V.).

Only Roba et al. (1972) and Sweet and Wenger (1976) were also able to detect the antihypertensive effect of propranolol in SHR although the latter authors found it only 


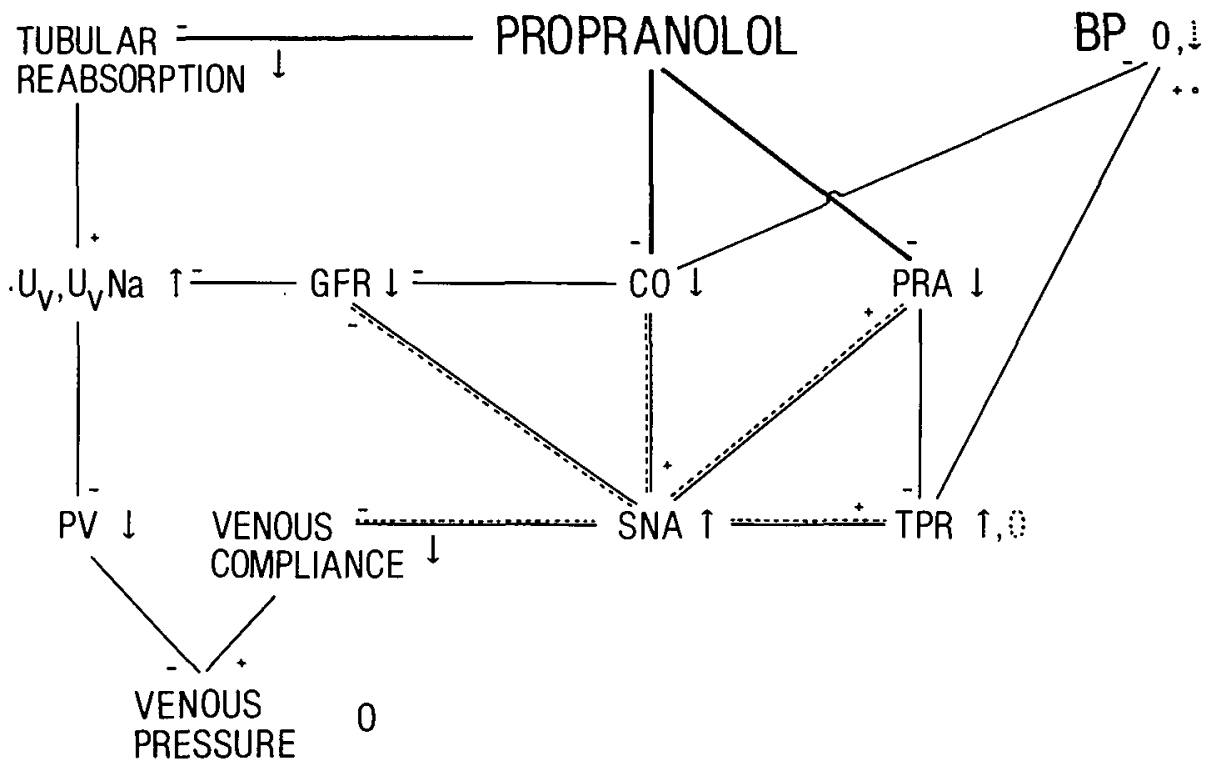

Figure 17.1. The sequence of events, occurring after acute beta-adrenoceptor blockade. Interrupted lines indicate events which gradually disappear because of adaptation. For further explanation: see section 17.2.

Abbreviations: BP: blood pressure; CO: cardiac output; GFR: glomerular filtration rate; PRA: plasma renin activity; PV: plasma volume; SNA: sympathetic nervous activity; TPR: total peripheral resistance; UV, UVNa: urinary excretion of water and sodium.

after i.c.v. injection of the drug. All other studies failed to show an antihypertensive effect. As was discussed in section 1.4 this undoubtedly results from a lack of patience encountered in these experimentists as is illustrated by the short duration of most experiments (cf. table 1.V.). It should, however, not be expected that a drug which causes a delayed antihypertensive effect in man, reduces blood pressure in other species immediately.

Detailed data on the exact time-course of hemodynamic changes are available from studies in man only during the first hours following propranolol for obvious experimental limitations. As far as comparison of hemodynamic effects in our SHR (chapter 6) and in man is possible, the pattern of the response is similar.

The sequence of events, occurring immediately after a single injection of propranolol is shown in fig. 17.1. First of all propranolol reduces cardiac output ( $\mathrm{CO}$ ) by blockade of cardiac beta-adrenoceptors (chapters 3 and 6).

This decrease of $\mathrm{CO}$ results in a decrease in renal glomerular filtration rate (GFR) through a decrease of renal blood flow as well as a baroreceptor-mediated increase in sympathetic nervous activity (SNA; chapter 8 ). 
The increase in SNA has in turn three major effects. First of all it diminishes GFR further as a consequence of increased afferent arteriolar resistance.

Furthermore, it increases the tone of both the venous vasculature and peripheral arterioles. This latter results in an increased total peripheral resistance (TPR), which together with the decreased $\mathrm{CO}$, keeps blood pressure constant.

The last consequence increased SNA is stimulation of renin release. However, since this is a beta-adrenoceptor-mediated effect, it will be blocked by propranolol. The net effect is even a decreased plasma renin activity (PRA; chapter 9) since also the resting sympathetic stimulation of renin release is blocked. Although the scheme in fig. 17.1. indicates a negative contribution of this renin blockade to TPR this does not seem to contribute dominantly (chapter 9 ).

Hypothetically, if this would be a complete description of effects caused by propranolol, there would be a complete negative feed-back loop, because the decrease in GFR would lead to a retention of water and sodium, which would increase plasma volume (PV). This, in turn, would lead to an increased venous pressure because of increased filling, whereas venous compliance is still decreased due to increased SNA (see above). This would tend to restore cardiac output, as is the case in a compensated cardiac insufficiency. However, in contrast to the processes described above, a single injection of propranolol leads to an augmented excretion of water and sodium (Uv, UvNa; chapter 11 ) which effectively reduces plasma volume (chapter 10). This effect is brought about by a diminished re-absorption of water and sodium from the renal tubules possibly as a result of blockade of sympathetic tubular innervation (chapter 11). The reduction of PV (together with the decreased venous compliance) keeps venous pressure constant, hence no restoration of cardiac output occurs.

The increase in SNA results from an increased baroreceptor-activity (chapter 8). However, this reflex is known to adapt to the prevailing hemodynamic situation within 4-48 hours (Purdy and Ashbrook, 1978; Salgado and Krieger, 1978). Thus, as is indicated in fig. 17.1 by the interrupted lines, after some time the effects of SNA will gradually disappear, as will beta-adrenoceptor blockade (chapter 4). The changes on the venous side of the circulation (reduction of venous filling) do, however, not disappear concomitantly, which will tend to keep cardiac output reduced for a prolonged period of time (chapter 6 ) although beta-adrenoceptor blockade is no longer present. This, in turn, will result in a late reduction of blood pressure (chapter $5)$, because the effects of SNA on TPR have disappeared.

The description of phenomena given above, may explain the delayed reduction of blood pressure up to $12 \mathrm{~h}$ after injection. However, the antihypertensive effect which we observed at $20 \mathrm{~h}$ post-injection was associated with a net decrease in TPR, whereas $\mathrm{CO}$ had returned to control values. No explanation can be given for this phenomenon. Auto-regulatory adjustments of peripheral resistance to reduced cardiac output have been described (Coleman and Guyton, 1969) and may play a role. In fig. 17.1 this would mean a direct (negative) inter-connection line between $\mathrm{CO}$ and TPR. It is, however, not to be expected that such adaptation occurs within a short time (Coleman and Guyton, 1969). 
For the moment, only an overshoot of regulatory mechanisms may be thought to explain the late reduction of TPR, although there is no evidence to support this assumption.

\subsection{Long-term hemodynamic effects of propranolol in SHR.}

When infused s.c. in a dose of $5 \mathrm{mg} / \mathrm{kg}$. day, propranolol was found to be capable of lowering blood pressure and heart rate in conscious unrestrained SHR. A lower dose of $1 \mathrm{mg} / \mathrm{kg}$. day did not elicit these effects.

Upon i.c.v. infusion propranolol lowered blood pressure too. However, the dose needed to produce an antihypertensive response was equal to that needed for obtaining an effect upon s.c. infusion. This occurred in spite of 100-fold higher brainconcentration for i.c.v. infused as compared to s.c. administered propranolol. Levels in peripheral tissues were equal. These observations definitely rule out the central nervous system as a site of antihypertension action for propranolol. Although an action of a metabolite of propranolol in the central nervous system could not be excluded, this is not likely. In fact, involvement of metabolites in the antihypertensive action of any beta-adrenoceptor blocking drug is not likely. Beta-adrenoceptor blocking drugs all cause an antihypertensive effect. They share the one pharmacological property of being capable of blocking beta-adrenoceptors. It is very unlikely that metabolites share any other property besides this one. Thus, beta-adrenoceptor blockade should be regarded to cause the lowering of blood pressure. The only known metabolite of propranolol which may be regarded as a beta-adrenoceptor blocking drug is 4-hydroxy-propranolol, which has an affinity for beta-adrenoceptors comparable to that of the parent drug.

Although it was not measured in this study, it has been shown to occur in extremely low concentrations in a number of species when given parenterally (see section 1.2). Thus, as compared to the parent drug, its concentrations are low and betaadrenoceptor blockade (which was said to be responsible for the antihypertensive effect) will result for the most from the parent drug.

The antihypertensive response to long-term infusion of propranolol in SHR was characterized hemodynamically to be associated with a reduction of cardiac output, which, in turn, resulted from a reduction of both heart rate and stroke volume. Peripheral resistance increased immediately.

From the results in the present thesis it should be concluded that the reduction of cardiac output is (one of) the major factor(s) determining the antihypertensive effects of propranolol. Thus, instead of explaining a reduced peripheral resistance (what most authors have tried to do) it should be answered why TPR adapts from an initial elevation and, more importantly, why cardiac output remains low.

Figure 17.2 summarizes the situation encountered during long-term beta-adrenoceptor blockade. On the first day of infusion, the processes described for the acute hemodynamics will still prevail for the infusion, i.e. there will be an increase in sympathetic nervous activitiy, as a consequence of the reduced cardiac output (see fig. 17.1). Possibly because of the lesser magnitude of the reduction of cardiac output as well as the fact that it will not be so sudden as after a single s.c. injection, the 
increase in sympathetic nervous activity will be less and baroreceptors adapt with a slower time-course. The result is an unchanged blood pressure on the first day of infusion (chapter 13). Also plasma volume is not changed (chapter 16). On the second day of infusion baroreceptors have adapted and blood pressure is reduced, although peripheral resistance is still elevated. TPR adapts gradually further during the next days, although it was still elevated significantly on the fifth day of infusion. Also in man, peripheral resistance remains slightly elevated or comes back to pretreatment levels (Lund-Johansen, 1979). This is in fact contradictory to the theory of total body auto-regulation which predicts a net reduction of TPR as a consequence of the chronically lowered cardiac output (Coleman and Guyton, 1969).

The question which now remains to be answered is, what keeps cardiac output low. The situation of lowered cardiac output may be compared to that occuring with cardiac failure. In that case, output and blood pressure are maintained at first by an increased sympathetic tone, but later (after the baroreceptor reflex adapted) by increased venous filling.

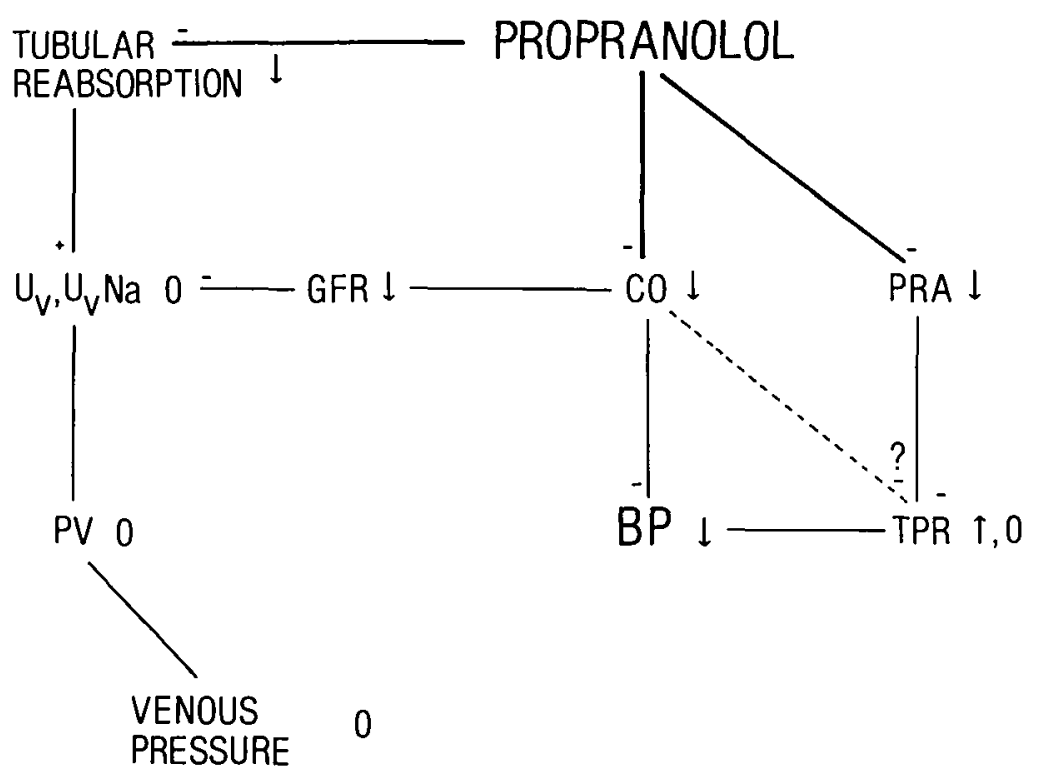

Figure 17.2. The new circulatory balance, resulting from long-term betaadrenoceptor blockade. The scheme is explained in section 17.3. The interrupted line stands for total body auto-regulation.

Abbreviations are the same as in fig. 17.1. 
The latter happens because of reduced glomerular filtration and the whole process is in fact the negative feed-back loop that was already mentioned in the previous section. The net effects are shown in a computer-simulation in appendix II.

The major difference between the effects observed during propranolol infusion and after cardiac failure is, that patients (and our SHR) do not restore their cardiac output, or better, no fluid retention occurs. Since GFR has been shown to be diminished during long-term propranolol therapy (see chapter 11) the lack of fluid retention should result from a decrease in tubular reabsorption, which, in turn, probably results from interference with sympathetic nervous control of tubular function. The hemodynamic changes which thus accompany beta-adrenoceptor blockade have been summarized in fig. 17.2. Furthermore, addition of a slight reduction of tubular reabsorption to the reduced cardiac output in the computer-simulation in appendix II. predicts the changes that are in fact observed during propranolol treatment.

An illustration of the importance of adaptation of renal function to the lowered cardiac output is found in clinical literature. In three studies on the hemodynamics of betaadrenoceptor blockade (Amery et al., 1976; Reybrouck et al., 1979; Rasmussen and Rasmussen, 1979) evidence was found for expansion of extra-cellular fluid volume in non-responding patients. This is to be expected as a "normal" response to cardiac beta-adrenoceptor blockade, as discussed above (see also appendix II).

Addition of a diuretic to metoprolol-therapy in the study of Rasmussen and Rasmussen (1979) converted non-responders into responders. It should, however, be noted that other studies have shown a lack of adaptation of peripheral resistance to cause the lack of effect of beta-adrenoceptor blockade in non-responding patients. A possible explanation may be that structural changes in the vessel-walls containing baro-sensitive elements do not permit adaptation of the baro-reflex, although this is mere speculation.

Thus, in conclusion, propranolol lowers blood pressure in conscious, unrestrained SHR, both after acute and long-term administration. In the latter case, the effect is brought about by a lowering of cardiac output and possibly an adaptation of baroreceptors, to explain the readjustment of TPR. The renal effect observed after acute administration of propranolol should be taken into account to explain the fact that cardiac output remains low. A diuretic effect should be present during long-term therapy, however, this is obscured by the reduction of renal blood flow and glomerular filtration rate which are to be expected (and have been shown to occur in man) as a consequence of the reduced cardiac output. Summation of renal and cardiac effects eventually leads to maintenance of a normal fluid balance at a lowered arterial blood pressure. 


\subsection{Conclusions}

The most important hypotheses that have been put forward in literature to explain the antihypertensive action of beta-adrenoceptor blocking drugs may be summarized as 1) an effect within the central nervous system

2) reduction of cardiac output

3) resetting of the baroreceptors

4) reduction of plasma renin activity (PRA).

On the basis of experiments in the present thesis, the first hypothesis may definitely be discarded. The second hypothesis, the reduction of cardiac output, seems to hold. Peripheral resistance strongly increases at first but it gradually adapts and returns to control-values. This is probably caused by adaptation of the baroreceptors to the new hemodynamic situation. Thus, also the third hypothesis has to be accepted. However, the resetting, or better adaptation, of the baroreceptors should not be interpreted as a direct action of the drug, but rather as a consequence of the primary reduced cardiac output.

The phenomenon contained in the fourth hypothesis, reduction of PRA, may play a role in the relative reduction of peripheral resistance. Experiments in this thesis do not allow firm conclusions on this.

In conclusion, in our view the antihypertensive effect of propranolol should be explained on the basis of a composite of three of the "classical" hypotheses.

Cardiac output is reduced primarily, which causes a secondary adaptation of baroreceptors and by that an adaptation of total peripheral resistance. In this latter phenomenon the reduction of plasma renin activity may play a role.

However, until now no attention has been paid to the question, what allows cardiac output to remain lowered during long-term therapy. As was discussed, one would expect that the reduction of cardiac output leads to retention of water and sodium, which in turn would restore cardiac output. On the basis of experiments in the present thesis we would like to add a new hypothesis to the composite of three, mentioned above: propranolol decreases tubular reabsorption of water and sodium. This reduced tubular reabsorption compensates the reduction of glomerular filtration rate, thus maintaining normal water- and sodium-excretion in spite of the reduced cardiac output.

The conclusion above may be reformulated by saying that beta-adrenoceptor blocking drugs are ideal diuretics since, by themselves, they block the side-effects normally encountered during diuretic therapy (i.e. increased heart rate and increased plasma renin activity). 


\section{SUMMARY}

Although since 1964 beta-adrenoceptor blocking drugs have been known to possess antihypertensive activity, the mechanism by which they lower blood pressure is still not known. The aim of this study was to investigate the dynamics of a number of hemodynamic, nervous, humoral and renal effects of these drugs in a hypertensive animal model, the spontaneously hypertensive rat (SHR). Possibly, careful analysis of effects occurring, might give a clue to the mechanism of antihypertensive action of beta-adrenoceptor blocking drugs. Propranolol, being one of the oldest and clinically most often used drugs of this class, was chosen as the substance for study.

Chapter 1 contains reviews on pharmacological properties of beta-adrenoceptor blocking drugs, pharmacokinetics of propranolol as well as a description of the pattern of the antihypertensive response in man and experimentally hypertensive rats. Finally, in section 1.5, the aim of the present thesis is stated in detail.

After a description of the methods used in this study in chapter 2, this thesis is divided into two parts, the first of which is dealing with effects observed after a single injection of propranolol in SHR. The pharmacokinetics of propranolol after a single subcutaneous (s.c.) injection of $1 \mathrm{mg} / \mathrm{kg}$ are studied in chapter 3 . Propranolol is rapidly absorbed and also distribution and elimination are rapid processes $\left(t_{1} / 2\right.$ alpha $=17 \mathrm{~min} ; \mathrm{t}_{1 / 2}$ beta $=59 \mathrm{~min}$ ). Levels in all tissues are maximal around $30 \mathrm{~min}$ after s.c. injection of the drug and high as compared to plasma levels.

Furthermore, protein-binding is extensive but saturable at plasma levels above $100 \mathrm{ng} / \mathrm{ml}$.

Beta-adrenoceptor blockade follows a time-course which is similar to that of plasma propranolol levels, as described in chapter 4 . It is maximal around $30 \mathrm{~min}$ after injection. Parallel to beta-adrenoceptor blockade, heart rate (HR) was found to be reduced in conscious SHR in chapter 5 . However, the time-course of the effect on blood pressure was different. It remained unaltered or even slightly elevated during the first few hours after injections, but fell after 2-4 hours. Mean arterial pressure (MAP) remained lowered for 20 hours following injection of either 1 or $5 \mathrm{mg} / \mathrm{kg}$ propranolol in unrestrained rats. In restrained SHR $0.2 \mathrm{mg} / \mathrm{kg}$ was capable of lowering MAP too. Effects of 1 or $5 \mathrm{mg} / \mathrm{kg}$ in these animals were larger than in unrestrained animals. The magnitude of the effects of propranolol on MAP was not dependent upon dose.

Chapter 6 describes further hemodynamic characterization of the response, for which cardiac output $(\mathrm{CO})$ and blood pressure were measured continuously in conscious SHR after propranolol. CO was lowered during 12 hours after s.c. injection of $5 \mathrm{mg} / \mathrm{kg}$ propranolol. Total peripheral resistance (TPR) increased immediately after the injection, but gradually adapted. As a consequence, MAP (=CO $\times$ TPR) was below control from 2-4 hours after injection. At 20 hours after injection $\mathrm{CO}$ was back at control values, however, TPR was lowered significantly after both 1 and $5 \mathrm{mg} / \mathrm{kg}$ propranolol. 
In chapter 7 a possible contribution of the central nervous system (CNS) to the antihypertensive effect of propranolol is studied, using intracerebroventricular (i.c.v.) bolus injections of the drug. Both chemical and physiological data do, however, indicate that this technique cannot be used for this type of study because propranolol immediately leaks out of the brain into the peripheral blood-stream.

In chapter 8 the involvement of the baroreceptor reflex in the hemodynamic effects of propranolol is investigated. First of all, by denervation of afferent baroreceptor fibres, it is shown that the increase in TPR immediately after injection of propranolol, results from activation of the baroreceptor reflex.

Furthermore, changes in baroreceptor sensitivity (BRS) following propranolol in SHR, as well as normotensive Wistar-Kyoto rats (WKy) are measured, because a change in the sensitivity may explain the late reduction of TPR. BRS does, however, not change after propranolol.

Chapter 9 deals with the effects of propranolol on plasma renin activity (PRA). It is shown that, following s.c. injection of $5 \mathrm{mg} / \mathrm{kg}$ propranolol, PRA is lowered at 1 but not 20 hours after injection, which makes a contribution of this parameter to the response doubtful. Injection of a lower dose $(0.2 \mathrm{mg} / \mathrm{kg})$ does not have any effects.

Plasma volume (PV) is diminished by $8 \%$ at 0.5 hour after injection of $5 \mathrm{mg} / \mathrm{kg}$ propranolol in SHR, as is shown in chapter 10. At 4 hours after injection this effect is no longer significant. Measurement of central venous pressure reveals no increase in this parameter, which indicates that the decrease in PV is not likely to be caused by increased capillary filtration. Fluid should escape via another route, and in chapter 11 this is shown indeed to occurvia the kidney, since in the first hours after injection of 5 $\mathrm{mg} / \mathrm{kg}$ propranolol there is a tremendous increase in urinary excretion of water and sodium in SHR with a precise balance in water-and sodium-intake and-excretion. These parameters then return to control levels when MAP falls. Interference of propranolol with sympathetic nervous regulation of tubular function is proposed to explain the diuresis and natriuresis.

Chapter 12 is the first chapter of part two of this thesis. In this part long-term effects of propranolol in SHR are studied. First the ALZET TM osmotic minipump is tested for its ability to create and maintain a pharmacokinetic steady-state for propranolol. From excretion-measurements as well as measurement of plasma concentrations during a 6 -day infusion of $1 \mathrm{mg} / \mathrm{kg}$.day propranolol it seems that a steady-state is reached after 1-2 days of s.c. or i.c.v. infusion. With regard to the distribution of propranolol it is shown that plasma levels are equal during s.c. and i.c.v. infusion. During s.c. infusion tissue levels in all organs (with the exception of the lungs) are comparable to those in plasma. However, during i.c.v. infusion levels in the brain are 100-fold higher than those in plasma. This should make the method applicable for the study of involvement of the CNS in the antihypertensive effect of propranolol.

In chapter 13 the hemodynamic effects of long-term s.c. infusion of propranolol in SHR are reported. Propranolol in a dose of $5 \mathrm{mg} / \mathrm{kg}$. day lowers heart rate (HR) and cardiac output $(\mathrm{CO})$ already on the first day of infusion. Total peripheral resistance 
(TPR) increases concomitantly, resulting in an unchanged mean arterial pressure (MAP) on the first day. During the following 4 days MAP is reduced significantly, which is associated with a decreased $\mathrm{CO}$ and an adapted TPR. However, TPR remains significantly elevated. Effects on stroke volume (SV) are only small. Infusion of 1 $\mathrm{mg} / \mathrm{kg}$.day is without effects on MAP and HR.

A combination of the methods and results from the two preceding chapters is used in chapter 14, where it is shown that upon i.c.v. infusion of propranolol $5 \mathrm{mg} / \mathrm{kg}$.day is needed to obtain an antihypertensive effect. Thus, in spite of 100 -fold higher brain levels during i.c.v. infusion than during s.c. infusion, the same dose is needed to obtain a lowering of blood pressure.

This definitely rules out a CNS-site of antihypertensive action for propranolol.

In chapter 15 the effects of s.c. infusion of $5 \mathrm{mg} / \mathrm{kg}$.day propranolol on PRA are studied. PRA is not lowered at 1 day after the start of infusions but it is significantly lowered on the 4th day of infusion. A possible contribution of this effect to the antihypertensive effect is discussed.

Finally, in chapter 16, plasma volume is measured during long-term s.c. infusion of 5 $\mathrm{mg} / \mathrm{kg}$.day propranolol. This parameter is not influenced on days 1 and 4 after the start of infusions.

The general discussion in chapter 17 includes the most important observations from pharmacokinetic and hemodynamic studies and a flow-diagram is presented to explain the different events occurring after acute and long-term administration of propranolol. It is concluded that renal effects or, more specifically, tubular effects are of extreme importance for the antihypertensive actions of beta-adrenoceptor blocking drugs.

In appendix I a model is presented for the description of pharmacokinetics of propranolol in SHR. This model is based upon physiological parameters. An explanation is provided for discrepancies which seem to exist between acute and long-term studies.

Appendix II shows computer-simulations of several proposed hypotheses for the antihypertensive action of beta-adrenoceptor blockade in a model for the over-all regulation of blood pressure. The outcome of the simulations is, that the model predicts that a combination of reduced cardiac output and a diminished tubular reabsorption does indeed lead to a lowering of blood pressure. 
180 


\section{SAMENVATTING}

Sinds 1964 is reeds bekend dat beta-adrenoceptor blokkerende middelen in staat zijn de bloeddruk te verlagen. Toch is nog steeds niet bekend via welk mechanisme ze dit doen. Het doel van de studies in dit proefschrift was, de dynamiek van een aantal hemodynamische, nerveuze, humorale en renale effecten van deze klasse van geneesmiddelen te bestuderen in een hypertensief diermodel, de spontaan hypertensieve rat (SHR). Mogelijk zou een zorgvuldige analyse van optredende effecten een aanwijzing geven tot het antihypertensieve werkings-mechanisme van de betaadrenoceptor blokkerende stoffen. Als model-stof werd gekozen voor het propranolol dat één van de oudste en klinisch meest gebruikte beta-adrenoceptor blokkerende stoffen is.

In hoofdstuk 1 worden literatuur-overzichten gegeven m.b.t. farmacologische eigenschappen van beta-adrenoceptor blokkerende stoffen, de farmacokinetiek van propranolol, alsook een beschrijving van het patroon van de antihypertensieve respons in de mens en in experimenteel hypertensieve ratten. Tenslotte wordt in sectie 1.5 het doel van de onderzoeken in dit proefschrift uitvoerig aangegeven.

$\mathrm{Na}$ een beschrijving van gebruikte methodes in hoofdstuk 2, is dit proefschrift verdeeld in twee delen. In het eerste daarvan wordt ingegaan op effecten die optreden na eenmalige toediening van propranolol in SHR.

De farmacokinetiek van propranolol na eenmalige subcutane (s.c.) toediening van 1 $\mathrm{mg} / \mathrm{kg}$ wordt beschreven in hoofdstuk 3. Propranolol wordt snel in het bloed opgenomen en ook de verdeling over het lichaam en eliminatie zijn snelle processen $\left(t_{1} / 2\right.$ alfa $=17 \mathrm{~min} ; t_{1 / 2 \text { beta }}=59 \mathrm{~min}$ ). In weefsels worden hoge spiegels gevonden, in vergelijking tot die in het plasma. Deze zijn maximaal rond 30 minuten na de injectie. Bovendien blijkt propranolol sterk aan plasma-eiwitten te binden. Deze binding is echter verzadigbaar als de plasma-spiegel boven $100 \mathrm{ng} / \mathrm{ml}$ komt.

De blokkade van beta-adrenoceptoren volgt een tijdsverloop dat vergelijkbaar is met dat van de plasma-spiegels van propranolol, zoals beschreven wordt in hoofdstuk 4 . Ook deze blokkade is maximaal rond 30 minuten na de injectie. Parallel aan de betaadrenoceptor-blokkade blijkt de hartfrequentie van wakkere SHR te worden verlaagd (hoofdstuk 5). Het tijdsverloop van de effecten op de bloeddruk is echter geheel anders. De gemiddelde arteriële bloeddruk (MAP) blijft onveranderd of is zelfs licht verhoogd gedurende de eerste uren na injectie. Na 2-4 uur zakt de MAP echter en hij blijft verlaagd gedurende meer dan 20 uur na de injectie van 1 of $5 \mathrm{mg} / \mathrm{kg}$ propranolol in vrij bewegende ratten. Wanneer de dieren in hun bewegingen beperkt worden, is niet alleen een dosis van $0.2 \mathrm{mg} / \mathrm{kg}$ ook in staat de bloeddruk te verlagen, maar bovendien zijn de effecten van 1 en $5 \mathrm{mg} / \mathrm{kg}$ groter. De mate van uiteindelijke bloeddruk-verlaging blijkt onafhankelijk te zijn van de dosis propranolol.

Hoofdstuk 6 beschrijft een verdere hemodynamische karakterizering van de antihypertensieve respons. Hiertoe werd het hartminuut-volume $(\mathrm{CO})$ en de bloed- 
druk continu gemeten in wakkere, vrij bewegende SHR na injectie van propranolol. $\mathrm{Na}$ injectie van $5 \mathrm{mg} / \mathrm{kg}$ is het hartminuut-volume gedurende 12 uur verlaagd.

De totale vaatweerstand (TPR) neemt echter meteen na de injectie toe. Deze parameter past zich geleidelijk aan. Tengevolge daarvan is de MAP (=COxTPR) verlaagd na 2-4 uur na de injectie. Twintig uur na de injectie van zowel 1 als $5 \mathrm{mg} / \mathrm{kg}$ propranolol is de $\mathrm{CO}$ terug op zijn uitgangswaarde, echter de vaatweerstand is significant verlaagd.

In hoofdstuk 7 wordt een mogelijke bijdrage van het centraal zenuwstelsel tot het antihypertensieve effect van propranolol onderzocht. De effecten van bolus-injecties van propranolol in de hersenventrikels van SHR worden beschreven. Zowel chemische als fysiologische gegevens laten echter zien dat deze techniek niet geschikt is voor dit type van onderzoek, daar propranolol onmiddellijk uit de hersenen naar het bloed weg-lekt.

Hoofdstuk 8 beschrijft onderzoeken naar de rol die de baro-reflex speelt in de hemodynamische effecten van propranolol. Op de eerste plaats blijkt dat de stijging van de vaatweerstand na injectie van propranolol het gevolg is van een activatie van deze reflex. Na doorsnijding van de afferente baroreceptor vezels blijkt propranolol $\mathrm{nl}$. in staat de bloeddruk onmiddellijk te verlagen. Verder worden in dit hoofdstuk mogelijke veranderingen van de gevoeligheid van de baro-reflex na propranolol gemeten, zowel in SHR als in normotensieve Wistar-Kyoto ratten. Een verandering in deze gevoeligheid zou een mogelijke verklaring kunnen bieden voor de late bloeddruk-verlaging. De resultaten geven echter geen verandering van de reflexgevoeligheid te zien.

De effecten van propranolol op de plasma renine activiteit (PRA) worden beschreven in hoofdstuk 9. Het blijkt dat de PRA 1 uur, maar niet 20 uur na s.c. injectie van 5 $\mathrm{mg} / \mathrm{kg}$ propranolol verlaagd is. Dit maakt een belangrijke bijdrage van deze parameter aan het antihypertensieve effect twijfelachtig.

Injectie van een lagere dosis $(0.2 \mathrm{mg} / \mathrm{kg})$ heeft geen effecten.

Het plasma volume (PV) is een half uur na de injectie van $5 \mathrm{mg} / \mathrm{kg}$ propranolol significant met $8 \%$ verlaagd, zoals blijkt in hoofdstuk 10 . Vier uur na de injectie is dit effect niet langer significant. Meting van de centraal veneuze druk laat geen verandering in deze parameter zien, hetgeen aangeeft dat de verlaging van het PV waarschijnlijk niet door een verhoogde capillaire vloe istof filtratie veroorzaakt wordt. Er moet dus vloeistof via een andere weg verdwijnen en in hoofdstuk 11 wordt aangetoond dat dit inderdaad gebeurt en wel via de nier.

Gedurende de eerste uren na injectie van $5 \mathrm{mg} / \mathrm{kg}$ propranolol is er een geweldige toename van de water-en zout-uitscheiding in de urine van SHR die tevoren in een nauwkeurige zout-balans zijn gebracht. Na enige uren keren deze parameters terug naar hun normale waarden, terwijl de bloeddruk zakt. Dit wordt bediscussiëerd in het licht van de sympathisch-nerveuze regulatie van de renale tubulus functie, waarop propranolol mogelijk effecten heeft. 
Hoofdtuk 12 is het eerste hoofdstuk van deel twee van dit proefschrift. In dit deel worden de lange termijn effecten van propranolol in de SHR bestudeerd.

Eerst wordt getest of het ALZET TM osmotische minipompje gebruikt kan worden om een stationaire toestand in farmacokinetische zin op te bouwen en te handhaven.

Zowel uit excretie-metingen als metingen van de plasma-spiegels gedurende een 6 dagen durende infusie van propranolol in een dosis van $1 \mathrm{mg} / \mathrm{kg}$. dag blijkt dat na 1-2 dagen een stationaire toestand wordt bereikt.

De infusies werden zowel s.c. als intracerebroventriculair (i.c.v.) gegeven. De plasmaspiegels van propranolol zijn identiek tijdens s.c. en i.c.v. toediening.

$\mathrm{Na}$ s.c. toediening van propranolol zijn bovendien de weefsel-spiegels in alle organen (m.u.v. die in de longen) hetzelfde als de plasma-spiegels.

Echter, na i.c.v. toediening van propranolol zijn de spiegels in de hersenen 100 maal hoger dan die in het plasma. Dit maakt het gebruik van deze methode geschikt om een mogelijke bijdrage van het centraal zenuwstelsel tot het antihypertensieve effect van propranolol nader te onderzoeken.

In hoofdstuk 13 wordt ingegaan op de hemodynamische effecten van langdurig s.c. toegediend propranolol in de SHR. In een dosis van $5 \mathrm{mg} / \mathrm{kg}$. dag blijkt propranolol in staat de hartfrequentie en het hartminuut-volume van SHR al op de eerste dag significant te verlagen. Tegelijkertijd stijgt echter de vaatweerstand wat tot gevolg heeft dat de bloeddruk op de eerste dag niet verandert. Gedurende de verdere 4 dagen van de experimenten is de bloeddruk echter wel verlaagd, hetgeen gepaard gaat met een verlaagd hartminuut-volume en een aangepaste vaatweerstand. Deze laatste blijft echter significant boven zijn uitgangswaarde. De effecten van propranolol op het slagvolume zijn slechts gering. Wanneer een dosis van $1 \mathrm{mg} / \mathrm{kg}$.dag wordt geinfundeerd, veranderen bloeddruk en hartfrequentie niet.

Een combinatie van de methodes en resultaten uit de twee voorgaande hoofdstukken wordt gebruikt in hoofdstuk 14, waar wordt aangetoond dat gedurende i.c.v. infusie van propranolol een dosis van $5 \mathrm{mg} / \mathrm{kg}$. dag nodig is om een antihypertensief effect te verkrijgen. Hieruit volgt dat dezelfde dosis nodig is als die, welke tijdens s.c. infusie de bloeddruk verlaagt, ondanks het feit dat de hersen-spiegels 100-voudig hoger zijn dan die tijdens s.c. infusie. Hierdoor kan een werkingsplaats van het propranolol in het centraal zenuwstelsel m.b.t. het antihypertensieve effect definitief worden uitgesloten.

In hoofdstuk 15 worden de effecten van infusie van $5 \mathrm{mg} / \mathrm{kg}$. dag propranolol op de PRA bestudeerd. De PRA is niet verlaagd op de eerste, maar wel op de vierde dag na de start van de infusie.

Een mogelijke bijdrage hiervan aan het antihypertensieve effect wordt bediscussiëerd.

Tenslotte wordt in hoofdstuk 16 het plasma volume van SHR tijdens infusie van 5 $\mathrm{mg} / \mathrm{kg}$.dag propranolol gemeten. Dit blijkt op dag 1 en dag 4 van de infusies niet veranderd te zijn, vergeleken met de controles.

De algemene discussie in hoofdstuk 17 bevat de belangrijkste waarnemingen uit de verschillende studies. Er wordt een flow-diagram uit geconstrueerd dat de verschil- 
lende effecten, die na eenmalige en langdurige toediening optreden, verklaart. De conclusie is dat renale, en meer in het bijzonder tubulaire, effecten uitzonderlijk belangrijk zijn voor de verklaring van het antihypertensieve effect van betaadrenoceptor blokkerende geneesmiddelen.

In appendix I wordt een model beschreven voor de farmacokinetiek van propranolol in de SHR. Dit model is gebaseerd op fysiologische grootheden.

Er wordt een verklaring geboden voor schijnbare discrepanties tussen de resultaten na eenmalige en langdurige toediening.

Appendix II bevat computer-simulaties van verschillende hypotheses voor het antihypertensieve werkingsmechanisme van beta-adrenoceptor blokkade. Deze werden gedaan in een model dat de belangrijkste componenten van de bloeddrukregulatie bevat. Het resultaat is dat het model voorspelt, dat de door ons voorgestelde combinatie van een verminderde tubulaire reabsorptie van water en zout samen met een verlaging van het hartminuut-volume inderdaad tot een langdurige bloeddrukverlaging zal leiden. 


\section{APPENDIX 1.}

A physiologocial model for the distribution and elimination of propranolol in the rat.

\section{Background}

Simulations:

- subcutaneous injection

- subcutaneous infusion

- intracerebroventricular infusion 


\section{BACKGROUND}

A general model for drug distribution and elimination is the two-compartment model (see fig. I.1). It consists of a central compartment, from which the drug is eliminated and distributed to the second compartment. Transfer of drug to and from the second compartment, as well as elimination from the central compartment may be described by first-order processes, depending upon concentrations in the compartments. Usually, volumes $\left(V_{C}\right.$ and $\left.V_{P}\right)$ and rate-constants $\left(k_{12}, k_{21}\right.$ and $\left.k_{e l}\right)$ are derived from plasma concentration-time curves obtained in experiments (cf. Notari, 1975; Gibaldi, 1977). The parameters thus obtained may give an adequate mathematical description of processes, however, the calculated volumes and rate-constants have no physiological meaning.

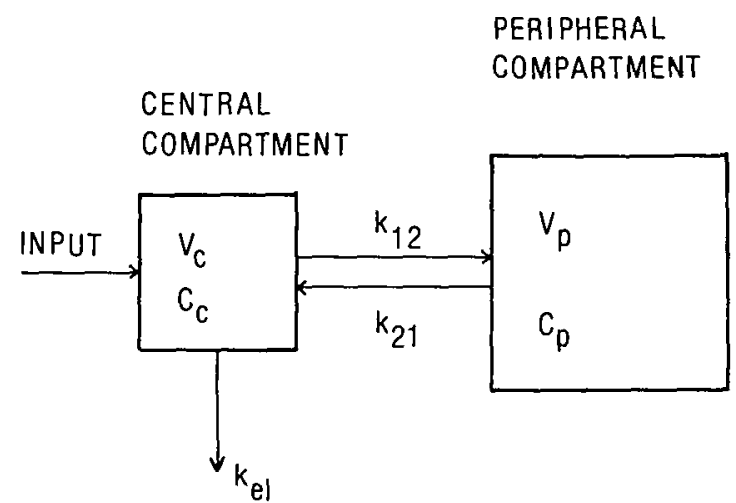

Figure 1.1 Schematic representation of the two-compartment open model.

$k_{12}$ and $k_{21}$ are rate constants for transfer of drug from the central to the second compartment and vice versa. $k_{e l}$ is the rate constant for elimination. $V_{c}$ and $V_{p}$ are (theoretical) volumes of the central and second compartment. $C_{c}$ and $C_{p}$ are concentrations in plasma and the second compartment.

Another approach which has been used for the description of pharmacokinetic processes is shown in fig. 1.2. This kind of model was first used successfully by Bischoff and Dedrick (1968) to describe the pharmacokinetics of thiopental. The model is based upon real organ-volumes and plasma-flows, assuming distribution to occur instantaneously and entirely through diffusion-processes. Binding to plasmaproteins and tissues is taken into account.

At any time, the concentration of the drug in a compartment is equal to the net amount of drug in that compartment divided by the volume of the compartment.

The net amount of drug (as a function of time) in any compartment may be described by integration of in-and outflow of the drug. This results in a flow-diagram as shown in 


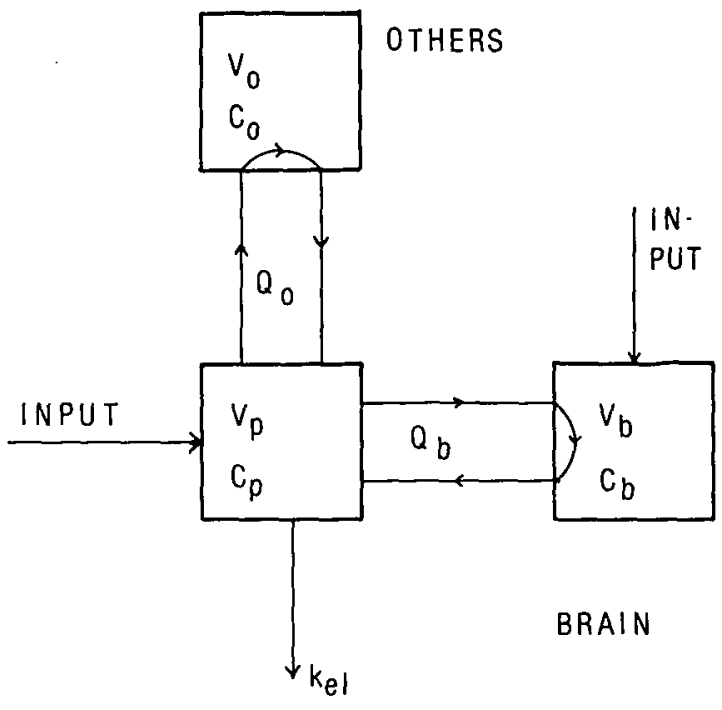

\section{PLASMA}

Figure 1.2. Schematic representation of a flow-dependent model for pharmacokinetics. Symbols: C: concentration; $Q$ : flow; V: volume.

Subscripts: B: brain; O: other tissues; P: plasma.

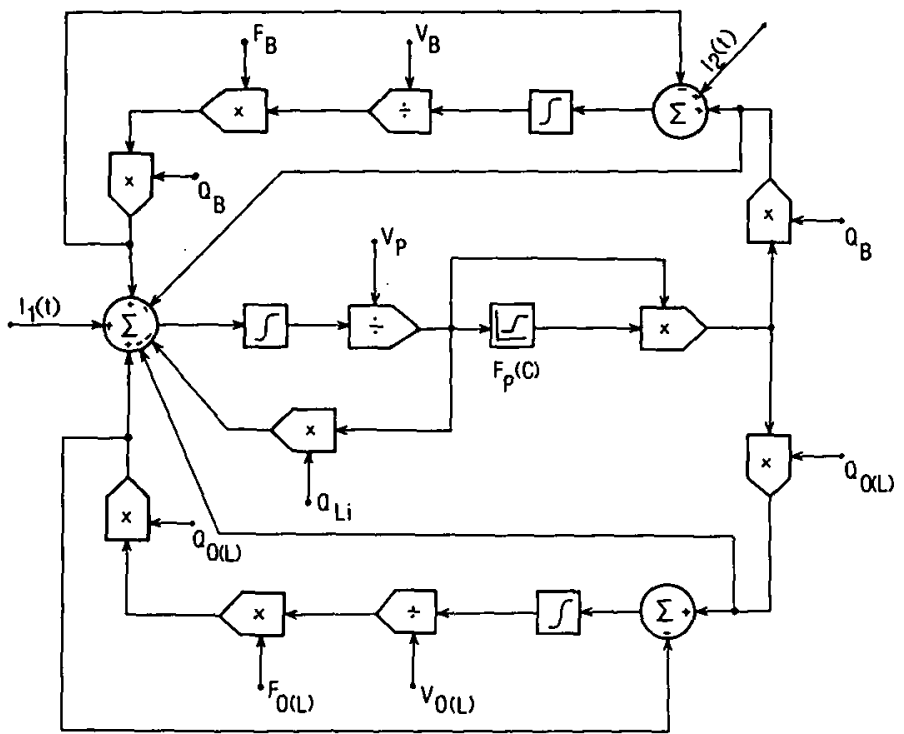

Figure 1.3. Flow-diagram for the pharmacokinetic model from figure 1.2. For explanation of symbols: see table I.I. $1(\mathrm{t})=$ input. 
fig. 1.3. This model contains 4 compartments, i.e. plasma (subscripts $p$ ), the brain (subscripts $B$ ), lungs (subscripts $L$ ) and "other organs" (subscripts $O$ ). Lungs have been taken separately because of their high blood flow as well as the fact that they bind the drug (see section 1.2). This may then contribute strongly to the net volume over which the drug distributes. The brain has been taken as a specific organ, because in this thesis experiments have been performed in which the drug was administered directly into the brain; we wanted to obtain a description of the processes occurring when the drug is administered via this route.

The values of the parameters used to simulate the kinetic processes of propranolol in SHR were taken from studies in this thesis as far as possible. Organ flows were derived from literature (Nishiyama et al., 1976; Yates and Hiley, 1979). All constants have been summarized in table 1.1 .

Table I.I. Constants used in the flow-dependent pharmacokinetic model for propranolol in SHR.

$\begin{array}{lll}\text { Constant } & \text { Description } & \text { Value } \\ V_{P} & \text { Plasma volume } & 10 \mathrm{ml} \\ V_{B} & \text { Brain-weight } & 2 \mathrm{grams} \\ V_{L} & \text { Lung-weight } & 3 \mathrm{grams} \\ V_{O} & \text { Weight of tissues which have good perfusion } & 200 \mathrm{grams} \\ Q_{L i} & \text { Liver plasma-flow } & 14 \mathrm{ml} / \mathrm{min} \\ Q_{B} & \text { Brain plasma-flow } & 0.5 \mathrm{ml} / \mathrm{min} \\ Q_{L} & \text { Lung plasma-flow }=\text { cardiac output } & 40 \mathrm{ml} / \mathrm{min} \\ Q_{O} & \text { Cardiac output } & 40 \mathrm{ml} / \mathrm{min} \\ F_{P} & \text { Free fraction of drug in plasma } & \text { (function }(\mathrm{Cp}) ; \\ & & \text { see chapter } 3 \text { ) } \\ F_{B} & \text { Free fraction of drug in brain } & 8 \% \\ F_{L} & \text { Free fraction of drug in lungs } & 1.5 \% \\ F_{O} & \text { Free fraction of drug in other tissues } & 8 \%\end{array}$

Elimination was taken to be equal to liver plasma-flow. Following a single injection of propranolol this will be reduced as a consequence of reduced cardiac output. This latter process cannot be described adequately as a function of concentrations, because it is governed not only by sympathetic influences, but also by others (see chapter 6).

Therefore, a mean value of $14 \mathrm{ml} / \mathrm{min}$ was taken for liver plasma-flow not only on the basis of physiological experiments (chapter 6) but also from pharmacokinetic experiments (chapter 3).

Plasma protein-binding was described as a function of concentration from data in chapter 3. It was assumed to be saturable. A maximal free fraction of $60 \%$ was assumed. Tissue-binding was calculated from experiments in which $1 \mathrm{mg} / \mathrm{kg}$ propranolol was infused s.c. during 6 days, assuming a plasma protein-binding of $8 \%$ at the prevailing plasma concentration. 
Absorption of the drug following a single s.c. injection was assumed to be a first-order process with a half-life of $0.9 \mathrm{~min}$ (see chapter 3 ).

Processes were simulated, using THTSIM (Technische Hogeschool, Twente, The Netherlands) as a simulation language. Numerical outputs were obtained, and graphs were drawn from them.

Figure 1.4 shows a listing of the model. Blocks $1-6$ describe processes in plasma. Concentrations in lungs, brain and other organs are calculated in blocks $20-26$, 14- 19 and 7-13 respectively. Blocks $28-40$ are used for conversion from linear to logarithmic values. Limiters are installed to prevent overflow of the logarithmic transformers. Finally, blocks 41 - 45 describe first-order absorption from a subcutaneous injection. Drug input can be in block 44 (first-order absorption after a single subcutaneous injection), block 1 (long-term, zero-order subcutaneous infusion) or block 27 (intracerebroventricular administration). 
MODEL:

$$
\begin{array}{r}
0.00000 \\
5000.0 \\
208.00
\end{array}
$$

0.00000

10.0000

14.000

$$
\begin{array}{rr}
1 & 0.00000 \\
2 & 100.000 \\
3 & 700.00 \\
4 & 800.00
\end{array}
$$

1 PLS

40.000

7 MUL

2 SUM

3 INT

4 ATT

5 GAI

6 FNC

0.00000

200.00

$0.80000 E-01$

40.000

0.50000

0.00000

2.0000

$0.80000 E-01$

0.50000

40.000

0.00000

2.0000

$0.15080 E-01$

8 GAI

9 SUM

10 INT

11 ATT

12 GAI

13 GAI

14 GAI

15 SUM

16 INT

17 ATT

$18 \mathrm{GAI}$

$19 \mathrm{GAI}$

20 GAI

21 SUM

ट2 INT

23 ATT

24 CON

25 MUL

40.000

0.00000

26 GAI

0.00000

0.00000

0.10000 E-06

0.10000 E 10

27 PLS

$$
\begin{array}{ll}
1 & -5 \\
2 & \\
3 \\
4 \\
4 \\
0.80000 E-01
\end{array}
$$

$0.80000 E-01$

0.60000

0.60000

46

$8-13$

10

11

12

7

$14-19 \quad 27$

15

16

17

18

7

$20-26$

21

ᄅe

$24 \quad 23$

25

28 LIM 4

29 LOG

30 DIU

$0.10000 E-06$

0.10000 E 10

31 LIM

28

2948

11

32 LOG

31

33 DIU

$0.10000 E-06$

$34 \mathrm{LIM}$

3240

0.10000 E 10

35 LOG

36 DIU

$0.10000 E-06$

37 LIM

0.10000 E 10

38 LOG

39 DIU

2. 3030

40 CON

17

34

3540

23

37

$38 \quad 40$

$-0.77000$

$41 \mathrm{TIM}$

42 GAI

43 EXP

0.00000

0.00000

44 GAI

110.00

45

42

43

41

$\begin{array}{lrrr}0.10000 E-10 & 46 \text { DIU } & 17 & 47 \\ 0.10000 E & \text { LIM } & 4 & \end{array}$ 
Figure 1.4. Computer-listing (THTSIM) for the model in figure 1.3. General structure: 2.000017 ATT 16:

means: block nr. 17: attenuate block 16 by a factor 2 .

Abbreviations:

ATT: attenuator

CON: constant

DIV: divider

EXP: exponential function

FNC: function-block (4 data-pairs define the function)

GAl: gain

INT: integrator

LIM: limiter (minimum and maximum are specified)

LOG: log-transformer

MUL: multiplier

PLS: pulse-input (begin-time, end-time and height are specified) SUM: summation

TIM: time 


\section{SIMULATIONS}

\section{SUBCUTANEOUS INJECTION}

Plasma- and brain-levels following a single s.c. injection of $1 \mathrm{mg} / \mathrm{kg}$ propranolol were simulated by giving block 44 a value of 230,000 . This results in a first order uptake from the depot into plasma with a half-life of $0.9 \mathrm{~min}$. Inputs in block 1 and 27 were zero.

The outcome of this simulation is shown in fig. 1.5. In this figure not only the curves derived from simulations are shown, but also the values actually measured (taken from chapter 3). The figure shows a good agreement of the plasma concentrationtime profile simulated in the model and that found in experiments. Also simulated brain-levels agree reasonably with those found in chapter 3, although the latter suggest a somewhat higher maximum, occurring later in time than that simulated. This discrepancy could be overcome by making the free fraction of the drug in the brain smaller than that in plasma, however the finding that during long-term infusion levels in the brain are equal to those in plasma, does not allow such a change of the model.

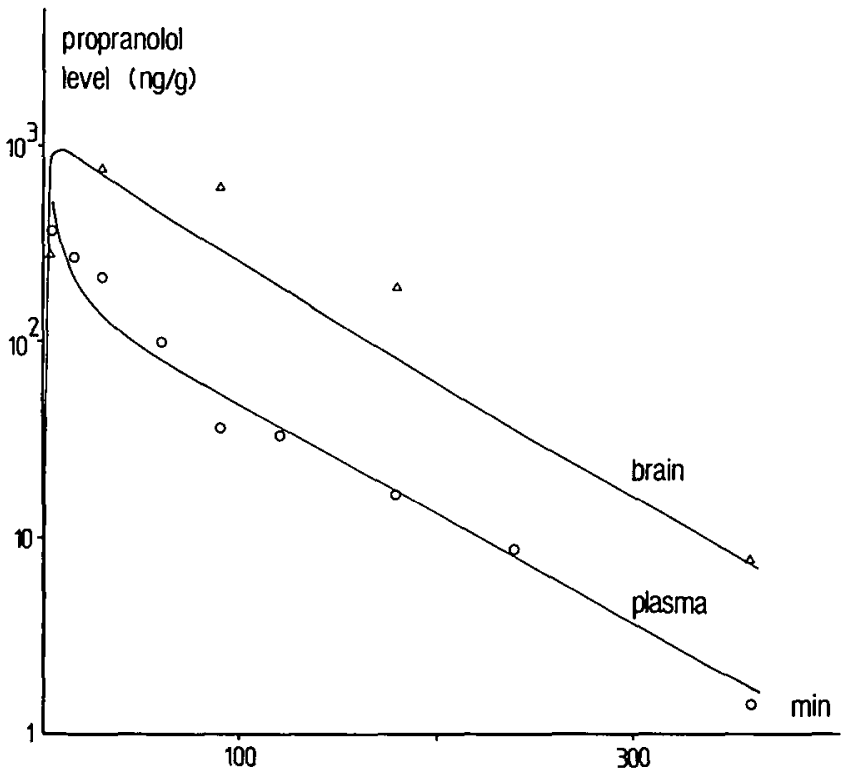

Figure 1.5. Outcome of simulation of plasma- and brain-levels of propranolol (drawn lines) as compared to levels actually measured $(0$ and $\Delta)$.

For explanation: see text. 
Figure 1.6 shows the numerical output of the model after assigning a value of 208 $\mathrm{ng} / \mathrm{min}$ propranolol to the input in block 1 . Output was every 60 minutes.

Plasma concentration was constant after 14 hours and had a value of $15 \mathrm{ng} / \mathrm{ml}$. In the brain, maximal levels were reached somewhat later and reached a value of $15 \mathrm{ng} / \mathrm{ml}$ too. The ratio between brain and plasma (4th column in the simulation-output) became equal to unity after $\sim 15$ hours. The plasma level found in simulations (15 $\mathrm{ng} / \mathrm{ml})$ and actually found in experiments $(22-38 \mathrm{ng} / \mathrm{ml})$ are in good agreement. The finding that brain-levels are equal to those in plasma was to be expected, because one of the most important factors in the model (equal plasma- and tissue-binding) was based upon that observation. Thus, in fact this is an input into the model, rather than a result.

$\begin{array}{cccc}\text { time } & \log C_{p} & \log C_{b} & C_{b}: C_{p} \\ 0.00000 & -6.9987 & -6.9987 & 0.00000 \\ 60.000 & 1.1312 & 0.95388 & 0.66470 \\ 120.00 & 1.1536 & 1.0966 & 0.87700 \\ 180.00 & 1.1635 & 1.1420 & 0.95164 \\ 240.00 & 1.1680 & 1.1592 & 0.98006 \\ 300.00 & 1.1700 & 1.1663 & 0.99150 \\ 360.00 & 1.1709 & 1.1693 & 0.99629 \\ 420.01 & 1.1714 & 1.1706 & 0.99835 \\ 480.01 & 1.1716 & 1.1712 & 0.99926 \\ 540.01 & 1.1716 & 1.1715 & 0.99967 \\ 600.02 & 1.1717 & 1.1716 & 0.99985 \\ 660.02 & 1.1717 & 1.1717 & 0.99993 \\ 720.03 & 1.1717 & 1.1717 & 0.99997 \\ 780.03 & 1.1717 & 1.1717 & 0.99998 \\ 840.03 & 1.1717 & 1.1717 & 0.99999 \\ 900.04 & 1.1717 & 1.1717 & 0.99999 \\ 960.04 & 1.1717 & 1.1717 & 0.99999 \\ 1020.0 & 1.1717 & 1.1717 & 0.99999 \\ 1080.0 & 1.1717 & 1.1717 & 0.99999 \\ 1140.0 & 1.1717 & 1.1717 & 0.99999 \\ 1200.0 & 1.1717 & 1.1717 & 0.99999\end{array}$

Figure 1.6. Numerical output of simulation of a long-term s.c. infusion of $1 \mathrm{mg} / \mathrm{kg}$.day propranolol in a $300 \mathrm{~g}$ rat. Columns represent (from left to right): time (min). $\log$ plasma concentration, log brain concentration and brain concentration : plasma concentration. 
Figure 1.7 shows numerical output of the model during simulation of i.c.v. infusion of 1 $\mathrm{mg} / \mathrm{kg}$.day propranolol. This was achieved by giving block 27 a value of $208 \mathrm{ng} / \mathrm{min}$. Inputs in blocks 1 and 44 were zero.

During equilibrium the plasma level was $15 \mathrm{ng} / \mathrm{ml}$, which is equal to that found in the previous simulation. The level in the brain was $5195 \mathrm{ng} / \mathrm{g}$. Furthermore, the ratio between brain- and plasma-level is given in column 4 again. This was found to be 351 and is in good agreement with the ratio found in experiments in chapter 12 (60-500).

The ratio can be calculated from the formula in section 17.1 of thesis, which was:

$$
\frac{c_{11}}{c_{1}}=\frac{k_{21}+k_{e l}}{k_{21}}
$$

By taking tissue-binding into account, substitution of organ-flows into this formula, together with tissue-binding results in

$$
\frac{C_{11}}{C_{1}}=\frac{F_{1} \cdot Q_{B}+F_{1} \cdot Q_{L i}}{F_{11} \cdot Q_{B}}
$$

where $F_{\mid}$and $F_{1 \mid}$ are the free fractions of the drugs in plasma and brain respectively. $Q_{B}$ and $Q_{L i}$ stand for brain and liver blood-flow. In the case of infusion of propranolol $F_{1}$ and $F_{11}$ are equal $(=0.08)$. Furthermore, elimination is not limited by proteinbinding. This then results in

$$
\frac{c_{I I}}{c_{I}}=\frac{0.08 Q_{B}+Q_{L i}}{0.08 Q_{B}}
$$

Substitution of a value of $0.5 \mathrm{ml} / \mathrm{min}$ for $Q_{B}$ and $14 \mathrm{ml} / \mathrm{min}$ for $Q_{\mathrm{Li}}$ results in

$$
\frac{C_{11}}{C_{1}}=\frac{0.08 \times 0.5+14}{0.08 \times 0.5}=351
$$




$\begin{array}{cccr}\text { time } & \log \mathrm{Cp}_{p} & \log \mathrm{Cb}_{b} & \mathrm{Cb}_{b}: \mathrm{C}_{p} \\ 0.00000 & -6.9987 & -6.9387 & 0.00000 \\ 60.000 & 0.95388 & 3.5602 & 404.40 \\ 120.00 & 1.0966 & 3.6749 & 379.09 \\ 180.00 & 1.1420 & 3.7043 & 365.46 \\ 240.00 & 1.1592 & 3.7129 & 358.21 \\ 300.00 & 1.1663 & 3.7155 & 354.50 \\ 360.00 & 1.1693 & 3.7162 & 352.67 \\ 420.01 & 1.1706 & 3.7165 & 351.79 \\ 480.01 & 1.1712 & 3.7165 & 351.37 \\ 540.01 & 1.1715 & 3.7166 & 351.17 \\ 600.02 & 1.1716 & 3.7166 & 351.08 \\ 660.02 & 1.1717 & 3.7166 & 351.04 \\ 720.03 & 1.1717 & 3.7166 & 351.02 \\ 780.03 & 1.1717 & 3.7166 & 351.01 \\ 840.03 & 1.1717 & 3.7166 & 351.00 \\ 900.04 & 1.1717 & 3.7166 & 351.00 \\ 960.04 & 1.1717 & 3.7166 & 351.00 \\ 1020.0 & 1.1717 & 3.7166 & 351.00 \\ 1080.0 & 1.1717 & 3.7166 & 351.00 \\ 1140.0 & 1.1717 & 3.7166 & 351.00 \\ 1200.0 & 1.1717 & 3.7166 & 351.00\end{array}$

Figure 1.7. Numerical output of simulation of a long-term i.c.v. infusion of $1 \mathrm{mg} / \mathrm{kg}$.day propranolol in a $300 \mathrm{~g}$ rat. For explanation: see figure 1.6 . 


\section{APPENDIX II}

Simulations of some proposed hypotheses for the mechanism of antihypertensive action of beta-adrenoceptor blocking drugs in a computer-model for blood pressure regulation.

A large number of processes is involved in the control of blood pressure.

Their abundance, as well as the complexity of inter-relationships between these processes, often makes it hard to predict the behaviour of blood pressure following an intervention in the system. By a detailed analysis of the processes which play a role in blood pressure control and translating them into mathematical equations, it is possible to build models of blood pressure control. Undoubtedly, at this moment the most advanced of these models is that of Guyton and co-workers (Guyton and Coleman, 1969; Guyton et al., 1972, 1974). It is built of approximately 400 mathematical equations, 37 of which are integrations. The equations describe the heart and circulation, as well as a number of nervous, endocrine, humoral, renal and autoregulatory processes involved in the regulation of blood pressure in great detail. The model has been shown to be useful not only in the study of basic hemodynamics, but also in that of the pathophysiology of a number of cardiovascular disease states (Guyton et al., 1972).

The effects of a number of drugs may, of course, also be simulated using this model. In the light of the present thesis it seemed useful to simulate three of the proposed hypotheses for the antihypertensive activity of beta-adrenoceptor blockade, including the one that was derived from experiments in this thesis. They are resp. a reduction of sympathetic influence on the heart, addition of reduction of plasma renin activity to the reduced cardiac sympathetics and finally the addition of a small decrease of tubular reabsorption of water and sodium to the latter.

Care should be taken with the interpretation of results from simulations.

They may learn us why certain interventions do not lead to a reduction of blood pressure, i.e. they help us to discard hypotheses and teach us the sequence of events occurring after a given intervention, which possibly tend to restore blood pressure. They may, however, never be interpreted as proof for hypotheses.

If an intervention, or a combination of interventions, predicts a reduction of blood pressure, they should always be substantiated with the appropriate experiments before they can be accepted. Thus, results from simulations may either lead us to experiments or they may confirm experimental findings. 


\section{Simulation 1}

\section{REDUCTION OF SYMPATHETIC INFLUENCE ON THE HEART}

Fig. 11.1 contains the effects of a $40 \%$ reduction of cardiac sympathetic influences at the point in time indicated by the arrow. There is an immediate reduction of cardiac output (CO), which is accompanied by a (transient) fall in blood pressure (MAP) and an increase in autonomic nervous outflow (AF).

Concomitantly, total peripheral resistance (TPR) increases, as does the angiotension concentration in the blood (ANC). As a consequence of the reduced cardiac output, the urinary excretion (UE) of water and sodium falls, causing an expansion of the extracellular fluid volume (EFV) and the blood volume (BV).

This, in turn, restores normal cardiac output. Eventually, cardiac output is reduced only very slightly. However, due to an increased total peripheral resistance, blood pressure is hardly affected. This computer-simulation therefore indicates that the reduction of sympathetic influence on the heart does not, by itself, explain the antihypertensive effect of beta-adrenoceptor blockade.

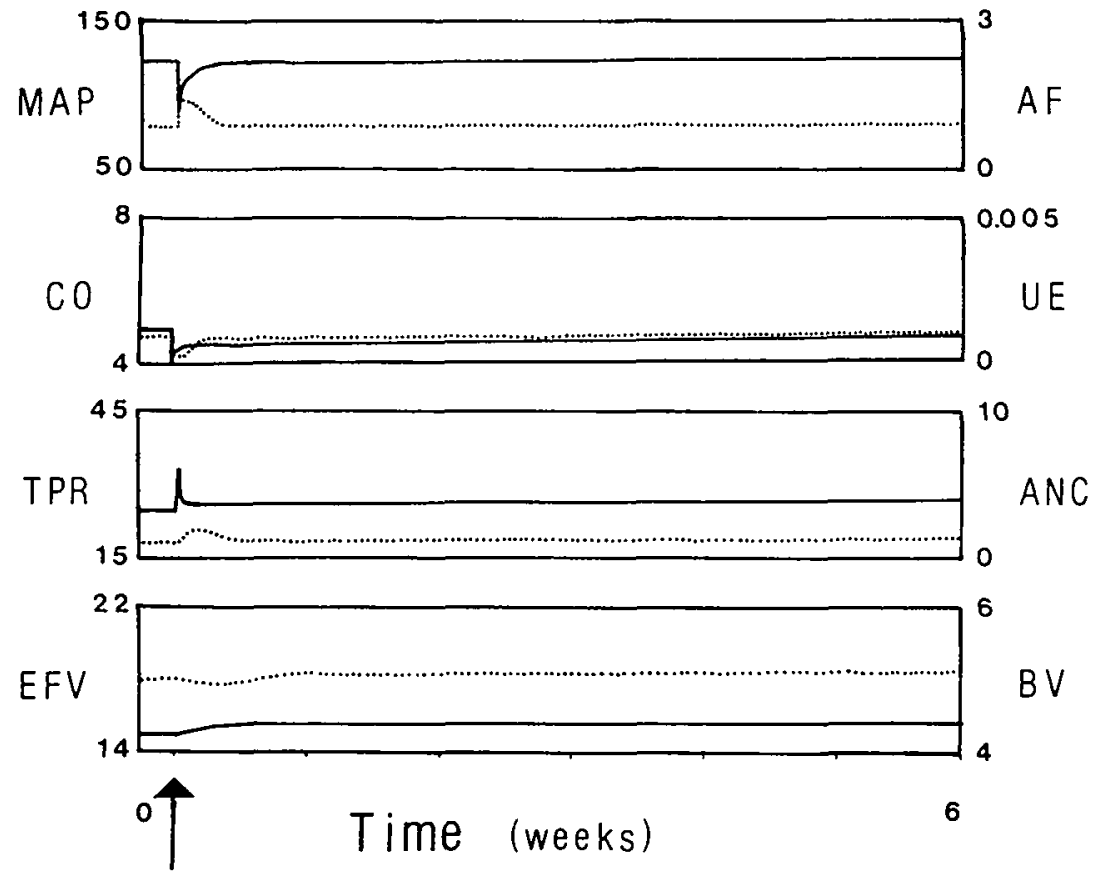

Figure II.1. Drawn lines represent parameters denoted on the left; interrupted lines represent parameters, specified on the right. For further explanation: see text. 


\section{Simulation 2.}

REDUCTION OF SYMPATHETIC INFLUENCE ON THE HEART AS WELL AS REDUCTION OF SYMPATHETIC INFLUENCE ON RENIN-RELEASE.

At the point indicated by the arrow in fig. 11.2 a simultaneous reduction of sympathetic influence on renin-release by $50 \%$ and a reduction of cardiac output (CO) by $20 \%$ were simulated. The ultimate effect is a slight reduction of peripheral resistance (TPR). Cardiac output returns to control values within a few days and blood volume (BV) and extracellular fluid volume (EFV) increase only slightly. Blood pressure is reduced by a few millimeters of mercury.

The results from this simulation indicate that also reduction of plasma renin activity (PRA), together with a reduced cardiac output, does not fully explain the antihypertensive activity of beta-adrenoceptor blockade.
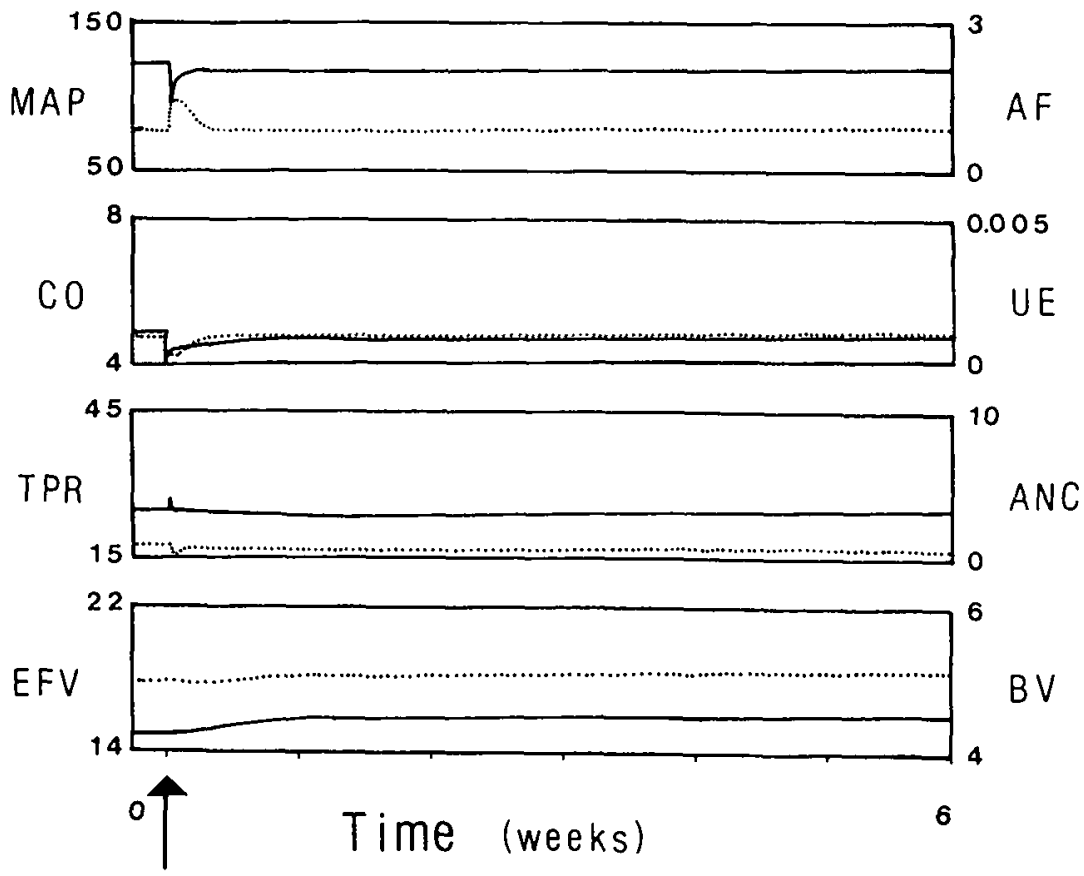

Figure II. 2. See text 


\section{Simulation 3.}

REDUCTION OF TUBULAR REABSORPTION OF WATER AND SODIUM, TOGETHER WITH REDUCED RENIN-RELEASE AND CARDIAC OUTPUT.

In fig. II.3 tubular reabsorption of water and sodium was reduced by $0.2 \%$, simultaneously with the reduction of renin-release and cardiac output as in the previous simulations.

Cardiac output is reduced instantaneously, whereas blood pressure falls only gradually. Initially, there is an increase in sympathetic nervous activity (AF), peripheral resistance (TPR) and urine excretion (UE).

These parameters do, however, adapt. Ultimately, blood pressure is reduced, together with cardiac output. All other paramaters are hardly different from control. The results from this simulation indicate, that the proposed mechanism of antihypertensive action of beta-adrenoceptor blockade cannot be ruled out.

However, as pointed out above, this should not be interpreted as proof for the hypothesis in this thesis, but rather as support for the experimental findings.

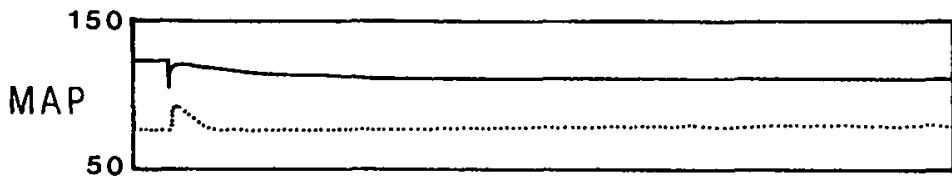

3

AF

$\mathrm{CO}$

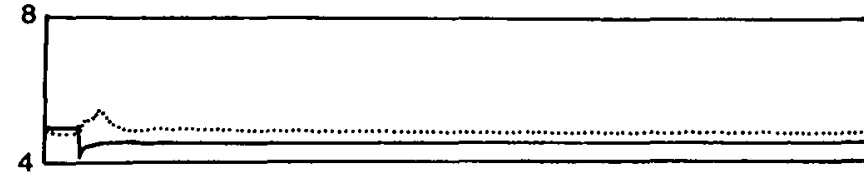

0.005

UE

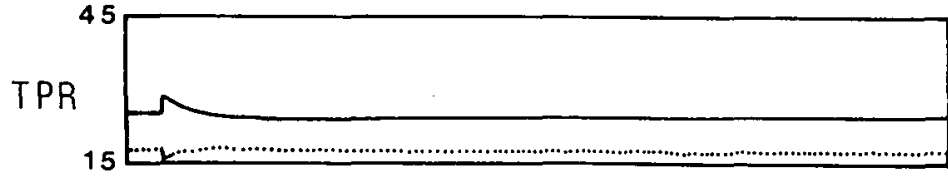

10

ANC

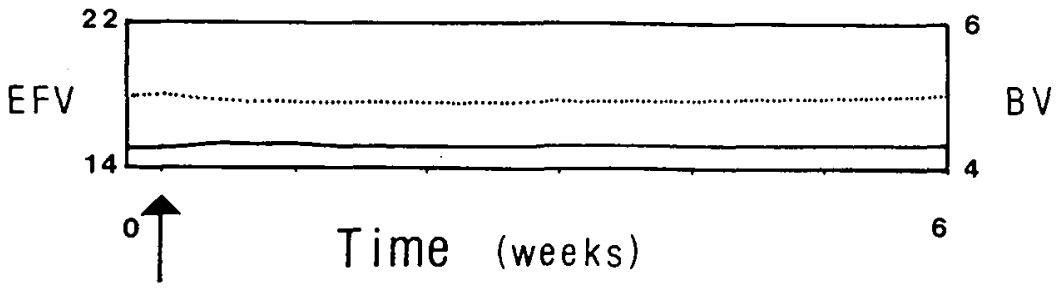

Figure II. 3. See text 


\section{REFERENCES:}

- Áblad, B., Brugàrd, M. and Ek, L.: Acta Pharmacol. Toxicol. 25 (suppl. 2), 9-40, 1967.

- Ảblad, B., Ek, L., Johansson, B. and Waldeck, B.: J. Pharm. Pharmacol. 22, 627-628, 1970.

- Ảblad, B., Almgren, O., Carlsson, A., Henning, M., Jonasson, J. and Ljung, B. Brit. J. Pharmacol. 61, 3.18-320, 1977.

- Ahlquist, R.P.: Am. J. Physiol. 153, 586-600, 1948.

- Amery. A., Billiet, L. and Fagard, R.: New Engl. J. Med. 290, 284, 1974.

- Amery, A., Billiet, L., Boel, A., Fagard, R., Reybrouck, T. and Willems, J.: Am. Heart J. 91, 634-642, 1976.

- Anderson, J.H., Anderson, R.C. and Ibsen, L.S.: J. Pharmacol. Exp. Ther. 206, 172-180, 1978.

- Anderson, W.P., Korner, P.I., Bobik, A. and Chalmers, J.P.: J. Pharmacol. Exp. Ther. 202, 320-325, 1977.

- Angell-James, J.E. and Bobik, A. In: Prophylactic approach to hypertensive diseases. (Ed. Y. Yamori), Pag. 259-267. Raven Press, New York, 1979.

- Avakian, O.V. and Gillespie, J.S.: Brit. J. Pharmacol. 32, 168-184, 1968.

- Barrett, A.M.: J. Pharm. Pharmocol. 21, 241-247, 1969.

- Bauer, J.H. and Brooks, C.S.: Am. J. Med. 66, 405-410, 1979.

- Bencsath, P., Asztalos, B., Szalay, L. and Takacs, L.: Am. J. Physiol. 236, 513-518, 1979.

- Benedict, C.R., Pickering, T.G. and Raine, E.G.: J. Physiol. (London) 271, 35P-36P, 1977.

- Bhagat, B.D.: Biochem. Pharmacol. 27, 1698-1700, 1978.

- Bischoff, K.B. and Dedrick, R.L.: J. Pharm. Sci. 57, 1346-1351, 1968.

- Black, J.W. and Stephenson, J.S.: Lancet ii, 311-314, 1962.

- Blendis, L.M., Auld, R.B., Alexander, E.A. and Levinsky, N.G.: Clin. Sci. 43, 569-576, 1972.

- Bonelli, J., Hörtnagl, H., Brücke, T., Magometschnigg, D., Lochs, H. and Kaik, G.: Eur. J. Clin. Pharmacol. 15, 1-8, 1979.

- Bousquet, P., Feldman, J., Bloch, R. and Schwartz, J.: Neuropharmacology 17, 605-609, 1978.

- Bravo, E.L., Tarazi, R.C., Dustan, H.P. and Lewis, J.W.:

, Circ. Res. Suppl. I vol. 36 \& 37, 1-241-I-247, 1975.

- Bristow, P.D., Honour, J., Pickering, G.W., Sleight, P. and Smyth, H.S.: Circ. 39, 48-54, 1969.

- Browning, C., Ledingham, J.M. and Pelling, D.: J. Physiol. (London) 208, $11 \mathrm{P}-12 \mathrm{P}, 1970$.

- Buckingham, R.E. and Hamilton, T.C.: Gen. Pharmacol. 10, 1-13, 1979.

- Bühler, F.R., Laragh, J.H., Baer, L., Vaughan, E.D. and Brunner, H.R.: New Engl. J. Med. 287, 1209-1214, 1972.

- Bühler, F.R., Laragh, J.H., Vaughan, E.D., Brunner, H.R., Gavras, H. and Baer, L.: Am. J. Cardiol. 35, 511-522, 1973.

- Bühler, F.R., Burkart, F., Lütold, B.E., Kung, M., Marbet, 
G. and Pfirsterer, M.: Am. J. Cardiol. 36, 653-669, 1975.

- Buñag, R.D.: Eur. J. Pharmacol. 43, 323-331, 1977.

- Caputi, A.P., Rossi, F., Lampa, E., Vacca, C., Giordano, L. and Marmo, E.: Agressologie 19, 325-330, 1978.

- Carrara, M.C. and Baines, A.D.: Can. J. Physiol. Pharmacol. 54, 683-691, 1976.

- Carrière, S.: Can. J. Physiol. Pharmacol. 47, 199-208, 1969.

- Chan, P.S. and Poorvin, D.: Clin. Exp. Hypertension 1, 817-830, 1979.

- Chidsey, C.A., Morselli, P., Bianchetti, G., Morganti, A., Leonetti, G. and Zanchetti, A.: Circ. 52, 313-318, 1975.

- Clement, D.L., Bogaert, M.G. and Pannier, R.: Eur. J. Clin. Pharmacol. 11, 325-327, 1977.

- Coleman, T.G. and Guyton, A.C.: Circ. Res. 25, 153-160, 1969.

- Coleman, T.G., Smith, T.L., Smits, J.F.M. and Struyker-Boudier, H.A.J.: Brit. J. Pharmacol. 68, 110P-111P, 1980.

- Colindres, R.E. and Gottschalk, C.W.: Fed. Proc. 37, 1218-1221, 1978.

- Coltart, D.J. and Shand, D.G.: Brit. Med. J. 3, 731-734, 1970.

- Conway, J., Darwin, K., Hilditch, A., Loveday, B. and Reeves, M.: Clin. Sci. Mol. Med. 48, 101 S-103S, 1975.

- Conway, J.: In: Clinical pharmacology of antihypertensive agents (Eds. Rahn. K.H. and Struyker-Boudier, H.A.J.) pag. 83-91, Gent, 1980.

- Cottrel, G.A. and Cobbet, P.: J. Pharm. Pharmacol. 30, 820, 1978.

- Cuthbert, M.F. and Collins, R.F.: Brit. J. Clin. Pharmacol. 2, 49-55, 1975.

- Davies, R., Pickering, T.G., Morganti, A., Bianchetti, P.L. Romankiewicz, J. and Laragh, J.H.: Lancet i, 407-410, 1978.

- Davies, R., Pickering, T.G., Morganti, A., Wilson, M. and Laragh, J.H.: Brit. Heart J. 41, 331-335, 1979.

- Davy, M., Midol-Monnet, M., Cohen, Y. and Wepierre, 1.: Arch. Int. Pharmacodyn. 230, 257-278, 1977.

- Dawes, P.M. and Faulkner, D.C.: Brit. J. Pharmacol. 53, 517-524, 1975.

- Day, M.D. and Roach, A.G.: Nature New Biol. 242, 30-31, 1973.

- Day, M.D. and Roach, A.G.: Brit. J. Pharmacol. 51, 325-333, 1974.

- Day, M.D. and Peters, A.: Brit. J. Pharmacol. 54, 253P-254P, 1975.

- DiBona, G.F.: Am. J. Physiol. 233, F73-F81, 1977.

- DiBona, G.F.: Fed. Proc. 37, 1214-1217, 1978.

- DiBona, G.F., Zambraski, E.J., Aguilera, A.J. and Kaloyanides, G.J.: Circ. Res. 40, (Suppl. I), 127-130, 1977.

- Dollery, C.T. and Junod, A.F.: Brit. J. Pharmacol. 57, 67-71, 1976.

- Drayer, J.I.M., Weber, M.A., Longworth, D.L. and Laragh, J.H.: Am. J. Med. 64, 187-192, 1978.

- Dusting, G.J. and Rand, M.J.: Clin. Exp. Pharmacol. Physiol. 1, 87-89, 1974.

- Ehrsson, H.: J. Pharm. Pharmacol. 28, 662-663, 1976.

- Elghozi, J.L., Bianchetti, G.; Morselli, P.L. and Meyer, P.: Eur. J. Pharmacol. 55, 319-322, 1979.

- Eliash. S. and Weinstock, M.: Brit. J. Pharmacol. 43, 287-294, 1971.

- Epstein, S.E., Robinson, B.F., Kahler, R.L. and Braunwald, E.: 
J. Clin. Invest. 44, 1745-1753, 1965.

- Epstein. S.E. and Braunwald, E.: Ann. Int. Med. 65, 20-27, 1966.

- Esler, M.D.: Clin. Pharmacol. Ther. 15, 484-489, 1974.

- Esler, M., Zweifler, A., Randall, O. and DeQuattro, V.: Clin. Pharmacol. Ther. 22, 299-308, 1977.

- Evans, G.H., Nies, A.S. and Shand, D.G.: J. Pharmacol. Exp. Ther., 186 114-122, 1973a.

- Evans, G.H., Wilkinson, G.R. ans Shand, D.G.: J. Pharmacol. Exp. Ther. 186, 447-453, 1973b.

- Evenwel, R.T. and Struyker-Boudier, H.A.J.: Pflügers Arch. 381, 19-24, 1979.

- Falch, D.K., Ödegaard, A.E. and Norman, N.: Acta. Med. Scand. 205. 91-95, 1979.

- Fernandes, M., Onesti, G., Fiorentini, R., Kim, K.E. and Schwartz, C.: Life Sci. 18, 967-970, 1976.

- Fernandes, M., Onesti, G., Fiorentini, R., Gould, A.B., Kim, K.E. and Schwartz, C.: Clin. Sci. Mol. Med. 52, 107-109, 1977.

- Finnerty, F.A.: Am. Heart J. 81, 563-565, 1971.

- Fitzgerald, J.D. and O'Donnell, S.R.: Brit. J. Pharmacol. 43, 222-235, 1971.

- Fitzgerald, J.D., Ruffin, R., Smedstadt, K.G., Roberts, R. and McAinsh, J.: Eur. J. Clin. Pharmacol. 13, 81-91, 1978.

- Folkow, B.U.G. and Halibäck, M.I.C., In: Hypertension (Eds. Genest, J., Koiw, E. and Kuchel, O.) pag. 507-529, Mc Graw-Hill, New York, 1977.

- Foo, J.W., Jowett, A. and Stafford, A.: Brit. J. Pharmacol, 34, 141-147, 1968.

- Forman, B.H. and Mulrow, P.J.: Circ. Res. 35, 215-221, 1974.

- Franco-Morselli, R., Baudouin-Legros, M. and Meyer, P.: Clin. Sci. Mol. Med. 55, 97S-100S, 1978.

- Friggi, A., Chevalier-Cholat, A.M. and Bodard, H.: Experientia 33, 1207-1208, 1977.

- Frishman, W.: Am. Heart J. 97, 663-670, 1979.

- Frishman, W. and Silverman, R.: Am. Heart J. 97, 797-807, 1979.

- Frohlich, E.D., Tarazi, R.C., Dustan, H.P. and Page I.H.: Circ. 27, 417-423, 1968.

- Fuxe, K., Bolme, P., Agnati, L. and Everitt, B.J.: Neurosci. Letters 3, 45-52, 1976a.

- Fuxe, K., Bolme, P., Agnati, L. and Everitt, B.J.: Neurosci. Letters 3, 53-60, 1976b.

- Garvey, H.L. and Ram, N.: J. Pharmacol. Exp. Ther. 194, 220-230, 1975 a.

- Garvey, H.L. and Ram, N.: Eur. J. Pharmacol. 33, 283-294, 1975b.

- Gavras, I., Gavras, H., Brunner, H.R. and Liang, C.S.: Brit. J. Clin. Pharmacol. 7, (Suppl. 2), 213S-217S, 1979.

- George, C.F., Fenyvesi, T., Conolly, M.E. and Dollery, C.T.: Eur. J. Clin. Pharmacol. 4, 74-77, 1972.

- Geyskes, G.G., Boer, P., Leenen, F.H. and Dorhout Mees, E.J.: Clin. Sci. Mol. Med. 48, 69S-71S, 1975.

- Gibaldi, M.: Biopharmaceutics and clinical pharmacokinetics. Lea and Fehiger, Philadelphia, 1977.

- Gill, J.R.: Nephron 23, 116-118, 1979.

- Gill, J.R. and Casper, A.G.T.: J. Clin. Invest. 50, 112-118, 1971. 
- Gomeni, R., Bianchetti, G., Sega, R. and Morselli, P.L.: J. Pharmacokin. Biopharmaceut. 5, 183-192, 1977.

- Gordon, R.D.: Drugs 11, (Suppl. 1), 156-163, 1976.

- Greef, K. and Wagner, J.: Naturwissenschaften 53, 40-41, 1966.

- Greven, J.: Naunyn-Schmiedeberg's Arch. Pharmacol. 282, 171-181, 1974.

- Gribbin, B., Pickering, T.G., Sleight, P. and Peto, R.: Circ. Res. 29, 424-431, 1971.

- Gulati, O.P. and Liard, J.F.: Arch. Int. Pharmacodyn. Ther. 240, 285-293, 1979.

- Guyton, A.C.: Textbook of Medical Physiology. W.B. Saunders Company, Philadelphia, 1976.

- Guyton, A.C. and Coleman, T.G.: Circ. Res. 24, (Suppl. 1) 1-19, 1969.

- Guyton, A.C., Coleman, T.G., Bower, J.D. and Granger, H.J.: Circ. Res. 26, (Suppl. 2), 135-147, 1970.

- Guyton, A.C., Coleman, T.G. and Granger, H.J.: Ann. Rev. Physiol. 34, 13-46, 1972.

- Guytori, A.C., Jones, C.E. and Coleman, T.G.: Cardiac output and its regulation. Saunders, Philadelphia, 1973.

- Guyton, A.C., Coleman, T.G., Cowley, A.W., Manning, R.D., Norman, R.A. and Ferguson, J.D.: Circ. Res. 35, 159-176, 1974.

- Hamilton, C.A., Littler, W.A., Reid, J.L. and Watson, R.D.S.: J. Physiol. (London) 284, 107P-108P, 1978.

- Hansen, J.F., Hesse, 8. and Christensen, N.J.: Eur. J. Clin. Invest. 8, 31-36, 1978.

- Hansson, L.: Acta Med. Scand. 550, (Suppl.), 7-40, 1973.

- Hansson, L., Zweifler, A.J., Julius, S. and Hunyor, S.N.: Acta Med. Scand. 196, 27-34, 1974.

- Harms, H.H.: J. Pharmacol. Exp. Ther. 199, 329-335, 1976.

- Harrison, L.I. and Gibaldi, M.: J. Pharm. Sci. 66, 1138-1142, 1977.

- Hayes, A. and Cooper, R.G.: J. Pharmacol. Exp. Ther. 176, 302-311, 1971.

- Heidenreich, O., Fülgraff, G., Laaff, H. and Balshüsemann, E.: Naunyn-Schmiedeberg's Arch. Pharmacol. Exp. Path. 263, 439-449, 1969.

- Heise, A. and Kroneberg, G.: Eur. J. Pharmacol. 17, 315-317, 1972.

- Henning, M. and van Zwieten, P.A.: J. Pharm. Pharmacol. 20, 409-417, 1968.

- Henning, M. and Rubenson, A.: J. Pharm. Pharmacol. 23! 407.411, 1971.

- Herwaarden, C.L.A. van: Selective and nonselective beta-blockade in hypertension.

- Hollenberg, N.K., Adams, D.F., McKinstry, D.N., Williams, G.H. Borucki, L.J. and Sullivan, J.M.: Brit. J. Clin. Pharmacol. 7, (Suppl. 2), 219S-225S, 1979.

- Hollifield, J.W., Sherman, K., Vander Zwagg, R. and Shand, D.G.: New Engl. J. Med. 295, 68-73, 19.76.

- HoPak, C., Matsunaga, M., Yamamoto, J., Kira, J., Ogino, K. and Kawai, C.: Jap. Heart J. 18, 392-297, 1977.

- Howe, R. and Shanks, R.G.: Nature 210, 1336-1338, 1966.

- Ibsen, H. and Sederberg-Olsen, P.: Clin. Sci. 44, 129-134, 1973.

- Irving, M.M., Britton, B.J., Wood, W.G., Padgham, C. and Carruthers, M.: Nature 248, 531-533, 1974.

- Johnsson, G., de Guzman, M., Bergman, H. and Sannerstedt, R.: 
Pharmacol. Clin. 2, 34-39, 1969.

- Johnsson, G. and Reghảrd, C.G.: Clin. Pharmacokin. 1, 233-263, 1976a.

- Johnsson, G. and Reghàrd, C.G.: Drugs 11, (Suppl. 1), 111-121, 1976b.

- Juhlin-Danfelt, A. and Aström, H.: Scand. J. Clin. Lab. Invest. 39, 179-183, 1979.

- Julius, S., Pascual, A.V., Albrecht, P.H. and London, R.:

Proc. Soc. Exp. Biol. Med. 140, 982-985, 1972.

- Kappagoda, C.T., Linden, R.J. and Sreeharan, N.: J. Physiol. (London) 287, 17P-18P, 1979.

- Karemaker, J.M.: Vagal effects of the baroreflex on heart rate, Opmeer B.V., Den Haag, 1980.

- Karlberg, B.E., Kảgedal, B., Tegler, L., Tolagen, K. and Bergman, B.: Am. J. Cardiol. 37, 642-649, 1976.

- Kato, H., Nishiyama, H., Nakao, K. and Takagi, K.: Jap. J. Pharmacol. 26, 772-775, 1976.

- Kelliher, G.J.: In: New antihypertensive Drugs (Eds. Scriabine, A. and Sweet, C.S.) page 257-271, Spectrum Publications, New York, 1976.

- Kelliher, G.J. and Buckley, J.P.: J. Pharm. Sci. 59, 1276-1280, 1970.

- Kilian, H.: Participation of the lymphatic system in the absorption of pharmaca from the gut. Drukkerij Brakkenstein, Nijmegen, 1973.

- Klevans, L.R., Kovacs, J.L. and Kelly, R.: J. Pharmacol. Exp. Ther. 196, 389-395, 1976.

- Kobinger, W.: Naunyn-Schmiedeberg's Arch. Pharmacol. Exp. Path. 258, 45-58, 1967.

- König, J.F.R. and Klippel, R.A.: The rat brain. Williams \& Wilkins, Baltimore, 1963.

- Kornhauser, D.M., Wood, A.J.J., Vestal, R.E., Wilkinson, G.R., Branch, R.A. and Shand, D.G.: Clin. Pharmacol. Ther. 23, 165-174, 1978.

- Krediet, R.T. and Dunning, A.J.: Brit. Heart J. 41, 106-110, 1979.

- Krieger, E.M.: Circ. Res. 15, 511-521, 1964.

- Krieger, E.M.: Am. J. Physiol. 218, 486-490, 1970.

- Kubo, T., Esumi, K. and Ennyu, K.: Arch. Int. Pharmacodyn. Ther. 227, 30-40, 1977.

- Laverty, R. and Taylor, K.M.: J. Pharm. Pharmacol. 20, 605-609, 1968.

- Lee, D.R. and Simpson, F.O.: Proc. Univ. Otago Med. School 51, 51-52, 1973.

- Leenen, F.H.H. and Ackerman, E.W.: Clin. Exp. Pharmacol. Physiol. 3, 575-586, 1976.

- Lees, P.: Brit. J. Pharmacol. 34, 429-444, 1968.

- Leeuw, P.W. de, Falke, H.E., Kho, T.L., Vandongen, R., Wester A. and Birkenhäger, W.H.: Acta Med. Scand. 202, 389-392, 1977.

- Lehtonen, A., Kanto, J. and Kleimola, T.: Eur. J. Clin. Pharmacol. 11. 155-157, 1977.

- Leth, A. and Ibsen, H.: J. Lab. clin. Med. 87. 781-191. 1976.

- Levi, J., Grinblat, J. and Kleeman, C.R.: Am. J. Physiol. 221, 1728-1732, 1971.

- Levy, J.V.: Am. J. Med. 61, 779-789, 1976.

- Levy, A., Ngai, S.H., Finck, A.D., Kawashima, K. and Spector, S.:

Eur. J. Pharmacol. 40, 93-100, 1976.

- LeWinter, M.W., Crawford, M.H., Karliner, J.S. and O'Rourke, R.A.: Clin. Pharmacol. Ther. 17, 709-712, 1975. 
- Lewis, P.J. and Haeusler, G.: Nature 256, 440, 1975.

- Linden, R.J. and Sreeharan, N.: J. Physiol. (London) 291, 43P-44P, 1979.

- Lisander, B. and Nilsson, H.: Eur. J. Pharmacol. 50, 275-278, 1978.

- Ljung, B., Ảblad, B., Dahlhöf, C., Henning, M. and Hultberg, E.: Blood Vessels 12, 311-315, 1975.

- Lokhandwala, M.F., Asaad, M.M. and Buckley, J.P.: Eur. J. Pharmacol. 38, $141-147,1976$.

- Lundgren, Y.: Acta Physiol. Scand. 91, 409-416, 1974.

- Lund-Johansen, P.: Eur. J. Clin. Pharmacol. 16, 149-153, 1979.

- Lütold, B.E., Bühler, F.R. and DaPrada, M.: Schweiz. Med. Wochenschr. 106. 1735-1738, 1976.

- LysboSvendsen, T., Hartling, O. and Trap-Jensen, J.:

Eur. J. Clin. Pharmacol. 15, 223-228, 1979.

- Leth, A. and Ibsen, H.: J. Lob. clin. Med. 87, 781-191, 1976.

- Maling, T.J.B., Ferrara, A., Mucklow, J.C., Reid, J.L., Hamilton, C.A. and Dollery, C.T.: Eur. J. Clin. Pharmacol. 15, 375-379, 1979.

- Masuoka, D., and Hansson, E.: Acta Pharmacol. et Toxicol. 25, 447-455, 1967.

- McDevitt, D.G.: Drugs 17, 267-288, 1979.

- McLean, A.J., McNamara, P.J., du Souich, P., Gibaldi, M. and Lalka, D.: Clin. Pharmacol. Ther. 24, 5-10, 1978.

- Melander, A., Danielson, K., Schersten, B. and Wahlin, E.: Clin. Pharmacol. Ther. 22, 108-112, 1977.

- Menard, J., Alexandre, J.M. Giudicelli, J.F., Auzan, C. and Chevillard, C.: Arch. Int. Pharmacodyn. 202, 298-303, 1973.

- Migdalof, B.H.: Drug. Metab. Rev. 5, 295-310, 1976.

- Montastruc, J.L. and Montastruc, P.: C.R. Acad. Sci. Paris 289, 37-40, 1979.

- Morganti, A., Pickering, T.G., Lopez-Ovejero, J.A. and Laragh, J.H.: Am. Heart J. 98, 490-494, 1979.

- Morinan, A. and Leonard, B.E.: Brit. J. Pharmacol. 61, 152P-153P, 1977.

- Mouillé, P., Sourdy, C. and Cheymol, G.: J. Pharmacol. (Paris) 8, 373-382, 1977.

- Myers, M.G., Lewis, P.J., Reid, J.L. and Dollery, C.T.: Neuropharmacol. 14, 221-226, 1975a.

- Myers, M.G., Lewis, P.J., Reid. J.L. and Dollery, C.T.: J. Pharmacol. Exp. Ther. 192, 327-335, 1975b.

- Myers, R.D. and Mora, F.: Brain Res. Bull. 2, 105-112, 1977.

- Mylecharane, E.J. and Raper, C.: Brit. J. Pharmacol. 39, 128-138, 1970.

- Nakao, K., Kato, H. and Takagi, K.: Jap. J. Pharmacol. 25, 25-34, 1975.

- Niarchos, A.P., Gulati, O.P. and Carretero, O.A.: Am. Heart J. 94, 81-86, 1977.

- Nies, A.S., McNeil, J.S. and Schrier, R.W.: Circ. 44, 596-604, 1971.

- Nies, A.S., Evans, G.H. and Shand, D.G.: J. Pharmacol. Exp. Ther. 184, 716-720, 1973a.

- Nies, A.S., Evans, G.H. and Shand, D.G.: Am. Heart J. 85, 97-102, 1973b.

- Nijkamp, F.P., van den Bosch, R. and de Jong, W.: Eur. J. Pharmacol. 56, 187-195, 1979.

- Nishiyama, K., Nishiyama, A. and Frohlich, E.D.: Am. J. Physiol. 230. 691-698, 1976. 
- Nishiyama, K., Nishiyama, A., Pfeffer, M.A. and Frohlich, E.D.: Blood Vessels 15, 333-347, 1978.

- Nomura, G., Arai, S., Uno, D., Shimao, M., Takata, M., Takabatake, T. and Hattori, N.: Renal Physiol. 1, 132-139, 1978.

- Notari, R.E.: Biopharmaceutics and Pharmacokinetics. Marcel Dekker Inc., New York, 1975.

- Offerhaus, L. and van Zwieten, P.A.: Cardiovasc. Res. 8, 488-495, 1974.

- Okamoto, K. and Aoki, K.: Jap. Circ. J. 27, 282-293, 1963.

- Palm, D. and Grobecker, H.: Drug Res. 27, 708-713, 1977.

- Parving, H.H. and Gyntelberg, F.: Circ. Res. 32, 643-651, 1973.

- Pedersen, G., Pedersen, A. van Pedersen, E.B.: Scand. J. Clin. Lab. Invest. 39, 167-170, 1979.

- Pessina, A.C., Corgnati, A., Palatini, P., Oneglia, C. and Dal Palu, C.: Clin. Sci. Mol. Med. 51, 447S-450S, 1976.

- Pfeffer, M.A., Pfeffer, J.M., Weiss, A.K. and Frohlich, E.D.: Am. J. Physiol. 232, 639-644, 1977.

- Piafsky, K.M., Borgà, O., Odar-Cederlöf, I., Johansson, C. and Sjöquist, E.: New Engl. J. Med. 299, 1435-1439, 1978.

- Pickering, T.G., Gribbin, B., Petersen, E.S., Cunningham, D.J.C. and Sleight, P.: Circ. Res. 30, 177-185, 1972.

- Popovic, V. and Popovic, P.: J. Appl. Physiol. 15, 727-728, 1960.

- Prichard, B.N.C.: Brit. Med. J. 1, 1227-1228, 1964.

- Prichard, B.N.C. and Gillam, P.M.S.: Brit. Med. J. 2, 725-727, 1964.

- Prichard, B.N.C. and Gillam, P.M.S.: Brit. Med. J. 1. 7-16, 1969.

- Privitera, P.J., Webb, J.G. and Walle, T.: Eur. J. Pharmacol. 54, 51-60, 1979.

- Purdy, R.E. and Ashbrook, D.W.: J. Pharm. Pharmacol. 30, 436-441, 1978.

- Rahn, K.H., Johnson, C.E. and McNay, J.L.: Circ. 38, (Suppl. VI), 159, 1968.

- Rahn, K.H., Hawlina, A., Kersting, F. and Planz, G.: Naunyn Schmiedeberg's Arch. Pharmacol. 286, 319-323, 1974.

- Rahn, K.H., Gierlichs, H.W., Planz, G., Planz, R., Schols, M. and Stephany, W.: Eur. J. Clin. Invest. 8, 143-148, 1978.

- Raine, A.E.G. and Chubb, I.W.: Nature 267, 265-267, 1977.

- Ram, N., Heilman, R.D. and Greenslade, F.C.: Arch. Int. Pharmacodyn. Ther. 224, 102-108, 1976.

- Rascher, W., Man, J.F.E., Schömig, A., Dietz, R. and Lüth, J.B.: Klin. Wochenstr. 56, (Suppl. I), 87-90, 1978.

- Rasmussen, S. and Rasmussen, K.: Eur. J. Clin. Pharmacol. 15, 305-310, 1979.

- Reid, J.L., Lewis, P.J., Myers, M.G. and Dollery, C.T.: J. Pharmacol. Exp. Ther. 188, 394-399, 1974.

- Reybrouck, T., Amery, A., Billiet, L. and Fagard, R.: Cardiol. 64, 97-109, 1979.

- Richer, C., Boissier, J.R. and Giudicelli, J.F.: Eur. J. Pharmacol. 47, 393-400, 1978.

- Riley, R.L., Scriabine, A. and Watson, L.S.: Proc. Soc. Exp. Biol. Med. 153, 454-458, 1976.

- Roach, A.G., Gomeni, R., Mitchard, M., Nicolas, J. and Caveso, I.:

Eur. J. Pharmacol. 49, 271-278, 1978. 
- Roba, J., Lambelin, G. and De Schaepdrijver, A.F.: Arch. Int. Pharmacodyn. 200, 182-190, 1972.

- Routledge, P.A. and Shand, D.G.: Clin. Pharmacokin. 4, 73-90, 1979.

- Sager G., Nilsen, O.G. and Jacobsen, S.: Biochem. Pharmacol. 28, 905-911, 1979.

- Salgado, H.S. and Krieger, E.M.: Am. J. Physiol. 234, H552-H556, 1978.

- Sannerstedt, R. and Conway, J.: Am. Heart J. 79, 122-127. 1970.

- Sannerstedt, R., Julius, S. and Conway, J.: Circ. 17. 1057-1064, 1970.

- Schirmeister, J., Decot, M., Hallauer, W. and Willmann, H.: Arzneimittel Forschung 16, 847-850, 1966.

- Schmitt, H., Schmitt, H., Boissier, J.R. and Giudicelli, J.F.: Eur. J. Pharmacol. 2, 147-148, 1967.

- Schneck, D.W., Pritchard, J.F. and Hayes Jr., A.H.: J. Pharmacol. Exp. Ther. 203, 621-629, 1977.

- Schrier, R.W., Liberman, R. and Ufferman, R.C.: J. Clin. Invest. 51, 97-111, 1972.

- Scott, E.M.: Brit. J. Pharmacol. 64, 394P, 1978.

- Sederberg-Olsen, P. and Ibsen, H.: Clin. Sci. 43, 165-170, 1972.

- Sekiya, A., Yamamoto, J. and Maekawa, M.: Jap. J. Pharmacol. 24, 879-883, 1974.

- Shand, D.G.: Postgrad. Med. J. 52, (Suppl. 4) 22-25, 1976.

- Shand, D.G., Branch, R.A., Evans, G.H., Nies, A.S. and Wilkinson, G.R.: Drug. Metab. Disp. 1, 679-686, 1973.

- Shand, D.G., Evans, G.H. and Nies, A.S.: Life Sci. 10, 1417-1421, 1971.

- Shand, D.G. and Rango, R.E.: Pharmacol. 7, 159-168, 1972.

- Shand, D.G., Rango, R.E. and Evans, G.H.: Pharmacol. 8, 344-352, 1972.

- Sheppard, H. and Burghardt, C.R.: Res. Comm. Chem. Path. Pharmacol, 21, 223-235, 1978.

- Shibouta, Y., Nishikawa, K., Kikuchi, S. and Shimamoto, K.: Eur. J. Pharmacol. 53, 201-208, 1979.

- Simon, G., Kiowski, W. and Julius, S.: Clin. Pharmacol. Ther. 22, 293-298, 1977.

- Smith, T.L. and Hutchins, P.M.: Fed. Proc. 36, 617, 1977.

- Smith, T.L. and Hutchins, P.M.: Hypertension 1, 508-517, 1979.

- Smyth, H.S., Sleight, P. and Pickering, G.W.: Circ. Res. 24, 109-121, 1969.

- Srivastava, R.K. Kulshrestha, V.K., Singh, N. and Bhargava, K.P.: Eur. J. Pharmacol. 21, 222-230, 1973.

- Stein, J.H., Osgood, R.W. and Ferris, T.F.: Proc. Soc. Exp. Biol. Med. 141. 901-905, 1972.

- Stjärne, L. and Brundin, J.: Acta Physiol. Scand. 97, 88-93, 1976.

- Stokes, G.S., Weber, M.A. and Thornell, I.R.: Brit. Med. J. 1, 60-62, 1974.

- Stokes, G.S., Graham, R.M. and Weber, M.A.: Drugs 11. (Suppl. 1), 150-156, 1976.

- Street, J.A., Hemsworth, B.A., Roach, A.G. and Day, M.D.: Arch. Int. Pharmacodyn. Ther. 237, 180-190, 1979.

- Struyker-Boudier, H.A.J.: Catecholamine receptors in nervous tissue. Stichting Studentenpers, Nijmegen, 1975.

- Struyker-Boudier, H.A.J., Smeets, G.W.M., Brouwer, G.M. and van Rossum. J.M.: 
Arch. int. Pharmacodyn. Ther. 213, 285-295, 1975.

- Struyker-Boudier, H., van Essen, H., Smits, J. and Evenwel, R.:

Therapiewoche 29, 7740-7743, 1979.

- Struyker-Boudier, H.A.J., Smits, J.F.M., Evenwel, R.T., Kleinjans, J.C.S. and Min, F.B.M.: Proc. 21 st. Dutch Fed. Meeting, 412, 1980.

- Stumpe, K.O., Kolloch, R., Vetter, H., Gramman, W., Krück, F., Ressel, C. and Higuchi, M.: Am. J. Med. 60, 853-865, 1976.

- Sullivan, J.M., Adams, F.A. and Hollenberg, N.K.: Circ. Res. 39, 532-536, 1976.

- Sweet, C.S. and Wenger, H.C.: Neuropharmacol. 15, 511-513, 1976.

- Sweet, C.S., Scriabine, A., Wenger, H.C., Ludden, C.T. and Stone, C.A.: In: Regulation of blood pressure by the central nervous system (Eds. Onesti, G., Fernandes, M. and Kim, K) pag. 317-330. Grune \& Stratton, New York, 1976.

- Sweet, C.S., Solar, J, and Gaul, S. L.: Clin. Exp. Hypertension 1, 449-471, 1979.

- Takeda, K., Sakurai, H. and Imai, S.: Jap. J. Pharmacol. 25, 82-84, 1975.

- Takeda, K., Nakagawa, Y., Hashimoto, T., Sakurai, H. and Imai, S.: Jap. J. Pharmacol. 29, 171-178, 1979.

- Takeshita, A., Tanaka, S. and Namura, M.: Cardiovasc. Res. 12, 148-151,11978.

- Tarazi, R.C., Frohlich, E.D. and Dustan, H.P.: Am. Heart J. 82, 770-776, 1971.

- Tarazi, R.C. ànd Dustan, H.P.: Am. J. Cardiol. 29, 633-640, 1972.

- Theeuwes, F. and Yum, S.I.: Ann. Biomed. Eng. 4, 343-353, 1976.

- Tindell, G.L., Waile, T. and Knapp, D.R.: Res. Comm. Chem. Path. Pharmacol. 19, 11-22, 1978.

- Tuttle, R.S. and McCleary, M.: J. Pharmacol. Exp. Ther. 207, 56-63, 1978.

- Uirych, M., Frohlich, E.D., Dustan, H.P. and Page, I.M.: Circ. 37, 411-417, 1968.

- Vavra, I., Tom, H. and Greselin, E.: Can. J. Physiol. Pharmacol. 51, 727-732, 1973.

- Vervloet, E., Pluym, B.F.M., Gilissen, J., Köhlen, K. and Merkus, F.W.H.M.: Clin. Pharmacol. Ther. 22, 853-857, 1977.

- Vlachakis, N.D.: Biochem. Med. 21, 253-261, 1979.

- Vlachakis, N.D.: J. Clin. Pharmacol. 19, 20-29, 1980.

- Waal-Manning, H.J.: Proc. Univ. Otago Med. School 48, 80-81, 1971.

- Walle, T., Conradi, E.C., Walle, K., Fagan, T.C. and Gaffney, T.E.: Clin. Pharmacol. Ther. 24, 668-677, 1978.

- Walle, T., Conradi, E.C., Walle, U.K., Fagan, T.C. and Gaffney, T.E.: Clin. Pharmocol. Ther. 27, 22-31, 1980.

- Watson, R.D.S., Stallard, T.J. and Littler, W.A.: Lancet i, 1210-1213, 1979a. 
- Watson, R.D.S., Stallard, T.J. and Littler, W.A.: Clin. Sci. 57, 241-247, 1979b.

- Weber, M.A., Stokes, G.S. and Gain, J.M.: J. Clin. Inv. 54, 1413-1419, 1974.

- Weidmann, P., Beretta-Piccoli, C., Ziegler, W., Hirsch, D., de Châtel, R. and Reubi, F.C.: Klin. Wochenschr. 54, 765-773, 1976.

- Weinberger, M.H., Aoi, W. and Henri, D.P.: Circ. Res. 37, 318-324, 1975.

- Weinstock, M.: Life Sci. 19, 1453-1466, 1976.

- Weiss, L., Lundgren, Y. and Folkow, B.: Acta Physiol. Scand. 91, 447-457, 1974.

- Weiss, Y.A., Safar, M.E., Chevillard, C., Frydman, A., Simon, A., Lemaire, P. and Alexandre, J.M.: Eur. J. Clin. Pharmacol. 10, 387-393, 1976.

- Wépierre, J., Lindenbaum, A., Porquet, D. and Cohen, Y.: Arch. Int. Pharmacodyn. Ther. 232, 158-165, 1978.

- Wiesel, F.A.: Prog. Neuro-Psychopharmac. 1, 83-89, 1977.

- Wilson, M., Morgan, G. and Morgan, T.: Brit. J. Clin. Pharmacol. 3, 857-861, 1976.

- Yamamoto, J., Sekiya, A. and Maekawa, H.: Jap. J. Pharmacol. 25, 465-471, 1975.

- Yates, F.E., Benson, H., Buckles, R., Urquhart, J. and Zaffaroni, A.: In: Advances in Biomedical Engineering 5, 1-34 (Eds. Brown, J.H.U. and Dickson, J.F.) Academic Press, New York, 1975.

- Yates, M.S. and Hiley, C.R.: Pflügers Arch. 379, 219-222, 1979.

- Yum, J.C., Kelly, G. and Bartter, F.C.: Life Sci. 21, 237-244, 1977.

- Zaagsma, J., Meems, L. and Boorsma, M.: Naunyn-Schmiedeberg's Arch. Pharmacol. 298, 29-36, 1977.

- Zaffaroni, A.: Drug. Metab. Rev. 8, 191-221, 1978.

- Zweifler, A. and Esler, M.: Am. J. Cardiol. 40, 105-109, 1977.

- Zwieten, P.A. van: Progr. Pharmacol. 1, 7-11, 1975. 


\section{CURRICULUM VITAE}

De auteur van dit proefschrift werd op 7 april 1953 geboren te Tilburg.

Vanaf 1965 bezocht hij de Pax Christi HBS te Druten, hetgeen resulteerde in het diploma HBS-B in 1970. Daarna studeerde hij scheikunde aan de Katholieke Universiteit te Nijmegen. In 1973 werd het kandidaats-diploma $\mathrm{S}_{2}$ (Scheikunde met wiskunde, natuurkunde en biologie) behaald. De doctoraalstudie, met als hoofdvak farmacochemie (begeleider Prof. Dr. J.M. van Rossum) en bijvakken organische. chemie (begeleider Prof. Dr. B. Zwanenburg) en biofysische chemie (begeleider Dr. C.W. Hilbers), werd afgesloten in 1976. Sinds die tijd is de auteur als wetenschappelijk medewerker werkzaam in de capaciteitsgroep farmacologie van de Rijksuniversiteit Limburg te Maastricht. Daar is het in dit proefschrift beschreven onderzoek verricht onder leiding van Prof. Dr. H.A.J. Struyker Boudier.

\section{Publicaties waaraan werd medegewerkt:}

Smits, J.F. and Struyker Boudier, H.A.J.:

Intrahypothalamic serotonin and cardiovascular control in rats.

Brain Res. 111, $422-427$ (1976).

Veenstra, G.E., Bronold, N.M., Smits, J.F.M., Tangerman, A., and Zwanenburg, B.: Preparation of sulfines by chlorination of dithiocarboxylic esters.

Rec. Trav. Chim. Pays Bas 96, 139-144 (1977).

Smits, J.F.M., van Essen, H. and Struyker Boudier, H.A.J.:

Serotonin-mediated cardiovascular responses to electrical stimulation of the raphe nuclei in the rat.

Life Sci. 23, 173-178 (1978).

Struyker Boudier, H.A.J. and Smits, J.F.M.:

The osmotic minipump: a new tool in the study of steady-state kinetics of drug distribution and metabolism.

J. Pharm. Pharmacol. 30, 576-578 (1978).

Smits, J.F.M.:

Central serotonin mechanisms and cardiovascular control in the rat.

Naunyn-Schmiedeberg's Arch. Pharmacol. 302, R39 (1978).

Struyker Boudier, H.A.J., Smits, J.F.M. and van Essen, H.:

The role of the baroreceptor reflex in the cardiovascular effects of propranolol in the conscious spontaneously hypertensive rat.

Clin. Sci. Mol. Med. 56, 163-167 (1979).

Smits, J.F.M. and Struyker Boudier, H.A.J.:

Steady-state disposition of propranolol and its total metabolites in the spontaneously hypertensive rat: chronic subcutaneous versus intracerebroventricular infusion with osmotic minipumps.

J. Pharmacol. Exp. Ther. 209, 317-322 (1979). 
Smits, J.F.M., van Essen H. and Struyker Boudier, H.A.J.:

Propranolol in conscious spontaneously hypertensive rats. 1. Cardiovascular effects after subcutaneous and intracerebroventricular administration.

Naunyn-Schmiederberg's Arch. Pharmacol. 309, 13-18 (1979).

Smits, J.F.M. and Struyker Boudier, H.A.J.:

Propranolol in conscious spontaneously hypertensive rats. II. Disposition after subcutaneous and intracerebroventricular administration.

Naunyn-Schmiedeberg's Arch. Pharmacol. 309. 19-24 (1979).

Struyker Boudier, H.A.J., van Essen, H., Smits, J.F.M. en Evenwel, R.:

Exaggerated diuresis and natriuresis in conscious spontaneously hypertensive rats.

Therapiewoche 29, 7740-7743 (1979).

Struyker Boudier, H.A.J., Smits, J.F.M. en van Essen, H.:

Is the central nervous system involved in the long-term

cardiovascular effects of propranolol?

Naunyn Schmiederberg's Arch. 307, suppl., R 45 (1979).

Struyker Boudier, H.A.J., Evenwel R., Min, R., and Smits, J.F.M.:

Antihypertensieve geneesmiddelen: interacties met de regulatie van de bloeddruk. In: Regulatie van de bloeddruk, (Ed.: H.A.J. Struyker Boudier), pp. 90-102.

Bunge, Utrecht, 1979.

Smits, J.F.M., Struyker Boudier, H.A.J. and van Essen, H.:

Effects of propranolol on baroreceptor reflex sensitivity in the conscious spontaneously hypertensive rat.

Brit. J. Pharmacol. 68, 109P (1980).

Coleman, T.G., Smith, T.L., Smits, J.F.M., and Struyker Boudier, H.A.J.: Acute hemodynamic effects of propranolol in the conscious spontaneously hypertensive rat.

Brit. J. Pharmacol. 68, 110P-111P (1980).

Smits, J.F.M., van Essen, H. and Struyker Boudier, H.A.J.:

Cardiovascular effects of chronic infusion of propranolol in the conscious spontaneously hypertensive rat.

J. Pharm. Pharmacol. 32, 139-140 (1980).

Smits, J.F.M.:

Hemodynamic effects of propranolol in the conscious spontaneously hypertensive rat.

Naunyn-Schmiedeberg's Arch. Pharmacol. 311, R48 (1980).

Smits, J.F.M., van Essen, H. and Struyker Boudier, H.A.J.:

Is the antihypertensive effect of propranolol caused by an action within

the central nervous system?

J. Pharmacol. Exp. Ther., in press. 